\title{
FAMILY DYNAMICS AND CHILDREN'S OUTCOMES: \\ THE ROLE OF SILENT INTERPARENTAL CONFLICT
}

by

Magdalena Maria Kielpikowski

\author{
A thesis \\ Submitted to the Victoria University of Wellington in \\ fulfilment of the requirements for the degree of \\ Doctor of Philosophy \\ in Psychology
}

Victoria University of Wellington 



\begin{abstract}
Conflict between parents has been widely studied and its detrimental consequences for children have been documented across domains of psychological functioning, academic performance and social adjustment. Research has focused on the verbal and physical expressions of interparental conflict, however, when tested for, strong indications have been emerging that its non-verbal non-physical forms have similarly serious implications for the young people's wellbeing as the overt ones. The scarceness of findings related to covert forms of interparental conflict provided impetus for qualitative research with parents and adolescents (Kielpikowski \& Pryor, 2008; Pryor \& Pattison, 2007). The research has resulted in proposing a construct of silent interparental conflict (SIC) and provided the conceptual foundation for this thesis. Adopting a systemic approach to the functioning of families characterised by interrelatedness and reciprocity of influences among the members, this thesis investigated processes related to silent interparental conflict through a series of empirical studies with New Zealand families.

The need for developing the Silent Interparental Conflict Scale (SICS) for parents was rationalised following a review of a comprehensive assembly of representative instruments for measuring couples' conflict. The items were derived from the qualitative data corpus (Kielpikowski, 2004). A three factor structure was established and supported by confirmatory factor analyses using data from two samples of parents ( $\mathrm{Ns}=108$ and 260). The SICS demonstrated excellent psychometric qualities and stability over time.

The modus operandi of SIC was hypothesises and tested from the perspectives of parents and adolescents. Drawing from multidisciplinary scholarship, predictors and psychological outcomes of SIC for parents were hypothesised. Theoretical models were tested concurrently and after a lapse of one year utilising data from 115 parental dyads. The findings suggested divergent processes for mothers and fathers. The hypothesised links between the incidence and the Costs of SIC and psychological maladjustment were supported concurrently. Additionally, uniquely for mothers, their perception of the Benefits of silent conflict resulted in reduced maladjustment over time.
\end{abstract}


SIC for fathers was consistently predicted by own avoidance of conflict both concurrently and over time. For mothers the consistent concurrent and longitudinal predictor of SIC was the perceived hostility from partner. Protectiveness towards children acted as a concurrent predictor of SIC for mothers and fathers, for whom additionally it predicted SIC over time. Tests for reciprocal influences using the Actor Partner Interdependence Model (Kenny, Kashy, \& Cook, 2006) indicated a significant Partner effect from fathers' own avoidance to mothers' perceptions of SIC. Parents differed significantly on Actor effects with path coefficients higher on conflict avoidance for fathers and on partner's hostility for mothers.

The impact of SIC on the wellbeing of adolescents was hypothesised within the cognitive contextual framework (Grych \& Fincham, 1990) and the spillover hypothesis (Erel \& Burman, 1995). Adolescents' adjustment was conceptualised as consisting of internalising and externalising problems measured with items from the SDQ (Goodman, Melzer, \& Bailey, 1998), and of positive expectations of the future measured with a scale designed for the study. Threat, self-blame and parental SIC-related spillover behaviour represented by hostility towards the adolescents were posed as mediators of the effects of SIC on adolescents' adjustment. Separate models were tested for boys and girls and for the parent-child gender constellations. Over time the effect of SIC on boys' internalising problems was fully mediated by father's hostility. In contrast, the longitudinal effect of SIC on girls' internalising problems was fully mediated by the appraisal of threat and the effect on their expectations of the future was fully mediated by mother's hostility. Analyses of longitudinal familywide models revealed that fathers' perceptions of SIC differentially influenced the boys' and girls' processes.

The findings advance our understanding of the functioning of SIC and highlight the relatedness and the uniqueness of associated processes for family members depending on their gender and role within the family system. 


\section{Acknowledgements}

Work on a doctoral thesis is like a long journey, lonely and trying but punctuated by fascinating people and discoveries and curiously rich and revealing. I certainly believe this of my experience and look forward to looking back. Numerous people, and at least two animals, have supported me throughout this journey and my gratitude to them is enormous.

First and foremost I am indebted to the parents and the adolescents, who generously gave their time to participate in my research. This project would not have been possible without you.

Two legends, my husband Leszek and my son Chris have always supported me and enthusiastically participated in our shared adventure of life. You have been my rocks. Your love, tolerance, sense of humour, and proofreading skills are beyond compare, not to mention your superb cooking and good looks.

I am immensely grateful to Dr Jan Pryor for her generous support and for sharing with me her passion for. In the process of supervision, both she and Dr Paul Jose have always treated me like an adult and allowed me to venture on my own, while providing valued advice and encouragement. Thank you both from the heart.

With gratitude and love, I would like to acknowledge Barbara Scelly, the former Head of VUW Student Finance, who in the darkest moments provided much needed advice and financial life line and over the years has become a precious friend.

I am grateful to Professor Janet Holmes from the School of Linguistics and Applied Language Studies at Victoria University of Wellington for her expert advice and her suggestions of literature pertaining to silence. Thank you for recognising your faithful disciple after so many years.

My warmest thanks go to Dr Sue Jackson for opening my qualitative eyes, as well as for her friendship and support.

Much love to Dr Carla Crespo, a dear friend and colleague from Portugal. Thank you for helping me reconnect with my European roots and rediscover the pleasure of loud laughter. 
I am indebted to my colleagues and staff at the Roy McKenzie Centre for the Study of Families and to the School of Psychology for providing me with a secure base.

I thank my magnificent doctoral cohort and the wonderful women from the cross cultural lab, especially Elena Maydell and Larissa Kus for their inner and outer beauty and friendship. Kudos to my university roommate Erica Chadwick for being understanding and giving me space for uninterrupted contemplation.

My friends gallantly restrained their bewilderment at the unexpected turn I took in my life and stood firmly behind me. Your karmic rewards for the intellectual and emotional support you gave me are assured.

Love to Cindy, my dear late cat, for accompanying me through endless hours of writing from the top of my old iMac, and to her successor, my darling puppy Lily, who reignited my enthusiasm for life.

I thank P.G. Wodehouse for creating Jeeves and Wooster, and Stephen Fry and Hugh Laurie for superbly portraying them in a TV series. The DVDs have provided me with the much-needed escape throughout the writing process and enriched my vocabulary by thingness and burglarious entry.

Finally, I would like to express my gratitude to everybody, who at formal and informal gatherings listened, nodded, identified with the subject of my dissertation, and expressed his or her enthusiasm. You gave my work a practical dimension and kept me grounded.

Generous support from Family Violence Taskforce, VUW Alumni Association scholarship, Joseph Samuel Beaglehole scholarship and VUW PhD submission scholarship made this research possible and enabled me to present my findings at national and international conferences.

I dedicate this work to the memory of my Mother, with love. 


\section{Table of Contents}

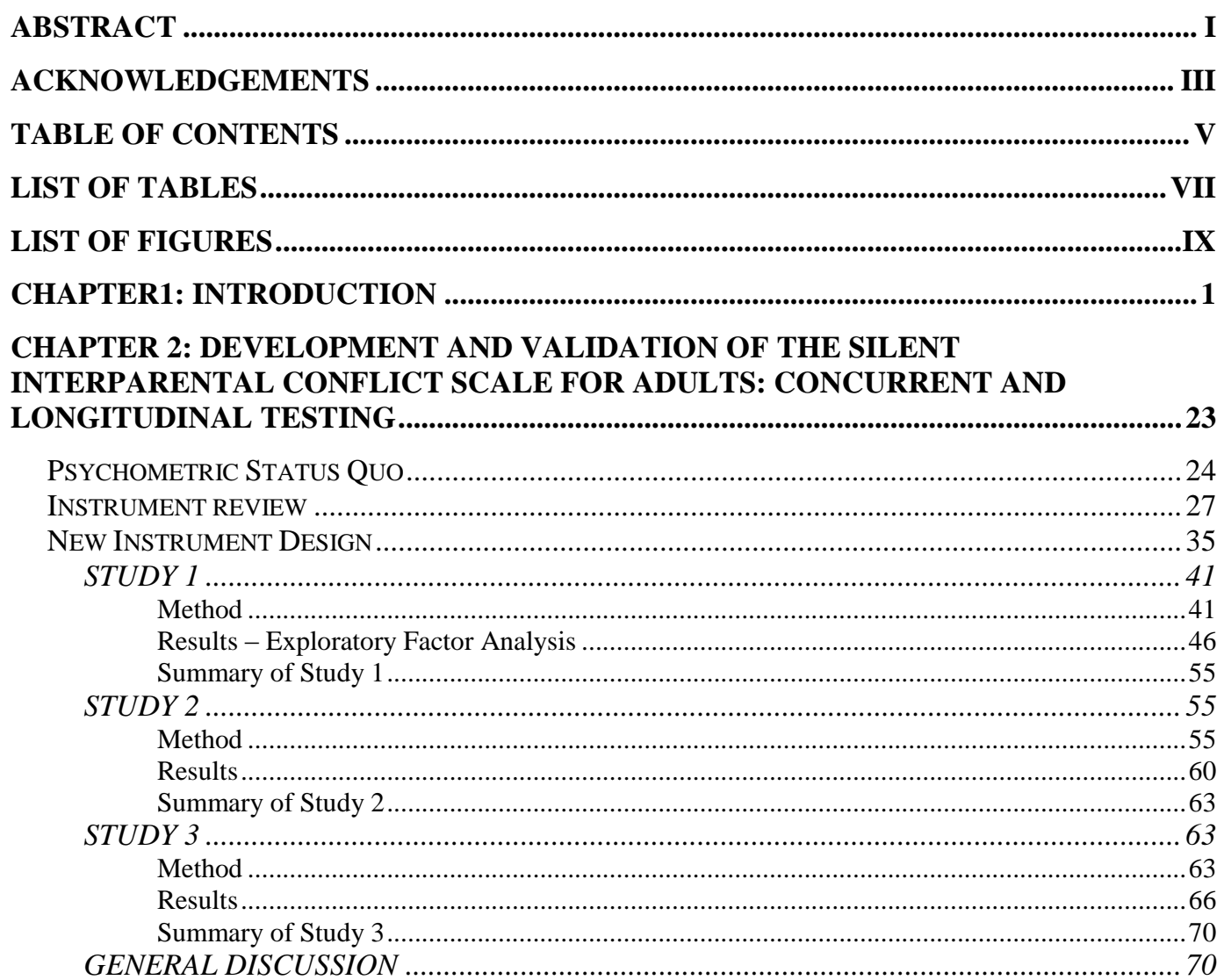

CHAPTER 3: SILENT INTERPARENTAL CONFLICT WITHIN COUPLES'

RELATIONSHIPS: ITS EFFECTS AND ITS SOURCES ...............................................73

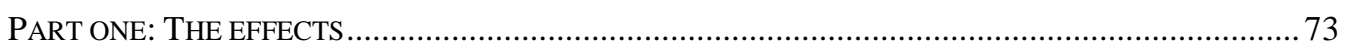

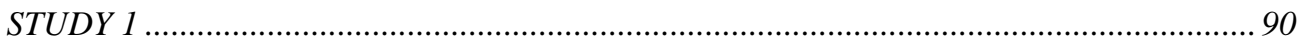

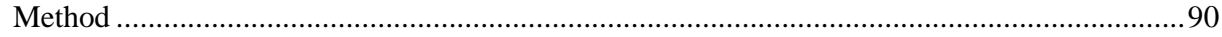

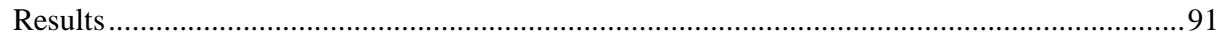

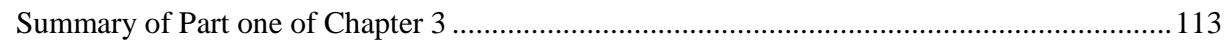

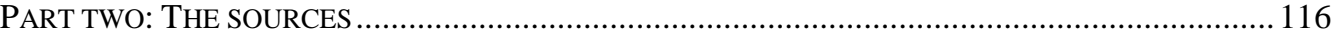

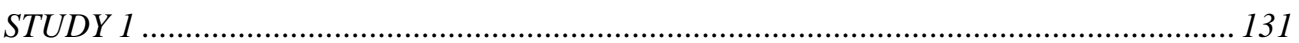

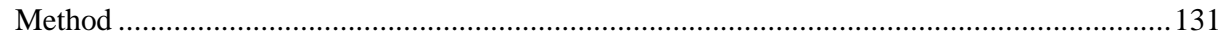

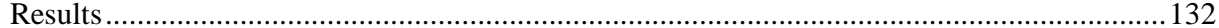

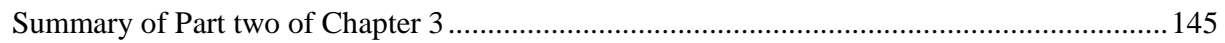

CHAPTER 4: IN A WORLD OF THEIR OWN? ADOLESCENTS' PERCEPTIONS OF

SILENT INTERPARENTAL CONFLICT AND ITS EFFECTS ON THEIR

PSYCHOLOGICAL ADJUSTMENT ..................................................................................... 149

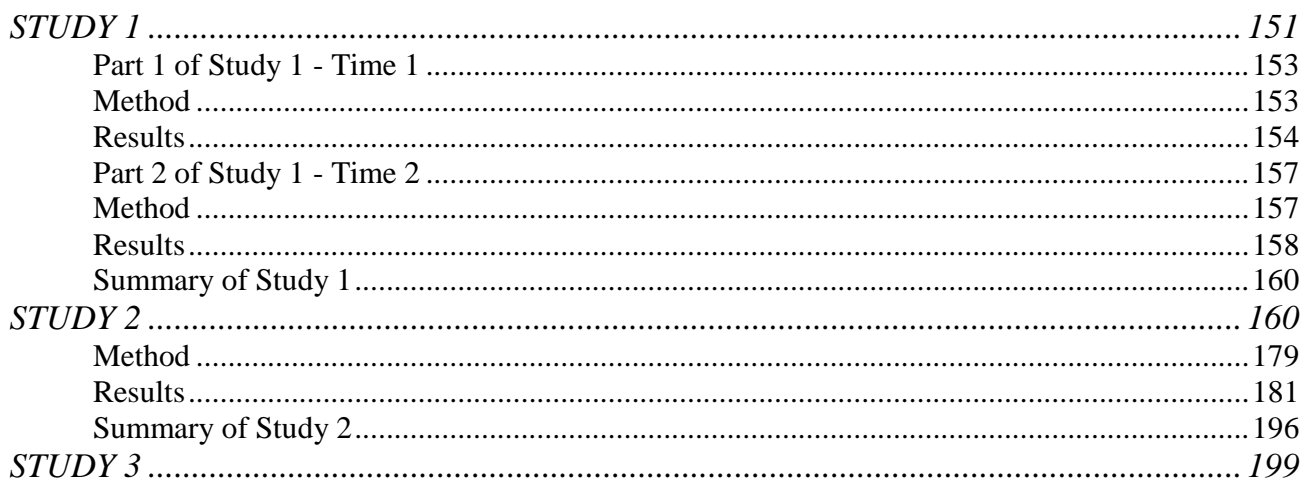




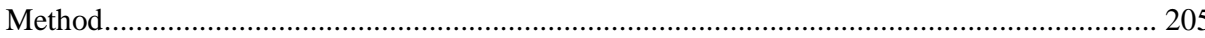

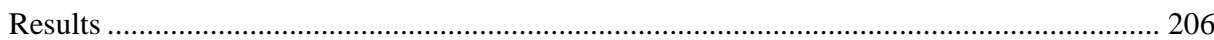

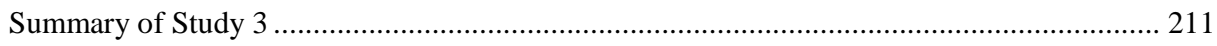

CHAPTER 5: GENERAL DISCUSSION ..............................................................................214

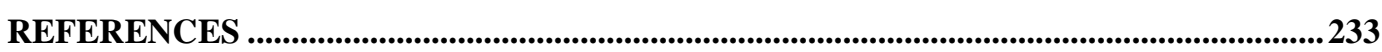

APPENDIX A: ORIGINAL LIST OF ITEMS PROPOSED FOR THE SILENT

INTERPARENTAL CONFLICT SCALE ................................................................................263

APPENDIX B: ITEMS FROM THE CONFLICTS AND PROBLEM-SOLVING SCALES

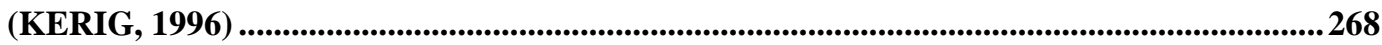

APPENDIX C: ITEMS FROM THE INEFFECTIVE ARGUING INVENTORY (KURDEK,

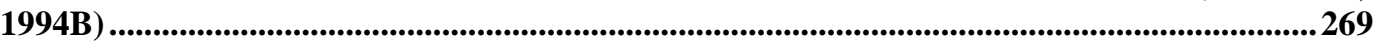

APPENDIX D: ITEMS FROM THE CONFLICT RESOLUTION STYLE INVENTORY

(KURDEK, 1994B) ............................................................................................................270

APPENDIX E: M-C 1(10) (STRAHAN \& GERBASI, 1972) ................................................271

APPENDIX F: ITEMS REPRESENTING SILENT INTERPARENTAL CONFLICT

ADMINISTERED TO PARENTS AT TIME 1 AND TIME 2 .................................................2272

APPENDIX G: ITEMS FROM THE IRRITABILITY, DEPRESSION, ANXIETY SCALE

(SNAITH, ET AL., 1978) .................................................................................................274

APPENDIX H: THE WARMTH AND HOSTILITY SUBSCALES FROM THE IOWA

YOUTH AND FAMILY PROJECT (MELBY, ET AL., 1993; MELBY, ET AL., 1995).....275

APPENDIX I: ADOLESCENTS' PERCEPTIONS OF SILENT INTERPARENTAL

CONFLICT SCALE (PRYOR, 2003) ....................................................................................276

APPENDIX J: THE EMOTIONAL SYMPTOMS AND THE CONDUCT PROBLEMS SUBSCALES OF THE STRENGTHS AND DIFFICULTIES QUESTIONNAIRE

(GOODMAN, 1997; GOODMAN, ET AL., 1998) .....................................................................2278

APPENDIX K: THE FUTURE OUTLOOK SCALE...................................................................279 


\section{List of Tables}

Table of Contents.

Table 1.1. Comparison of themes identified in studies of parents'(Kielpikowski \& Pryor, 2008) and adolescents' perceptions of silent conflict (Pryor \& Pattison, 2007)............. 19

Table 2.1. Inventory of Psychometric Instruments for Measurement of Couple Conflict..... 30

Table 2.2. Reliability Coefficient Obtained for Adapted Subscales of Conflict and Problem Solving Scales (Kerig, 1996).

Table 2.3. The 12-Item Interparental Silent Conflict Scale (SICS) Interpreted According to Principal Axis Factoring Subject to PROMAX Rotation - Pattern and Structure Matrices.

Table 2.4. Comparison of Eigenvalues obtained from EFA and Monte Carlo PA. .................52

Table 2.5. SICS Factor Intercorrelations, Reliability Coefficients and Descriptive Statistics $(\mathrm{N}=108)$

Table 2.6. Correlations between Factors of SICS, Other Measures of Relationship Conflict

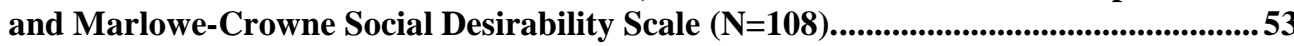

Table 2.7. Correlations between Items of SICS and scores on M-C 1(10)................................54

Table 2.8. Time1: SICS Factor Intercorrelations, Reliability Coefficients and Descriptive Statistics $(\mathbf{N}=\mathbf{2 6 0})$.

Table 2.9. T1: Intercorrelations between scores on SICS and IDA measures of psychological wellbeing $(\mathbf{N}=\mathbf{2 6 0})$.

Table 2.10. Time2: SICS Factor Intercorrelations, Reliability Coefficients and Descriptive Statistics $(\mathrm{N}=242)$.

Table 2.11. T 2: Intercorrelations between scores on SICS and measures of psychological wellbeing $(\mathrm{N}=\mathbf{2 4 2})$.

Table 2.12. Standardised regression weights (factor loadings) at Times 1 and 2 for the longitudinal structural stability model of SICS.

Table 2.13. Covariances, standard errors, critical ratio values and significance values for the longitudinal structural stability model of SICS.

Table 3.1. Means and standard deviations for men and women $(\mathrm{N}=115$ each) on measured variables.

Table 3.2. Intercorrelations between measured variables for men (in red above the diagonal) and women (in black below the diagonal) at $\mathrm{T} 1$ and $\mathrm{T} 2(\mathrm{~N}=115$ each).

Table 3.3. Intercorrelations between subscales of SIC and psychological maladjustment (IDA) at $\mathrm{T} 1$ for men (M) and women (W).

Table 3.4. Intercorrelations between subscales of SIC and psychological maladjustment (IDA) at $\mathrm{T} 2$ for men (M) and women (W).

Table 3.5. Intercorrelations between subscales of SIC and psychological maladjustment (IDA) at T1 for men (M) and subscales of SIC and psychological maladjustment (IDA) at $\mathrm{T} 2$ for women $(\mathrm{W})$.

Table 3.6. Intercorrelations between subscales of SIC and psychological maladjustment (IDA) at T1 for women (W) and subscales of SIC and psychological maladjustment (IDA) at $\mathrm{T} 2$ for men (M).

Table 3.7. Longitudinal models of silent conflict factors (Maker, Costs and Benefits) and psychological maladjustment for parental dyads $(\mathrm{N}=115)$ - Standardized path coefficients $(M=$ men; $W$ = women $)$.

Table 3.8. Model fit indices for the Marker, Costs and Benefits models of distress $(\mathbf{N}=115)$.

Table 3.10. Means and standard deviations for men and women $(\mathrm{N}=115 \ldots \ldots . . . . . . . . . . . . . . . . . . .133$

each) on measured variables.........................................................................................133

Table 3.11. Intercorrelations among measured variables for men (in red above the diagonal) and women (in black below the diagonal) at $\mathrm{T} 1$ and $\mathrm{T} 2$......................................... 134

Table 3.12. Intercorrelations among predictor variables at $\mathrm{T} 1$ and men's and women's scores on SICS at T2.

Table 3.13. Concurrent intercorrelations among predictor variables and men's and women's

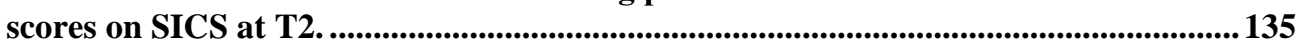

Table 3.14. Standardised path coefficients for concurrent predictor models........................ 142

Table 3.15. Standardised path coefficients - longitudinal dyadic predictors.......................... 143 
Table 3.16. Model fit comparison for nested longitudinal SIC predictors models.

Table 4.1. Time1: APSICS factor intercorrelations, reliability coefficients and descriptive statistics $(\mathbf{N}=\mathbf{1 3 1})$

Table 4.2. APSICS CFA at T1 - Model fit indices..........................................................156

Table 4.3. Time 2: APSICS factor intercorrelations, reliability coefficients and descriptive statistics $(\mathbf{N}=123)$.

Table 4.4. CFA T2 - Model fit indices. ......................................................................................160

Table 4.5. Reliability coefficients for the whole sample and descriptive statistics for boys and girls at Time 1 and Time 2 .

182

Table 4.6. Intercorrelations between boys' $(N=61)$ and girls' $(N=54)$ perceptions of SIC, adolescent-directed maternal and paternal hostility, emotional symptoms, conduct problems, and future outlook at Time 1 and Time 2. (Boys' correlations are shown in blue below the diagonal and girls' are shown in red above the diagonal.)

Table 4.7. Descriptive statistics and intercorrelations among the variables constituting the hypothesised familywide model for boys $(\mathrm{N}=61)$

Table 4.8. Descriptive statistics and intercorrelations among the variables constituting the hypothesised familywide model for girls $(\mathrm{N}=54)$. 


\section{List of Figures}

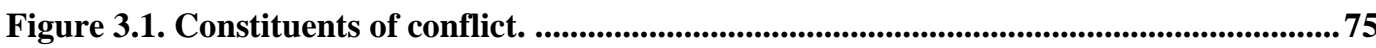

Figure 3.2. The socio-pragmatic model of responding in conversation (Kurzon, 1997)......... 79

Figure 3.11. Hypothesised longitudinal model of silent interparental conflict and

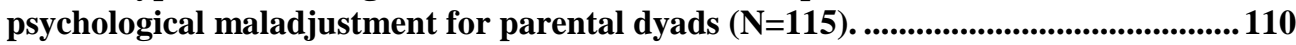

Figure 3.12. Dual Concern Model (from Pruitt and Kim, 2004). .......................................117

Figure 3.13. Concurrent predictors of SIC for men at T1- standardised estimates............... 136

Figure 3.14. Concurrent predictors of SIC for men at T2 - standardised estimates.............. 136

Figure 3.16. Concurrent predictors of SIC for women at T1- standardised estimates......... 138

Figure 3.17. Concurrent predictors of SIC for women at T2 - standardised estimates........ 138

Figure 3.18. Longitudinal predictors of SIC for women controlling for effects of SICS scores at T1- standardised estimates.

Figure 3.19. Hypothesised concurrent APIM for predictors of SIC for fathers and mothers at Time 1 and Time 2.

141

Figure 3.20. Hypothesised longitudinal APIM for predictors of SIC for fathers and mothers.

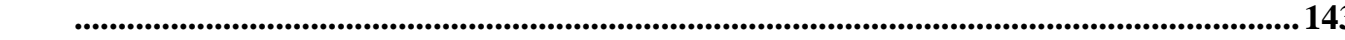

Figure 4.1. Hypothesised four factor model of the APSICS fitted to Time 1 adolescents' data $(N=131)$; item labels correspond to the content of questionnaire presented in Appendix I.

Figure 4.2. Hypothesised four factor model of the APSICS fitted to Time 2 adolescents' data $(\mathrm{N}=123)$; item labels correspond to the content of questionnaire presented in Appendix I. 159

Figure 4.3. Hypothesised cross-sectional process model of the effects of SIC on adolescents' adjustment.

Figure 4.4. Hypothesised process model of the effects of SIC on adolescents' adjustment over time.

Figure 4.5. Hypothesised concurrent model for boys $(N=61)$ showing significant correlations between the IV, MVs and DVs at Time 1 in red ink.

Figure 4.6. Hypothesised concurrent model for boys $(N=61)$ showing significant correlations between the IV, MVs and DVs at Time 2 in red ink.

Figure 4.7. Hypothesised concurrent and longitudinal models for boys $(N=61)$ showing significant correlations between the IV, MVs and DVs in red ink

Figure 4.8. Hypothesised concurrent model for girls $(N=54)$ showing significant correlations between the IV, MVs and DVs at Time 1 in red ink.

Figure 4.9. Hypothesised concurrent model for girls $(N=54)$ showing significant correlations between the IV, MVs and DVs at Time 2 in red ink.

Figure 4.10. Hypothesised longitudinal model for girls $(N=54)$ showing significant correlations between the IV, MVs and DVs in red ink.

Figure 4.11. Boys' path model of the concurrent effect of SIC on Internalising at T1, standardised estimates $(* p<.05)(C E m P=$ internalising $)$.

Figure 4.12. Boys' mediation model of the concurrent effect of SIC on Externalising and Internalising at T2, standardised estimates $(* * * p<.001 ; * * p<.01 ; * p<.05),($ HostCM $=$ Mother's hostility to child $;$ HostCF $=$ Father's hostility to child, $\mathbf{C E m P}=$ internalising)

Figure 4.13. Boys' longitudinal path model of the effect of SIC on Internalising mediated by Father's hostility, standardised estimates $(* * * p<.001 ; * * p<.01 ; * p<.05),($ HostCF $=$ Father's hostility to child, CEmP = internalising).

Figure 4.14. Girls' composite mediation model of the concurrent effect of SIC on Future Outlook at T1, standardised estimates $(* * p<.01 ; * p<.05),($ HostCM $=$ Mother's hostility to child; FutO $=$ Future Outlook)

Figure 4.15. Girls' path model of the concurrent effect of SIC on Externalising mediated by Mother's hostility at T2, standardised estimates $(* * \mathrm{p}<.01),($ HostCM $=$ Mother's hostility to child).

Figure 4.16. Girls' longitudinal model of the effects of SIC on Future Outlook and Internalising, standardised estimates $(* * * p<.001 ; * * p<.01 ; * p<.05),($ HostCM $=$ Mother's hostility to child; CEmP = internalising, FutO = Future Outlook). 
Figure 4.17. Conceptual path model of the effects of SIC on adolescents' adjustment after Harold and colleagues (1997).

Figure 4.18. Familywide path model of the effects of SIC on boys' internalising problems $(* * * p<.001 ; * * p<.01 ; * p<.05),($ HostCF $=$ Father's hostility to child, CEmP = internalising)...................................................................................................................208

Figure 4.19. Familywide path model of the effects of SIC on girls' Future Outlook $(* * p<.01$; * p <.05), (HostCM = Mother's hostility to child; FutO $=$ Future Outlook). ................209 


\section{Chapter 1: Introduction}

Conflict is one of the fundamental human interactions and due to its universality has been studied extensively within numerous disciplines. A widely accepted contemporary view of conflict is that it is a normal and inevitable part of interpersonal relations (Cummings \& Davies, 1994; Wilmot \& Hocker, 2007).

Notwithstanding its ubiquity, conflict is not a simple phenomenon. The multifaceted nature of conflict is reflected in a number of coexisting definitions varying in emphases indicative of the investigative perspectives of their authors. For example, a definition used by the family psychology scholars Cummings and Davies (2002) focuses on behaviour: 'Any dispute, disagreement or expression of unfavourable emotions' (p. 34). In contrast, the social psychological viewpoint of Pruitt and Kim (2004) centres on perceptions, as may be seen in the definition they propose: 'Perceived divergence of interests, a belief that the parties' current aspirations are incompatible' (pp. 7-8). Alternatively, a definition of the conflict scholars and practicing mediators Wilmot and Hocker (2007) offers a more comprehensive synthesis: 'An expressed struggle between at least two interdependent parties who perceive incompatible goals, scarce resources, and interference from others in achieving their goals' (p. 9).

Our understanding of interparental conflict is informed by two extensive bodies of literature, one encompassing family research and the other marriage research. The two differ in focus, manifested by the dependent variables of interest to each of these scholarly domains. Accordingly, central to conflictrelated marriage research have been the issues of marital quality and distress, whereas the conflict-focused family research has concentrated in the main on the 
psychosocial adjustment of children. These two bodies of research refer to largely distinct theoretical resources to pose questions and provide explanations.

Nevertheless, although separate, the theories drawn upon by the relationship and by the family scholars may be brought together under an overarching structure of the ecological framework (Bronfenbrenner, 1979, 1986) and the family systems theory (Cox \& Paley, 1997, 2003; Minuchin, 1985).

In this chapter a rich background is sketched in broad strokes, whereas more focused theory and empirical evidence are called upon in specific chapters dedicated to parents' and to adolescents' processes.

\section{Overarching theories}

There can be little doubt that Uri Bronfenbrenner's ecological model (1979) has paved a path of no return for the acceptance of human development as occurring in a complex intertwined system of environmental influences. The model provides a conceptualisation of the ecological environment as a set of nested dimensions. The most immediate and concrete is the Microsystem, a dimension within which operate proximal processes sustaining development, with the family providing a crucial setting. The most abstract is the time dimension or the Chronosystem. These two extreme dimensions are highlighted here in order to emphasise two salient points. First, this work focuses on the family as the primary and the most influential environment for the functioning of young people; second, recognising the time dimension makes it possible to acknowledge that while searching for objective truths, it is important to recognise that findings about the families in this research are subject to the socio-cultural confines of the time and 
space we inhabit. To this end, the ecological model situates and provides a sense of the environmental structure.

The idea of dynamic embeddedness is also central to the conceptualisation of families as systems (Cox \& Paley, 1997, 2003; Minuchin, 1985). According to family systems theory, families are complex dynamic structures characterised by interdependence of their members. Consequently, in order to fully understand the functioning of individual family members, the context of the family system has to be taken into account. Family members form multiple subsystems (parents, children, siblings, males, females) within the greater structure and interact and influence one another both on systemic and individual levels, between and within the subsystems. The subsystemic bonds vary in magnitude of influence and in longevity, as may be expected of a dynamic arrangement. In this work I draw on family systems theory to plot and interpret the processes taking place between the husbands and the wives (the marital subsystem) and between the mothers, the fathers and the children, who combine into family subsystems such as parental dyads and parent - child dyads, to interact and influence one another. These influences are bi-directional, transactive and ongoing over time. Subsystems are greater than sums of their parts, therefore dyads display properties absent in individuals; dyadic links may also 'amplify and channel' weak individual characteristics. Consequently, without considering the nested relationships individuals are involved in one may reach incomplete and incorrect conclusions (Shanahan \& Sobolewski, 2003, p. 247).

In this thesis the family systems theory (Cox \& Paley, 1997, 2003; Minuchin, 1985) and the ecological framework (Bronfenbrenner, 1979, 1986) have been applied as 'macro' theories organising the multitude of 'micro' theories 
invoked to pose questions and interpret the findings. Consequently, the work that follows should be viewed through the lenses they provide.

\section{Conflict in marriage ${ }^{1}$ research}

The study of marital relationships has been stimulated to a large extent by practical considerations, namely by the problems and distress experienced by couples and by the consequent desire on the part of practitioners and researchers to offer better informed and effective interventions (Fincham \& Beach, 1999).

Significant insights into marital conflict have been gained from comparisons of behaviours and cognitions characteristic of distressed and nondistressed couples. Observations of couples' interactions in the context of problem solving have uncovered important indicators of marital quality (Gottman, 1994). Conflict behaviour researchers have documented specific patterns of dyadic interactions, such as negative affect reciprocity (Gottman, 1998), reactivity (Jacobson, 1990), and demand-withdraw (Christensen \& Heavey, 1990; Heavey, Layne, \& Christensen, 1993). Negative affect reciprocity refers to a tendency of partners in relationships characterised by distress to reciprocate negative behaviours of their spouses, over and above the base rate differences (Gottman, 1998). Accordingly, it has been observed that distressed spouses reacted to negative affect, such as sadness or irritation of their partners, which in turn resulted in perpetuating the destructive cycle (Fincham \& Beach, 1999). Reactivity (Jacobson, 1990) denotes the propensity of distressed couples to be particularly responsive to recent or immediate relationship events. In contrast, happy couples have been found to exhibit a more long-term relational orientation.

\footnotetext{
${ }^{1}$ The present research makes no distinction between married and cohabiting parents. However, I refer to existing marriage research, rather than general research on 'romantic relationships', in an endeavour to focus on family units.
} 
Perhaps the most studied of the three interactions is the demand-withdraw, which refers to a contingent pattern involving active instigation of change by one partner, which is met with passivity or defensiveness of the other partner, who effectively (or literally) withdraws from the interaction (Christensen \& Heavey, 1990; Gottman, 1994; Heavey, et al., 1993).

Research focused on cognitions (Bradbury \& Fincham, 1990, 1992) has indicated that the attributions couples make exert a significant influence on the course of their relationships and their marital satisfaction. Consequently, spouses who attributed causes and responsibility for marital problems to their partners tended to display destructive conflict behaviours in contrast to spouses who made more positive and benevolent attributions. Additionally, the pattern of negative attributions was more predictive of destructive conflict behaviours for distressed than for non-distressed spouses (Bradbury \& Fincham, 1990). Moreover, nondistressed partners displayed a tendency towards more positive attributions in contrast to a generally more negative attributive tendency of distressed couples.

In an attempt to situate marital conflict within a greater relational context Karney and Bradbury (1995) proposed the vulnerability - stress - adaptation model. The model posits that all couples experience transitions and environmental challenges that affect their relationships (stressful events). The stressful events encompass traumatic incidents, economic challenges, work-related problems, transition to parenthood and serious illnesses (Belsky, 1990; Bradbury, Fincham, \& Beach, 2000; Kluwer, 2000). The adversarial and ineffective ways of responding to conflict amplify the stressful life events and add to individual and family distress (Bradbury, et al., 2000). The way partners relate to each other, and their behaviours and cognitions in dealing with problems (adaptive processes) 
influence the quality and stability of marriage. The resources families are able to mobilise in the face of adversity act as moderators of the effects of these stressors on the family wellbeing. Additionally, partners bring into relationships their personal characteristics such as personality or attachment styles (vulnerabilities) that influence the adaptive processes or contribute to the stressful events.

Unsurprisingly, couples' conflict holds a significant place within the study of marital relationships as a potential source and a contributor to distress and psychological maladjustment. Research to date has shown consistent associations between marital discord and mental health problems of spouses ranging from depression (Beach, Fincham, \& Katz, 1998; Fincham \& Beach, 1999; Fincham, Beach, Harold, \& Osborne, 1997; O'Leary, Christian, \& Mendell, 1994); through eating disorders (Van den Broucke, Vandereycken, \& Norre, 1997) to alcohol abuse (e.g. Murphy \& O'Farrell, 1994). In view of the ubiquity of relationship conflict, the findings are particularly troubling.

Relationship conflict may be expressed in many forms, from the overt extreme of physical aggression, through varying in degrees of hostility verbal disagreements, to the opposite end of the spectrum expressed by breakdowns in communication and distancing between partners. It is important to note that marital conflict scholarship has focused on the verbal and physical expressions of conflict, and in comparison, the non-verbal non-physical conflict interactions have been inadequately conceptualised and studied empirically. Nevertheless, stonewalling (or listener withdrawal), while notably low on palpable aggression, has been identified by John Gottman together with criticism, defensiveness and contempt (ominously named the "Four Horsemen of the Apocalypse"), as a 
conflict behaviour associated with long- term marital dissatisfaction and predictive of divorce (Gottman, 1994; Gottman \& Krokoff, 1989).

Conflict-focused scholarship in multiple disciplines has placed much importance on the goal of resolution (Cupach \& Canary, 1997; Deutsch \& Coleman, 2000; Pruitt \& Kim, 2004; Wilmot \& Hocker, 2007). In order to achieve a resolution of a conflict the opposing parties need to engage with each other in a collaborative way. Both the competitive engagement (arguments) and the disengagement strategies (withdrawal, inaction) prevent, or at least delay, conflict resolution (Wilmot \& Hocker, 2007). Similarities among various social conflict interactions are undeniable regardless of the level of intimacy between the adversaries. However, intimate relationships are characterised by a unique interrelatedness of the involved parties, which is absent among the political or business ones. For example, marital partners are tied by emotional bonds; additionally they cannot be treated as purely competing entities acting to maximise individual gains, as they also act to benefit the family unit they are invested in, which may therefore motivate them to act more altruistically. Nevertheless, it is quite transparent that avoidance, withdrawal and stonewalling act to sabotage and erode any attempts at collaborative engagement intrinsic to conflict resolution process.

\section{Conflict in family research}

According to Shantz and Hobart (1989), families probably engage in more conflict than other social groups, as the closeness and the amount of time spent together provides family members with ever-present and ongoing opportunities for interpersonal boundary violations. Most likely, a majority of people experience conflict for the first time within the family context. Therefore, as a 
member of a family, it is inevitable that at some point in time every child will be exposed to some degree of parental conflict. According to social learning theory (Bandura, 1977) parents provide powerful models for children's social behaviours, therefore family home is where conflict interaction behaviour is modelled and learnt in interactions with parents and siblings, which evolve through childhood (Dunn, 1983). Consequently, the social learning perspective implicates the family home as the learning ground for conflict interaction behaviours, which children learn and apply in their own relationships. These learnt behaviours might be ineffective or even violent; however, models of effective conflict strategies also act as developmental contributors to children's future conflict resolution abilities and equip them to manage their future disagreements productively.

Interparental conflict has been the focus of research for a number of family psychologists for some decades. The first generation of studies resulted in a wealth of correlational findings that have directed more recent research towards exploring the underlying processes (Cummings \& Davies, 2002). At the same time, contemporary family research has been criticised for its largely atheoretical character (Fincham \& Beach, 1999) and for the absence of a coherent macro theory that would act to integrate the 'micro' theories researchers call upon in a somewhat eclectic fashion. In this regard, family research focused on interparental conflict has largely called upon two theoretical frameworks, namely the emotional security hypothesis of Davies and Cummings (1994) and the cognitive contextual framework of Grych and Fincham (1990). Despite commonly citing both theories, most researchers utilise one or the other, with few 
studies attempting integration; for examples of exceptions see Buehler, Lange \& Franck (2007), Mann \& Gilliom (2002) or Turner \& Barrett (1998).

The focus on process has resulted in a twofold conceptualisation of the modus operandi of interparental conflict in relation to children, the direct and the indirect. As witnesses, children are directly affected by parental discord. The responses of children witnessing interparental conflicts have been conceptualised within the aforementioned complementary theories. The cognitive-contextual framework of Grych and Fincham (1990) conceptualises interparental conflict as a stressor appraised by children in regard to threat, causes, attributions of blame for the arising of conflict, and coping efficacy. The appraisals result from children's attempts to make sense of the experience and are both affected and themselves affect children's emotions in the context of interparental conflict (Grych \& Cardoza-Fernandes, 2001). These appraisals guide children's future behaviours in the face of parental conflicts and have implications for their wellbeing and potential adjustment problems. The emotional security hypothesis proposed by Davies and Cummings (1994) draws on attachment theory of John Bowlby (1969) and centres on children's striving to preserve their emotional security in response to interparental discord, seen as posing a threat to this security by compromising both the interparental and the parent-child relations. Children's responses involve their management of emotions, cognitive representations of conflict and their coping behaviours, which if maladaptive, may result in emotional and behavioural problems. In turn, children's attributions and how they cope with the conflict depend on the level of emotional security. The two frameworks differ mainly in emphases, one on cognitions, and the other on affect, and they both contain affective, cognitive and behavioural components. 
Moreover, both frameworks acknowledge the importance of children's appraisals of interparental conflict. Unsurprisingly, the individual's own experiences are the best predictors of his or her outcomes, a regularity that has been demonstrated in regard to children's perceptions of interparental conflict and their adjustment (Emery \& O'Leary, 1982; Wild \& Richards, 2003)².

The indirect effects of marital conflict on children are conveyed through the changes in the parent-child relationship, especially in the deterioration of the parenting effectiveness and practices (E. M. Cummings \& Davies, 1994; Erel \& Burman, 1995; Fauber, Forehand, Thomas, \& Wierson, 1990). Conflicted parents may enforce atypically harsh discipline, exercise less control, and be inconsistent in their parenting decisions; additionally their emotional availability to children reduces, resulting in lower than normal levels of support and acceptance (Krishnakumar \& Buehler, 2000).

Interparental animosity may also generalise to parents' relations with children in the form of scapegoating, hostility and negative co-parenting. All of these behaviours have been identified by Erel and Burman (1995) in a metaanalysis of 68 studies and subsumed by the authors within the spillover hypothesis. In contrast, the simultaneously proposed compensatory hypothesis, which posed that conflicted parents seek satisfaction missing in the relationship with the spouse in the relationships with children, has found no support.

The ongoing investigations of interparental conflict have resulted in an imposing body of evidence documenting adverse effects of interparental discord on children's social and emotional functioning. Interparental conflict has been

\footnotetext{
2 In contrast, longitudinal studies have generally failed to find a direct link between interparental conflict and child adjustment (e.g. Grych, Harold, \& Miles, 2003; Harold, Fincham, Osborne, \& Conger, 1997; Shelton \& Harold, 2007).
} 
implicated in such detrimental children's outcomes as internalising problems (Dadds, Atkinson, Turner, Blums, \& Lendich, 1999; Gerard, Buehler, Franck, \& Anderson, 2005; Harold, et al., 1997); externalising problems (Grych, Fincham, Jouriles, \& McDonald, 2000; Katz \& Gottman, 1993); lowered self esteem (Tschann, Flores, Pasch, \& Marin, 1999); lowered social competence demonstrated in relationships with siblings and peers (Du Rocher Schudlich, Shamir, \& Cummings, 2004; Paley, Conger, \& Harold, 2000); academic underachievement (Harold, Aitken, \& Shelton, 2007) and biological dysregulation exhibited by disrupted sleep patterns (El-Sheikh, Buckhalt, Cummings, \& Keller, 2007; El-Sheikh, Buckhalt, Mize, \& Acebo, 2006).

Conflicts between parents span a wide range of expressions between the extremes of physical violence, through degrees of verbal disagreement, to the covert end of the spectrum evidenced by distancing between parents. Particularly harmful to children appear to be conflicts involving high levels of hostility, physical aggression, verbal aggression, threats, and personal insult, which have be described as destructive (Goeke-Morey, Cummings, Harold, \& Shelton, 2003). Unsurprisingly therefore, an extensive body of research exists related to parental verbal and physical conflicts and their effects on children. In comparison there is a striking dearth of studies regarding the nature and the outcomes for children of parental non-verbal and non-physical conflict. Nearly two decades ago, Cummings and Davies (1994) noted that 'non-verbal anger' between parents is commonplace but under-researched. They went on to observe that due to its relative subtlety and ambiguity, compared to other conflict expressions, nonverbal anger may be difficult to discern and to remember, and that it may not have 'appreciable' or long-term effects on children's adjustment; nevertheless, in their 
opinion, more research was needed (p. 68). The paucity of research on non-verbal non-physical interparental conflict has persisted, yet undeniable effects of this type of conflict on children have been demonstrated persuasively in a handful of studies. For example, a video vignette study by DeArth-Pendley and Cummings (2002) found children's reactions to be similar in response to verbal and nonverbal parental conflict, with non-verbal expressions of fear causing the most negative responses. The result led the researchers to conclude that children evaluate the meaning of conflict, and not the form of its expression. El-Sheikh and Reiter (1996) conducted a laboratory simulation of verbal, physical and covert arguments (the latter represented by sighs and angry looks) performed by actors and found that children showed that same levels of distress in response to verbal and non-verbal anger manipulations. A home diary-based study by Cummings, Goeke-Morey and Papp (2003) found relations between parental diary reports of conflict tactics and global reports of conflict or distress for nonverbal hostility alongside such destructive strategies as insult, verbal hostility, defensiveness and physical distress. Further support for destructiveness of nonverbal parental conflict came from the findings of an analogue study by GoekeMorey, Cummings, Harold and Shelton (2003), which classified parental conflict strategies into constructive and destructive from the perspective of children's outcomes based on the criteria derived from the emotional security hypothesis (Davies \& Cummings, 1994). The study found that according to children's emotional reactions, marital non-verbal hostility belonged among the destructive conflict tactics together with physical aggression, aggression against objects, verbal hostility and threat to intactness of marriage. 
Links between parental conflict withdrawing behaviours and behaviour problems of children have been shown by a study of Katz and Woodin (2002). Further supporting evidence came from research by Tschann, Flores, Pasch and Marin (1999), which found that parental withdrawal from each other in the context of conflict predicted children's lowered self esteem and academic competence. Additionally, two recent studies compared the processes of interparental hostility and withdrawal; the findings supported the sensitisation hypothesis and indicated that interparental withdrawal had a long-term effect on children's internalising, externalising and school adjustment (P. T. Davies, Sturge-Apple, Winter, Cummings, \& Farrell, 2006; Sturge-Apple, Davies, \& Cummings, 2006a, 2006b). Moreover, adolescents' perceptions of covert interparental conflict comprising triangulating were related to internalising problems (Buehler, et al., 1998) and both depression and antisocial behaviour (Bradford, Vaughn, \& Barber, 2007).

The reported compilation of findings is characterised by conceptual heterogeneity, as diverse behaviours ranging from frowns and sighs (El-Sheikh \& Reiter, 1996) to triangulation (Bradford, et al., 2007; Buehler, et al., 1998) and stonewalling (Katz \& Woodin, 2002) are put together under one rubric. Equally diverse are the methodologies used in the studies, ranging from observations (e. g. De Arth-Pendley \& Cummings, 2002) to home diaries (E. Mark Cummings, et al., 2003). Additionally, although observational laboratory studies, including analogue live enactments and video vignettes, provide valuable immediate insights into children's reactions to interparental conflict, they are devoid of family context and consequently report focused experiences free from noise characteristic of natural environments. As a result, the reported experiences 
may be augmented. Moreover, the interpretation of the effects on children relies on expertise of observers, who regardless of training have access only the overt responses to the conflict stimuli, which they code. The methodological status quo has been reflected to some degree in the recent comment made by Cummings, Davies and Campbell: "Nonverbal forms of conflict expression are not adequately assessed by any of the questionnaire instruments used to record rates of different forms of marital conflict in the home" (2000, p. 263).

Notwithstanding the conceptual heterogeneity and methodological diversity apparent in reporting the phenomenon and its effects on children, the scant empirical evidence of the detrimental effects of interparental discord that is neither a physical nor a verbal confrontation is strikingly unequivocal. The combination of a strong message conveyed by the results of the reported research, the small number of existing studies, together with the lack of conceptual unity, as well as the apparent absence of a psychometric instrument to capture the nonverbal interparental conflict declared by Cummings and colleagues (2000) compelled us to embark on a systematic research programme (Kielpikowski, 2004; Pryor, 2003), which resulted in introducing the concept and term of silent interparental conflict.

Initially, qualitative methodology was employed, which may in itself be seen as addressing a specific research gap. By framing our object of enquiry broadly as 'a conflict that is neither verbal nor physical', we have effectively introduced a conceptualisation of the underlying construct as the outcome of subtracting physical aggression and verbal interactions from the entirety of conflict expressions. The semi-structured interview format was chosen, as it is 
particularly appropriate for exploratory inquiry in allowing participants considerable freedom to express their views.

The study with parents (Kielpikowski, 2004; Kielpikowski \& Pryor, 2008) was primarily focused on how they made sense of a conflict that was neither verbal nor physical. Participants were 13 parents $^{3}$ (seven females and six males) aged between 27 and 47 years, recruited by word of mouth. The group consisted of eight New Zealanders of European descent, one Maori, and four people who identified themselves as Europeans.

Participants were asked whether they recognised a conflict that was neither verbal nor physical in their relationships and how they would describe it. I also asked whether their children were aware of this type of conflict and to explain the answer. Data were analysed using inductive thematic analysis (Braun \& Clarke, 2006).

The analysis resulted in five key themes: (1) Behavioural change as a marker of silent conflict, (2) Lack of resolution, (3) Avoidance and withdrawal, (4) Costs of silent conflict, and (5) Benefits of silent conflict.

The findings indicated that the participants easily recognised the nonverbal non-physical type of conflict interaction with their partners. Behavioural change served as a diagnostic criterion of silent conflict. Although not articulated verbally, partner behaviour acted to communicate the presence of conflict. Indeed, combined with the absence of interpersonal communication, parental behaviours expressed conflict resoundingly enough to convey the message of conflict between parents to children.

\footnotetext{
${ }^{3}$ Fourteen parents were interviewed for the study; however, due to a technical problem, the content of one audio taped interview was irretrievable and could not be included.
} 
The lack of resolution was an intrinsic feature of silent conflict, which often resulted from an interaction that was interrupted rather than resolved. Besides, according to the participants, reconciliation between partners frequently occurred without explicit resolution of the issues underlying the silent conflict, indicating that effectively disputes did not cease to exist, but were suspended.

According to the reports of a number of participants, their avoidant and withdrawing conflict behaviours occurred in order to contain, de-escalate or prevent verbal disagreements. Some of the parents reported deliberately opting for silent conflict in place of a heated verbal exchange in order to protect the children from witnessing an argument. Alas, this motivation in relation to children might be mistaken in view of the available findings of the effects of non-verbal nonphysical type of conflict on children.

Parents in the study reported significant negative effects of silent conflict on their emotional and physical wellbeing. These costs of silent conflict were augmented by the concerns for the emotional wellbeing of children and guilt related to the spill over of conflict incidents to them. Additionally, the participants indicated that silent conflict was emotionally and mentally absorbing. Both the emotional fallout of silent conflict and its preoccupying nature have the potential to influence parent-child relationships and compromise the quality of parenting in terms of consistency, attention to the children, support and emotional availability. The cost-benefit appraisal of the silent conflict alternative is therefore likely to indicate that a well-managed and resolved verbal disagreement between parents is the most beneficial option for the family system. Notwithstanding these conclusions it is important to recognise that parents interviewed in my study acknowledged the beneficial and adaptive side of silent conflict. Despite its 
considerable negative effects, parents appreciated the benefits of silent conflict and defended it as an alternative preferable to intense arguments and arguments in front of the children and as a means to regulate emotions.

The parallel perspective of adolescents was explored in a qualitative study by Pryor and Pattison (2007), who interviewed 27 young people aged between 17 and 21 years, five of whom were male; 22 were European, 11 were Maori and six were Pacific Nation. As in the study with adults, semi-structured interviews of approximately one hour duration were conducted.

The derived themes were reported within three broad categories: the nature of silent conflict, the impact on young people, and the young people's coping behaviours. Young people described the build up of negative emotions including tension, anxiety and fear when parents engaged in silent conflict. All of the young people mentioned the role of silence in creating a barrier between the conflicted parents. A wide range of parental behaviours was identified as indicative of interparental silent conflicts. The behaviours included actions intended to annoy the partner; a reduction in normal or affectionate behaviours, and avoidance of partner and other family members. A third aspect of silent conflict identified in the study was its role in maintaining conflict over time. Moreover, the nonverbal nature of this type of conflict meant that the underlying issues were not resolved by parents, which was distressing to children.

In response to interparental silent conflicts the young people described feelings of helplessness, lack of control, insecurity, inability to monitor what was happening, confusion, and self-blame. Mixed messages from parents were also problematic, as children were clearly able to discern interparental silent discord even when parents attempted to assure them that nothing was wrong. 
The participants reported a range of coping strategies they employed in response to silent interparental conflict. Some young people misbehaved in order to divert their parents' attention away from conflict. Two participants reported self-harming as a means of distracting parents and gaining control over the ambiguous situation. Others stayed away from home to avoid the tense atmosphere. Taking sides with a parent perceived as disadvantaged by the conflict was also reported, alongside efforts to comfort the parent and helping out with the chores. Some young people talked about seeking support from extended family and friends.

In sum, the findings of my study with parents (Kielpikowski, 2004; Kielpikowski \& Pryor, 2008) are in a remarkable agreement with the themes derived by Pryor and Pattison (2007) from adolescents' interview data, as may be seen in Table 1.1. Both the adults and the adolescents described parental behaviours related to silent conflict and the lack of explicit resolution. The emotional effects of silent conflict reported by parents were experienced by the adolescents as interpersonal emotional atmosphere in the home. However, when discussing the effects of silent conflict, the adolescents focused only on how it impacted upon them, whereas the parents demonstrated the awareness that it affected both themselves and the children. Moreover, the resultant feelings of guilt and shame had a contribution to the parents' distress. Finally, only the parents recognised the benefits of silent conflict. The differences in perceptions of silent conflict by parents in my study and the adolescents interviewed by Pryor and Pattison (2007) may be contingent on their respective roles in the conflict process. Parents were the actors and the young people were the observers of 
parental silent conflicts or the 'casualties' of their spillover, without access to parental cognitions and motivations.

Table 1.1. Comparison of themes identified in studies of parents'(Kielpikowski \& Pryor, 2008) and adolescents' perceptions of silent conflict (Pryor \& Pattison, 2007).

Parents' themes Adolescents' themes

Behavioural change as marker of silent conflict

Emotional atmosphere

Lack of resolution

Parental behaviour

Avoidance and withdrawal

Lack of resolution

Costs of silent conflict

Impact on young people

Benefits of silent conflict

Adolescents' coping behaviours

In summary, although parents recognised negative consequences of silent conflict, they also saw it as preferable in some instances to overt conflict, due to their understandable desire to restrict overt confrontations in front of their children. Nevertheless, the young people indicated numerous severe consequences of silent interparental conflicts to their wellbeing, suggesting that parents might need to be reconciled with the adverse effects of their well-intended efforts that result in silent conflicts.

\section{Goals for this research}

Qualitative studies with parents and adolescents (Kielpikowski, 2004; Kielpikowski \& Pryor, 2008; Pryor, 2003; Pryor \& Pattison, 2007) provided a springboard for the empirical programme of this research. Broadly, the goals of the programme consisted of development and validation of a measurement scale of silent interparental conflict for parents and validation of the instrument proposed by Pryor (2003) for adolescents. Systematic investigation was to be conducted in order to advance the understanding of the phenomenon of silent interparental conflict and the associated processes from the perspective of parents and adolescents, concurrently and over time. Design of the analyses was to 
recognise the systemic perspective characterised by interrelatedness and reciprocal influences among family members.

\section{Overview of studies}

The empirical work conducted to meet the goals set for this research programme is reported in Chapters 2, 3 and 4.

In Chapter 2 the development and validation of a new measure of silent interparental conflict are described. The design of the scale followed a review of reputable psychometric instruments for measuring couples' conflict, which indicated that the new scale being designed tapped a unique construct that had not been assessed previously. Items were developed on the basis of the findings of my qualitative study (Kielpikowski, 2004; Kielpikowski \& Pryor, 2008). Three studies were conducted. In Study 1 the newly developed items were piloted on a sample of parents in order to establish the structure, reliability and validity of the scale. Exploratory factor analysis was conducted and the convergent validity was tested using the Conflicts and Problem-Solving Scales (CPS) (Kerig, 1996), the Ineffective Arguing Inventory (IAI) and the Conflict Resolution Style Inventory (CRSI) (Kurdek, 1994b). In Study 2 conducted with a sample of parents recruited for the central longitudinal study of this research, the factorial structure of the new scale was corroborated using confirmatory factor analysis. Study 3, with the same sample of parents, was conducted one year later to test the longitudinal stability of the scale. The criterion validity was tested at both measurement times by examining the relationship of the scale with psychological problems of the participating parents measured with Irritability, Depression, Anxiety (IDA) Scale (Snaith, Constantopoulos, Jardine, \& McGuffin, 1978). 
Chapter 3 describes the attempt to illuminate the reasons why silent conflict might have detrimental effects on psychological functioning of the involved parents and the reasons why parents engaged in silent conflict. In the first study of Chapter 3 the effects of silent interparental conflict on wellbeing were hypothesised and tested using structural equation modelling. Following previous research indicating differences in men's and women's paths to distress in the context of marital conflict (e.g. Fincham, et al., 1997), separate models were tested for the husbands and the wives in the sample. Reflecting the systemic perspective taken in this work, mutual influences of partners were assumed and tested. The aim of Study 2 in Chapter 3 was to propose and test the potential predictors of silent interparental conflict. Consistent with the systemic approach taken in this work, the potential role of children in silent conflict was considered, as well as the mutual reciprocal influences partners might exert on each other's processes. Predictors of SIC hypothesised on the basis of my qualitative work (Kielpikowski, 2004; Kielpikowski \& Pryor, 2008) were tested using structural equation modelling. To isolate their potentially distinct processes, separate models were built for mothers and fathers concurrently and over time. Mutual influences between partners were tested with the Actor Partner Interdependence Model (Kenny, et al., 2006).

The aim of Chapter 4 was to gain further understanding of the young people's perspective on silent interparental conflict and to examine the mechanisms behind the effects this conflict might have on their psychological adjustment. The chapter includes three studies. The aim of Study 1 was to corroborate the factorial structure of the psychometric instrument for the measurement of adolescents' perceptions of silent interparental conflict (APSIC) 
designed by Pryor (2003). To that end the measure was subjected to confirmatory factor analyses at two measurement points separated by one year. Study 2 comprised analyses of the processes linking silent interparental conflict with adolescents' psychological adjustment. Explanatory process models of the effects of APSIC on adolescents' functioning were hypothesised using the cognitivecontextual framework (Grych \& Fincham, 1990) and the spillover hypothesis (Erel \& Burman, 1995) and tested with structural equation modelling. The aim of Study 3 was to bring together the perspectives of parents and adolescents reflecting the systemic nature of family processes. To that end the process of the effects of SIC on adolescents' adjustment was modelled using parents' reports of silent conflict alongside adolescents' in the spillover based structural models inspired by familywide process models of Harold and colleagues (Harold \& Conger, 1997; Harold, et al., 1997). The main findings of the whole investigative process are discussed in Chapter 5. 


\section{Chapter 2: Development and Validation of the Silent Interparental Conflict Scale for Adults: Concurrent and Longitudinal Testing}

The objective of this chapter is to describe the development and validation of a new measure of silent interparental conflict. First an attempt was made to establish the status quo of the reputable psychometric instruments used by researchers to measure conflict between couples. Once assembled, the content of the scales was analysed in order to assess their potential usefulness to this study and to ensure that the new scale being designed tapped a unique construct that had not been measured previously. Next, on the basis of the findings of my qualitative study (Kielpikowski \& Pryor, 2008) an extensive pool of items was developed. Three studies were then conducted. In the first study the newly developed items were piloted on a sample of parents. The goal was to select the best performing items to form the proposed scale and to establish its structure, reliability and validity. An exploratory factor analysis was conducted and the convergent validity was tested using the Conflicts and Problem-Solving Scales ${ }^{4}$ (CPS) (Kerig, 1996), the Ineffective Arguing Inventory (IAI) and the Conflict Resolution Style Inventory (CRSI) (Kurdek, 1994b). The aim of Study 2 conducted with a sample of parents recruited for the longitudinal family study was to corroborate the factorial structure of the new scale using confirmatory factor analysis. Study 3, involving the same sample of parents, was conducted one year later to test the longitudinal stability of the scale. Criterion validity of the scale was tested at both

\footnotetext{
${ }^{4}$ To aid brevity, when possible names of psychometric instruments are given in full when cited for the first time and subsequently their acronyms are used.
} 
measurement times by examining its relationship with psychological problems measured with Irritability, Depression, Anxiety (IDA) Scale (Snaith, et al., 1978).

\section{Psychometric Status Quo}

Before constructing a new psychometric instrument it was considered prudent to establish the status quo regarding instruments used by family researchers to measure partners' self reports of interparental conflict in order to identify the available resources and eliminate the potential for duplication. My goal was to assemble a representative list of contemporary psychometric scales used in the field of family psychological research and to critically examine their contents. A twofold strategy was employed for this purpose. First, it was elected that the primary source of instruments for this purpose would be the Handbook of Family Measurement Techniques by Touliatos, Perlmutter and Straus (2001), a compendium of family related measurement instruments spanning the period from 1929 to 1996 . The collection was selected on the strength of the premise behind its inception that encompassed assembling an extensive number of family measurements and techniques supported by ample validity and reliability information (Schumm, 2001, p.1) and the scientific standing of its editors and contributing authors. The Handbook index comprises 55 instruments under the heading of 'conflict', whose descriptions and content were closely examined. This process led to exclusion of instruments that did not meet the criterion of usefulness for the purpose of this investigation. First, instruments based on methodology other than self reports (e.g. observation, behavioural ratings) were excluded, along with instruments targeting children rather than parents or main caregivers in families. The next level of exclusions involved measures targeting narrowly specified adult participant groups (e.g. violent men, newlyweds, spouses 
of alcoholics, pregnant spouses, solely women or solely men) and those conceptualising conflict with high level of specificity, for example as related to work-family balance or as a struggle for control in a relationship. Measures designed for the purpose of testing of specific hypotheses, such as Gottman's conflict development stages (Eggeman, Moxley, \& Schumm, 1985) were also excluded. Finally, a close examination of the remaining instruments was conducted in order to ensure that their object of measurement was conflict per se, and this resulted in eliminating further scales, whose purpose was to measure variables other than conflict. The final number of eligible instruments thus obtained was 26 . The content of the instruments was closely scrutinised and as a result four broad thematic domains were identified. These were: areas of conflict/reasons for conflict; efficacy of conflict resolution; types of conflict behaviour; and multiple dimensions of conflict. The instruments were grouped thematically.

The second strategic step was to update the thus assembled inventory to include any potential instruments created since 1 January 1997, the date immediately following the most current scales listed by Touliatos et al., and to ensure that any existing instruments recently used in family research have not been omitted. For that purpose I conducted computerised searches of PsycARTICLES, ERIC and Proquest databases using interparental conflict as the keyword. The term was chosen deliberately as it accurately reflected my rationale for inclusion of instruments from the Handbook of Family Measurement Techniques (Touliatos, et al., 2001). The searches were conducted prior to finalising the composition of the new scale in August 2005 and, in order to maintain the selection standards of the compendium, were narrowed to peer 
reviewed articles published in the English language. The searches produced 23 results from PsycARTICLES, 15 from ERIC and 69 from Proquest, with the expected substantial content overlaps between databases. Having eliminated the overlaps, the next level of selection involved closely reading the abstracts of the resulting 82 articles in order to ensure their relevance on the basis of meeting the following criteria: a) parental participation in the study, b) quantitative methodology, and c) parental self reports of conflict between spouses. Thirty potential articles were identified and their full text versions were then consulted, resulting in 19 articles fulfilling the methodological criteria. Finally, the conflict scales administered by the authors to participating parents were examined and compared to the previously tabled list. The analysis revealed the following distribution of measures: O'Leary Porter Scale (OPS) (1980) was used in seven studies; Locke-Wallace Marital Adjustment Test (MAT) (Locke \& Wallace, 1959) was used in five studies (either in a short or a full form); Conflict Tactics Scale (CTS) (Straus, 1979; Straus, Hamby, Boney-McCoy, \& Sugerman, 1996) was used in three studies; Conflicts and Problem-Solving Scales (CPS) (Kerig, 1996) was used in two studies; Marital Hostility subscale from Iowa Youth and Families Project Rating Scales (Melby, et al., 1993) was used in two studies and Dyadic Adjustment Scale (DAS) (Spanier, 1976) was used in one study. Only Tschann, Flores, Pasch and Marin (1999) described the development and validation of a new scale, the Multidimensional Assessment of Interparental Conflict Scale (MAIC). (Five studies employed specially created items; however, as their authors did not refer to them as psychometric scales or report the validation processes, they were disregarded). Additionally, two studies used the Marital Conflict Questionnaire (MCQ), a measure by Rands, Levinger and 
Mellinger (1981) that had not been included in the list being compiled.

Accordingly, the instrument inventory was revised to include the two scales and is presented in Table 2.1.

\section{Instrument review}

The assembled instruments provide a representative overview not only of the available scales for measuring parental conflict, but also of the rationales underpinning them prevalent in research and clinical practice over the last half century. In the analysis of the content of the scales three specific foci of measurement became apparent. Based on identified topics of conflict between romantic partners a number of scales have been created to measure frequency of disagreements; four scales were specific tools for measuring broadly understood perceptions of efficacy of conflict resolution; and a number of scales focused on various behaviours demonstrated by disagreeing partners that ranged from withdrawal to physical violence. Additionally, a substantial proportion of the identified instruments was classified as multidimensional, due to their comprehensiveness and breadth of scope. It needs to be noted that scales in this rubric represent two types of dimensionality. The first is the dimensionality of conflict and is illustrated by scales like MAIC (Tschann, et al., 1999) or like CPS (Kerig, 1996), which constitute attempts at comprehensively assessing interparental conflict including frequency, intensity, child involvement, as well as conflict resolution efficacy. The second is the dimensionality of marital functioning, whereby conflict constitutes one of the dimensions of interest, and may be illustrated by measures like DAS (Spanier, 1976) or like Managing Affect and Differences Scale (MADS) (Arellano \& Markman, 1995), which also assess dimensions such as satisfaction and cohesion. 
As discussed, in a qualitative study of parents (Kielpikowski \& Pryor, 2008) we identified five main themes related to silent conflict (behavioural change as its marker, lack of resolution, avoidance and withdrawal, costs of silent conflict, and advantages of silent conflict). Consequently, with the exception of scales focusing on frequency of topic-related disagreements, the remaining instruments were of interest for establishing their conceptual and substantive commonalities with silent interparental conflict. Close inspection of the scales indicated that items for measuring withdrawal and avoidance could be found within the existing measures tapping these discrete conflict behaviours, e.g. CPS (Kerig, 1996), CRSI (Kurdek, 1994b), Marital Coping Inventory (MCI) (Bowman, 1990) or MCQ (Rands, et al., 1981), or assessing a contingent dyadic interaction demand - withdraw, e.g. Relationship Styles Questionnaire (RSQ) (Markman, Silvern, Clements, \& Kraft-Hanak, 1993). Similarly, items related to lack of resolution of conflict could be found within Kurdek's IAI (1994b) or in MAIC (Tschann, et al., 1999). It became evident however, that in contrast to our findings, which pointed to silent conflict as a distinct complex phenomenon encompassing behavioural, cognitive and affective dimensions, research to date has addressed avoidance and withdrawal not as symptoms of conflict, but as constituents of the assortment of conflict behaviours. Comparably, as illustrated in Table 2.1, conflict resolution has been studied from the perspective of efficacy of couples' efforts, rather than as a trigger of conflict or its intrinsic feature, as found in a study by Kielpikowski and Pryor (2008).

Due to the novel nature of the construct, I did not anticipate finding an existing measure satisfactorily tapping the changes in partners' behaviour and the evaluations attendant to silent conflict. The review of the inventory of instruments 
I compiled (Table 2.1) confirmed that in order to attempt the measurement of silent conflict reflective of the conceptualisation derived from the qualitative findings, none of the existing scales would be adequate and that design and construction of a new psychometric tool was justified. 
Table 2.1. Inventory of Psychometric Instruments for Measurement of Couple Conflict.

\begin{tabular}{|c|c|c|c|}
\hline Instrument Name & Variables Measured & Purpose & Description \\
\hline \multicolumn{4}{|c|}{ Areas of conflict/Reasons for conflict } \\
\hline $\begin{array}{l}\text { Relationship Problems } \\
\text { Questionnaire (RPQ) } \\
\text { (Douglass \& Douglass, } \\
\text { 1995) }\end{array}$ & $\begin{array}{l}\text { Marital adjustment, } \\
\text { happiness, and divorce risk }\end{array}$ & $\begin{array}{l}\text { Screening in marital therapy to } \\
\text { measure areas of difficulty } \\
\text { experienced in problem } \\
\text { marriages }\end{array}$ & $\begin{array}{l}\text { Sixty items in total. The } 39 \text { possible problem areas scored on a 5- } \\
\text { point scale from 'almost never' to 'weekly' are added to a single } \\
\text { score. The remaining items are not added but supplement clinical } \\
\text { information or research classification. }\end{array}$ \\
\hline $\begin{array}{l}\text { Survey of Areas of } \\
\text { Relationship Conflict } \\
\text { (SARC) } \\
\text { (Kurdek, 1994a) }\end{array}$ & $\begin{array}{l}\text { Power, social issues, } \\
\text { personal flaws, distrust, } \\
\text { intimacy, distance }\end{array}$ & $\begin{array}{l}\text { Evaluation of relationship issues } \\
\text { with a focus on content of } \\
\text { conflict }\end{array}$ & $\begin{array}{l}\text { Twenty items tapping six dimensions: power ( } 8 \text { items), social issues } \\
\text { ( } 3 \text { items), personal flaws ( } 3 \text { items), distrust, intimacy and personal } \\
\text { distance, two items each. Frequency of each is rated on a 5-point } \\
\text { scale from 'never' to 'always'. }\end{array}$ \\
\hline $\begin{array}{l}\text { Measure of Marital } \\
\text { Satisfaction (MMS) } \\
\text { (Kelso, Stewart, Bullers, \& } \\
\text { Eginton, 1984) }\end{array}$ & Areas of marital conflict & $\begin{array}{l}\text { Enabling therapists to recognise } \\
\text { and intervene in stressful home } \\
\text { environments and marriages }\end{array}$ & $\begin{array}{l}\text { Thirteen items including yes/no and } 3 \text { - } 5 \text { point scale response } \\
\text { options. Some items include multiple parts.' }\end{array}$ \\
\hline $\begin{array}{l}\text { Schwarz Inter-Parental } \\
\text { Conflict Scale (IPC) } \\
\text { (Schwarz \& Zuroff, 1979) }\end{array}$ & $\begin{array}{l}\text { Frequency of arguments } \\
\text { between parents }\end{array}$ & $\begin{array}{l}\text { Assessing parents and children's } \\
\text { perceptions of frequency of } \\
\text { arguments between parents }\end{array}$ & $\begin{array}{l}\text { Thirty seven items scored on a 7-point Likert scale comprises four } \\
\text { categories: finances and spouse's responsibilities, spouse's personal } \\
\text { characteristics, child rearing practices, joint family activities. Scores } \\
\text { are obtained for overall conflict and conflict over child-rearing } \\
\text { methods. Separate forms are used for parents and children. }\end{array}$ \\
\hline $\begin{array}{l}\text { A Scale of Marriage } \\
\text { Problems } \\
(\text { Swensen \& Fiore, 1975)) }\end{array}$ & $\begin{array}{l}\text { Marriage problems as they } \\
\text { relate to common areas of } \\
\text { difficulty for married } \\
\text { couples }\end{array}$ & $\begin{array}{l}\text { For use with married couples of } \\
\text { all ages. Based on problems } \\
\text { reported by couples seeking help } \\
\text { to five counselling centres }\end{array}$ & $\begin{array}{l}\text { Forty three item Likert style questionnaire rated on a 3-point scale } \\
\text { ('never a problem', 'occasionally a problem', 'serious or always a } \\
\text { problem'). Scores are obtained for total marriage problems and six } \\
\text { subscales: problem solving, decision making, goal setting, child } \\
\text { rearing, housework, relatives and in-laws, personal care and } \\
\text { appearance, money management, expression of affection, } \\
\text { relationships with people outside the marriage. }\end{array}$ \\
\hline $\begin{array}{l}\text { Spousal Argument Scale } \\
\text { (Nye \& MacDougall, 1959) }\end{array}$ & $\begin{array}{l}\text { Husband-wife arguments } \\
\text { related to money, children, } \\
\text { recreation; use of house, } \\
\text { furniture, television, radio. }\end{array}$ & $\begin{array}{l}\text { Assessment of spousal } \\
\text { disagreements }\end{array}$ & $\begin{array}{l}\text { Six items related to common reasons for arguments between } \\
\text { partners with five response options for each item. }\end{array}$ \\
\hline
\end{tabular}




\begin{tabular}{|c|c|c|c|}
\hline Instrument Name & Variables Measured & Purpose & Description \\
\hline \multicolumn{4}{|c|}{ Efficacy of conflict resolution } \\
\hline $\begin{array}{l}\text { Ineffective Arguing } \\
\text { Inventory (IAI) } \\
\text { (Kurdek, 1994b) }\end{array}$ & $\begin{array}{l}\text { Styles of resolving } \\
\text { arguments with partner }\end{array}$ & $\begin{array}{l}\text { Assessment of arguing and } \\
\text { conflict resolutions styles seen } \\
\text { from the perspective of a joint } \\
\text { communication strategy; } \\
\text { measuring dyadic behaviour }\end{array}$ & $\begin{array}{l}\text { Eight items scored on a } 5 \text { - point Likert scale from 'disagree } \\
\text { strongly' to 'agree strongly'. The item content has been } \\
\text { conceptualised on a premise that ineffective arguing is grounded in } \\
\text { a dyadic interaction pattern characterised by arguments involving } \\
\text { repetitive issues, prejudging of outcomes, ending arguments before } \\
\text { resolving main issues, ending arguments without partners believing } \\
\text { they have been afforded a fair hearing. }\end{array}$ \\
\hline $\begin{array}{l}\text { Problem Inventory (Ryder, } \\
\text { 1964) }\end{array}$ & $\begin{array}{l}\text { Reactions to marital } \\
\text { disputes }\end{array}$ & $\begin{array}{l}\text { Assessment of ability to } \\
\text { reconcile difference }\end{array}$ & $\begin{array}{l}\text { Partners are presented with two disputes from each of seven } \\
\text { problem areas. Options available are to agree with the hypothetical } \\
\text { response, modify the response, or disagree with the response. }\end{array}$ \\
\hline $\begin{array}{l}\text { Relationship Styles } \\
\text { Questionnaire (RSQ) } \\
\text { (Markman, et al., 1993) }\end{array}$ & $\begin{array}{l}\text { Complaints about partner } \\
\text { relating to demand - } \\
\text { withdraw conflict } \\
\text { behaviours }\end{array}$ & $\begin{array}{l}\text { Assessing the demand - } \\
\text { withdraw behaviour pattern } \\
\text { among couples }\end{array}$ & $\begin{array}{l}\text { Eleven items scored on a } 5 \text { - point Likert scale: six items focus on } \\
\text { complaints about partner's withdrawal, four items on partner's } \\
\text { pursuit, one item refers to pursuit by self. }\end{array}$ \\
\hline
\end{tabular}




\begin{tabular}{|c|c|c|c|}
\hline Instrument Name & Variables Measured & Purpose & Description \\
\hline $\begin{array}{l}\text { Marital hostility subscale } \\
\text { from Iowa Youth and } \\
\text { Families Project Rating } \\
\text { Scales (Melby, et al., 1993) }\end{array}$ & $\begin{array}{l}\text { Interparental conflict } \\
\text { between mothers and } \\
\text { fathers }\end{array}$ & $\begin{array}{l}\text { Assessing conflict between } \\
\text { parents using reports of both. }\end{array}$ & $\begin{array}{l}\text { A subset of items from a multidimensional scale rated on a Likert } \\
\text { scale from } 1 \text {-'always' to } 7 \text { - 'never'. }\end{array}$ \\
\hline $\begin{array}{l}\text { Abusive Behaviour } \\
\text { Inventory (ABI) } \\
\text { (Shepard \& Campbell, } \\
\text { 1992) }\end{array}$ & $\begin{array}{l}\text { Psychological and physical } \\
\text { abuse }\end{array}$ & $\begin{array}{l}\text { Originally intended to measure } \\
\text { male to female abuse }\end{array}$ & $\begin{array}{l}\text { Thirty items scored on a } 5 \text { - point Likert scale from 'never' to 'very } \\
\text { frequently'. }\end{array}$ \\
\hline $\begin{array}{l}\text { Nebraska Scale of Marital } \\
\text { Disagreements } \\
\text { (Johnson, White, Edwards, } \\
\& \text { Booth, 1986) }\end{array}$ & Marital disagreement & $\begin{array}{l}\text { Developed for use in interviews } \\
\text { including phone and paper and } \\
\text { pencil surveys of the general } \\
\text { population of married persons. }\end{array}$ & $\begin{array}{l}\text { Four items assessing on a } 5 \text { - point Likert scale the frequency of a } \\
\text { particular level of disagreement occurs between spouses (e.g. } \\
\text { quarrels, physical violence). }\end{array}$ \\
\hline $\begin{array}{l}\text { Verbal Problems Checklist } \\
\text { (VPC) } \\
\text { (Haynes, Chavez, \& } \\
\text { Samuel, 1984) }\end{array}$ & $\begin{array}{l}\text { Dysfunctional verbal } \\
\text { strategies used by spouses } \\
\text { during arguments }\end{array}$ & $\begin{array}{l}\text { Developed for use with both } \\
\text { spouses }\end{array}$ & $\begin{array}{l}\text { Twenty seven items scored on a } 5 \text { - point scale from 'never' to } \\
\text { 'always'. Originally proposed as a unidimensional scale, however } \\
\text { three differential dimensions for men (critical/defensive, } \\
\text { withdrawn/submissive, dominant/controlling) and women } \\
\text { (critical/defensive, withdrawn, submissive) were found by Epstein, } \\
\text { Pretzer and Fleming (1987). }\end{array}$ \\
\hline $\begin{array}{l}\text { O’Leary Porter Scale (OPS) } \\
\text { (Porter \& O'Leary, 1980) }\end{array}$ & $\begin{array}{l}\text { Parental perceptions of } \\
\text { spousal interactions } \\
\text { enacted in the presence of } \\
\text { children. }\end{array}$ & $\begin{array}{l}\text { Assessing the quantity of } \\
\text { parental open arguing in the } \\
\text { presence of children }\end{array}$ & $\begin{array}{l}\text { Ten items rated on a Likert scale ranging from } 1 \text {-'never' to } 5 \text { - } \\
\text { 'very often'. }\end{array}$ \\
\hline $\begin{array}{l}\text { Conflict Tactics Scale } \\
\text { (CTS) (Straus, 1979) }\end{array}$ & $\begin{array}{l}\text { Reasoning, verbal } \\
\text { aggression and physical } \\
\text { violence in response to } \\
\text { conflict or anger. }\end{array}$ & $\begin{array}{l}\text { Assessment of individual } \\
\text { responses to situations within the } \\
\text { family involving conflict }\end{array}$ & $\begin{array}{l}\text { Nineteen item, } 7 \text { - point Likert type questionnaire measuring } \\
\text { frequency of behaviours within the three categories (reasoning, } \\
\text { verbal aggression, physical violence) asked in respect of the } \\
\text { respondent and the partner. Can be used for any members of the } \\
\text { family. }\end{array}$ \\
\hline
\end{tabular}




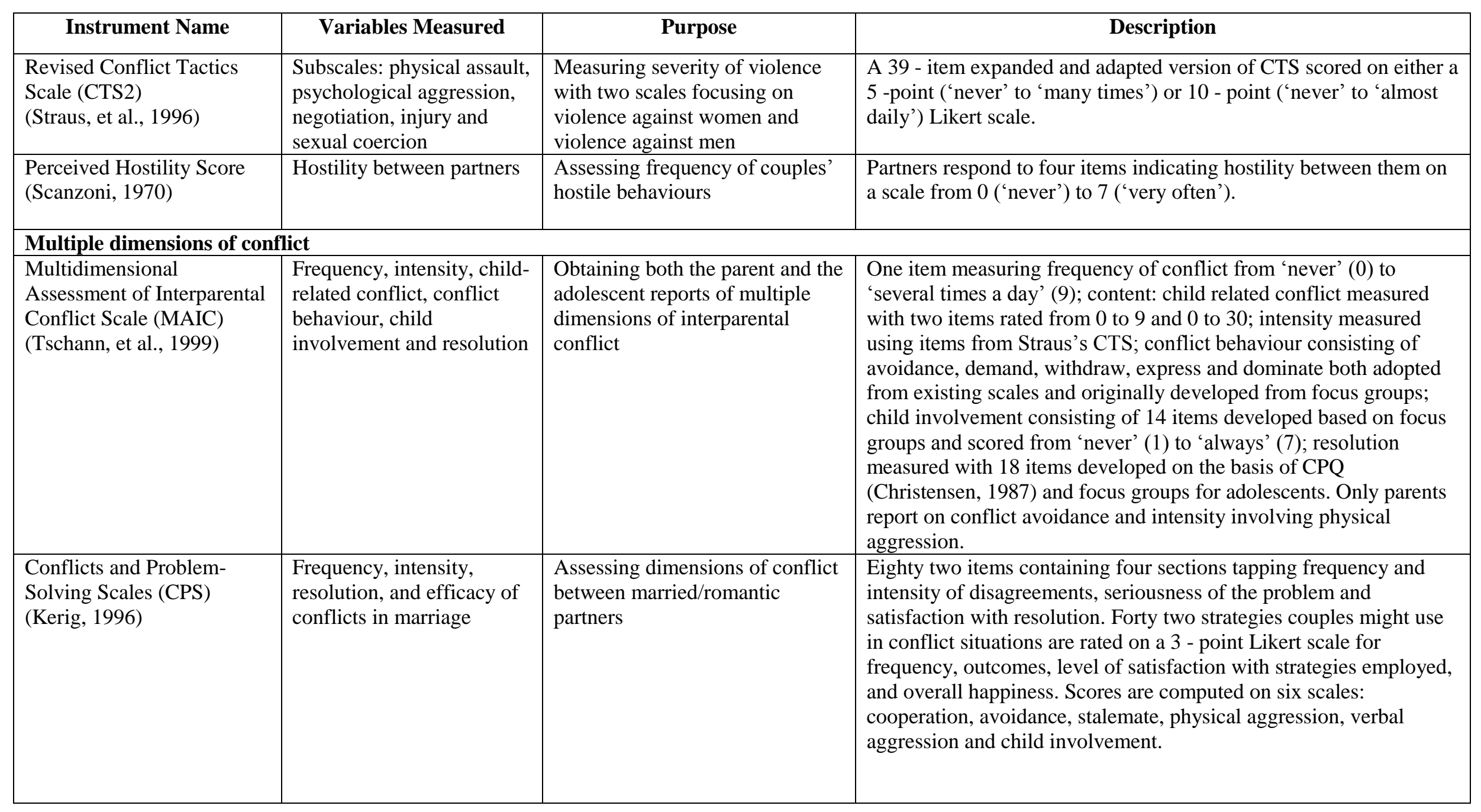




\begin{tabular}{|c|c|c|c|}
\hline Instrument Name & Variables Measured & Purpose & Description \\
\hline $\begin{array}{l}\text { Managing Affect and } \\
\text { Differences Scale (MADS) } \\
\text { (Arellano \& Markman, } \\
\text { 1995) }\end{array}$ & $\begin{array}{l}\text { Happiness, satisfaction, } \\
\text { communication, conflict } \\
\text { management }\end{array}$ & $\begin{array}{l}\text { Assessment of couple } \\
\text { functioning for research and } \\
\text { therapy use }\end{array}$ & $\begin{array}{l}\text { One hundred and eighteen items; mixed measurement: } 7 \text { - and } 5 \text { - } \\
\text { point Likert scales and yes/no options. Scores are calculated for } \\
\text { each subscale for self-perceptions, perceptions of partner and } \\
\text { perceptions of couple. }\end{array}$ \\
\hline $\begin{array}{l}\text { Marital Coping Inventory } \\
\text { (MCI) } \\
\text { (Bowman, 1990) }\end{array}$ & $\begin{array}{l}\text { Strategies used to cope } \\
\text { with recurring marital } \\
\text { problems }\end{array}$ & $\begin{array}{l}\text { Assessing frequency of strategies } \\
\text { used by couples in long term } \\
\text { relationships }\end{array}$ & $\begin{array}{l}\text { Respondents describe the most serious problem recurring in the } \\
\text { relationship with their partner and rate it on a } 5 \text { - point scale for } \\
\text { seriousness. A list of } 64 \text { strategies used to deal with the problem is } \\
\text { scored on a } 5 \text { - point scale from 'usually' to 'never'. Five subscales } \\
\text { obtained through factor analysis are conflict, introspective self- } \\
\text { blame, positive approach, self interest, and avoidance. }\end{array}$ \\
\hline $\begin{array}{l}\text { Sharing of Hurts Scale } \\
\text { (SOH) } \\
\text { (Stevens \& L'Abate, 1989) }\end{array}$ & $\begin{array}{l}\text { Hurt, vulnerability, conflict } \\
\text { resolution, physical } \\
\text { intimacy, imperfection, } \\
\text { values, desirability }\end{array}$ & $\begin{array}{l}\text { Assessing different aspects or } \\
\text { areas in which a person has } \\
\text { experienced personal or } \\
\text { emotional hurt }\end{array}$ & $\begin{array}{l}\text { Thirty nine items scored on a Likert scale are worded to tap } \\
\text { interactions with a partner or self perceptions in respect to the } \\
\text { relationship. Totals are computed for each subscale. }\end{array}$ \\
\hline $\begin{array}{l}\text { Marital Conflict } \\
\text { Questionnaire (MCQ) } \\
\text { (Rands, et al., 1981) } \\
\end{array}$ & $\begin{array}{l}\text { Conflict strategies and } \\
\text { resolution }\end{array}$ & $\begin{array}{l}\text { Assessing conflict strategies and } \\
\text { resolution patterns between } \\
\text { married couples }\end{array}$ & $\begin{array}{l}\text { Spouses rate } 14 \text { items of resolution patterns and } 15 \text { items of conflict } \\
\text { strategies including marital attack and avoidance from } 1 \text { ('never') to } \\
4 \text { ('very often/well'). }\end{array}$ \\
\hline $\begin{array}{l}\text { Adapted Dyadic } \\
\text { Adjustment Scale (ADAS) } \\
\text { (Busby, Christensen, Crane, } \\
\text { \& Larson, 1995) }\end{array}$ & $\begin{array}{l}\text { Adjustment of partners to } \\
\text { issues in relationships }\end{array}$ & $\begin{array}{l}\text { Modification of Dyadic } \\
\text { Adjustment Scale }\end{array}$ & $\begin{array}{l}\text { Fourteen items scored on a } 5 \text { - and } 6 \text { - point scale; a three factor } \\
\text { model consisting of consensus, satisfaction and cohesion. }\end{array}$ \\
\hline $\begin{array}{l}\text { Dyadic Adjustment Scale } \\
\text { (DAS) (Spanier, 1976) }\end{array}$ & $\begin{array}{l}\text { Marital and dyadic } \\
\text { adjustment }\end{array}$ & $\begin{array}{l}\text { Assessing quality of dyadic } \\
\text { relationships }\end{array}$ & $\begin{array}{l}\text { Thirty two-item Likert scale. Factor analysis indicated four factors: } \\
\text { dyadic satisfaction, dyadic cohesion, dyadic consensus, and } \\
\text { affectional expression. Fifteen areas of potential disagreement are } \\
\text { rated on a } 6 \text { - point scale from 'always agree' to 'always disagree'. }\end{array}$ \\
\hline $\begin{array}{l}\text { Locke-Wallace Marital } \\
\text { Adjustment Test (MAT) } \\
\text { (Locke \& Wallace, 1959) }\end{array}$ & $\begin{array}{l}\text { Areas of satisfaction, } \\
\text { agreement, and } \\
\text { cooperation with spouse }\end{array}$ & $\begin{array}{l}\text { Assess levels of accommodation } \\
\text { and satisfaction of husbands and } \\
\text { wives with each other }\end{array}$ & $\begin{array}{l}\text { Fifteen items tap general level of happiness with each other; level of } \\
\text { agreement in eight key areas of marital interaction; conflict } \\
\text { behaviours ('when arguments arise they usually result in': 'husband } \\
\text { giving in', 'wife giving in', 'agreement by mutual give and take'). } \\
\text { Widely used in research and for validation. }\end{array}$ \\
\hline
\end{tabular}




\section{New Instrument Design}

In order to ensure robustness of the newly developed measurement instrument rigorous procedures were observed in the design process. Development of the Silent Interparental Conflict Scale (SICS) described in this chapter followed in principle a procedure that may be segmented into the following main stages: conceptualisation of the object of measurement, decisions regarding the format for measurement, generating the pool of items, expert review of the items, and construction of the pilot questionnaire including a set of validating items (Netemeyer, Bearden, \& Sharma, 2003; DeVellis, 2003; Giles, 2002) .

Conceptualisation of the object of measurement

According to DeVellis (2003), clearly defining the construct to be measured is of critical importance for developing items representing the construct accurately, however, despite being obvious, this proves surprisingly difficult to achieve in respect of latent variables characterised by inherent elusiveness (2003, p. 60). This observation appears particularly pertinent to the construct of silent conflict, whose conceptualisation was arrived at in the process of the qualitative study and consisted of five themes: behavioural change as marker of silent conflict, lack of resolution, avoidance and withdrawal, costs of silent conflict and benefits of silent conflict. As noted previously, research to date has recognised the existence of non-verbal non-physical behaviours observable in the process of couple disagreements; however the conceptualisation of a discrete multifaceted phenomenon of silent interparental conflict reaches beyond behaviours to include cognitions and emotions of the involved partners. These aspects of silent conflict 
became apparent as a result of interviews with parents and may not have been obvious had the findings been informed solely by observation.

Deciding the format for measurement

Decisions regarding the measurement format focused on the following main issues: the length of the scale, item redundancy, inclusion of reverse scored items and type of rating scales for items. Careful consideration was also given to the question of whether the situational (contextual) or the generalised approach was more appropriate for the construct and should be conveyed in the instruction preambles.

It is desirable for a psychometric instrument to demonstrate good internal consistency represented by Cronbach's $\alpha>.70$, which increases with the number of items and greater semantic similarity between the items. Neither is desirable however, as pointed out by Kline (2000), as substantial length reduces the feasibility of a scale, whereas in the case of short scales the aim for high internal consistency should not be achieved at a cost of high redundancy of items, which effectively become 'bloated specifics' (Cattell, 1978). The objective was therefore to ultimately obtain a parsimonious instrument consisting of essential items without compromising its content and reliability. Some redundancy of items was seen as necessary at the pilot stage to allow the selection of the best performing ones.

As items of the scale were based on interview data, they were, as a result, phrased in the form of positively worded statements. Absence of reverse-scored items is often seen as a potential trigger for a response set or respondents' acquiescence. Opinion is however divided, as presence of both positively and negatively worded items has been found to be confusing to participants in long 
surveys (DeVellis, 2003) and may have even resulted in a statistical artefact of structural composition reflective of the polarity of the items (Fredman \& Sherman, 1987, p.11).

In order to represent the themes identified in the qualitative data, the items of the proposed measure were designed to relate to behaviours, cognitions and emotions. It was found that behaviours and emotions lent themselves to being scored for frequency; attitudes on the other hand required a measure of agreement. Therefore, despite certain complexity, both the scores based on the ratings of frequency and the level of endorsement were used in the new measure. Although an attempt was made to order the items randomly, the logical grouping appeared to be by response type: frequency and then endorsement.

Assessment of a subtle phenomenon like silent interparental conflict, with the aim to involve reports of both the parents and a child presents inevitable challenges. At the early point of exploration of the phenomenon we cannot unequivocally state that the parents and the child have equal access to it, due to its covert nature. Moreover, this reservation may apply even to couples themselves, as was found by Kielpikowski and Pryor (2008), whereby one of the partners appeared to remain oblivious to the conflict having arisen and its expression by the other partner. For this reason attempts at situational measurement were seen as having a potential to yield disparate results for the three family members, therefore a generalised approach was chosen. It was believed that it had the advantage of capturing family members' perceptions of silent interparental conflicts regardless of their situational salience to each person and of them being simultaneously recognised by parents and children. 
Generating the pool of items

It is advisable to create and pilot a large number of items exceeding the length of the ultimately desired scale, so that only the best performing items are retained without compromising the content of the measure. The size of the initial item pool depends on the complexity of a construct and may range from double the size of the desired scale to 250 items in the case of a multifaceted construct (Netemeyer, et al., 2003). Notwithstanding the complexity of the construct of silent conflict, it was decided that consideration needed to be given to participants' fatigue, and the potential for response set created by excessively long surveys.

Proposing an unequal number of items to represent various content areas of the instrument is acceptable, when this distribution is reflective of their varying complexity and the importance granted them by the researcher. It is preferable for the decision process to be grounded in theory or in empirical findings (Giles, 2002); the latter applies to this study founded on the qualitative results of Kielpikowski and Pryor (2008).

A large preliminary pool of items was developed, with each theme identified in the qualitative study represented by several items. Initially, twenty items were created for Behavioural change as marker of silent conflict, thirteen items for Lack of resolution, nineteen items for Avoidance and withdrawal, twenty for Costs of silent conflict and seven for Benefits of silent conflict. Having access to the qualitative data corpus allowed me to use verbatim quotes and close paraphrases of the interviewees' statements in the measurement scale. This was considered a valuable opportunity to convey some of the authenticity of the 
interviews to the surveys administered to the participants of the quantitative study.

The initial pool of items was carefully scrutinised for accessibility as relatively simple sentence structure and vocabulary were desired to make the content of the survey intelligible to the participants without the need for conducting a reading level assessment. Items were examined several times for ambiguity and the potential for expressing multiple concepts and as a result 24 of the initially proposed items were deleted, leaving 55 items for piloting. All items were closed-ended statements rated on a five point Likert scale in order to allow for neutral responses represented by the mid-point. Eighteen items were rated from $1=$ never to $5=$ always. The instructions for completion of these items read:

"We are interested in what happens between couples when they are in disagreement but not discussing the issues. Please reflect on your relationship with your partner. Please read the statements listed below and for each of them circle the option that best describes your experience."

Thirty seven items that followed were rated from $1=$ strongly disagree to $5=$ strongly agree and were preceded by this instruction:

"We would like to know your views about silent disagreements between you and your partner. Please read the statements that follow and circle the number that best reflects your feelings and thoughts."

\section{Expert review of the item pool}

The proposed pool of items was carefully inspected several times and discussed with fellow researchers working within the family domain. The ultimate expert review however was to be performed by the participants in the pilot study, who were explicitly invited to comment on the form and content of the survey. 
Construction of the pilot questionnaire including validating items

The purpose of the pilot questionnaire was to provide data for establishing the factorial structure of SICS and for testing its internal consistency and validity. In the process of the analysis of existing conflict measures described earlier, three scales were selected as most appropriate for testing convergent validity of the new instrument. Twenty one items each for rating behaviours of self and partner and representing various aspects of conflict from verbal to stalemate were selected from CPS (Kerig, 1996). Additionally, on the grounds of their conceptual proximity to SICS due to their focus on ineffective conflict behaviours and failure to resolve disagreements, three interactional items were selected from IAI and three items each for rating self and partner from CRSI (Kurdek, 1994b).

Establishing the level of potential social desirability bias in the obtained participant responses is advisable as part of the scale validation process (King \& Bruner, 2000; DeVellis, 2003). Social desirability responding (SDR) has been conceptualised as an individual's need for approval from others (Crowne \& Marlowe, 1960). SDR may take effect in a twofold manner: on the one hand, personally or socially sensitive instrument items may incite participants to respond in a particularly approval seeking manner, while on the other hand, certain participants may exhibit a particularly socially desirable response tendencies. To counteract such 'contaminating' effects, measures of SDR have been extensively used to statistically control for social desirability bias [for discussion see Leite and Beretvas (2005) and King \& Bruner (2000)]. For example, establishing the strength of correlations between items of the focal instrument and a SDR measure, with weak correlations desired (Paulhus, 1991), enables subsequent informed decisions regarding inclusion of items in the final 
version of an instrument. Individual participants' SDR scores may also be examined enabling informed decisions regarding their exclusion from the sample, as recommended by Paulhus (1991). There is no consensus, however, regarding either the treatment or indeed the need for measuring SDR. Some authors find it sufficient that the presence of SDR is established or disestablished and acknowledged as such in the reports; others do not measure it at all, presumably considering it a phenomenon intrinsic to the process of participation in research and inherent to the content of obtained responses. Ultimately, the choice between the described approaches rests with the researcher and in the present case it was considered prudent to attempt to assess the level of SDR in the data using a short version of Marlowe-Crowne Social Desirability scale $M-C$ 1(10) (Strahan \& Gerbasi, 1972).

\section{STUDY 1}

\section{Method}

\section{Procedure}

Two main methods were used to recruit participants. Flyers inviting interest in participation in the study were displayed on community notice boards in several public places in Wellington, Lower Hutt and Porirua areas of the lower North Island of New Zealand, such as libraries, churches, supermarkets, health practitioners' surgeries, workplace cafeterias and schools. Additionally, personal contact networks were used to initiate snowballing. Each flyer contained a brief invitation to parents to take part in a family dynamics study by completing a questionnaire about how parents relate to each other and handle their disagreements. My phone and email contact details were provided in order to 
register expressions of interest in the study. Potential participants either contacted me to provide their postal addresses for the mailing of questionnaires or in some cases were able to collect the questionnaire packs from the receptionists or contact persons. A number-coded copy of the questionnaire was sent to each interested parent in a pack containing an information sheet, an addressed stamped envelope for return of a completed questionnaire, and a separate form printed on coloured paper for the participants to indicate if they wished to receive feedback. Participants filled out the surveys in their own time. As exploration of the topic of relationship conflict by the participants had the potential to trigger associations with stressful personal experiences, the concluding part of the survey contained names and contact details of local counselling services. Informed consent was implied by the event of returning a completed questionnaire. ${ }^{5}$ The feedback request sheets containing participants' postal addresses were separated from the questionnaires immediately on receipt to maintain the anonymity of individual responses. Each participant was sent a thank you note and a gift voucher to the value of $\$ 10$. In total 173 surveys were distributed and 112 completed surveys were returned, giving a return rate of nearly $65 \%$. Brief summaries of results were posted to interested participants upon completion of analyses.

\section{Participants}

One hundred and twelve adults returned completed questionnaires, however four of them were excluded from the sample as they appeared not to have children, and therefore did not meet the set participation criteria. ${ }^{6}$ The final

\footnotetext{
${ }^{5}$ All studies described in this dissertation were approved by the Victoria University Ethics Committee.

${ }^{6}$ As explained previously, parents were specifically targeted for this research on the premise that parents and childless couples may not display identical relationship conflict attitudes and behaviours.
} 
sample of 108 parents consisted of 44 males and 64 females aged between 22 and 60 years $(M=41.62, S D=7.06)$. Participants reported their highest attained level of education as follows: secondary $-15 \%$, additional training $-12 \%$, tertiary $47 \%$, postgraduate $-23 \%$; three parents did not provide their education details. The ethnic composition of the sample was as follows: 73\% European/Pakeha, 4\% Maori, $15 \%$ Asian, $1 \%$ Pacific Nation and 7\% other, consisting of adults who described their ethnic background as Kiwi or New Zealander. One person did not provide ethnicity. Married participants constituted $82 \%$ of the sample, $17 \%$ of the participants cohabited and one participant did not provide an answer. The reported length of relationships ranged from two to 40 years $(M=14.88, S D=$ 7.30), with no data from two participants. The number of children in the households ranged from one to five, with the modal number of 2. Only the ages of the eldest children were recorded and these spanned from one to 28 years $(M=$ $11.65, S D=6.06)$. The over-representation of the European/Pakeha group, the prevalence of high levels of education and the high proportion of marriages in reference to New Zealand population reflect the self-selected nature of the sample.

Measures

Participants completed a survey consisting of 55 items proposed for SICS (Appendix A), as well as items from Conflict and Problem Solving Scales (Kerig, 1996) (Appendix B), Ineffective Arguing Inventory (Kurdek, 1994b) (Appendix C) and Conflict Resolution Style Inventory (Kurdek, 1994b) (Appendix D) for the purpose of establishing the convergent validity of the new instrument.

Additionally, in order to assess the level of social desirability bias in the data M-C 1(10) (Strahan \& Gerbasi, 1972) was included (Appendix E). 
Conflict and Problem Solving Scales (CPS) is a comprehensive 82-item instrument for assessment of frequency, intensity, strategies and outcomes of conflicts between romantic partners. Participants rate frequencies of their own and their partners' forty two conflict strategic behaviours scored on a four point Likert-type scale ranging from $0=$ never to $3=$ often. Kerig (1996) identified a six factor structure of the measure (cooperation, avoidance-capitulation, stalemate, physical aggression, verbal aggression, and child involvement) and reported satisfactory Cronbach's alphas between .74 and .98 . Seventeen of the CPS strategy items judged to be most relevant (e.g. excluding involvement of third parties) and linguistically accessible were selected for inclusion in the questionnaire for the purpose of validation of the SICS. Five items were selected for cooperation, four for avoidance/capitulation, two for stalemate and six for verbal aggression. Cronbach's alphas for this sample were calculated on scores obtained for each partner and were generally satisfactory (see Table 2.2) except for inadequate Cronbach's alphas for stalemate, which may have been affected by the selection of only two items to represent the construct.

Table 2.2. Reliability Coefficient Obtained for Adapted Subscales of Conflict and Problem Solving Scales (Kerig, 1996).

\begin{tabular}{lcc}
\hline \multicolumn{1}{c}{ CPS subscale } & \multicolumn{2}{c}{ Cronbach's Alpha } \\
\cline { 2 - 3 } & Self & Partner \\
\hline Co-operation & .76 & .80 \\
Avoidance-Capitulation & .73 & .70 \\
Stalemate & .68 & .56 \\
Verbal Aggression & .86 & .89 \\
\hline
\end{tabular}

Three thematically relevant items were selected from Kurdek's Ineffective Arguing Inventory (IAI) (Kurdek, 1994b). The IAI is intended to assess couple conflict behaviour patterns from the interactional perspective, taking into account a joint strategy employed by a couple in a conflict situation. Participants indicate 
their endorsement of eight items on a five point Likert scale from $1=$ strongly disagree to $5=$ strongly agree. Kurdek (1994b) reported good reliability coefficients ranging between .86 and .89 for the scale tested on four target groups of couples (gay, lesbian, married non-parents and married parents). A matching level of internal consistency was demonstrated for this dataset $(\alpha=.89)$.

Three corresponding items for self and partner were selected from the Withdrawal subscale of Conflict Resolution Style Inventory (CRSI) (Kurdek, 1994b). The CRSI is a 16-item instrument designed to assess four arguing and conflict resolution styles with an identical set of items rated for self and partner. In contrast to Kurdek's previously described scale, the purpose of this instrument is to assess styles of individual partners. Participants rate their own as well as their partners' conflict behaviour on a five point Likert scale (from $1=$ never to 5 = always). Kurdek (1994b) reported Cronbach's alphas for the Withdrawal subscale based on the same sample described above for the IAI ranging from .65 to .87. The three item Withdrawal subscale used in this study demonstrated good internal reliability ( $\alpha=.84$ for self and $\alpha=.85$ for partner).

To assess the presence of social desirability responding in the data $M-C$ 1(10) (Strahan \& Gerbasi, 1972), the short form of the widely used 33- item Marlowe- Crowne Social Desirability Scale (Crowne \& Marlowe, 1960) was administered. M-C 1(10) is a ten item version of the original scale consisting of items representing both the behaviours that are considered highly acceptable socially but uncommon and those considered common but socially undesirable. Kuder-Richardson 20 reliability scores reported for the M-C 1(10) ranged from .59 to .70 (Fraboni \& Cooper, 1989; Strachan \& Gerbasi, 1972) and the scale has been recommended for use when short administration time is prioritised, 
notwithstanding the associated decrease in reliability. Additionally, according to Fraboni and Cooper (1989), compared to other short forms of the M-C scale, the M-C 1(10) appeared the least affected by age and socioeconomic status.

Cronbach's alpha obtained for the present data was at the lower end of the previously reported results at .61 .

Aiming at maximising the quality of the proposed new instrument both in regards to the comprehensiveness of its content and the structure and clarity of the items, three open ended questions were asked at the end of the survey. The instruction read:

We greatly value any comments you would like to make. For example, have we missed anything? Have you found this questionnaire or any particular questions confusing? Have you found this questionnaire or any particular question upsetting in any way?

\section{Results - Exploratory Factor Analysis}

As noted previously, a strict item selection process was anticipated in order to ensure the retention of the best performing variables for the measure, therefore an extensive number of items with a considerable level of redundancy were administered to participants. Multiple methods were used in the process of selecting items for the instrument.

The preliminary data analyses were performed as follows. The correlation table and the corresponding significance table produced by SPSS as part of factor analytic procedures were scrutinised in order to verify the assumption underlying the factorial structure of the studied group of variables, which is evidenced by significant moderate intercorrelations (Hair, Anderson, Tatham, \& Black, 1998). Visual inspection of the correlation table allows locating the presence of 
multicollinearity $(r>.80)$ and singularity $(r=1)$ and it is recommended to delete thus identified variables. This possibility was signalled by the determinant value of less than $.00001 \mathrm{obtained}$ for this sample. Four items were deleted due to existing or potential multicollinearity ( $r$ ranging form .78 to .86 ) identified when examining the correlation matrix. The significance table was examined for items demonstrating non-significant values greater than .05 , with the purpose of further deletions. It was found that nine items did not correlate significantly with $35 \%$ $83 \%$ of other proposed items and they were consequently eliminated from further analyses.

Final scrutiny of item quality was carried out with consideration to comments from the participants. This resulted in exclusion of six items. Five items were found to be ambiguous and two items were perceived as double barrelled, as expressed in the following comment: "I wanted to put different answers for different parts of each question". Indications of redundancy, as pairs of variables were judged highly similar and repetitive, resulted in discarding of five further items.

The missing values patterns were examined in the remaining dataset and in order to maintain an adequate sample size, a substitution with the items' means was performed. Finally, stringent screening for normality of distribution was performed on the remaining variables. The process resulted in exclusion of further seven variables due to their bimodal distribution.

Cronbach's alpha for the remaining dataset was calculated to be .90 , indicating a strong possibility of the presence of one factor only. The initial exploratory factor analysis (Principal Axis Factoring) of the remaining twenty three items was performed subject to Promax oblique rotation allowing the factors 
to correlate. It needs to be noted, that although Principal Component Analysis (PCA) is the most commonly used and described factor extraction method (Preacher \& MacCallum, 2003), its use for the purpose of establishing the factorial structure of measurement instruments has been challenged (Fabrigar, Wegener, MacCallum, \& Strahan, 1999; Widaman, 1993). In contrast to exploratory factor analytic (EFA) methods such as maximum likelihood (ML) or principal factors (PF), PCA does not differentiate between common and unique variance and the solutions obtained through it are aimed at accounting for the variance rather than at explaining the correlations among the observed measures. EFA is therefore a preferable approach to precede confirmatory factor analysis (CFA) in the process of scale validation, as both EFA and CFA are based on the common factor model (Brown, 2006). Accordingly, SPSS PF was selected as the exploratory factor extraction method for this study in preference to ML extraction due to its greater tolerance of data nonnormalities (Brown, 2006).

The significant factor loading for this study was set at .40 (Hair, et al., 1998). Based on Kaiser's criterion that allows accepting factors with eigenvalues greater than 1, the initial analysis produced a five factor solution explaining $54.92 \%$ of variance. The Kaiser-Meyer-Olkin measure of sampling adequacy (KMO) was .82; the Bartlett's test of sphericity was significant, $p<.001$, approximate $\chi^{2}(276)=1193.52$; both indices pointed to the factorability of the data (Tabachnick \& Fidell, 2007, p. 614). However, it is accepted that Kaiser's criterion tends to lead to overextraction of factors (Giles, 2002), therefore the scree plot, according to Cattell's interpretation (1966), was scrutinised and appeared to indicate a three factor solution, as from the third point the eigenvalues 
appeared to level off. Closer examination of the items comprising the Kaiser five factor solution (structure matrix) led to the following conclusions:

1. One factor consisted of only two items.

2. Five items were low loading (loading < .400)

The three lowest loading items were removed from the data set and the PF procedure was repeated on the revised data set specifying three factors for extraction as suggested by the scree plot. This procedure was then repeated several times in order to maximise parsimony of the solution, retain a similar number of items per factor, and eliminate semantic redundancy of items. The accepted solution consisted of 12 items and is shown in Table 2.3.

It is currently generally recommended that in preference to the Kaiser criterion and alongside Cattell's scree plot analysis, parallel analysis (Horn, 1965) be used to help determine the number of factors to retain during exploratory factor analysis (Henson \& Roberts, 2006). The technique consists of creating multiple sets (e.g. 100 or 200) of random data of the same size as the actual research data file and calculating the average eigenvalues for these randomly generated samples. The sizes of the eigenvalues generated are then compared to the eigenvalues produced by SPSS in the process of EFA. The criterion for accepting a particular factor is that the eigenvalue for the factor obtained from EFA is to be greater than the corresponding eigenvalue for the factor produced by parallel analysis. For the purpose of this study a free statistical programme developed by Marley Watkins (2000) and downloadable from www.public.asu.edu/ mwwatkin/Watkins3.html was used. The comparison of eigenvalues obtained through the two methods supported the retention of three factors and is presented in Table 2.4. 
The three factors are easily interpretable and conceptually homogenous (see Table 2.3). The first factor is composed of five items characterising silent conflict and has therefore been named Marker of Silent Conflict. The second reflects the negative effects of silent conflict on the respondent and accordingly has been named Costs of Silent Conflict, whereas the third factor reflects the positive aspects participants recognise in this type of disagreement and has been named Benefits of Silent Conflict.

The obtained factorability indices were satisfactory; the Kaiser-MeyerOlkin measure of sampling adequacy for the resulting solution was .79 and the Bartlett's test of sphericity was significant, $p<.001$; approximate $\chi^{2}(66)=$ 582.05. The cumulative variance explained for the unrotated solution was $58.36 \%$. The item loadings on factors were generally high and greater than .500 , except for the item Discord between my partner and me shuts me down for everybody loading on Costs of Silent Conflict at .444, however the item was retained due to the importance of its conceptual content.

Cronbach's alphas, correlation coefficients and descriptive statistics are in Table 2.5. Cronbach's alphas for the individual factors and the whole measure were very acceptable ranging between .83 and .85 . This result was very satisfactory, as it demonstrated that despite the efforts to produce a parsimonious instrument by eliminating redundancy of the retained items and reducing their number, the internal consistency of the instrument was not compromised.

Calculation of bivariate correlations between the three factors rendered positive moderate correlations with the correlation between Marker of Silent Conflict and Costs of Silent Conflict the strongest $r=.42, p<.01$ (see Table 2.5). This result indicates that the more partners engage in silent conflict, the greater 
their reports of its attendant negative consequences. On the other hand, the greater the perceived benefits of silent conflict the more of it is reported. Undoubtedly the most interesting relationship found was the moderate positive correlation $(r=.23$, $p<.01)$ between the costs and benefits of silent conflict perceived by the disagreeing partners, as it indicates the complexity of the phenomenon expressed in the tension between realising both its good and detrimental aspects. It needs to be noted that the mean scores on the factors (subscales) and the whole measure of silent conflict obtained by the participants in this sample are slightly above the Likert scale middle points indicating only moderate levels of silent conflict between the participating couples.

In order to test for potential gender differences in perceptions of silent conflict, a one way Analysis of Variance was conducted to compare scores on individual factors and on the total SICS for men and women in this sample. No significant differences were found, indicating that the perceptions did not differ between the sexes. 
Table 2.3. The 12-Item Interparental Silent Conflict Scale (SICS) Interpreted According to Principal Axis Factoring Subject to PROMAX Rotation - Pattern and Structure Matrices.

\begin{tabular}{|c|c|c|c|c|c|c|c|}
\hline & & Pat & $\mathbf{r n M}$ & trix & Strt & ure $\mathrm{N}$ & trix \\
\hline No & Item & 1 & 2 & 3 & 1 & 2 & 3 \\
\hline sc24 & $\begin{array}{l}\text { There is little warmth in our relationship } \\
\text { when we are in conflict. }\end{array}$ & .80 & -.14 & -.13 & .81 & .40 & .29 \\
\hline sc27 & $\begin{array}{l}\text { During conflict there is a lot of tension } \\
\text { between us even though we do not } \\
\text { communicate. }\end{array}$ & .78 & .06 & .02 & .75 & .39 & .26 \\
\hline sc 49 & $\begin{array}{l}\text { Unresolved issues lead to silence between } \\
\text { my partner and me. }\end{array}$ & .72 & .07 & .01 & .70 & .16 & .08 \\
\hline sc9 & $\begin{array}{l}\text { When we are annoyed with each other we } \\
\text { avoid each other around the house. }\end{array}$ & .64 & .28 & .39 & .68 & .29 & .41 \\
\hline sc44 & $\begin{array}{l}\text { We cannot agree on some issues, so they } \\
\text { remain unresolved between us. }\end{array}$ & .60 & .11 & -.03 & .63 & .36 & .20 \\
\hline $\operatorname{sc} 30$ & $\begin{array}{l}\text { I can't concentrate on anything else when } \\
\text { we don't speak to each other. }\end{array}$ & -.18 & .99 & .04 & .27 & .93 & .32 \\
\hline sc31 & $\begin{array}{l}\text { When we are in conflict I can't stop } \\
\text { mulling things over. }\end{array}$ & .10 & .74 & .02 & .43 & .79 & .30 \\
\hline sc29 & $\begin{array}{l}\text { I get a knot in my stomach when my } \\
\text { partner and I are not talking to each other. }\end{array}$ & .03 & .71 & -.04 & .32 & .71 & .21 \\
\hline sc32 & $\begin{array}{l}\text { Discord between my partner and me shuts } \\
\text { me down for everybody. }\end{array}$ & .32 & .44 & -.08 & .49 & .56 & .17 \\
\hline sc19 & $\begin{array}{l}\text { A period of silence and staying away from } \\
\text { each other helps to put a disagreement into } \\
\text { perspective. }\end{array}$ & -.01 & .01 & .85 & .26 & .28 & .85 \\
\hline $\operatorname{sc} 21$ & $\begin{array}{l}\text { Silence between us gives me a chance to try } \\
\text { and understand my partner's behaviour. }\end{array}$ & -.03 & -.05 & .80 & .20 & .20 & .78 \\
\hline sc20 & $\begin{array}{l}\text { A period of silence and staying away from } \\
\text { each other helps to calm the emotions. }\end{array}$ & .03 & .05 & .74 & .29 & .31 & .77 \\
\hline
\end{tabular}

Note. Item numbers refer to questionnaire presented in Appendix F.

Table 2.4. Comparison of Eigenvalues obtained from EFA and Monte Carlo PA.

\begin{tabular}{ccc}
\hline Eigenvalue \# & Random Eigenvalues from PA & Eigenvalues from EFA \\
\hline 1 & 1.96 & 4.53 \\
2 & 1.78 & 1.95 \\
3 & 1.64 & 1.77 \\
4 & 1.54 & .70 \\
5 & 1.45 & .62 \\
\hline
\end{tabular}

Table 2.5. SICS Factor Intercorrelations, Reliability Coefficients and Descriptive Statistics $(N=108)$.

\begin{tabular}{cccccc}
\hline Factor & 1 & 2 & Number of items & Cronbach's alpha & Mean(SD) \\
\hline 1 & - & & 5 & .84 & $15.66(3.89)$ \\
2 & $.42^{* *}$ & - & 4 & .83 & $12.64(3.33)$ \\
3 & $.27^{* *}$ & $.23^{* *}$ & 3 & .84 & $10.69(2.23)$ \\
SICS & - & - & 12 & .85 & $38.89(7.11)$ \\
\hline
\end{tabular}

Note. ${ }^{* *} p<.01$. 
Convergent validity of the newly constructed scale was tested by correlating scores on the individual factors of SICS with participants' scores on selected items from well-established measures of conflict. Moderate to strong correlations (see Table 2.6) were found for the Marker of SICS with all measures. Specifically, the greater incidence of SIC measured with the Marker of SIC was accompanied by the perceptions of greater avoidant/capitulating behaviours from self and partner, more stalemates and verbal conflict. The moderate negative correlations between the Marker of SIC and the Cooperation subscale of CPS (Kerig, 1996) indicated that couples who engaged in SIC more frequently showed less cooperative conflict behaviours. The perceptions of SIC Costs were weakly positively associated with the perceptions of Stalemate (Kerig, 1996) and Ineffective Arguing (Kurdek, 1994b). The Benefits of SICS correlated significantly only with the participants' perceptions of partner withdrawal measured with items of CSRI (Kurdek, 1994b), indicating that parents involved in silent conflict associate their partners' conflict withdrawing behaviour with opportunities to calm down and reassess the argument. The direction and strength of the obtained correlations supported the convergent validity of SICS.

Table 2.6. Correlations between Factors of SICS, Other Measures of Relationship Conflict and Marlowe-Crowne Social Desirability Scale $(N=108)$.

\begin{tabular}{|c|c|c|c|c|c|c|c|}
\hline \multirow[b]{2}{*}{ Factor } & \multicolumn{4}{|c|}{$\begin{array}{c}\text { CPS } \\
\text { Self/Partner }\end{array}$} & \multirow[t]{2}{*}{ IAI } & \multirow{2}{*}{$\begin{array}{c}\text { CRSI } \\
\text { Self/Partner } \\
\text { Withdrawal }\end{array}$} & \multirow[t]{2}{*}{$\begin{array}{l}\mathrm{M}-\mathrm{C} \\
1(10)\end{array}$} \\
\hline & $\begin{array}{c}\text { Co- } \\
\text { operation }\end{array}$ & $\begin{array}{l}\text { Avoidance- } \\
\text { Capitulation }\end{array}$ & Stalemate & $\begin{array}{c}\text { Verbal } \\
\text { Aggression }\end{array}$ & & & \\
\hline SICS & $-.26 * * /$ & $.44^{* *} /$ & $.44 * * /$ & $.35 * * /$ & $.59 * *$ & $.50 * * /$ & $-.30 * *$ \\
\hline Marker & $-.38 * *$ & $.37 * *$ & $.42 * *$ & $.33 * *$ & & $.54 * *$ & \\
\hline SICS & $-.01 /$ & $.10 /$ & $.23 * /$ & $.07 /$ & $.20 *$ & $.10 /$ & -.19 \\
\hline Costs & -.08 & .11 & $.22 *$ & .08 & & .16 & \\
\hline SICS & $-.08 /$ & $-.04 /$ & $-.03 /$ & $-.02 /$ & .06 & $-.03 /$ & .06 \\
\hline Benefits & -.02 & .02 & .11 & -.01 & & $.25 * *$ & \\
\hline
\end{tabular}

Note. CPS = Conflict and Problem-Solving Scales; IAI = Ineffective Arguing Inventory; CRSI = Conflict Resolution Style Inventory; M-C 1(10) = short form of Marlowe-Crowne Social Desirability Scale. $* * p<.01, * p<.05$. 


\section{Socially desirable responding (SDR)}

SDR was measured with M-C 1(10), and as reported earlier, the Cronbach's alpha obtained for this scale in the study was .61, indicating questionable internal consistency of the instrument for this dataset. Consequently, the findings involving the measure presented below need to be interpreted with caution. Comparison of means (independent samples $t$-test) revealed no significant differences on SDR scores between men and women. Three outliers were found when examining participants' total scores on M-C 1(10): two participants had maximum scores of 10 and one participant had a minimum score of zero. However, when a one way ANOVA was conducted to compare these participants' scores on the three factors of SICS with the rest of the sample, no significant differences were found.

Table 2.7. Correlations between Items of SICS and scores on M-C 1(10).

\begin{tabular}{clc} 
No & \multicolumn{1}{c}{ Item } & M-C 1(10) \\
\hline sc27 & $\begin{array}{l}\text { During conflict there is a lot of tension between us even though we do } \\
\text { not communicate. }\end{array}$ & $-.27^{* *}$ \\
sc49 & Unresolved issues lead to silence between my partner and me. & -.19 \\
sc24 & There is little warmth in our relationship when we are in conflict. & -.19 \\
sc9 & $\begin{array}{l}\text { When we are annoyed with each other we avoid each other around the } \\
\text { house. }\end{array}$ & $-.26^{* *}$ \\
sc44 & We cannot agree on some issues, so they remain unresolved between us. & $-.24 *$ \\
sc30 & I can't concentrate on anything else when we don't speak to each other. & -.09 \\
sc31 & When we are in conflict I can't stop mulling things over. & $-.20 *$ \\
sc29 & $\begin{array}{l}\text { I get a knot in my stomach when my partner and I are not talking to each } \\
\text { other. }\end{array}$ & -.13 \\
sc32 & $\begin{array}{l}\text { Discord between my partner and me shuts me down for everybody. } \\
\text { sc19 }\end{array}$ & $\begin{array}{l}\text { A period of silence and staying away from each other helps to put a } \\
\text { disagreement into perspective. }\end{array}$ \\
sc21 & $\begin{array}{l}\text { Silence between us gives me a chance to try and understand my partner's } \\
\text { behaviour. } \\
\text { A period of silence and staying away from each other helps to calm the } \\
\text { emotions. }\end{array}$ & .07 \\
\hline
\end{tabular}

Note. Item numbers correspond to the questionnaire presented in Appendix F. 
Participants' total scores on M-C 1(10) were correlated with the scores on the subscales (factors) of SICS and on its individual items; the results are presented in Tables 2.6 and 2.7, respectively. Only the SICS Marker and four of the twelve SICS items were correlated to M-C 1(10). The negative correlations indicate that people, who exhibited greater social desirability bias tended to minimise their reports of silent conflict. However, in view of the magnitude of the correlations, either weak or at the lower end of moderate, it was concluded that social desirability bias did not have a serious effect on participants' responses to SICS.

\section{Summary of Study 1}

The newly developed measure of silent interparental conflict was subjected to exploratory factor analysis. A three factor structure of the 12-item SICS was accepted. The factors reflected the marker characteristics of silent conflict, the negative consequences of silent conflict to the involved partners (costs) and the perceived benefits of silent conflict. The scale demonstrated excellent internal consistency as well as face and convergent validities. Additionally, no significant issues were found with potential effects of social desirability on the participants' responses to SICS.

\section{STUDY 2}

\section{Method}

\section{Procedure}

Participants were recruited using multiple methods. In addition to snowballing from established contacts and advertising via community notice 
boards and flyers dropped off in letterboxes in Wellington, twenty four high schools from various regions in New Zealand were identified from the Ministry of Education website (http://wwwminedu.govt.nz/NZEducation.aspx $)$ as sources of potential participants. The criteria guiding the school selection were high student enrolment (between 300 and 1600) and a balanced mix of school deciles (from 2 to 9) and of students' genders. I sent letters to principals of the colleges describing this research and requesting assistance in recruiting participants by alerting students and their parents to the study. A sample copy of the flyer was enclosed. Out of the twelve schools that agreed to publicize the study, ten published a notice in a newsletter, one distributed 200 flyers to parents, and one agreed to distribute questionnaire packs to families for community snowballing ${ }^{7}$.

Flyers contained a brief invitation to families with a teenage child to take part in a family dynamics study by completing a questionnaire about family dynamics at two time points. My phone and email contact details were provided for registering expressions of interest in the study. Potential participants either contacted me directly providing their postal address for the mailing of questionnaires or received their questionnaire packs from the families involved in snowballing. Each participating family received a pack containing information sheets for parents and the participating adolescent; consent forms for each participant (young people under the age of 16 completed assent forms with parents signing a consent form for them) and a number-coded questionnaire for each participant. Addressed stamped envelopes were provided for convenient return of completed surveys. The concluding part of the survey contained names

\footnotetext{
7 The recruitment methods used to attract participants resulted in the following composition of the sample: $82 \%$ - recruited through schools; $14 \%$ recruited through flyers; $4 \%$ recruited through snowballing.
} 
and contact details of local counselling services and in lieu of debriefing participants were offered a summary of research results on completion of the study. Upon receipt of completed questionnaires each participating family was sent a thank you letter and a gift voucher to the value of $\$ 30$. Forty eight families opted for a donation to their college travel fund in place of vouchers.

\section{Participants}

Two hundred and sixty-six adults returned completed questionnaires, however six of them were excluded from the sample due to incompleteness of their responses. The final sample of 260 parents consisted of 131 males and 129 females aged between 32 and 62 years $(M=46.28, S D=5.23)$. Participants reported their highest attained level of education as follows: secondary $-29 \%$, additional training $-25 \%$, tertiary $-29 \%$, postgraduate $-16 \%$; five parents did not provide their education details. The ethnic composition of the sample was as follows: $79 \%$ European/Pakeha, 5\% Maori, $12 \%$ Pacific Nation, $11 \%$ other European, $1 \%$ other; nine people did not provide ethnicity. Married participants constituted $89 \%$ of the sample and $11 \%$ of the participants cohabited. The reported length of relationships ranged from less than one year to 36 years $(M=$ $19.87, S D=6.54$ ), with no data from three participants. The number of children in the households ranged from one to eight with the modal number of 2 . The reported frequencies with the over-representation of the European/Pakeha group, the prevalence of high level of education and the high proportion of marriages, once again reflect the self-selected nature of the sample. 


\section{Measures}

Participants completed a comprehensive questionnaire ${ }^{8}$ including items for the proposed SICS and a measure of psychological wellbeing for adults adapted from the well known Irritability, Depression, Anxiety (IDA) Scale (Snaith, et al., $1978)^{9}$. The original IDA scale consists of four subscales assessing depression and anxiety (five items each), as well as outwardly directed irritability or aggression and inwardly directed irritability or self harm (four items each). Due to ethical concerns only the first three subscales were used in this study. The items are rated for frequency on a four-point Likert scale. In their original paper, Snaith and colleagues, (1978) provide several satisfactory reliability coefficients obtained using the Spearman-Brown method; similarly satisfactory were Cronbach's alphas ranging from .78 to .81 obtained in the present study. Data screening

Data were carefully screened prior to conducting a confirmatory factor aAnalysis (CFA), as missing values and non-normality of distribution are problematic in Structural Equation Modelling (SEM) due to the assumptions underlying its estimation methods (e.g. R. B. Kline, 2005, p. 45). However, Tabachnick and Fidell (2007) observe that in large samples (e.g. > 200), such as the present one, the effects of non-normality, such as skewness and kurtosis are lessened. Therefore, given a large sample size, statistically significant skewness will not result in "a substantive difference to the analysis" and in the case of kurtosis 'underestimates of variance will disappear with samples of 200 or more' (Tabachnick \& Fidell, 2007, p.80).

\footnotetext{
${ }^{8}$ The content of the questionnaire is described further in Chapters 3 and 4.

${ }^{9}$ The administered SIC and IDA items are presented in Appendices F and G respectively.
} 
Close examination of the missing data patterns led to a twofold approach. Twelve cases were found to be missing one value and one case was missing two values and for these cases data were imputed using the series mean substitution function of SPSS $16.0^{10}$. Six cases were found to be missing three or more values and on close inspection these omissions appeared intentional, therefore nonrandom, consequently the cases were excluded from further analyses, reducing the sample to 260 participants.

\section{Confirmatory Factor Analysis}

Having established a factorial structure of SICS through EFA, the next step was to verify it by conducting a confirmatory factor analysis (CFA). In this procedure findings of the exploratory factor analysis are effectively treated as theory to be subjected to testing through the statistical procedure of structural equation modelling. The factorial solution accepted as a result of EFA and described earlier consisted of twelve items loading on three factors labelled Marker of Silent Conflict (F1), Costs of Silent Conflict (F2), and Benefits of Silent Conflict (F3).

Prior to fitting the model to the Time 1 data, correlations between factors of SICS were computed and the overall reliability of the twelve item instrument was calculated, as well as Cronbach's alphas for the individual factors. Once again, the whole scale and the subscales demonstrated satisfactory reliability coefficients. Additionally, the correlations among the factors of SICS were similar in strength to those obtained in the previous study. Intercorrelations

\footnotetext{
${ }^{10}$ Mean substitution was used in this work due to low rates of missing data. However, it needs to be noted that, although a conservative method of estimating missing values (Tabachnick \& Fidell, 2007), mean substitution may result in a reduction in variance and loss of statistical power. Therefore, with higher rates of missingness, other methods of missing data treatment would be preferable.
} 
among the three factors of SICS, reliability coefficients and descriptive statistics at Time 1 are presented in Table 2.8.

\section{Hypothesised model}

Confirmatory analysis was performed using AMOS 16.0 (Arbuckle, 2006) on the hypothesised model of SICS consisting of three factors and 12 indicators. It was further hypothesised that the three factors covaried and that the measurement errors associated with the indicators were unrelated. Leaving the errors uncorrelated is a stringent approach favouring model parsimony over fit, as the correlating of errors generally results in an improvement to model fit (R. B. Kline, 2005, pp. 315-316).

Table 2.8. Time 1: SICS Factor Intercorrelations, Reliability Coefficients and Descriptive Statistics $(N=260)$.

\begin{tabular}{cccccc}
\hline Factor & 1 & 2 & Number of items & Cronbach’s alpha & Mean(SD) \\
\hline SICS Marker & - & & 5 & .81 & $15.01(3.91)$ \\
SICS Costs & $.46^{* *}$ & - & 4 & .82 & $12.28(3.38)$ \\
SICS Benefits & $.27^{* *}$ & $.21^{* *}$ & 3 & .87 & $10.31(2.46)$ \\
SICS & - & - & 12 & .83 & $37.60(7.33)$ \\
\hline
\end{tabular}

Note. $* * p<.01$.

\section{Results}

The standardised results are presented in Figure 2.1. In keeping with the SEM convention, latent variables are represented by ellipses (factors) and circles (error terms), and manifest variables by rectangles. All regression weights and covariances were significant at $p<.001$ level (two-tailed). The obtained item loadings were satisfactory and the covariances between the latent factors resembled the pattern of the raw correlations.

Several model fit indices were examined in order to establish if the hypothesised SICS model fit the data well. A long established index is the chi- 
square $\left(\chi^{2}\right)$ statistic, which when significant, indicates inadequate fit between the proposed model and the data, as the null hypothesis cannot be accepted. However, this index has been found to be sensitive to sample sizes (Raykov \& Marcoulides, 2006, p. 43) and when samples are large the chi-square statistic tends to be associated with small p-values, thus indicating rejection of admissible models. In response to this indicative inaccuracy of chi-square, several subsequent goodnessof-fit indices have been developed to guide model acceptance decisions and are now customarily reported. The indices used in this study were: the ratio of $\chi^{2}$ to degrees of freedom, the Goodness of Fit Index (GFI) and the Adjusted Goodness of Fit Index (AGFI), the Comparative Fit Index (CFI) and two indices of residual fit, namely the standardized Root Mean Squared Residual (sRMR) and the Root Mean Square Error of Approximation (RMSEA). In order to indicate a well fitting model, Kline (2005) recommends that the value of $\chi^{2} / d f$ ratio ought to be less than 3 and the GFI and AGFI ought to be greater than 0.90. The value of the CFI should be greater than 0.95 (Byrne, 2001; Kline, 2005). Hu and Bentler (1999) consider values below 0.08 acceptable for sRMR and of less than 0.06 for the RMSEA. According to these criteria the three factor model of SICS fit the data well, producing $\chi^{2} / d f=1.71 ; \mathrm{GFI}=.944 ; \mathrm{AGFI}=.914 ; \mathrm{CFI}=.968 ; \mathrm{sRMR}=.046$ and RMSEA $=.052$. It may be concluded with some confidence that the CFA procedure confirmed the proposed three factor model of SICS. 


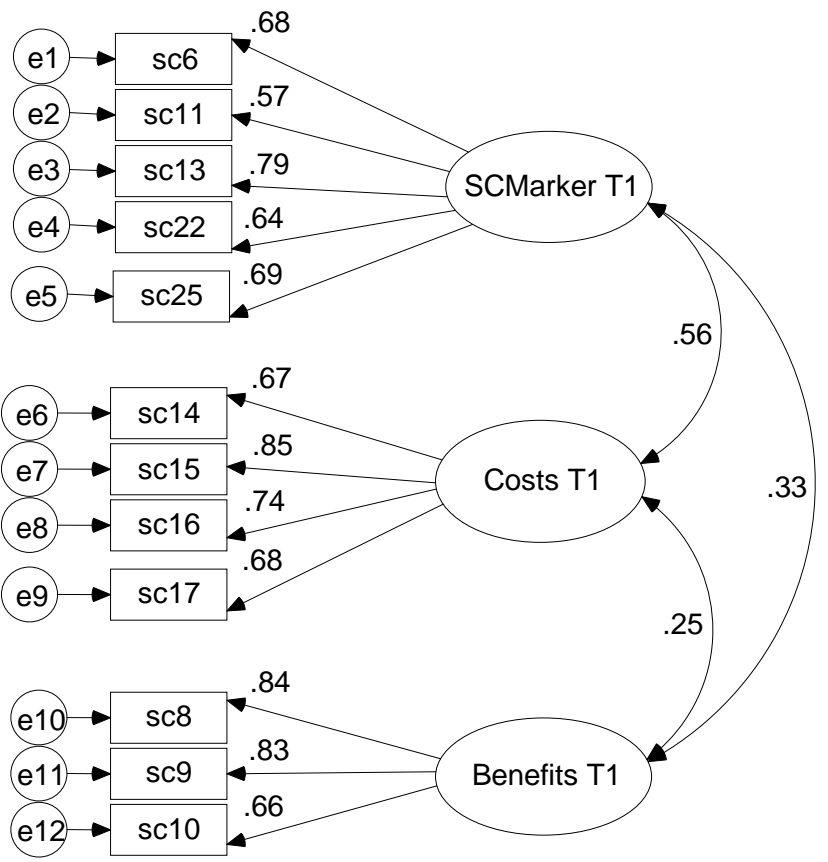

Figure 2.1. Confirmatory model of the SICS at Time 1, standardised estimates (Item numbers refer to questionnaire presented in Appendix F).

\section{Criterion validity}

Research to date has shown consistent associations between marital discord and mental health problems ranging from depression (Beach, et al., 1998; Fincham, et al., 1997; O'Leary, et al., 1994); through eating disorders (Van den Broucke, et al., 1997) to alcohol abuse (e.g. Murphy \& O'Farrell, 1994).

Therefore, in order to explore the criterion validity of SICS, scores on the Total SICS as well as on individual factors of SICS were correlated with scores on the subscales of IDA (Snaith, et al., 1978). Consistent with existing conflict research, higher scores on the overall SICS, the SICS Marker and the Costs of Silent Conflict factor were associated with greater maladjustment (see Table 2.9), indicating that the experience of silent conflict coincided with greater psychological problems for the involved parties. The only exception was the Benefits factor of SICS, which did not correlate significantly with any of the tested maladjustment measures. 
Table 2.9. T1: Intercorrelations between scores on SICS and IDA measures of psychological wellbeing $(N=260)$.

\begin{tabular}{cllll}
\hline & Anxiety & \multicolumn{1}{c}{ Depression } & Irritability & \multicolumn{1}{c}{$\begin{array}{c}\text { Total } \\
\text { Problems }\end{array}$} \\
\hline SICS Marker & $.29^{* *}$ & $.29^{* *}$ & $.25^{* *}$ & $.35^{* *}$ \\
SICS Costs & $.35^{* *}$ & $.19^{* *}$ & $.18^{* *}$ & $.30^{* *}$ \\
SICS Benefits & .04 & .02 & -.01 & .02 \\
SICS Total & $.32^{* *}$ & $.25^{* *}$ & $.21^{* *}$ & $.32^{* *}$ \\
\hline
\end{tabular}

Note. $* * p<.01$

\section{Summary of Study 2}

The purpose of this study was to confirm the factorial structure of the SICS and to test its criterion validity on a sample of 260 parents. The conducted CFA produced very satisfactory model fit indices and thus the factorial validity of the SICS was supported. Additionally, as expected the whole SICS and its two factors of Marker and Costs correlated positively with psychological problems of participating parents, thus providing general support for criterion validity of the instrument.

\section{STUDY 3}

The aim of Study 3 was to repeat the SICS validation process consisting of CFA and testing the concurrent criterion validity with the same sample of parents after a lapse of approximately one year. Additionally, as longitudinal data became available, the temporal stability of the SICS was to be tested.

\section{Method}

\section{Procedure}

Families participating in Study 2 were re-contacted approximately one year later. All families were sent a letter reminding them of the study, a 
questionnaire pack with surveys for each participating family member and a franked self addressed envelope for return of the completed forms. The nonresponders were approached again up to two times, in order to maintain the balance between maximum retention and respect for the principle of voluntary participation. Families received incentives identical to those selected previously.

\section{Participants}

In total, 246 parents returned completed questionnaires, however data for two men and two women had to be excluded due to high levels of non responses. The resulting sample of 242 parents $^{11}$ consisted of 121 males and 121 females aged between 33 and 63 years $(M=47.37, S D=5.21)$. Participants reported their highest attained level of education as follows: secondary $-27 \%$, additional training $-26 \%$, tertiary $-29 \%$, postgraduate $-17 \%$; five parents did not provide their education details. The ethnic composition of the sample was as follows: $80 \%$ European/Pakeha, $4 \%$ Maori, $11 \%$ other European, $1 \%$ other; eight people did not provide ethnicity. Married participants constituted $91 \%$ of the sample, $9 \%$ of the participants cohabited. The reported length of relationships ranged from one year to 37 years $(M=21.09, S D=6.54)$. The reported frequencies mirror those from Study 2 and over-represent the European/Pakeha group, the prevalence of high level of education and the high proportion of marriages reflecting the self-selected nature of the sample.

\section{Measures}

Participants completed identical sets of measures as administered one year previously and described in Study 2.

\footnotetext{
${ }^{11}$ Non-respondents at Time 2 were compared with the participating sample on study variables. No significant differences were found between the two groups.
} 


\section{Data screening}

Data were carefully screened for nonnormality and missing value patterns examined. Four aforementioned cases demonstrated high ratios of missing data in excess of $25 \%$ and were excluded from the dataset. The remaining missing values were imputed using the series mean substitution function of SPSS 16.0.

\section{Confirmatory Factor Analysis}

The factorial solution accepted as a result of EFA and confirmed on the T1 dataset consisted of twelve items loading on three factors labelled Marker of Silent Conflict (F1), Costs of Silent Conflict (F2), and Benefits of Silent Conflict (F3). Prior to fitting the model to the Time 2 data, correlations between factors of SICS were computed and the overall reliability of the twelve item instrument was calculated as well as Cronbach's alphas for the individual factors. The whole scale and the subscales demonstrated satisfactory reliability coefficients. All of the obtained results resembled very closely those obtained at Time 1 . Intercorrelations among the three factors of SICS, Time 2 reliability coefficients and descriptive statistics are presented in Table 2.10.

Table 2.10. Time2: SICS Factor Intercorrelations, Reliability Coefficients and Descriptive Statistics $(N=242)$.

\begin{tabular}{cccccc}
\hline Factor & 1 & 2 & Number of items & Cronbach's alpha & Mean(SD) \\
\hline SICS Marker & - & & 5 & .81 & $14.49(3.86)$ \\
SICS Costs & $.43^{* *}$ & - & 4 & .84 & $11.94(3.53)$ \\
SICS Benefits & $.39^{* *}$ & $.26^{* *}$ & 3 & .84 & $10.13(2.41)$ \\
SICS & - & - & 12 & .85 & $36.57(7.54)$ \\
\hline
\end{tabular}

Note. $* * p<.01$.

\section{Hypothesised model}

Confirmatory analysis was once again performed using AMOS 16.0

(Arbuckle, 2006) on the hypothesised model of SICS consisting of three factors 
and 12 indicators. As before, it was hypothesised that the three factors covaried and that the measurement errors associated with the indicator variables were unrelated.

\section{Results}

The standardised results are presented in Figure 2.2. All regression weights and covariances were significant at $p<.001$ level (two-tailed). The three factor model of SICS fit the Time 2 data well, producing $\chi^{2} / d f=1.665$; GFI $=$ $.945 ; \mathrm{AGFI}=.916 ; \mathrm{CFI}=.972 ; \mathrm{sRMR}=.045$ and $\mathrm{RMSEA}=.053$. The confirmatory factor analytic procedure repeated after a year's interval on a sample of parents produced a strong confirmation of the proposed three factor model of SICS

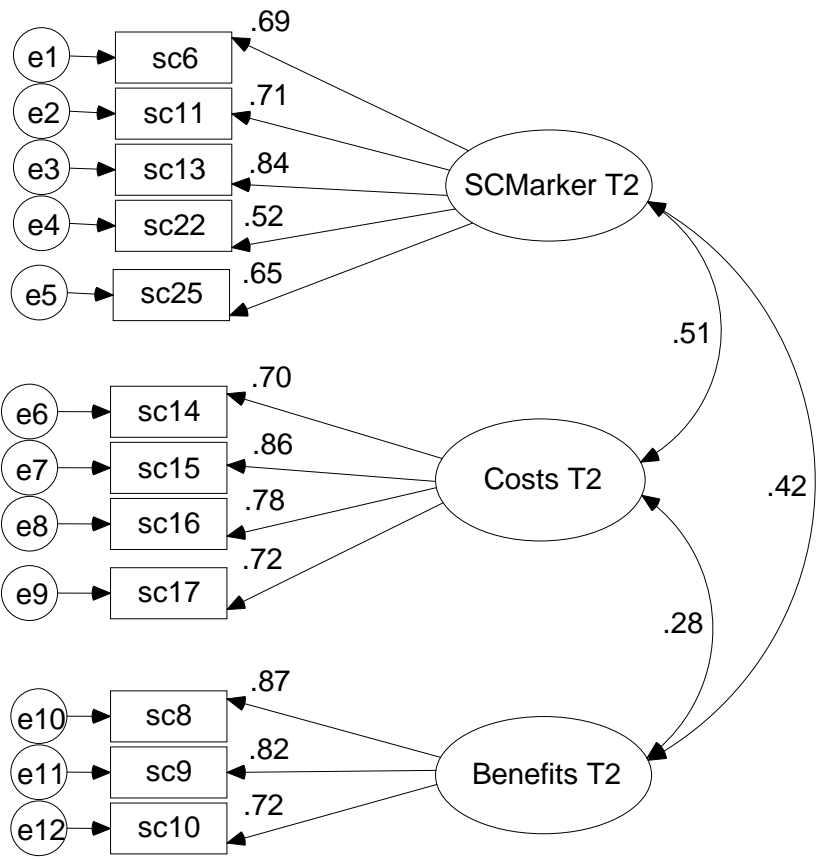

Figure 2.2. Confirmatory model of the SICS at Time 2, standardised estimates (Item numbers refer to questionnaire presented in Appendix F). 


\section{Criterion validity}

Time 2 Scores on the Total SICS and on individual factors were correlated with anxiety, depression and irritability subscales of IDA (Snaith, et al., 1978) in order to confirm the criterion validity of the SICS (Table 2.11). As at T1, it was found that higher scores on SICS Marker and Costs were associated with greater maladjustment and there were no significant concurrent relationships between psychological wellbeing and perceived Benefits of silent conflict. These results corroborate the findings at $\mathrm{T} 1$ that the experience of silent conflict is concurrently associated with compromised psychological wellbeing of the involved parties.

Table 2.11. T 2: Intercorrelations between scores on SICS and measures of psychological wellbeing $(N=242)$.

\begin{tabular}{cllll}
\hline & \multicolumn{1}{c}{ Anxiety } & \multicolumn{1}{c}{ Depression } & Irritability & \multicolumn{1}{c}{$\begin{array}{c}\text { Total } \\
\text { Problems }\end{array}$} \\
\hline SICS Marker & $.29^{* *}$ & $.26^{* *}$ & $.25^{* *}$ & $.31^{* *}$ \\
SICS Costs & $.39^{* *}$ & $.19^{* *}$ & $.21^{* *}$ & $.34^{* *}$ \\
SICS Benefits & .04 & -.01 & -.01 & .01 \\
SICS Total & $.36^{* *}$ & $.24^{* *}$ & $.23^{* *}$ & $.35^{* *}$ \\
\hline
\end{tabular}

Note. $* * p<.01$

\section{Longitudinal structural stability}

As the last step of the analyses, tests of the longitudinal structural stability of the SICS were conducted. Brown (2006) points out that despite its importance this test is rarely attempted in research. The value of the test lies in helping to clarify whether the longitudinal differences in measurement of the phenomenon are affected by the instability of the instrument, which obscures the actual changes in the phenomenon under investigation over time. A high level of structural stability is therefore desirable. 
In an attempt to test the longitudinal invariance of the SICS the fully

articulated latent models of SICS at T1 and T2 were allowed to covary (Brown, 2006). All stipulated covariances were found to be significant except for the covariances between Benefits of silent conflict at T1 with Marker of silent conflict and Costs of silent conflict at T2, which proved to be marginally significant. The regression weights showed consistency over time. The hypothesised model of longitudinal stability of the SICS is presented in Figure 2.3; the obtained standardised regression weights are summarised in Table 2.12 and the covariances in Table 2.13.

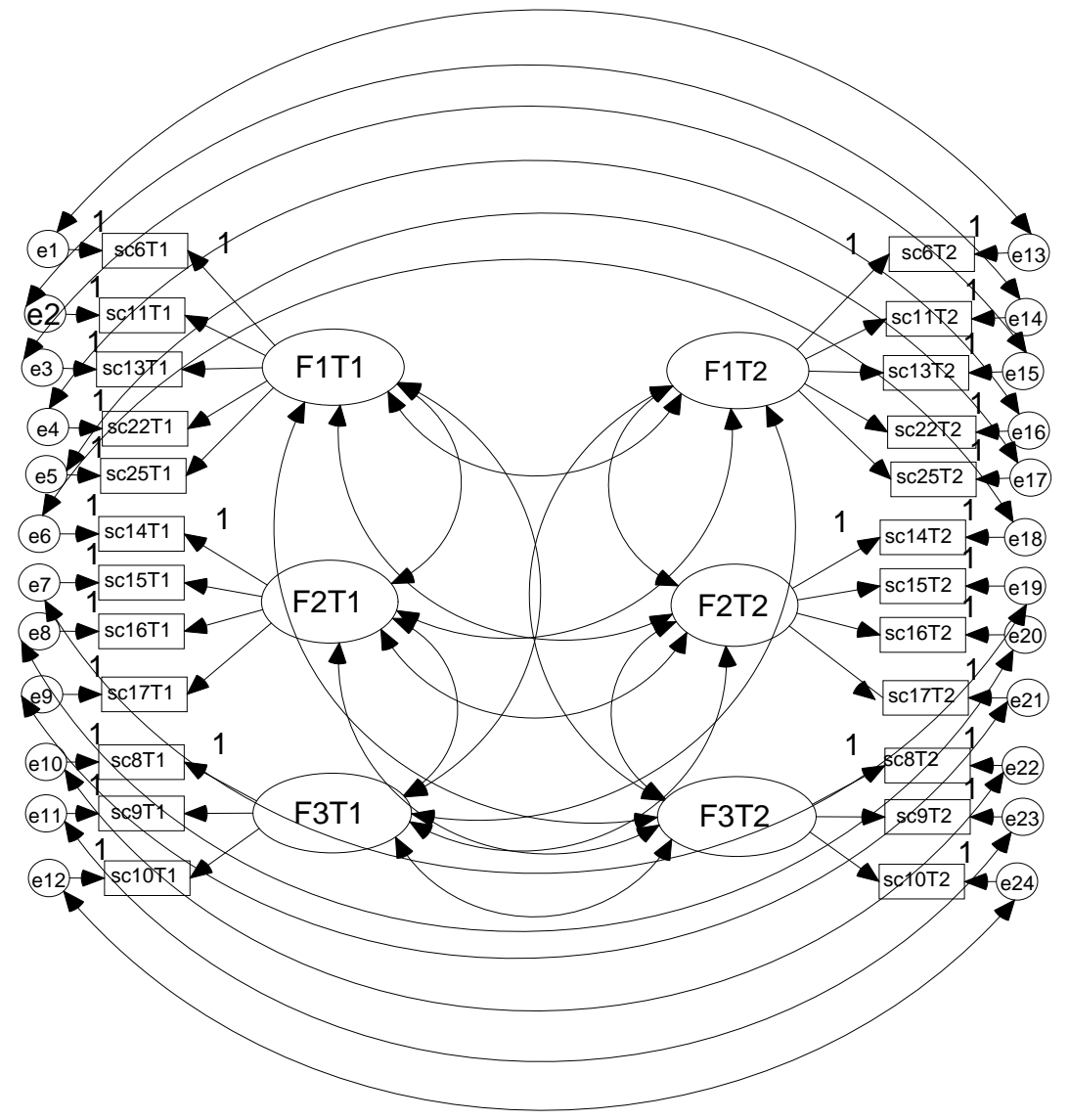

Figure 2.3. Longitudinal measurement model of SICS (Item numbers refer to questionnaire presented in Appendix F). 
Table 2.12. Standardised regression weights (factor loadings) at Times 1 and 2 for the longitudinal structural stability model of SICS.

\begin{tabular}{lcc}
\hline & \multicolumn{2}{c}{ Standardised regression weights } \\
\cline { 2 - 3 } & T1 & T2 \\
\hline F1 - sc6 & .66 & .69 \\
F1 - sc11 & .61 & .69 \\
F1 - sc13 & .79 & .88 \\
F1 - sc22 & .59 & .51 \\
F1 - sc25 & .65 & .64 \\
F2 - sc14 & .66 & .69 \\
F2 - sc15 & .84 & .86 \\
F2 - sc16 & .74 & .76 \\
F2 - sc17 & .60 & .72 \\
F3 - sc8 & .82 & .86 \\
F3 - sc9 & .80 & .82 \\
F3 - sc10 & .62 & .72 \\
\hline
\end{tabular}

Note. F1 = SC Marker; F2 = Costs; F3 = Benefits; Item numbers refer to questionnaire presented in Appendix F.

Table 2.13. Covariances, standard errors, critical ratio values and significance values for the longitudinal structural stability model of SICS.

\begin{tabular}{|c|c|c|c|c|}
\hline & Covariance & $S E$ & $C . R$ & $p$ \\
\hline $\mathrm{F} 1 \mathrm{~T} 1-\mathrm{F} 2 \mathrm{~T} 1$ & .244 & .048 & 5.062 & $* * *$ \\
\hline $\mathrm{F} 1 \mathrm{~T} 1-\mathrm{F} 3 \mathrm{~T} 1$ & .112 & .044 & 2.545 & .011 \\
\hline $\mathrm{F} 2 \mathrm{~T} 1-\mathrm{F} 3 \mathrm{~T} 2$ & .099 & .048 & 2.069 & .039 \\
\hline $\mathrm{F} 1 \mathrm{~T} 1-\mathrm{F} 1 \mathrm{~T} 2$ & .370 & .063 & 5.867 & $* * *$ \\
\hline $\mathrm{F} 1 \mathrm{~T} 1-\mathrm{F} 2 \mathrm{~T} 2$ & .235 & .049 & 4.822 & $* * *$ \\
\hline $\mathrm{F} 1 \mathrm{~T} 1-\mathrm{F} 3 \mathrm{~T} 2$ & .190 & .047 & 4.067 & $* * *$ \\
\hline $\mathrm{F} 2 \mathrm{~T} 1-\mathrm{F} 1 \mathrm{~T} 2$ & .152 & .041 & 3.712 & $* * *$ \\
\hline $\mathrm{F} 2 \mathrm{~T} 1-\mathrm{F} 2 \mathrm{~T} 2$ & .434 & .074 & 5.889 & $* * *$ \\
\hline $\mathrm{F} 2 \mathrm{~T} 1-\mathrm{F} 3 \mathrm{~T} 2$ & .142 & .049 & 2.886 & .004 \\
\hline F3T1 - F1T2 & .070 & .041 & 1.703 & .089 \\
\hline $\mathrm{F} 3 \mathrm{~T} 1-\mathrm{F} 2 \mathrm{~T} 2$ & .091 & .050 & 1.816 & .069 \\
\hline F3T1 - F3T2 & .355 & .063 & 5.611 & $* * *$ \\
\hline $\mathrm{F} 1 \mathrm{~T} 2-\mathrm{F} 2 \mathrm{~T} 2$ & .250 & .048 & 5.203 & $* * *$ \\
\hline $\mathrm{F} 1 \mathrm{~T} 2-\mathrm{F} 3 \mathrm{~T} 2$ & .228 & .047 & 4.889 & $* * *$ \\
\hline $\mathrm{F} 2 \mathrm{~T} 1-\mathrm{F} 3 \mathrm{~T} 2$ & .177 & .052 & 3.398 & $* * *$ \\
\hline
\end{tabular}

Note. F1 = SC Marker; F2 = Costs; F3 = Benefits; $* * * p<.001$.

The hypothesised fully covaried model of SICS at Times 1 and 2 produced satisfactory fit indices: $\chi^{2}=314.69, d f=225, p<.001 ; \chi^{2} / d f=1.40 ; \mathrm{GFI}=.901$; $\mathrm{AGFI}=.868 ; \mathrm{CFI}=.969 ; \mathrm{sRMR}=.050$ and $\mathrm{RMSEA}=.041$ indicating an overall good stability of the SICS factor structure. 


\section{Summary of Study 3}

The process of validating of the SICS was continued in Study 3. Both the CFA and the testing of the concurrent criterion validity with the sample of parents from Study 2 after a lapse of approximately one year produced very satisfactory results in support of the findings at Time 1. Additionally, longitudinal data were used to test the temporal stability of SICS and the unambiguous results obtained may be considered very promising, notwithstanding the need for continuing to test the measure with other samples.

\section{GENERAL DISCUSSION}

The purpose of the research described in this chapter was to develop a new measure of silent interparental conflict for adults (SICS), based on qualitative findings of Kielpikowski and Pryor (2008), and to assess its psychometric characteristics. This was accomplished over a series of three studies with two different samples of parents; the first, a pilot study; the second and third comprised of a longitudinal study with two measurement points separated by a one year interval.

To prevent duplication in developing the new scale, an inventory of reputable instruments used to measure couples conflict was compiled by selecting appropriate scales from the Handbook of Family Measurement Techniques (Touliatos, et al., 2001) and through searches of PsycARTICLES, ERIC and Proquest databases. Examination of the content of the assembled instruments indicated that the proposed new construct of 'silent conflict' was indeed unique and that the development of a scale to measure it was warranted. 
An extensive pool of items was developed, drawing on the qualitative dataset and piloted on a sample of parents. A three factor structure of the measure was proposed as a result of exploratory factor analysis. Additionally, convergent validity of the SICS was established in correlations with items from the Conflicts and Problem-Solving Scales (CPS) (Kerig, 1996), the Ineffective Arguing Inventory (IAI) and the Conflict Resolution Style Inventory (CRSI) (Kurdek, 1994b).

The factorial structure of the SICS was corroborated in Studies 2 and 3 by confirmatory factor analyses conducted using data collected from parental dyads twice with a one year interval. Longitudinal analyses indicated stability of the scale. The criterion validity was evidenced at both measurement times by positive associations between the Marker and the Costs factors of the SICS with the subscales of the Irritability, Depression, Anxiety Scale (IDA) (Snaith, et al., 1978).

Apart from the psychometric validation of the scale, the analytic process added support to the findings of the preceding qualitative study (Kielpikowski \& Pryor, 2008), as the qualitative themes were generally mirrored by the identified factors, except that 'Behavioural change', 'Lack of resolution' and 'Avoidance and withdrawal' were subsumed within the Marker subscale of the SICS.

Importantly, the factorial structure of SICS exposed the ambivalent nature of silent conflict, as the Costs (its negative consequences) and the Benefits (its favourable aspects) were positively correlated. This finding highlights the demanding decisions and complex relationship dynamics negotiated by parents in their daily lives. 
Although multidimensional, consisting of 12 items, the SICS is short, accessible and easy to administer. The scale may be used to collect data from one parent representing a family, but it is preferable that it be used with parental dyads, in keeping with the systemic conceptualisation of families propounded in this work.

In view of its excellent psychometric properties the SICS may be a useful addition to the existing list of family measurement instruments. Importantly, the SICS enables comprehensive measurement of a new concept of silent interparental conflict offering the potential to open a new area for research and ultimately for professional intervention within family relationships. 


\title{
Chapter 3: Silent Interparental Conflict within Couples' Relationships: Its Effects and Its Sources
}

\section{Part one: The effects of silent interparental conflict}

\author{
Silence is the unbearable repartee. \\ G. K. Chesterton
}

In Chapter two I discussed the design and validation of the measurement scale of silent interparental conflict (SIC). Aside from serving its primary purpose of validating the psychometric nature of the scale, the process resulted in several substantive findings illuminating the construct validity of SIC. First, the three identified factors of the measure (the Marker of SIC, the Costs, and the Benefits) were positively correlated. This result indicated that the more couples engaged in silent conflict the greater their reports of its attendant negative consequences, however at the same time, the greater the perceived benefits. Additionally, the positive association between the costs and the benefits of silent conflict exposed the heterogeneous nature of SIC, as the positive aspects of silent conflict appeared to accompany and coexist with the negative ones.

Previous research has shown associations between marital discord and mental health problems of spouses (e.g. Beach, et al., 1998; Fincham, et al., 1997; Kiecolt-Glaser, et al., 1996; O'Leary, et al., 1994). Consistent with these findings, scores on the Total SICS as well as on the Marker of SIC and the Costs of SIC were related to psychological maladjustment measured with the Irritability, Depression, Anxiety Scale (Snaith, et al., 1978) at both measurement times. This 
finding indicated that the experience of silent conflict was concurrently associated with compromised psychological wellbeing of the involved partners.

The aim of this chapter is twofold; first, an attempt is made to understand the reasons why silent conflict may have detrimental effects on psychological functioning; and second, the reasons why parents engage in silent conflict are explored, in view of its association with psychological distress.

This section of Chapter 3 addresses the consequences of SIC for parents' wellbeing. The effects of silent conflict on couples are theorised from two perspectives; first, silence is examined from a linguistic standpoint as a challenging communicative device; and second, the social psychological findings regarding interpersonal rejection and ostracism and their implications are discussed in relation to couples' perceptions of SIC.

Based on the qualitative findings obtained earlier (Kielpikowski, 2004; Kielpikowski \& Pryor, 2008) the effects of the Marker, the Costs and the Benefits of SIC on wellbeing are hypothesised and tested using structural equation modelling. Following previous research indicating differences in men's and women's paths to distress in the context of marital conflict (e.g. Fincham, et al., 1997), separate models are tested for the husbands and the wives in the sample. Mutual influences of partners reflecting the systemic perspective taken in this work are assumed and tested.

Why does silent conflict impact on psychological wellbeing of partners?

In order to try to understand the relationship between SIC and maladjustment it is helpful to locate silent conflict within the spectrum of conflict expressions. Broadly, the composition of any conflict encounter may be reduced 
to the subject matter at the core of a disagreement 12 and the act of conveying the disagreement to the other party in conflict (Figure 3.1). Indeed, Wilmot and Hocker (2007) stress that conflict has to be expressed in order to be recognised as one. Consequently, episodes of conflict may be understood as communication acts, with language an obvious and most direct medium of message delivery.

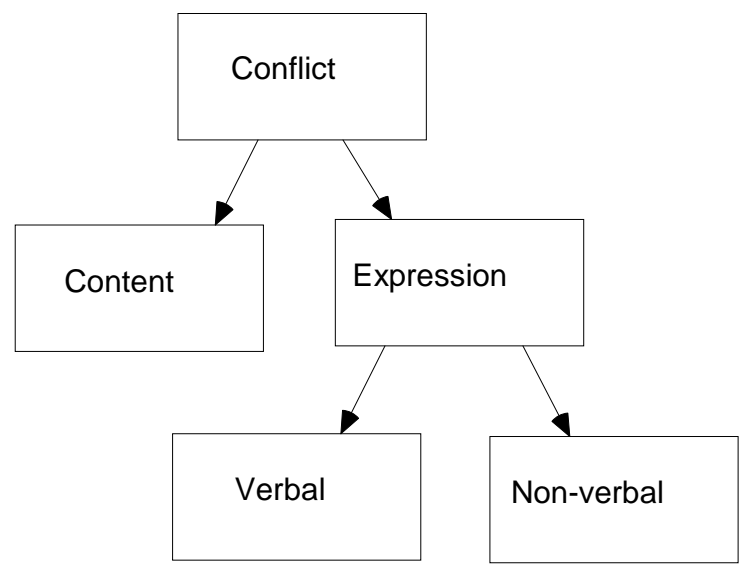

Figure 3.1. Constituents of conflict.

Verbal conflict encounters encompass a spectrum of direct exchanges from skilful amicable negotiations to highly adversarial verbal attacks. Paralinguistic features, such as facial expressions, body postures, and gestures typically accompany verbal communication and at times in situations of conflict may eclipse it or supplant it. So much so, that enactments of violence may be construed as the extremes of such nonverbal conflict expressions and it has been argued that this is particularly applicable to people who are unskilful at problem

\footnotetext{
${ }^{12}$ Regarding the content of couples' conflict, there seems to be a consensus among conflict researchers. Although communication, finances, children and sex are the most commonly named topics of disagreements, couples may and do disagree about virtually anything (Fincham, 2003).
} 
solving and negotiation (Infante, Sabourin, \& Rudd, 1989; Infante, Sabourin, Rudd, \& Shannon, 1990).

Where does silent conflict fit in? It is not expressed verbally; however the use of silence by partners in conflict remains problematic, unless the status of silence itself is clarified. Is silence indeed absence of communication as was reported by the participants in my qualitative study with parents (Kielpikowski, 2004)?

Linguists ${ }^{13}$ differentiate between acoustic and communicative silences (CS) (Sobkowiak, 1997). According to this division, the former exists without speech, while the latter takes on meaning when surrounded by verbal and non verbal symbols. The latter type of silence is produced deliberately and purposefully and it is perceived as communicative (Johannesen, 1974). In sum, in Sobkowiak's words CS is characterised by its volitional, teleological, substitutive and contextual aspects (p. 44).

Silence belongs on the spectrum of linguistic communicative behaviours, from the most verbal to the least, as the latter. It is distinct from communicative nonverbal behaviours such as gestures, facial expressions, etc., which contribute to interpretation of a communicative processes. In regards to form, silence is the simplest among linguistic signs and therefore relatively effortless to produce. Decoding of meaningful silence and speech involves virtually the same interpretive processes, however, due to its semantic opacity, CS requires a considerable effort to be decoded (Sobkowiak, 1997). In sum, silence clearly carries meaning and possesses rich communicative potential, which is fraught,

\footnotetext{
${ }^{13}$ The literature pertaining to silence cited in this chapter has been generously suggested by Professor Janet Holmes from the School of Linguistics and Applied Language Studies at Victoria University of Wellington.
} 
nonetheless, with the inherent risk of imperfect interpretations. The problem has been famously illustrated by Johannesen, who offered twenty possible answers to a deceptively simple question "What's her silence supposed to mean?" (1974, pp. 29-30).

Importantly, unlike members of some cultures (e.g. the Japanese, Navajo Indians, Western Apache Indians, Igbo of Nigeria), Westerners favour speech over communicative silences and consider talk a desirable behaviour to be expected of competent language users (Saville-Troike, 2003). Therefore, in Western societies speech is a signal of both linguistic and social competence. However, proficient language users characterise themselves also by their abilities to recognise and use CS (Sifianou, 1997; Sobkowiak, 1997). Accordingly, successful participation in social interactions includes appropriate interpretation and observance of norms of nonverbal behaviours and silence. For instance, communicative competence includes familiarity with 'formulaic silences', that is socially acceptable customary expectation of saying nothing in response to specific situations and stimuli (Jaworski, 1993), such as social faux pas. Consequently, successful communication relies on speakers' ability to use silence and to correctly interpret silences of others.

An expectation of a communication process needs to take place in order for an interpretation of someone's silence to occur. In other words, when there is a perceived or expected initiation of communication between people, silence on the part of one of them will be subject to interpretation. [From a linguistic perspective, the ambiguity of silence may lead to a 'pragmatic failure' (Thomas, 2000) occurring when the purpose of silence intended by the addressor is differently attributed by the addressee]. In view of the interactional expectation of 
talk, Eckert and McConnell-Ginet observe: 'Silence in social situations is never neutral. We talk about awkward silences, ominous silences, stunned, strained, awed, reverent, and respectful silences. Silences take on meaning because in Anglo-American culture we expect social exchange to involve fairly continuous talk. ...A protracted silence between turns at talk, therefore, signals something unusual.' (2003, p. 119).

Notably, in English there is no monolexical verb to denote that the subject is silent and instead a structure including a verb be plus silent is used. In some languages, however, the purposeful communicative action involving silence is represented by simple verbs, e.g. Polish milczec, German schweigen, or Russian молчать , semantically closer to being silent in the sense of intentionally refraining from speech, than to being quiet in the acoustic sense (Jaworski, 1993, p. 71). The use of a composite structure in the absence of a specific verb in English somewhat detracts from the active nature of using silence communicatively (in the sense of 'doing') and instead implicitly emphasises the more passive alternative (encompassed in 'being' silent).

In his discussion of a silent answer, Kurzon (1992) proposes a sociopragmatic model (see Figure 3.2). 


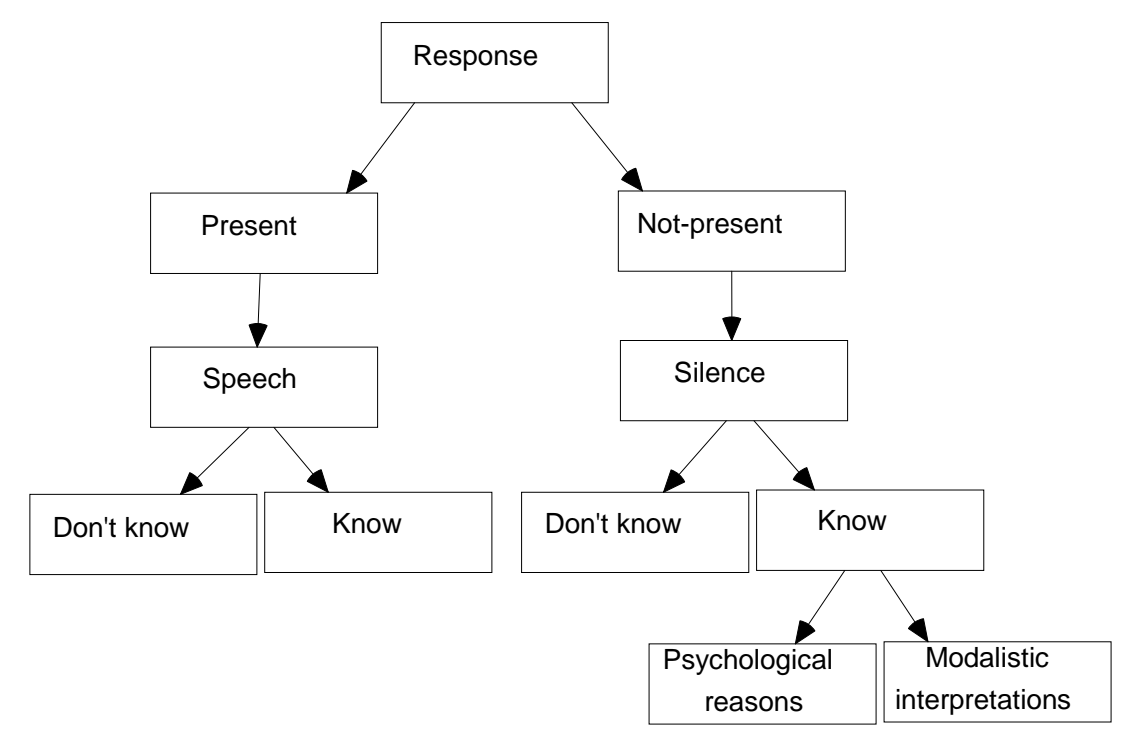

Figure 3.2. The socio-pragmatic model of responding in conversation (Kurzon, 1997).

The model represents a decision tree of sorts, with labels 'present' and 'not-present' referring to participation and non-participation in a conversation. According to the model, the silent addressee who knows the answer may be silent due to psychological reasons (e.g. shyness, fear, helplessness), or for a 'modalistic' reason is prevented from speaking. Kurzon equates modalistic silence to a speech act of the type 'I may not/cannot/will not/must not tell you' (p.93). That it is possible to be silent about something is richly illustrated by examples in Zerubavel's book "Elephant in the room" (2006), which range from employee quiescence, through secrets in the family (male battering, child abuse) to atrocities, and may involve collective silence and co-denial. The 'elephants' or taboo topics have been reported in the context of silent conflict by participants of my qualitative study (Kielpikowski \& Pryor, 2008), as illustrated by the following extract:

It doesn't get spoken about but you can feel the tension, you both know that you're not speaking about it. (Female, 45) 
Similarly, the notion of 'some things are better left unsaid', which according to Zerubavel underscores the role of silence in preventing conflict (p. 76), is expressed in the following extracts from the same study:

You don't talk about things because you don't know how the other person is going to react.

Or you know and you don't want the response. (Female, 42)

Someone is offering a challenge and you decide that you don't want to go down there. (Female, 45)

It needs to be noted that a more accurate description of this particular role of silence would be that it prevents overt conflict.

Kurzon (1992) notes that in conversational situations the initial control (power) resides with the questioner, who is the initiator of the exchange. However, power may also reside with the addressee, who may or may not opt for non participation. In other words, the addressee gains power of granting or refusing the response desired by the addressor. Silence thus may constitute a refusal to cooperate and simultaneously an attempt to seize power in the encounter, resulting in a reversal of the power structure. The withholding of an expected or socially appropriate conversational reciprocity constitutes a challenge to the addressor. Referring to the model (Figure 3.2), Kurzon concludes that silence that originates from psychological reasons is likely to indicate powerlessness; in contrast, a refusal to reciprocate equivalent to 'I may not/cannot/will not/must not tell you' (modalistic interpretation) may point to a power shift (p. 94) between interlocutors. Nevertheless, neither dominance nor powerlessness per se may be located in linguistic strategies including silence, for the simple reason that the same strategies may be used to different and even opposing effects in different contexts (Tannen, 1996, p. 21). So, it would be a mistake to confine silence in communication to negative and harmful tactics. 
For example, whether communicative acts are based on speech or silence they are equally able to convey lack of communication; both speech and the use of silence may act to keep the channels of communication open, both may terminate it. Termination of communication through silence, however, allows for easier resumption of communication than termination through overt acts of speech, as due to its inherent obliqueness silence is more open to reinterpretation. Jaworski (1993, pp. 24-25) observes that the directness of speech is less ambiguous than the indirectness of silence, but that this indirectness allows the recipient of silence in communication to choose the interpretation that suits her or him best. This, in turn may prove either more or less problematic. Jaworski points out the axiological ambiguity of silence, saying that it does both good and bad for communication: it offers an option of advantageous interpretation, but it is also often associated with concealing the truth; it may signify acquiescence (as in agreeing to something or with something through silence), but may also be a sign of aggression.

What happens when the exchange between the addressor and the addressee take place in front of others? Akman (1994) ponders examples which involve 'audiences' (p.212) and concludes that the silent response of an addressee and the audience's knowledge of certain qualities of the addressee and the addressor, such as the addressee's ability to respond, may work to construct a message of contempt towards the addressor.

Relevance to the effects of silent conflict on wellbeing

Conceptualising conflict as an act of communication places silence among communicative meaning-carrying devices. The linguistic analyses of communicative silence indicate numerous reasons for its potential for causing 
distress to its recipients. First of all, a silent response constitutes an intentional act of communication, the content of which is ambiguous and open to multiple interpretations, and may even signify a concealment of truth. Moreover, a silent response violates the conversational expectations of reciprocity, as well as the more global western social norms. Communicative silence may therefore be construed as an act of defiance, with an ability to shift power from the addressor to the addressee. Importantly, silent response in the presence of an audience may be interpreted as a display of disrespect towards the addressee. This is particularly significant in the context of families, where children are the 'audience' of parental conflicts, as any disempowering behaviour from a partner interpretable as humiliating is additionally felt by the receiving party as a loss of face in the eyes of children, thus magnifying the distress.

"Language most obviously serves a role in social control by providing a medium for telling people directly what to do... One of the strongest control forms in many societies is silence or 'shunning', which is also a part of communicative system" (Saville-Troike, 2003, p. 34) (emphases added).

The analogies between silent conflict and communicative silence provide some arguments for the effects both of them may have on psychological wellbeing of the involved parties. Due to their grounding in linguistics, the conclusions reached in the previous section focus on the role silence plays in the process as an alternative to language. A different approach of potential use in better understanding of the likely psychological hazards related to silent conflict comes from the social psychological research on interpersonal rejection and ostracism. 
Despite its apparent importance, the research of the phenomena of social and interpersonal rejection has gained impetus only in the last decade of the twentieth century (Williams, 2007). Leary (2001) conceptualises interpersonal rejection in relation to relational evaluation. The latter is understood as the degree of importance, value, and closeness ascribed to a relationship with another person. Relational evaluations rely on perceptions - that is, how people subjectively perceive they are valued by others on the basis of how others behave towards them. The perception of being rejected arises when people infer a lower than desired social evaluation of themselves from actions of other people. Leary points out that, due to inevitable inaccuracy of their perceptions, at times people may feel rejected even though objectively rejection has not occurred.

Perceptions of rejection are inferred from behaviours such as ignoring, avoiding and exclusion from activities, each of which conveys low relational valuation. Research has found that experiencing rejection has adverse effects on state self esteem and strongly predicts psychological distress in the form of irritation, sadness, social anxiety and depression (K. M. Kelly, 2001). Additionally, distress appears to inevitably trigger perceptions of lower than desired evaluation by others. This bidirectionality of effects echoes the well established mutual influences between the relational and the psychological problems (e.g. Beach \& O'Leary, 1993a, 1993b; Fincham, et al., 1997).

Leary (2001) notes that people respond to perceived low relational evaluations with attempts to improve or restore their desired value in the relationship. If such efforts prove unsuccessful, however, the usual reaction is to withdraw or seek appreciation in an alternative relationship. The last tactic is particularly interesting in the context of families, as it mirrors the compensatory 
hypothesis (Erel \& Burman, 1995), according to which parents may compensate for dissatisfaction in marital relationships by increasing their involvement and investment in their relationships with children.

\section{Relevance to silent conflict}

Interestingly, the concept of rejection was not explicitly referred to by the participants in my qualitative study nor was it identified as a theme in the analysis of the data (Kielpikowski, 2004). At the conclusion of their interview sessions, however, the interviewees were given a list of words I compiled on the basis of an earlier pilot study and were asked to select words that according to them were pertinent to the concept they have been describing. Rejection ${ }^{14}$ was selected by $75 \%$ of the participants, a level of endorsement only surpassed by 'tension' $(83 \%)$, a term regularly articulated in the participants' narratives. This somewhat incongruous outcome may be potentially attributed to people's difficulty in admitting subtle and emotionally hurtful actions, such as rejection, during interviews. Apart from inevitable incidence of impression management in interview situations (Paulhus, 1984, 1991) it is also important to recognise sensitivity of certain topics to interviewees. Despite informed consent, at times even the most willing and well informed participants may find themselves hesitant to fully disclose in respect to some topics, especially those of hurtful or shameful nature. Interpersonal rejection is potentially one of these topics. On the one hand, it may be only reluctantly revealed by the 'rejectee' (the rejected person) due to the feeling of degradation it entails and the related distress. On the other hand, the 'rejecter' (a person who performs/inflicts the rejection on another)

\footnotetext{
${ }^{14}$ As the used word list did not specify the direction of rejection, self to partner or partner to self, it is not possible to determine which of the options was being selected.
} 
may be equally averse to disclosing rejection due to the social disagreeableness of causing humiliation.

Another concept of significance to the discussion of silent conflict is ostracism, a specific form of social rejection, which according to Williams (2007) consists of " ignoring and excluding individuals or groups by individuals or groups' (p. 427). Williams considers the importance of group acceptance and inclusion from the evolutionary perspective and argues that it is crucial to the survival and the successful procreation of the species, whereas, in contrast, rejection and abandonment threaten these basic biological imperatives. From the social psychological perspective, Williams and Zadro (2005) stress that ostracism poses a threat not only to the need to belong, but also to other basic human needs, for example the need of self esteem and the need of control.

The inherent features of ostracism, namely the relational disconnection between its source and its target and the resulting inability of the target to negotiate and re-establish the connection with the ostraciser, resemble the experiences of silent conflict articulated by subjects of my qualitative interviews (Kielpikowski, 2004). The following extract provides an illustration:

I hate it... because it gives me no way of responding to it. It's like a shut off. I'm shut out as opposed to made part of it. I can't change it. I don't feel like I can take action and I am a very action orientated person. (Female, 44)

The effect of the experience of ostracism on an individual is a sense of loss of control over his or her social environment (Williams \& Zadro, 2005). Additionally, as the motives or specific reasons for ostracism are often undeclared by the source, they leave the target speculating about his or her possible transgression. Again this resonates with the interview data as expressed by the following observation: 
...me personally, I'm thinking maybe there's other things that are contributing, you might be thinking that there might be something else happening here and I'm not aware of it. (Female, 44)

Williams and Zadro (2005) propose the following three stages in the temporal sequence of responding to ostracism: 1) a reflexive experience of pain; 2) a perception of threat to the basic human needs, followed by increased sadness and anger; and 3) a cognitive appraisal of the episode aimed at identifying an appropriate response. The self esteem of the target of ostracism is undermined by the signal of low relational evaluation communicated by the act. Additionally, the element of ambiguity characteristic of ostracism and the speculation it evokes damage it further. However, Williams (2007) argues that from the perspective of survival, pain and distress are adaptive reactions to being rejected, excluded or ignored, with the evolutionary purpose to signal a threat to survival.

A specific form of ostracism that occurs between people in close relationships is commonly referred to as silent treatment. Broadly, silent treatment amounts to the absence of communication or interaction when either of them is expected. Williams (2001) equates silent treatment with emotional withdrawal, as it does not preclude the physical presence of the source, but rather relies on the lack of eye contact, not talking and not listening. Williams (2001, p. 9) cites results of a survey of 2,000 Americans he conducted with Faulkner and colleagues, which revealed that silent treatment was a tactic commonly and deliberately used. Astonishingly, $67 \%$ of the participants declared using silent treatment on a loved one and $75 \%$ reported having been targets of it from loved ones. The high overlap of these percentages indicates that the majority of the surveyed partners both inflicted silent treatment and were its objects. According to the respondents of the survey, they used silent treatment mostly in the context of conflict and saw it as an efficacious way of obtaining a desired end. 
An apparent general bias was that the sources saw it as more effective than the targets.

Interestingly, the narrative analysis studies conducted by Williams (2001) reveal that the emotional consequences of silent treatment apply to both its targets and its sources. Although the costs were higher for the targets and involved a broader spectrum of negative outcomes including anger, inflicting silent treatment was also detrimental to the wellbeing of its sources.

The uses of silent treatment are primarily coercive and punitive; however they may also be defensive. For example, Sommer (2001) reported that people with low self esteem were more likely to both receive and use silent treatment. The silent treatment they inflicted was defensive and they applied it to pre-empt and fend off the anticipated rejection. Consequently, Sommer concluded that people low in self esteem use the maladaptive strategy of rejecting their critical or potentially rejecting partners as a means of protecting themselves.

In my qualitative study I deliberately avoided using the term silent treatment (ST) due to its common use, in order not to focus the responses of the participants on a familiar concept. Consequently, the content of the reports on SIC was much broader and revealed greater complexity and ambivalence, beyond the instrumentality of ST. Silent treatment was efficacious in the words of Williams's participant in obtaining a desired end, however such singularity of purpose was absent in the reports on SIC. Moreover, whereas silent treatment was deployed by one partner against the other and was therefore essentially unidirectional, SIC typically involved both partners and was essentially bidirectional.

The similarities between the two phenomena lie in the absence of explicit communication and in the use of silence with its attendant ambiguity of meaning. 
This ambiguity combined with the norm violation and the consequently inferred low relational valuation has been shown to affect wellbeing in the case of ST. If one were to draw an analogy between interpersonal rejection in the broad sense and silent conflict, one would be justified in expecting detrimental psychological consequences from SIC, similar to those documented by the contributors to "The Social Outcast" (Williams, Forgas, \& Hippel, 2005), who demonstrated robust links between ostracism and sadness, anxiety and depressed mood. Moreover, the lack of control over one's social environment and failures in regaining it might result in learned helplessness (Abramson, Seligman, \& Teasdale, 1978; Seligman, 1975).

The linguistic findings regarding the communicative role of silence and the social psychological scholarship on interpersonal rejection, ostracism and silent treatment appear to resonate with the reports of the parents in my qualitative study (Kielpikowski, 2004; Kielpikowski \& Pryor, 2008). Moreover, they powerfully suggest links with distress. Whilst detrimental effects of 'shunning' on the recipient of the behaviour are easily understood, the particularly interesting aspect of ostracism for the study of silent conflict is the distress it was shown to cause the person who inflicted it. This is because, unlike rejection, ostracism or silent treatment, silent conflict is a bidirectional phenomenon; therefore both participating partners may be seen as taking on the roles of the inflictor and the recipient.

\section{Hypotheses}

It needs to be noted that the largely exploratory nature of this research has a bearing on the possible level of precision in formulating the hypotheses.In sum, it was hypothesised that: 
H1. Silent conflict would be linked to psychological consequences both concurrently and over time. In particular it was expected that:

- Perceptions of the incidence of silent conflict would lead to increased distress.

- Perceptions of costs of silent conflict would lead to increased distress.

- Perceptions of benefits of silent conflict would be linked to distress; however no direction was predicted due to the ambivalent nature of silent conflict demonstrated by the positive correlations between costs and benefits found in this study.

$\underline{\mathrm{H} 2}$. The processes of the influence of SIC on wellbeing of the spouses would vary between the sexes.

Evidence regarding the differing paths to psychological maladjustment for men and women in relation to marital functioning is accumulating (Fincham, et al., 1997; Heene, Buysse, \& Oost, 2005; Proulx, Helmes, \& Buehler, 2007). However, the existing findings are inconsistent, as demonstrated by the results of a recently conducted meta-analysis (Proulx, et al., 2007). The variability of findings suggests complex underlying processes and provides little decisive guidance for future research. Nonetheless, Proulx and colleagues conclude that dismissing the possibility of gender-related differences would be premature at this point in time (p. 586).

$\underline{\mathrm{H} 3}$. As mutual influences of psychological distress and interpersonal dynamics have been demonstrated consistently (Beach \& O'Leary, 1993a, 1993b; Fincham, et al., 1997; Kouros, Papp, \& Cummings, 2008), this bidirectionality of effects was generalised to the hypothesised relationship between SIC and psychological maladjustment. 
H4. In keeping with the systemic conceptualisation of family functioning adopted in this work, it was expected that one partner's perceptions would influence the other partner's perceptions both concurrently and over time.

\section{STUDY 1}

\section{Method}

\section{Participants}

Two hundred and forty two parents ${ }^{15}$, who completed both the Time 1 and the Time 2 questionnaires, were matched into couples. Six participants (two women and four men) could not be matched as their spouses did not return Time T2 surveys, which resulted in exclusion of their data. The final sample consisted of 115 parental dyads.

\section{Measures}

The SICS was described in Chapter 2. NB. The individual factors of the SICS were used to assess the incidence of silent interparental conflict (the Marker), as well as its perceived costs and benefits.

Psychological distress was assessed with the Irritability, Depression, Anxiety Scale (Snaith, et al., 1978). The IDA scale was previously described in Chapter 2.

Analytic strategy

Structural equation modelling (SEM) was used to build and estimate structural models. In order to test the hypothesised concurrent effects of the factors of SIC on maladjustment at Times 1 and 2 and the mutual influences between partners Actor-Partner Interdependence Models (APIM) proposed by

\footnotetext{
${ }^{15}$ The sample and procedure are described in detail in Chapter 2.
} 
Kenny (1996; Kenny, et al., 2006) were built. Kenny and colleagues (2006) argue that measures taken from married couples are 'nonindependent' owing to the partners being linked both voluntarily (unlike, for example, siblings) and by kinship and that due to their relationship roles, husbands and wives are considered 'distinguishable' members of dyads. The APIMs provide simultaneous estimates of both the effects of the person's own variables (Actor effects) and the partner's variables (Partner effects). The longitudinal hypotheses were tested with separate cross-lagged models for men and women that depicted relationships between silent interparental conflict and maladjustment at two measurement times. As SEM allows simultaneous estimation of all parameters in a hypothesised model, it made it possible to control for autocorrelation (stability) effects of variables and also to obtain estimates of reciprocal effects between the SICS and the distress measure (IDA).

\section{Results}

Data were organised in SPSS into a set enabling dyadic level analyses (Kenny, et al., 2006, p.17). As a result, each parental dyad was assigned an identity number, with men's and women's scores on measured variables recorded against it.

Descriptive statistics and correlations for the measured variables at both measurement times are presented in Tables 3.1 and 3.2. 
Table 3.1. Means and standard deviations for men and women $(N=115$ each) on measured variables.

\begin{tabular}{lccccc}
\hline Scale & $\begin{array}{c}\text { Number } \\
\text { of }\end{array}$ & \multicolumn{1}{c}{ Men } & Women & Men & Women \\
\cline { 3 - 6 } & items & Mean(SD) & Mean(SD) & Mean(SD) & Mean(SD) \\
\cline { 3 - 6 } & 5 & $14.89(3.82)$ & $14.93(3.89)$ & $14.53(3.88)$ & $14.64(3.80)$ \\
Marker SIC & 4 & $12.18(3.28)$ & $12.20(3.50)$ & $12.02(3.50)$ & $12.01(3.46)$ \\
Costs SIC & 3 & $10.23(2.17)$ & $10.19(2.43)$ & $10.25(2.43)$ & $10.11(2.29)$ \\
Benefits SIC & 12 & $37.29(6.99)$ & $37.32(6.82)$ & $33.21(7.23)$ & $33.21(6.77)$ \\
SIC Total & 14 & $10.73(5.52)$ & $10.30(5.17)$ & $12.50(4.82)$ & $12.12(4.40)$ \\
IDA Total & 14 & & & & \\
\hline
\end{tabular}

\section{Mean group differences}

Paired samples t-tests were conducted to compare scores of men and women on all variables. No significant differences were found between the sexes at either time point.

Concurrent and Longitudinal Links among Study Variables.

A majority of correlations between subscales of the SICS and the measure of psychological distress (IDA) was positive and significant at both measurement times for both male and female partners (see Table 3.2). A notable exception was the Benefits subscale, which for men produced no significant correlations with the IDA either concurrently or longitudinally and for women produced nonsignificant results concurrently, but a significant negative correlation $(r=-.25, p<.01)$ between the SIC Benefits at T1 and the IDA at T2, indicating that for mothers their more positive perceptions of SIC contributed to the lessening of their psychological distress over time. 
Table 3.2. Intercorrelations between measured variables for men (in red above the diagonal) and women (in black below the diagonal) at T1 and T2 $(N=115$ each $)$.

\begin{tabular}{|c|c|c|c|c|c|c|c|c|}
\hline Variable & Marker SIC T1 & Costs SIC T1 & Benefits SIC T1 & IDA T1 & Marker SICS T2 & Costs SIC T2 & Benefits SIC T2 & IDA T2 \\
\hline Marker SIC T1 & - & $.44 * *$ & $.28 * *$ & $.27 * *$ & $.81 * *$ & $.41 * *$ & $.30 * *$ & $.33 * *$ \\
\hline Costs SIC T1 & $.42 * *$ & - & $.21 *$ & $.32 * *$ & $.33 * *$ & $.67 * *$ & $.29 * *$ & $.22 *$ \\
\hline Benefits SIC T1 & .04 & .07 & - & .04 & $.20 *$ & .16 & $.35^{* *}$ & .09 \\
\hline IDA T1 & $.34 * *$ & $.31 * *$ & -.05 & - & $.27 * *$ & $.32 * *$ & .15 & $.75^{* *}$ \\
\hline Marker SIC T2 & $.79 * *$ & $.30 * *$ & -.03 & $.32 * *$ & - & $.42 * *$ & $.62 * *$ & $.41 * *$ \\
\hline Costs SIC T2 & $.37 * *$ & $.76 * *$ & .02 & $.23^{*}$ & $.44 * *$ & - & $.34 * *$ & $.23 *$ \\
\hline Benefits SIC T2 & $.32 * *$ & .14 & $.56 * *$ & .04 & $.31 * *$ & .14 & - & .16 \\
\hline IDA T2 & $.32 * *$ & $.25 * *$ & $-.25 * *$ & $.73 * *$ & $.29 * *$ & $.24 *$ & -.12 & - \\
\hline
\end{tabular}

Note. $* * p<.01 ; * p<.05$. 
Correlations among the reports of men and of women (between sexes) on the subscales of SICS and psychological maladjustment (IDA) at Times 1 and 2 are presented in Tables 3.3 and 3.4 respectively. Notably, neither the fathers' nor the mothers' scores on the Benefits subscale at Time 1 or Time 2 correlated significantly with the partners' scores on any of the scales. Moreover, the patterns of significance for the corresponding inter-partner correlations differed between the measurement times, which may indicate a situational character of some of the associations.

Table 3.3. Intercorrelations between subscales of SIC and psychological maladjustment (IDA) at T1 for men (M) and women (W).

\begin{tabular}{|c|c|c|c|c|}
\hline Variable & MMarker SIC T1 & MCosts SIC T1 & $\begin{array}{c}\text { MBenefits SIC } \\
\text { T1 }\end{array}$ & MIDA T1 \\
\hline WMarker SIC T1 & $.30^{* *}$ & $.23 *$ & .13 & .07 \\
\hline WCosts SIC T1 & $.30^{* *}$ & $.24 *$ & -.01 & $.22 *$ \\
\hline WBenefits SIC T1 & -.04 & .07 & .07 & .14 \\
\hline WIDA T1 & $.21 *$ & .12 & .09 & .09 \\
\hline
\end{tabular}

Note. ${ }^{* *} p<.01 ; * p<.05$.

Table 3.4. Intercorrelations between subscales of SIC and psychological maladjustment (IDA) at T2 for men $(M)$ and women $(W)$.

\begin{tabular}{llllc}
\hline \multicolumn{1}{c}{ Variable } & MMarker SIC T2 & MCosts SIC T2 & \multicolumn{2}{c}{ MBenefits SIC } \\
T2 & MIDA T2 \\
\hline WMarker SIC T2 & $.36^{* *}$ & .11 & .17 & $.19^{*}$ \\
WCosts SIC T2 & $.33^{* *}$ & $.22^{*}$ & .18 & $19^{*}$ \\
WBenefits SIC T2 & .05 & -.04 & .18 & -.01 \\
WIDA T2 & $.27^{*}$ & -.02 & .07 & .13 \\
\hline
\end{tabular}

Note. ${ }^{* *} p<.01 ; * p<.05$.

Actor-Partner Interdependence Models were constructed to test the hypothesised relationships including the mutual effects of partners on each other in respect of each of the factors of SIC and the psychological maladjustment measure (IDA) at Time 1 and Time 2 . The summary models are presented in Figures 3.3 and 3.4 respectively. 


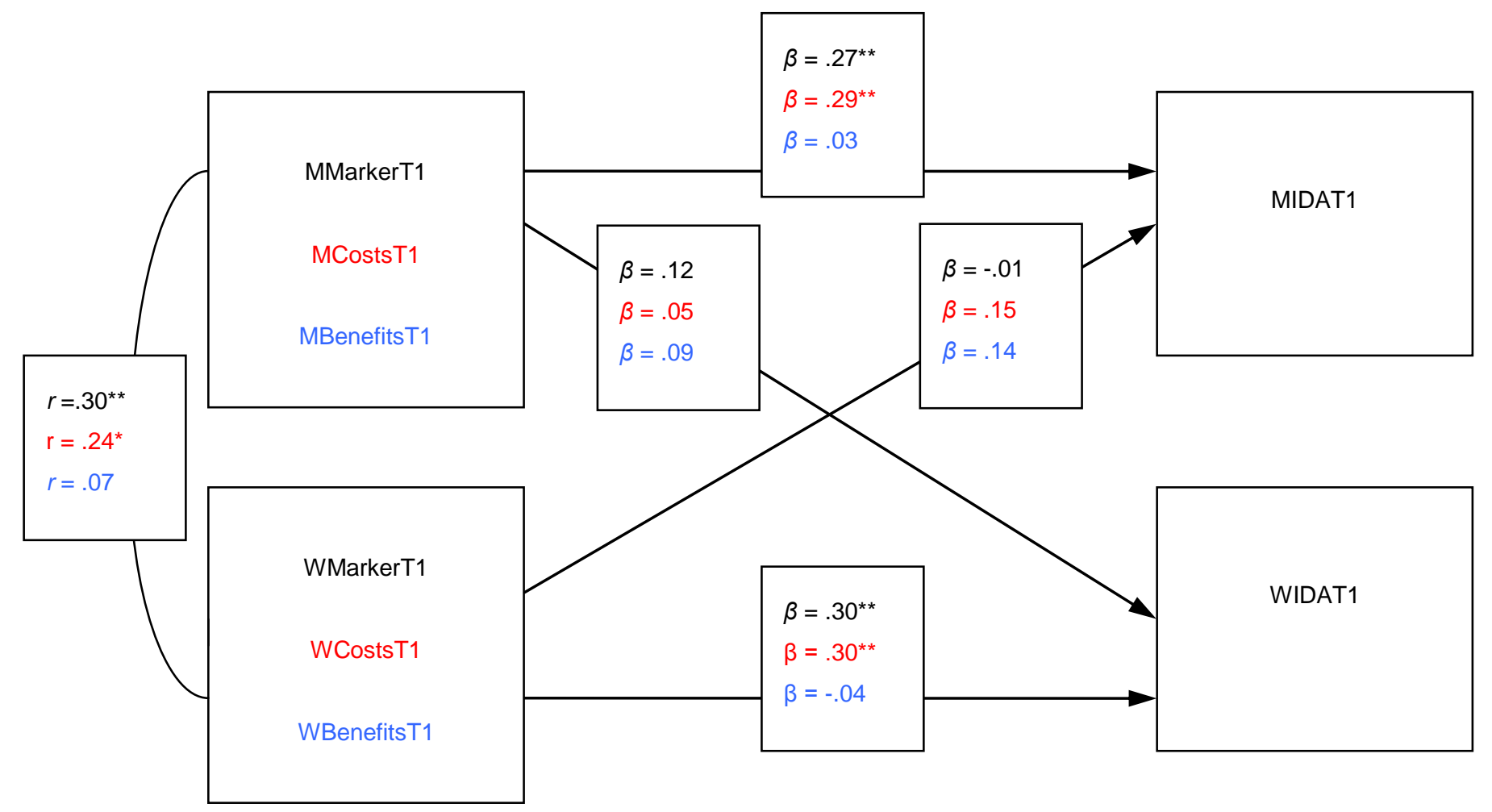

Figure 3.3. Summary of Time 1 Actor-Partner Interdependence Models of the effects of the Marker, the Costs and the Benefits of silent interparental conflict on psychological wellbeing for parental dyads $(\mathrm{N}=115)$. For ease of presentation correlated errors are not shown; $* * p<.01 ; * p<.05(\mathrm{M}=$ men; $\mathrm{W}=$ women $)$. 


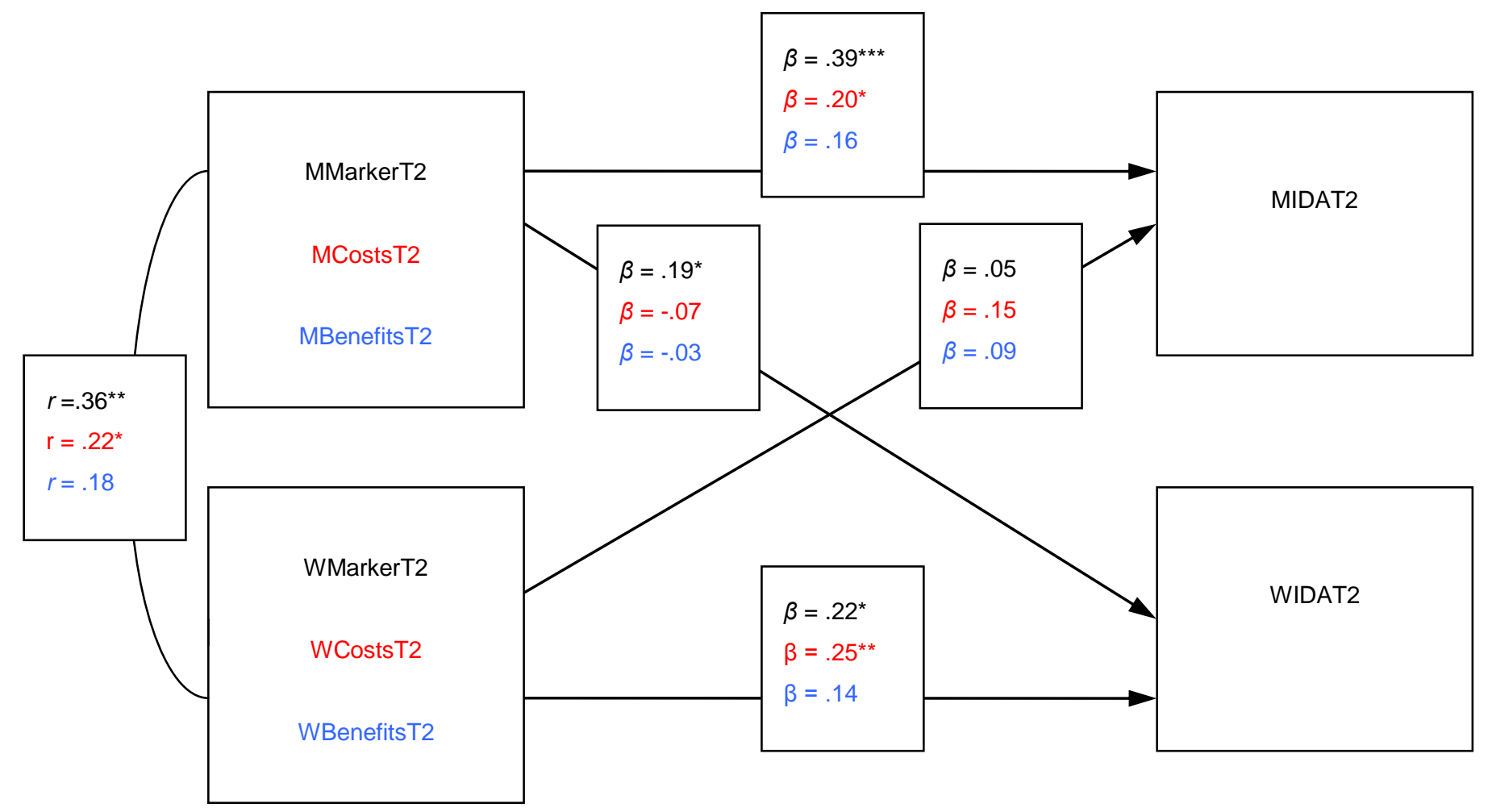

Figure 3.4. Summary of Time 2 Actor-Partner Interdependence Models of the effects of the Marker, the Costs and the Benefits of silent interparental conflict on psychological wellbeing for parental dyads $(\mathrm{N}=115)$. For ease of presentation correlated errors are not shown; ** $p<.01 ; * p<.05(\mathrm{M}=$ men; $\mathrm{W}=$ women $)$. 
The testing of the APIMs for the effects of the Marker, the Costs and the Benefits of silent interparental conflict on psychological wellbeing for parental dyads rendered similar results at both measurement times. The Actor effects for the Marker of SIC and the Costs of SIC were significant at both measurement points for both men and women. No significant Partner effects were found at Time 1; however one significant Partner effect was found at Time 2 from the Marker of SIC for men to women's maladjustment. Finally, no significant Actor or Partner effects were found for the Benefits of SIC and maladjustment model at either measurement time.

In order to test the hypothesised longitudinal relationships between the factors of SIC and maladjustment, separate cross-lagged stability models were constructed for men and women in the sample. This enabled testing for the longitudinal effect of each of the factors of SIC on IDA while controlling for the stability link between IDA measured at T1 and T2. At the same time the longitudinal effect of IDA on each of the factors of SIC was estimated controlling for the stability link between the factors at T1 and T2. The fathers' models are summarised in Figure 3.5 and the mothers' models in Figure 3.6. The models were saturated with no degrees of freedom, so no fit indices were produced.

All of the models for both the husbands and the wives showed good stability of the factors of SIC $(\beta$ s between .35 and $.79, p<.001)$ and the IDA $(\beta \mathrm{s}$ between .71 and .76, $p<.001)$ over time. Additionally, one significant positive cross-lag path was found for fathers between their perceptions of the incidence of silent conflict (measured with the Marker of SIC) at Time 1 and their psychological distress (measured with the IDA) at time $2(\beta=.14, p<.05)$. Additionally, for mothers a significant negative cross-lag path was found between 
their perceptions of the benefits of silent conflict at Time 1 and their psychological distress at Time $2(\beta=-.22, p<.001)$. Stacked modelling procedure was used to determine whether fathers and mothers differed significantly on the two paths. No significant difference between partners was found for the path from Marker of SIC at Time 1 to distress at T2 $\left(\Delta \chi^{2}(1)=.67, p\right.$ $>$.05). In contrast, the unconstrained and the parameter constrained model comparison showed a significant difference for the path from Benefits of SIC at Time 1 to distress at Time $2\left(\Delta \chi^{2}(1)=8.96, p<.01\right)$, indicating that, for women, perceiving more benefits in silent conflicts with their partners resulted in less distress over time. 


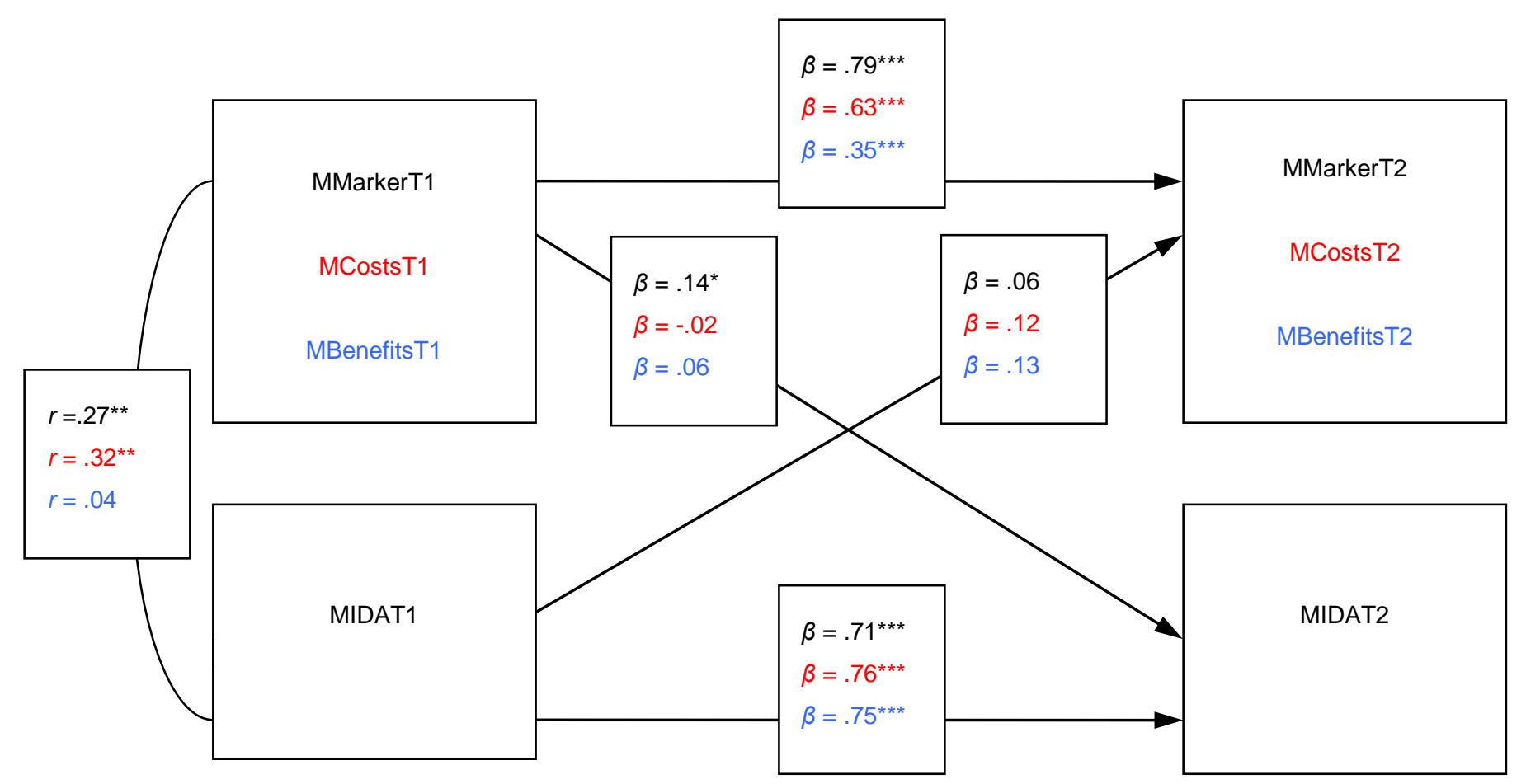

Figure 3.5. Summary of cross-lagged stability models of the Marker, the Costs and the Benefits of silent interparental conflict and psychological wellbeing for men $(\mathrm{N}=115)$. For ease of presentation correlated errors are not shown; $* * * p<.001 ; * p<.05(\mathrm{M}=$ men) 


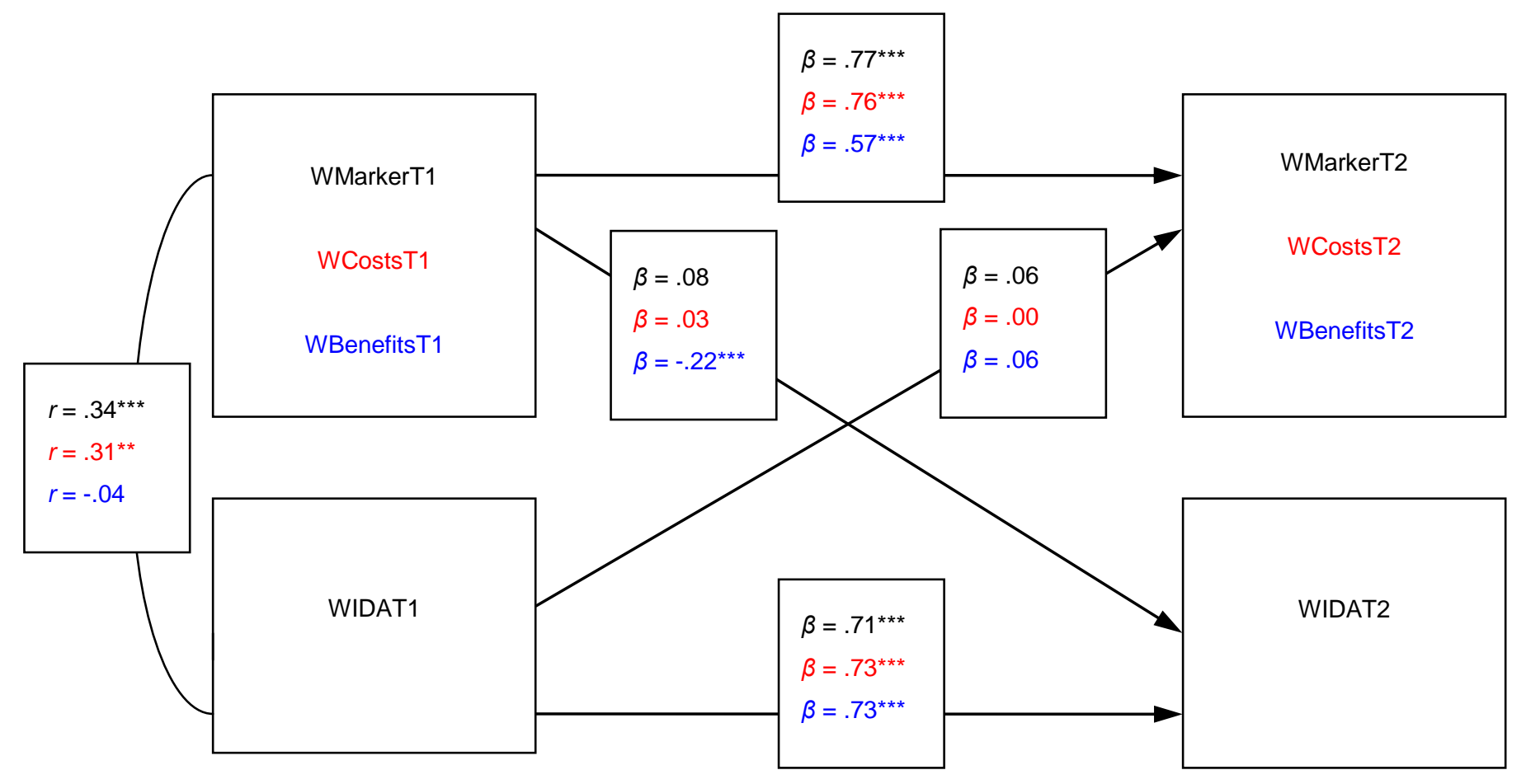

Figure 3.6. Summary of cross-lagged stability models of the Marker, the Costs and the Benefits of silent interparental conflict and psychological wellbeing for women $(\mathrm{N}=115)$. For ease of presentation correlated errors are not shown; $* * * p<.001(\mathrm{~W}=$ women $)$. 
The obtained cross-lag effects were further examined following the strategy used by Fincham, Harold, Beach, and Osborne (1997) and Fincham and Beach (2007). Simple recursive models were utilised to determine whether the cross-lagged effects were mediated by the concurrent levels of the predictor variables. The strategy allows some insight into the question of whether the causal nature of the studied processes is more concurrent or more long term.

Two sets of models were built for fathers and for mothers. Fathers' models are summarised in Figures 3.7 and 3.9; mothers' models are summarised in Figures 3.8 and 3.10.

The first set of models examined paths from Time 2 Factors of SIC (the Marker, the Costs, and the Benefits) to Time 2 maladjustment (IDA), while controlling for Time 1 Factors of SIC.

As shown in Figure 3.7, the previously significant path depicting the longitudinal relationship between the Marker of SIC at T1 and maladjustment at $\mathrm{T} 2$ for fathers became nonsignificant, indicating that it was fully mediated by Time 2 maladjustment. The standardised indirect effect of the Marker of SIC at $\mathrm{T} 1$ on IDA at $\mathrm{T} 2$ for fathers was $.33, \mathrm{p}<.01^{16}$. No other significant effects were found for fathers.

Mothers' models are summarised in Figure 3.8. Unlike for fathers, no mediational effects were found for mothers' effects of T1 factors of SIC on maladjustment at T2. However, the original significant negative effect from Benefits at T1 to IDA at T2 $(\beta=-.22, p<.001)$ remained significant $(\beta=-.26, p<$ $.05)$, indicating a long term, rather than concurrent, effect of the perception of

\footnotetext{
${ }^{16}$ The significance of mediation effects in this work was calculated using AMOS 16.0 bootstrap approximation obtained by constructing two-sided bias-corrected confidence intervals.
} 
benefits of SIC in reducing distress for women. In contrast, for men, the long term effect of perceived incidence of SIC on distress was fully mediated by the concurrent perceptions of SIC incidence, indicating a more immediate mechanism of influence.

The second set of models was created to examine paths from Time 2 maladjustment (IDA) to Time 2 Factors of SIC (the Marker, the Costs, and the Benefits), while controlling for Time 1 maladjustment. The associations between Time 1 maladjustment and Time 2 Factors of SIC (the Marker, the Costs, and the Benefits) were nonsignificant for both fathers and mothers, therefore they failed to meet the criteria of mediational paths according to Baron and Kenny (1986). Recently, it has been argued, however, that an independent variable (IV) can have an indirect effect on the dependent variable (DV) through an intervening third variable MV), which it influences and which in turn influences the dependent variable (Hayes, 2009; MacKinnon, Lockwood, Hoffman, West, \& Sheets, 2002), even if the IV to DV relationship is nonsignificant. If both the independent variable and the dependent variable are related to the proposed intervening variable (mediator), a statistical mediation may be performed and assessed. Following this rationale, mediational models for mothers and fathers were constructed and are summarised in Figures 3.9 and 3.10.

It appeared that for fathers, the relationship between Time 1 maladjustment and Time 2 perception of incidence of SIC (Marker) was fully mediated by Time 2 maladjustment. The standardised indirect effect of distress (IDA) at Time 1 on perceptions of incidence of SIC at Time 2 for fathers was .36, $\mathrm{p}<.001$. Additionally a significant direct effect was found for fathers from IDA 
at Time 1 to their perception of the Costs of SIC at Time 2; the standardised effect was $.33, p<.05$. 


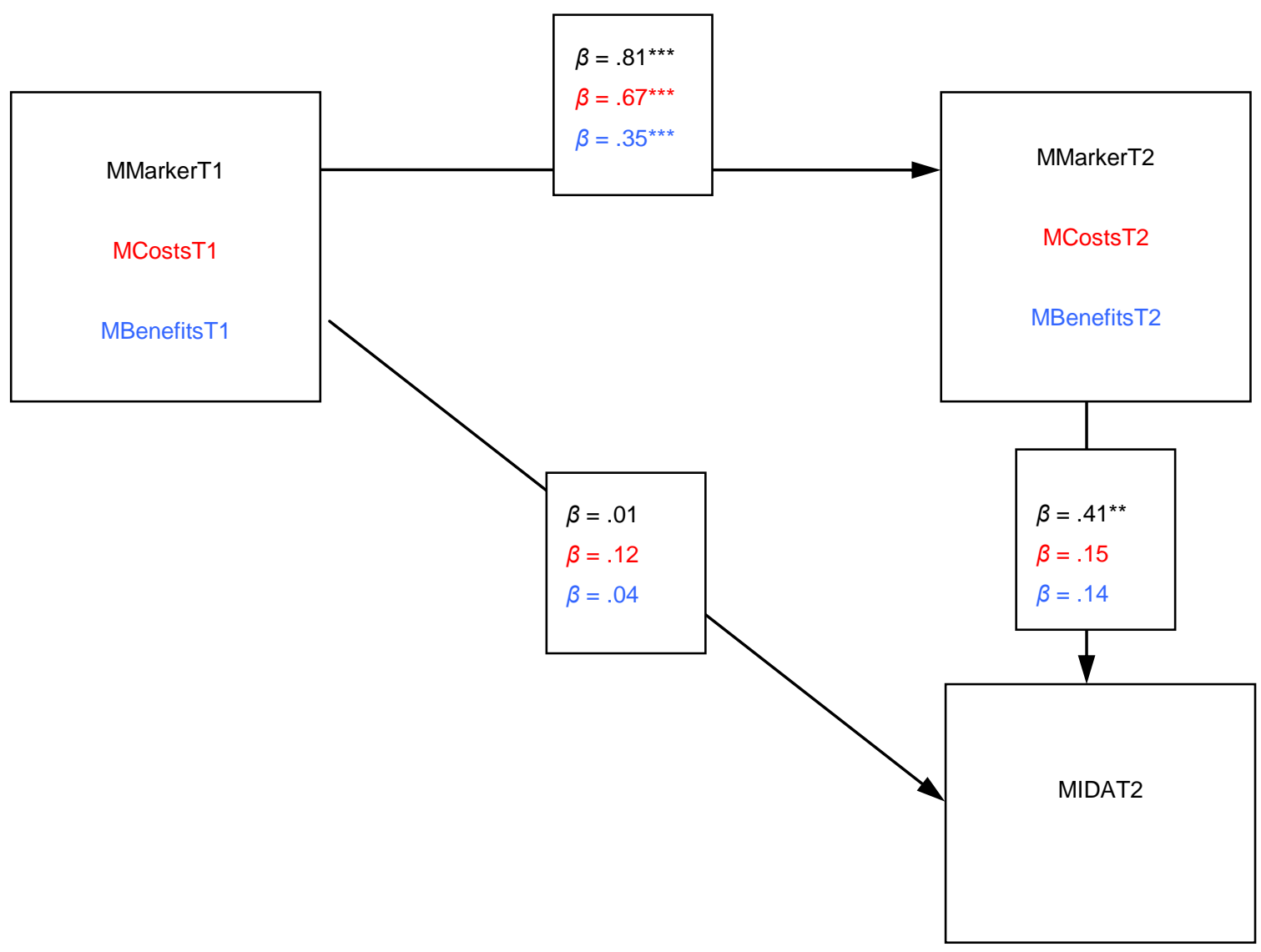

Figure 3.7. Summary of relationship models between the Marker, the Costs and the Benefits of silent interparental conflict and psychological maladjustment for men $(\mathrm{N}=115)$. For ease of presentation error terms are not shown; $* * * p<.001, * * p<.01(\mathrm{M}=\mathrm{men})$. 


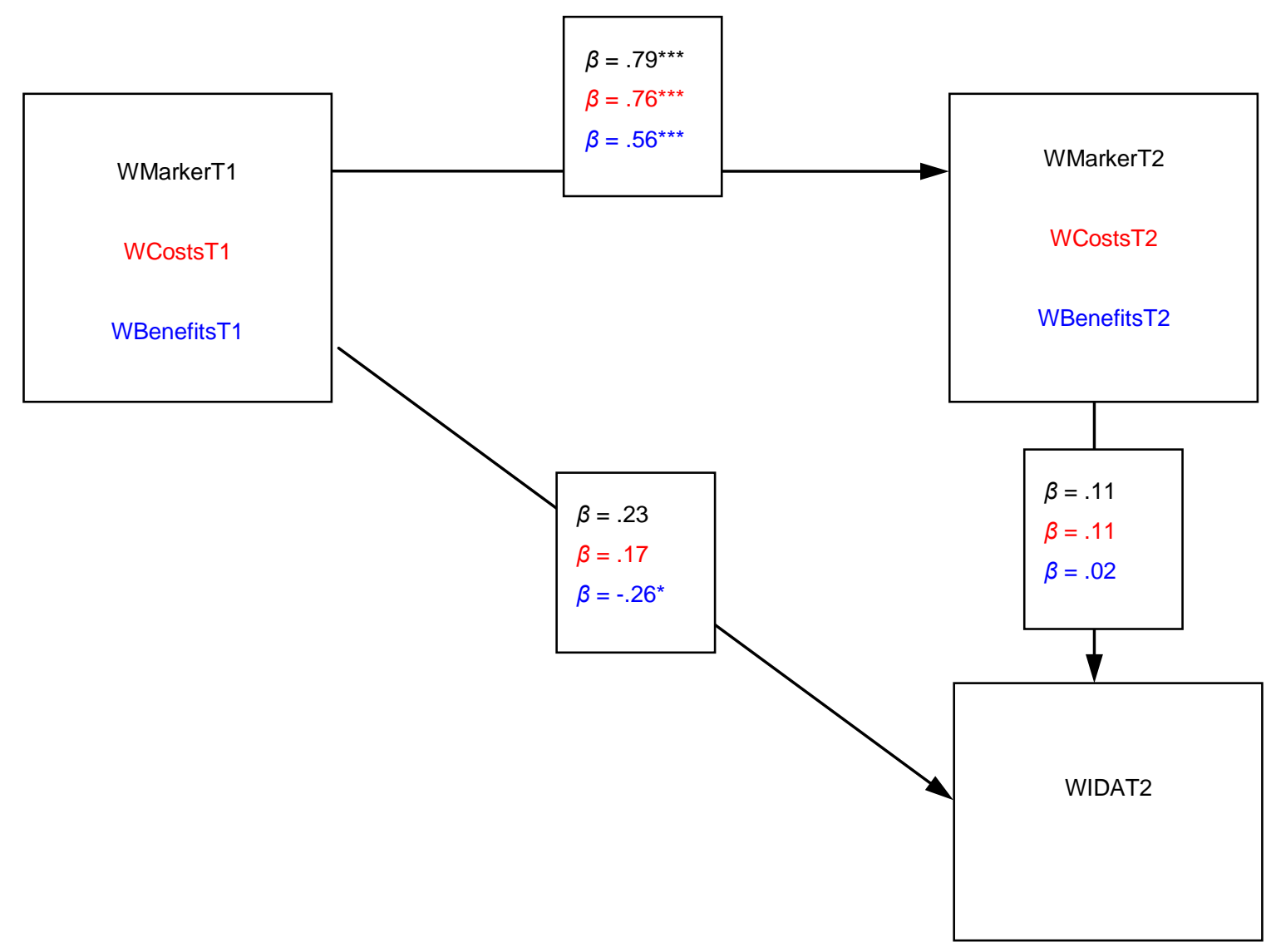

Figure 3.8. Summary of relationship models between the Marker, the Costs and the Benefits of silent interparental conflict and psychological maladjustment for women $(\mathrm{N}=115)$. For ease of presentation error terms are not shown; ${ }^{* * *} p<.001, * p<.05(\mathrm{~W}=$ women). 
Scrutiny of the proposed mediational models for mothers revealed that the influence of psychological distress on women's perceptions of the Benefits of SIC was complex and appeared to operate in opposite directions concurrently $(\beta=.28$, $p<.05)$ and over time $(\beta=-.33, p<.05)$. On the whole, women who experienced greater distress at $\mathrm{T} 1$ perceived more benefits of silent conflict at Time 2; however this link was significantly partially mediated by distress at Time 2 . The standardised indirect effect of distress (IDA) at Time 1 on perceptions of Benefits of SIC at Time 2 for mothers was $-.25, p<.01$. No other significant effects were found for mothers. 


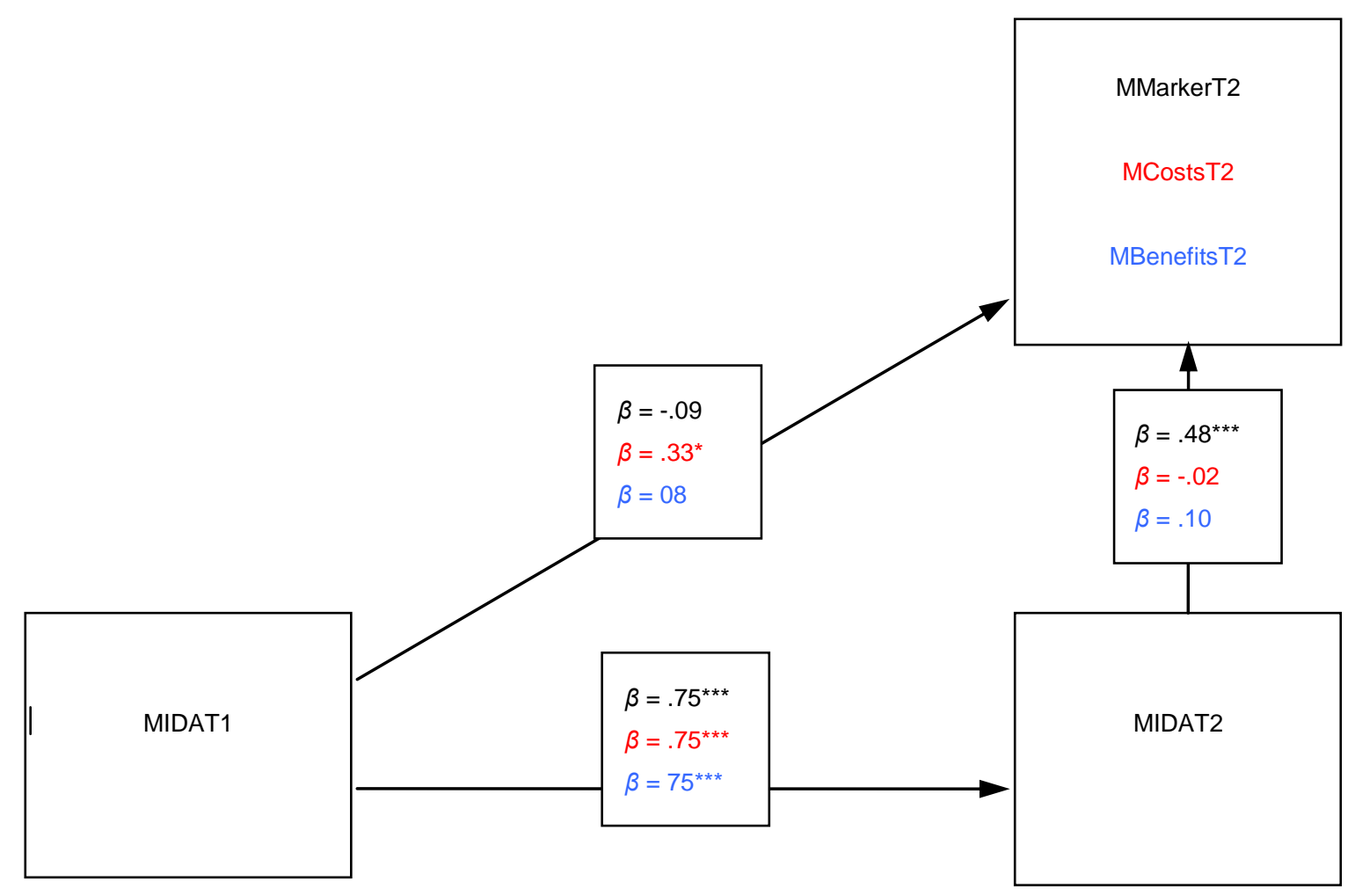

Figure 3.9. Summary of relationship models between psychological maladjustment (IDA) and the Marker, the Costs and the Benefits of silent interparental conflict for men $(\mathrm{N}=115)$. For ease of presentation error terms are not shown; $* * * p<.001, * p<.05(\mathrm{M}=$ marker $)$. 


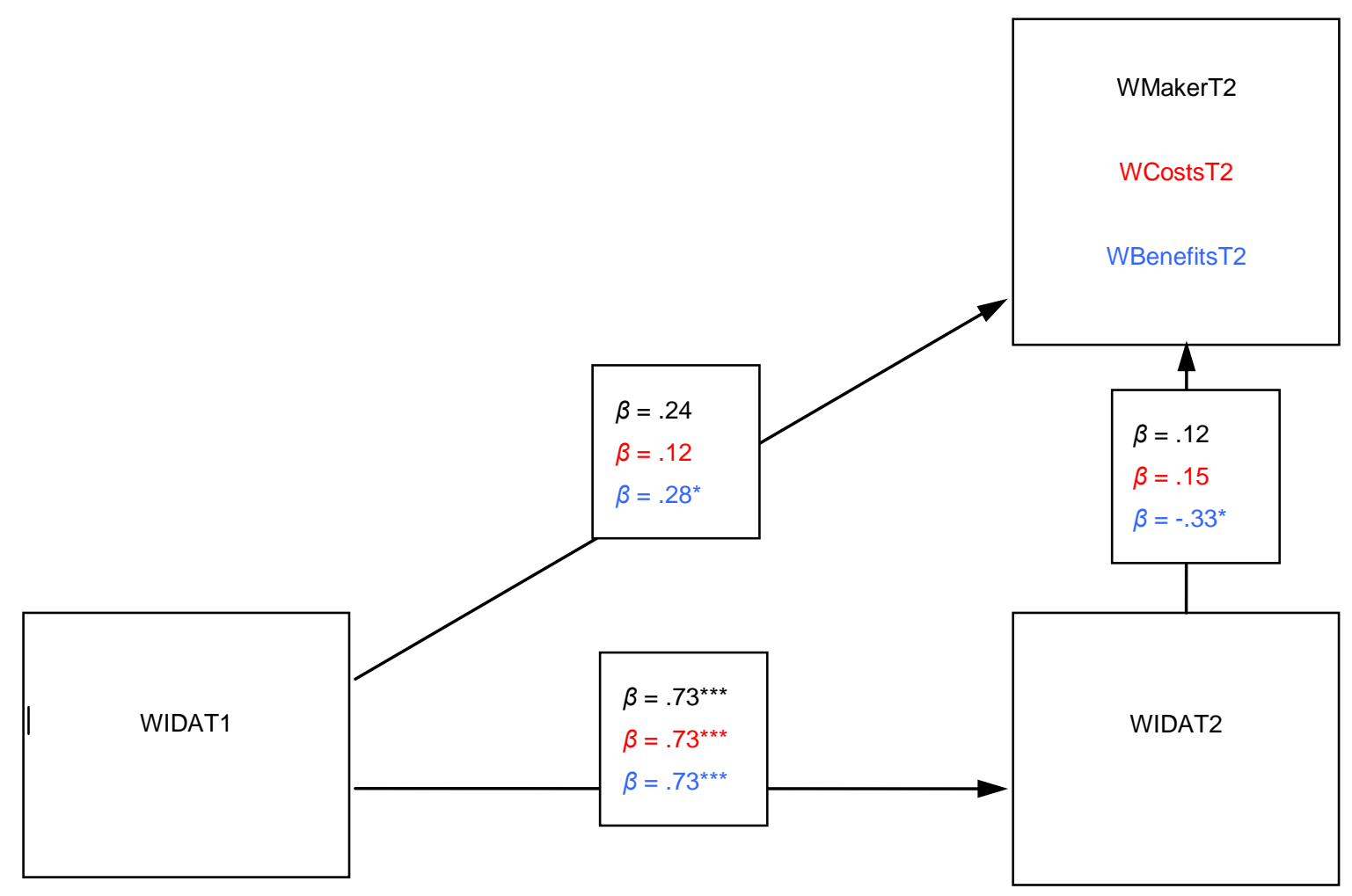

Figure 3.10. Summary of relationship models between psychological maladjustment (IDA) and the Marker, the Costs and the Benefits of silent interparental conflict for women $(\mathrm{N}=115)$. For ease of presentation error terms are not shown; $* * * p<.001, * p<.05(\mathrm{~W}=$ women). 
In order to test the hypothesised interrelatedness between the factors of SIC and distress for the parental dyads over time three autoregressive crosslagged models were constructed. Correlations among the reports of men and of women (between sexes) on the subscales of SICS at T1 and psychological maladjustment (IDA) were computed and are presented in Tables 3.5 and 3.6. The relationships between fathers' scores on the study variables at T1 and mothers' scores on corresponding variables at $\mathrm{T} 2$ were mostly nonsignificant, with the exception of Marker of SIC and Costs of SIC. The distributions of significant and nonsignificant correlations between mothers' scores at T1 and fathers' scores at T2 were more balanced, however neither fathers' nor mothers' scores on the Benefits subscale at T1 correlated significantly with the partners' scores on any of the scales at $\mathrm{T} 2$.

Table 3.5. Intercorrelations between subscales of SIC and psychological maladjustment (IDA) at T1 for men (M) and subscales of SIC and psychological maladjustment (IDA) at T2 for women $(W)$.

\begin{tabular}{|c|c|c|c|c|}
\hline Variable & MMarker SIC T1 & MCosts SIC T1 & $\begin{array}{c}\text { MBenefits SIC } \\
\text { T1 }\end{array}$ & MIDA T1 \\
\hline WMarker SIC T2 & $.33^{* *}$ & $.27 * *$ & .09 & .02 \\
\hline WCosts SIC T2 & $.28 * *$ & $.26^{* *}$ & -.02 & .12 \\
\hline WBenefits SIC T2 & .07 & .09 & .15 & -.04 \\
\hline WIDA T2 & .17 & .05 & 01 & .04 \\
\hline
\end{tabular}

Note. ${ }^{* *} p<.01 ; * p<.05$.

Table 3.6. Intercorrelations between subscales of SIC and psychological maladjustment (IDA) at T1 for women (W) and subscales of SIC and psychological maladjustment (IDA) at T2 for men (M).

\begin{tabular}{|c|c|c|c|c|}
\hline Variable & WMarker SIC T1 & WCosts SIC T1 & $\begin{array}{c}\text { WBenefits SIC } \\
\text { T1 }\end{array}$ & WIDA T1 \\
\hline MMarker SIC T2 & $.36^{* *}$ & $.36^{* *}$ & -.13 & $.28^{* *}$ \\
\hline MCosts SIC T2 & .13 & $.29 * *$ & -.02 & .06 \\
\hline MBenefits SIC T2 & $.26^{* *}$ & $.23^{*}$ & .07 & $.19^{*}$ \\
\hline MIDA T2 & .17 & .18 & -.04 & .12 \\
\hline
\end{tabular}

Note. ${ }^{*} * p<.01 ; * p<.05$. 
The archetype for the cross-lagged models to be analysed is presented in Figure 3.11. (The labels MSICFact and WSICFact represent men's and women's factors of SIC: the Marker, the Costs and the Benefits in turn, annotated Time 1 and Time 2). Three separate models were constructed to capture relationships of each of the factors with maladjustment (IDA). This was done to aid the interpretability of the processes and to circumvent the statistical power issues that would arise from testing the three factors simultaneously.

On the basis of existing findings regarding relationship conflict and psychological distress (e.g. Kouros, et al., 2008), it was expected that the two variables would affect each other reciprocally. This prediction was expressed by the cross-lag paths in the model and also by allowing the error terms between each partner's scores on the factors of SIC and their scores on IDA to correlate. With two degrees of freedom, model fit indices were available.

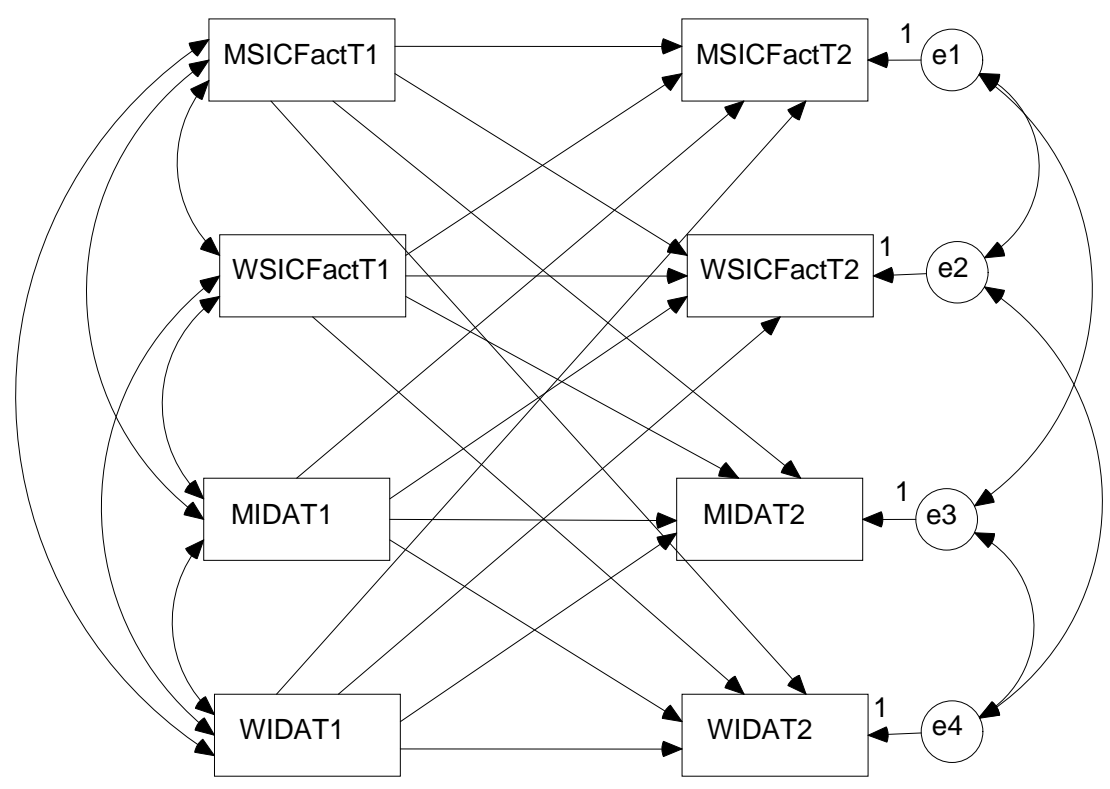

Figure 3.11. Hypothesised longitudinal model of silent interparental conflict and psychological maladjustment for parental dyads $(\mathrm{N}=115)$. 
The models were analysed separately using SEM. The standardised path coefficients for the model are presented in Table 3.7.

Table 3.7. Longitudinal models of silent conflict factors (Maker, Costs and Benefits) and psychological maladjustment for parental dyads $(N=115)$ Standardized path coefficients $(M=$ men; $W=$ women $)$.

\begin{tabular}{|c|c|c|c|}
\hline \multicolumn{4}{|c|}{ Estimate } \\
\hline Path & Marker & Costs & Benefits \\
\hline MSICFactT1 - MSICFactT2 & $.74 * * *$ & $.61 * * *$ & $.33^{* * *}$ \\
\hline WSICFactT1 - MSICFactT2 & .11 & .14 & .04 \\
\hline WSICFactT1- WSICFactT2 & $.75^{* * *}$ & $.76^{* * *}$ & $.58 * * *$ \\
\hline MSICFactT1 - WSICFactT2 & .11 & .10 & .11 \\
\hline WIDAT1 - MIDAT2 & .00 & .06 & .04 \\
\hline WIDAT1 - WIDAT2 & $.71 * * *$ & $.73 * * *$ & $.73^{* * *}$ \\
\hline MIDAT1 - WIDAT2 & -.03 & -.02 & .01 \\
\hline MSICFactT1 - MIDAT2 & .12 & -.03 & .06 \\
\hline MSICFactT1 - WIDAT2 & .00 & -.04 & -.04 \\
\hline WSICFactT1 - MIDAT2 & .08 & .00 & $-.15^{*}$ \\
\hline WSICFactT1 - WIDAT2 & .08 & .04 & $-.22 * * *$ \\
\hline MIDAT1 - MSICFactT2 & .06 & .10 & .12 \\
\hline MIDAT1 - WSICFactT2 & -.07 & -.08 & -.13 \\
\hline WIDAT1 - MSICFactT2 & .08 & -.07 & .15 \\
\hline WIDAT1 - WSICFactT2 & .06 & -.01 & .06 \\
\hline MIDAT1 - MIDAT2 & $.71 * * *$ & $.75^{* * *}$ & $.76^{* * * *}$ \\
\hline
\end{tabular}

Note. ${ }^{*} p<.05 ; * * * p<.001$.

The three models demonstrated satisfactory stability coefficients for the measured variables $(\beta$ s ranged from .33 to $.76, \mathrm{p}<.001)$. No significant cross-lag paths were found in the Marker model of distress and the Costs models of distress. However, two significant cross-lag paths were found in the Benefits model: from mothers' Benefits at T1 to fathers' distress at T2 $(\beta=-.15, \mathrm{p}<.05)$ and from mothers' Benefits at T1 to mothers' distress at T2 $(\beta=-.22, \mathrm{p}<.001)$. As presaged by the raw correlations, several paths in the models were found to be nonsignificant, which somewhat affected the fit of the models. Nevertheless, the fit indices for the three models were acceptable and are presented in Table 3.8. 
Table 3.8. Model fit indices for the Marker, Costs and Benefits models of distress $(N=115)$.

\begin{tabular}{cccccccccc}
\hline Model & $\chi^{2}$ & $d f$ & $p$ & $\chi / d f^{2}$ & GFI & AGFI & CFI & RMSEA & sRMR \\
\hline Marker & 6.35 & 2 & .04 & 3.17 & .99 & .76 & .99 & .14 & .02 \\
Costs & 6.23 & 2 & .04 & 3.12 & .99 & .76 & .99 & .14 & .02 \\
Benefits & 4.82 & 2 & .09 & 2.41 & .99 & .81 & .99 & .11 & .02 \\
\hline
\end{tabular}

To establish whether apparent differences between mothers and fathers found in the paths of the Benefits model of distress were significant, the corresponding parameters of the model were fixed to be equal with equality constraints. The fit of the constrained model (model 2) was then compared with the original model (model 1). Fit indices are presented in Table 3.9.

Table 3.9. Model fit comparison for nested models.

\begin{tabular}{lrlllllllllll}
\hline Model & $\chi^{2}$ & $d f$ & $p$ & $\chi / d f^{2}$ & GFI & AGFI & CFI & RMSEA & sRMR & $\begin{array}{l}\text { Comp. } \\
\text { to } \\
\text { Model }\end{array}$ & $\begin{array}{l}\Delta \\
\chi^{2}\end{array}$ & $\begin{array}{l}\Delta \\
d f\end{array}$ \\
\hline 1 & 4.82 & 2 & .09 & 2.41 & .99 & .81 & .99 & .11 & .02 & & & \\
2 & 14.52 & 5 & .01 & 2.90 & .97 & .79 & .96 & .13 & .04 & 1 & $9.70^{*}$ & 3 \\
3 & 14.17 & 3 & .01 & 4.72 & .97 & .65 & .96 & .18 & .04 & 1 & $9.35^{* *}$ & 1 \\
4 & 6.14 & 3 & .11 & 2.05 & .99 & .84 & .99 & .10 & .02 & 1 & 1.32 & 1 \\
\hline
\end{tabular}

Note: $* * p<.01 ; * p<.05$.

The difference between the unconstrained and the parameter-constrained models was significant $\left(\Delta \chi^{2}(3)=9.70, p<.05\right)$. Separate equality constraints were then performed for the two paths of the model.

A significant difference $\left(\Delta \chi^{2}(1)=9.35, p<.01\right)$ was located between the mothers' path from Benefits at $\mathrm{T} 1$ to own distress at $\mathrm{T} 2(\beta=-.22, p<.001)$ and the fathers' path from Benefits at T1 to own distress at T2 $(\beta=.06, p>.05)$; see Model 3 in Table 3.9. This finding confirms the earlier described robustness of this link for mothers and indicates that the perceptions of greater benefits of silent conflict with their partners reduced distress over time for women but not for men. In contrast, the apparent difference between the paths from mothers' Benefits at 
T1 to fathers' distress at T2 $(\beta=-.15, \mathrm{p}<.05)$ and fathers' Benefits at T1 to mothers' distress at T2 $(\beta=-.04, \mathrm{p}>.05)$ could not be interpreted as statistically different, as constraining the parameters to be equal did not make a significant difference to the model fit $\left(\Delta \chi^{2}(1)=1.32, p>.05\right)$; see Model 4 in Table 3.9.

\section{Summary of Part one of Chapter 3}

In this section of Chapter 3 it was proposed that silent interparental conflict would detrimentally affect the psychological adjustment of the involved partners. In order to consider the underlying processes resulting in distress, two approaches were adopted; first, silence was examined from a linguistic perspective as a challenging communicative device (e. g. Jaworski, 1993; Kurzon, 1997; Tannen, 1996); and second, the social psychological findings regarding interpersonal rejection and ostracism (Leary, 2001; Williams, 2001) and their implications for wellbeing were discussed in relation to the perceptions of SIC.

Based on the reviewed research and my qualitative findings (Kielpikowski, 2004; Kielpikowski \& Pryor, 2008), the effects of the Marker, the Costs and the Benefits of SIC on wellbeing were hypothesised and tested using structural equation modelling. Following previous research indicating differences in men's and women's paths to distress in the context of marital conflict (e.g. Fincham, et al., 1997), separate models were tested for the husbands and the wives. Reflecting the systemic perspective taken in this work, mutual influences of partners were assumed and tested. The interplay between silent conflict and maladjustment variables was also examined.

In support of Hypothesis 1 consistent concurrent effects of the incidence and the Costs of SIC on maladjustment were found for both men and women at both measurement times; however all of the tested concurrent effects of the 
Benefits of SIC on maladjustment were nonsignificant. Therefore, the awareness of the positive aspects of SIC did not appear to lessen the concurrent distress it caused for either mothers or fathers.

Cross-lagged analyses revealed a significant longitudinal link between the incidence of silent conflict and maladjustment for fathers and a significant longitudinal link between the Benefits of silent conflict and maladjustment for mothers. Mediation models were created to explore the underlying relationships between the study variables. It was found that for fathers the effect of their perceptions of incidence of SIC at Time 1 on maladjustment at Time 2 were fully mediated by the perceptions of incidence of SIC at Time 2, pointing to a short term pattern of relationships between the variables. In contrast, for mothers no mediation effects were found, thus supporting the purely long term nature of the effect their perceptions of the Benefits of SIC at Time 1 exerted in reducing their maladjustment at Time 2 .

Some support for the hypothesised effects of maladjustment on perceptions of silent conflict $(\mathrm{H} 3)$ was found. For fathers a direct effect was found from maladjustment at Time 1 to the perception of Costs of SIC at Time 2 indicating a long term association between the variables. Effectively, for men, greater distress foretold experiencing silent conflict as more emotionally costly over time. Additionally, an immediate association between fathers' distress (IDA) and the perception of incidence of SIC was demonstrated by a full mediation of the effect of IDA at Time 1 on perceived incidence of SIC at Time 2 by IDA at Time 2. In contrast, for mothers it was found that the effect of distress at Time 1 on their perceptions of Benefits of SIC at Time 2 was partially mediated by their distress at Time 2. Women, who were more distressed perceived SIC as more 
beneficial over time, however this perception was weakened by the concurrent experiences of distress.

Testing for longitudinal links between the study variables for parental dyads was conducted with cross-lagged models and revealed good stability coefficients for the measured variables for both partners. Two significant crosslag effects were found: from mothers' Benefits of SIC at Time 1 to fathers' distress at Time 2 and from mothers' Benefits of SIC at Time 1 to their distress at Time 2, however the equality constraint analyses revealed that only the latter could be interpreted as significantly different between men and women. Consequently, the perceptions of greater benefits of SIC resulted in reduced distress over time for women, but not for men.

In sum, it may be concluded that all of the hypothesised relationships were partially supported, except for the interrelatedness of partners' perceptions postulated in Hypothesis 4, as no significant effects between partners were found ${ }^{17}$. Of particular interest is the evidence that emerged in support of the expected differences in the examined links from SIC to adjustment between men and women (H2). The processes of detrimental effects of SIC (the incidence and the Costs) on wellbeing appeared to be situational for men. For women, however, apart from the concurrent effects of the incidence and the Costs of SIC in increasing distress, a longitudinal effect was found, as their perceptions of greater benefits of SIC resulted in reduced distress over time. Importantly, this long-term effect of perceiving SIC as Beneficial was unique to women.

\footnotetext{
${ }^{17}$ The apparent exception was the effect from mothers' Benefits of SIC at Time 1 to fathers' distress at Time 2; however this finding is inconclusive, as the equality constraint analysis showed that it was not significantly different from a corresponding non significant estimate for fathers.
} 
The presented findings add to the evidence from my qualitative study in indicating that silent conflict is indeed related to distress and affects wellbeing. They are also congruent with the existing literature documenting associations between marital discord and psychological adjustment of partners (Beach, et al., 1998; Fincham, et al., 1997; Kiecolt-Glaser, et al., 1996; O'Leary, et al., 1994). In the context of families, parental wellbeing is particularly important, as parents provide an influential and ongoing context for children's development. Therefore, psychological functioning of parents is fundamental to the functioning of children and compromised parental wellbeing threatens providing for children's needs, both on the material and psychological level. In view of its demonstrable consequences on wellbeing, in the next part of this chapter I attempt to shed some light on the question why parents engage in silent conflict.

\section{Part two: The sources of silent interparental conflict}

The aim of this section of Chapter 3 is to propose and test the potential predictors of SIC. To this end, I discuss the theoretical Dual Concern model explaining strategic motivations of disagreeing partners and critically review empirical findings regarding conflict behaviours of potential relevance to silent conflict. Then pertinent existing research regarding the moderating role of gender is examined. Consistent with the systemic approach taken in this work, I consider the potential role of children in silent interparental conflict and the mutual reciprocal influences partners may exert on each other's processes.

Predictors of SIC hypothesised on the basis of my qualitative work (Kielpikowski, 2004; Kielpikowski \& Pryor, 2008) are tested using structural equation modelling. To isolate their potentially distinct processes, separate models are built for mothers and fathers concurrently and over time. Mutual 
influences between partners are tested with the Actor Partner Interdependence Model (Kenny, et al., 2006).

Conflict strategies of disagreeing couples

It has been argued that couples make strategic choices regarding their type of response in conflict situations (e.g. Klein \& Johnson, 2000). According to the Dual Concern Model (Pruitt \& Kim, 2004) presented in Figure 3.12, partners' responses to conflict may be understood to be motivated by some combination of concern for the self- and for the other (partner) - related outcomes.

The matrix consists of four quadrants contingent on the amount of concern attached by the party in conflict to the outcome for self or the partner. The four main classes of conflict strategies that emerge as a result of the possible combinations of the high and the low levels of self and other concern are: problem solving, contending, yielding and avoiding.

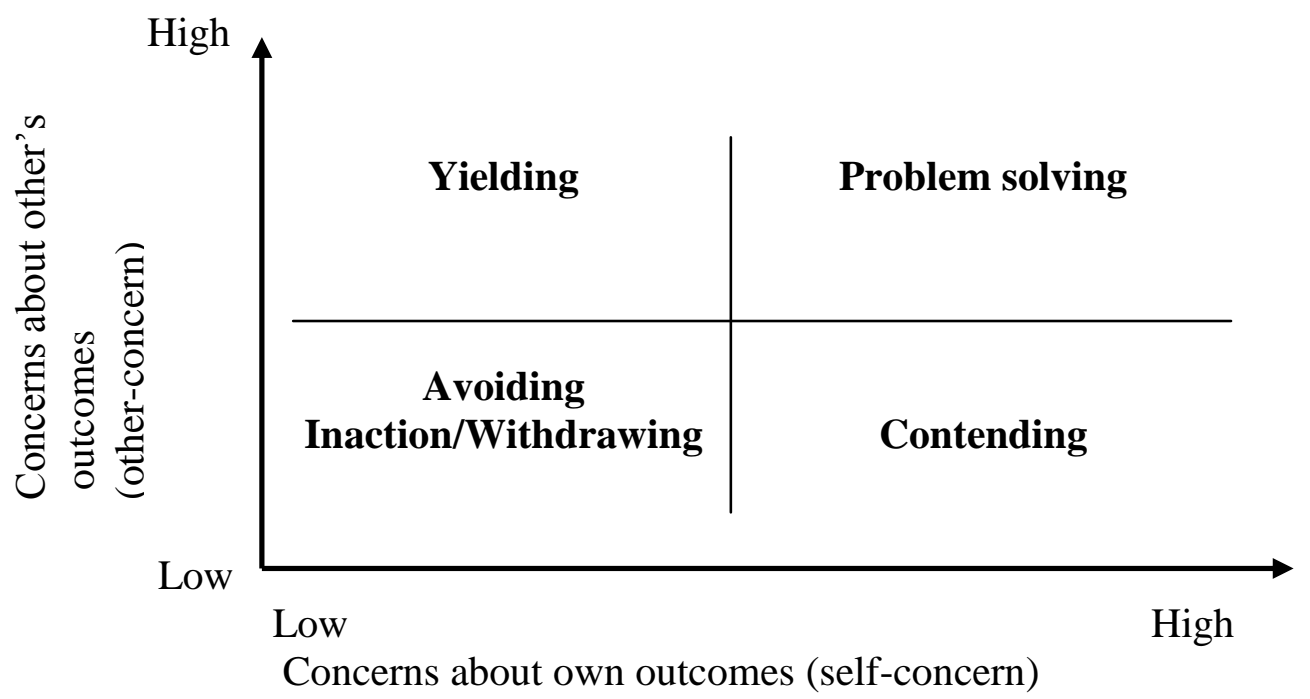

Figure 3.12. Dual Concern Model (from Pruitt and Kim, 2004).

According to the Model, problem solving occupies the quadrant charted by dimensions of high concern both for one's own and for other's outcome. It is an 
active, cooperative, and productive strategy, considered optimal by conflict scholars, due to its focus on seeking an alternative to satisfy the aspirations of both conflicted parties. Contending, an active competitive strategy is characterised by high concern for one's own outcome and low concern for the other's outcome. It is considered destructive in that it entails trying to impose one's preferred solution on the other party. As bilateral verbal interactions problem solving and contending are of less interest to the topic of SIC than the remaining two strategies. Yielding is charted within dimensions of high concern for other's outcome and low concern for own outcome. In adopting this strategy one effectively sacrifices one's own goals, therefore the tactic resembles selfsilencing proposed by Jack (1991). However, unlike Jack's conceptualisation, the Dual Concern Model is not gender-specific, therefore yielding as a tactic is available to both men and women. According to the model, avoiding, or not engaging in conflict, is a strategy implemented when one's concerns for both one's own and other's outcomes are low; it may be expressed through inaction or withdrawal. Significantly, in their review of couples' conflict interactions, Guerrero and Floyd (2006) observe that avoiding and withdrawal have been reported by conflicted partners more often than either the cooperative or the competing strategies.

As the relationally driven complexities of conflict behaviours come to light it becomes apparent that the phenomenon of conflict itself cannot be conceptualised as a purely adversarial contest aiming at a surrender of one party to the other. Klein and Johnson (2000, p. 83) emphasise the heuristic nature of the Dual Concern Model, pointing out that when dimensions such as power and/or gender are introduced into the analysis, the choices represented in the model may 
take on different meanings. For example, yielding by a partner with less relational power may be a sign of a limited choice of responses and powerlessness, whereas yielding by a partner with more relational power may be interpreted as a sign of benevolence and respect.

The Dual Concern Model is useful for explaining the paths to strategic choices made in conflict situations by an individual, yet as a relational phenomenon conflict essentially involves such decisions by both partners. Reaching a satisfactory resolution of a conflict requires that the opposing parties engage with each other in a collaborative way. Both the competitive engagement (arguments) and the disengagement strategies (withdrawal, inaction) prevent, or at least delay, conflict resolution (Wilmot \& Hocker, 2007).

Naturally, decisions and choices of tactics by one partner are not necessarily matched by the choices of the other partner. However, except for mutual problem solving, the remaining 'matched' conflict interactions ${ }^{18}$ are all problematic and necessitate a problem solving effort to achieve a conflict resolution. The 'mismatched' tactics are more complex to interpret. Hypothetically, for example, a problem solving inclined partner may encounter an avoiding, a contending or a yielding response, with only the latter resulting in a termination of the disagreement.

As yielding amounts to giving up one's aspirations, it may become problematic and lead to relationship dissatisfaction on the part of the yielding partner (Cloven \& Roloff, 1993), especially if people surrender when issues of significance to them are at stake. An even less optimal conflict termination

\footnotetext{
${ }^{18}$ Using the quadrants of the model these would be: mutual avoiding, mutual contending and mutual yielding.
} 
results from yielding in response to contending. This process contains not only the potential seeds of relationship discontent inherent to the act of yielding, but also the relationally destructive element of pressure and coercion. The combination of avoiding and yielding is probably the most subtle, however, it makes it plain that if the conflict avoiding behaviour by one partner elicits yielding from the other partner, then avoiding per se may be a powerful method of achieving a desired outcome for the avoider. In view of this, it becomes apparent that in interpreting dyadic conflict encounters, the sequence of partners' conflict behaviours, namely, what type of behaviour by one partner elicits what type of behaviour by the other partner, is not inconsequential.

Not all of the dyadic behaviours possible by combining the cells of Dual Concern Model matrices for couples make logical sense if one were to assume that the sole objective of a disagreement is achieving a desired outcome. A promising explanation for these hypothetical dyadic patterns is that another relational dimension might come to play, such as affect. For example, a partner responding by contending to the other's problem solving may be venting heightened emotions, whereas avoiding in response to yielding may constitute a reprisal for hurt feelings. Consequently, the immediate affective goals might interrupt the instrumental pursuit of an outcome, which highlights a possibility for certain intrapersonal incompatibility and asynchrony between emotions and cognitions occurring in dyadic encounters.

Among the 'mismatched' tactical pairings is the often studied 'demandwithdraw' pattern of couple conflict interactions (e.g. Christensen, 1988; Sullaway \& Christensen, 1983). The joint designation 'demand-withdraw' refers to a contingent dyadic behaviour pattern whereby active instigation of change by 
one partner is met with passivity or evasiveness of the other partner, who literally (e.g. by leaving the room) or effectively (e.g. by changing the subject of a discussion) withdraws from the conflict interaction.

Although conceptualised as situational, the options expressed in the Dual Concern Model may over time lead to a preferred strategy a person chooses in conflict situations, especially when proven to produce desired outcomes. Furthermore, for committed couples in long-term relationships the result may be habitual and somewhat rigid dyadic conflict behaviour. Such rigid reliance on the 'demand-withdraw' pattern combined with the stereotyped roles of the demander (female) and the withdrawer (male) has been found in distressed couples (Eldridge \& Christensen, 2002). Compared to nondistressed couples the distressed ones were more predictable in their conflict behaviours and displayed greater dyadic behaviour inflexibility regardless of conflict structure, that is which of the partners sought change and which acted to protect the status quo. This role entrenchment was also related to the length of the relationship, with newer couples demonstrating greater flexibility in the reversal of roles.

Relevance to silent conflict research

Applying the Dual Concern Model in an attempt to determine the processes leading to SIC results in ambiguous conclusions. Evidently, behaviours displayed by partners during SIC are most appropriately located within the Avoiding/Inaction/Withdrawing quadrant. However, the low concern for own and other outcomes that according to the model elicits this group of conflict strategies contradicts both my qualitative findings (Kielpikowski, 2004; Kielpikowski \& Pryor, 2008) and the validated content of the SIC scale. The emotional component of SIC demonstrated by tension and a lack of mutual warmth, the emotional costs 
of SIC to self and family, as well as the perceived benefits of SIC suggest a much more powerful set of motives than low dual concern, thus eluding the simplicity of the model. Therefore, in keeping with the content of the qualitative interviews discussed in Chapter 1, it is proposed that SIC will be predicted by avoidance and withdrawing from overt verbal confrontation. This may apply to both partners in which case avoidance is matched by avoidance. Additionally, it is proposed that hostile confronting behaviour from one partner may accompany evasive behaviour from the other partner and also act as a predictor of silent conflict. Importantly, neither of these dyadic behaviours results in termination of a conflict, but rather in it changing its semblance from overtly verbalised to notverbalised.

\section{Gender controversy}

The stereotyping of roles taken by partners in verbal conflict into nagging wives and withdrawing husbands mirrors the communication styles traditionally seen as feminine and masculine. According to popular culture, in men the quality of silence is compatible with strength. In contrast, women are seen as verbose, a notion with a long history in Western culture amply illustrated by English proverbs through the ages. The purpose of the proverbs is to point out and admonish women's omnipresent normative talkativeness, e. g. 'Many women, many words; many geese, many turds' and to produce an aspirational ideal of a silent women, e. g. 'Silence is the best ornament of a woman' (Coates, 2004; Eckert \& McConnell-Ginet, 2003; Romaine, 1999). Shakespeare contributes a literary example: 'Do you not know I am a woman? When I think, I must speak' (Rosalind, As you like it, III.2.264). 
Concurring with the longstanding stereotypes, marital conflict research that cast women in the roles of pursuers characterised by confronting behaviour and men in the roles of withdrawers (Christensen, 1988; Gottman \& Levenson, 1986, 1988; Sullaway \& Christensen, 1983) had a significant and lasting impact. Explanations for the gender-specific division of demand - withdraw behaviours could be linked to differential socialisation of males and females ${ }^{19}$ propounded by Gilligan (1992) and Maccoby and Jacklin (1974). The contrasting upbringing of girls and of boys, with an emphasis on affiliativity and expressiveness in the former, versus independence and staunch inexpressiveness in the latter, has been seen as leading to disparity in preferences for relational closeness and autonomy between the sexes (Napier, 1978) as well as to their inevitable communication difficulties (Tannen, 1990). Additionally, the perceived societal power structure and the structure of traditional marriages have been posited by some scholars as benefiting men more than women, therefore affording the former greater power within relationships (e.g. Noller, 1993). Consequently, conflict situations were interpreted as instances of seeking change by women, who employed approaching and confronting behaviours, whereas in response, men withdrew to protect their privileged position (Christensen, 1988; Christensen \& Heavey, 1990).

This gendering of demand-withdraw behaviour, however, has not been consistently supported in subsequent research (Heavey, et al., 1993; Klinetob \& Smith, 1996; McGinn, McFarland, \& Christensen, 2009). Instead, the more recent findings have indicated that the assuming of the roles of the pursuer or the

\footnotetext{
${ }^{19}$ An alternative explanation has been put forward by Gottman (1994), who proposed that man had greater physiological reactivity to conflict and therefore were compelled to avoid it. Subsequently, however Kiecolt-Glaser and colleagues (e.g. Kiecolt-Glaser, et al., 1996) found greater reactivity to conflict in women in her sample, rendering the issue of reactivity equivocal.
} 
withdrawer appeared to be related to seeking change or protecting the status quo in respect to a particular contentious issue, and might accordingly fluctuate between the partners.

Significant insights into gendering of conflict behaviours may be gleaned also from research of Kluwer and colleagues (Kluwer, 2000; Kluwer, Heesink, \& Vliert, 1997) focused on gender role interpretations among participating partners. Its results indicated that compared with egalitarian wives and wives of egalitarian husbands, traditional wives and wives of traditional husbands demonstrated greater avoidance and withdrawal during conflict episodes, and therefore less impetus for change, regardless of their level of discontent. Similarly, empirical evidence from research focused on self-silencing points to its links with the level of acceptance of traditional gender roles in particular samples (Whitton, Stanley, \& Markman, 2002).

Numerous, mostly cross-sectional studies support the relationship between demand-withdraw couple conflict interaction and marital dissatisfaction. However, these results are mixed and cannot be easily reduced to a single conclusion. For example, although Christensen and Heavey (1990) found the inverse link between marital satisfaction and husbands' withdrawal, Gottman and Krokoff (1989) reported that it was the wives' withdrawal that was related to marital dissatisfaction of both partners. Roberts' (2000) cross-sectional research indicated that the main predictor of marital dissatisfaction for women was hostile behaviour of their husbands, whereas for men it was the wives' withdrawal. In contrast, a longitudinal study by Kurdek (1995) found support for the links between marital dissatisfaction of both spouses and the dyadic conflict resolution style consisting of wives' conflict engagement and husbands' withdrawal, both 
concurrently and over time. However, in this study women's dissatisfaction was related to their own, not their husbands' withdrawing behaviour.

\section{Relevance to silent conflict research}

The contradictory and inconclusive findings regarding gendering of conflict behaviours provide no clear empirical indications for predictions regarding behaviours of men and women in silent conflict. Similarly ambivalent are the theoretical guidelines. On the one hand, combining the differential socialisation perspective (Block, 1983; Maccoby \& Jacklin, 1974) that results in high affiliativity of women with the social psychological findings that ostracism is a tactic better suited to people with lower affiliative characteristics (Williams, 2001) suggests that men might be the suitable sources of silence. On the other hand, accepting Jack's hypothesis (1991; Jack \& Dill, 1992) that women self silence to maintain marital harmony could point to a reverse scenario, whereby direct antagonistic behaviour of husbands is met by wives' silent responses.

The moderating function of gender role interpretation (Kluwer, et al., 1997) highlights the need for additional caution when generalising gender-related findings over contexts and over time. Such caution may be applicable to this research conducted with New Zealand couples, as it is reasonable to posit that New Zealand society is comparatively progressive and equalitarian in their interpretation of gender roles (e.g. King, 2003; Sauers, Kennedy, \& O'Sullivan, 2002). That is perhaps why self-silencing was not identified as a theme in the qualitative study guiding this research (Kielpikowski, 2004; Kielpikowski \& Pryor, 2008). In conclusion, it appears that according to existing theory and empirical evidence differences in behaviour of men and women in silent conflict 
may be expected, bearing in mind that they are contingent on numerous factors, not only personal and relational, but also societal and temporal.

\section{Child effect}

"Child effect on parents?" I was once asked by an incredulous clinician. "Surely, you mean how parents treat their children?" (Ambert, 2001, p. 1)

The roles within families are traditionally conceptualised as divided into carers and dependants, with children and adolescents cast as the latter. Perhaps as a result, the direction of influence has been constructed persistently as issuing from parents towards children. In keeping with this prevailing 'top down' approach children have been regarded as recipients of parental behaviours and as neutral inhabitants of environments created by parents, and therefore studied as such. Consequently, children's behaviours have been hypothesised as outcomes of processes initiated and controlled by parents.

In 2003 Crouter and Booth edited a volume titled "Children's influence on family dynamics: The neglected side of family relationships", containing materials from a national symposium held at the Pennsylvania State University. The sentiments expressed in the volume's title echo the premise of Anne-Marie Ambert's book (2001) titled 'The effects of children on parents', now in its second edition. In her volume Ambert provides numerous compelling examples of 'child to parent' influences through the lifespan on such areas of parents' lives as space, activities, employment, economic resources ${ }^{20}$, marital and familial relations, life plans, and feelings of control over one's life, among others. Indeed,

\footnotetext{
${ }^{20}$ To illustrate, Beaver and Wright (2007) found economic effects on families of child delinquency. They proposed a tentative explanation that attending to a problem child interferes with a parent's ability to perform in a job or even hold one.
} 
as observed by McHale and Crouter (2003), children define the structure of their families and their very presence facilitates specific family interactions.

Maccoby (2003b) has observed that the common failure to acknowledge the reciprocity of influence between parents and children arose due to the obvious differences in power between them. As a result, children in families have not been construed as agentic, which in turn has contradicted and disallowed the idea of reciprocity in the parent - child relations.

Regardless of the apparent power imbalance, over the course of time, parents and children interact in an attempt to influence one another's behaviour. Child characteristics play as important a role in the process as do parental ones. For example, it has been found that difficult temperament of children acts to increase mothers' negative reactions through compromised maternal wellbeing (Crockenberg \& Leerkes, 2003). The degree of compatibility between child characteristics and parental behaviours (e.g. parental firmness appropriate to child's temperament) and mutuality in the interactions of parents and children is also crucial, as demonstrated by longitudinal research on mothers and young children (Kochanska, 1997a, 1997b). The research has provided support for the importance of mutual responsiveness and reciprocity of affect between a parent and a child for the child's successful future socialisation.

Scholars studying interactions between parents and children admit considerable challenges in clearly determining who influences whom, adding that it is even harder to establish who affects whom first. In order to attempt a chronology of mutual influences one needs to study the evolution of a relationship; when this relationship history is unknown, the order of who actually influences whom is difficult to capture. As argued by Shanahan and Sobolewski 
(2003), it might therefore be a fallacy to seek 'pure' child effects as much as it is to seek pure parent effects. Therefore the strictly 'top down' parent to child or the reverse 'bottom up' conceptualisations regarding socialising may be too simplistic, and reciprocal socialisation appears to be a more appropriate approach. In keeping with the systemic perspective, it is best to understand children's influence on parents as bidirectionally linked to parents' influence on children.

A somewhat overlooked aspect of the evolving relationships within families is that not only children but also parents are developing individuals (McHale \& Crouter, 2003, p. 219). Once this is acknowledged, it makes it a viable proposition that parents adapt behaviours, attitudes and values in response to children. Research discussed by the contributors to Crouter and Booth's volume (2003) emphasises the bidirectional and mutual nature of the effects of children and parents, pointing out that changes in behavioural responses are not an exclusive domain of children, but that parents also respond to children's actions by changing their own parenting behaviours (Kerr \& Stattin, 2003). Correspondingly, in a recent prospective study Huh, Tristan, Wade and Stice (2006) tested such bidirectional influences between parenting behaviours and behaviour problems in a sample of 496 American girls. The research found that effects of children's behaviour on parenting were more powerful and consistent than the effects of poor parenting on behaviour problems.

Research has only begun making inroads into 'child effects' on parents. Consequently, notwithstanding the acceptance of the reciprocity of processes, it is still unknown which child effects in respect of which phenomena are situational and which continue their influence over time. 


\section{Child effect and conflict research}

The prevalent 'parent to child' research perspective is reflected in a relative shortage of conflict-focused studies that include the aspect of the influence children exert on the family system. Moreover, as a rule, studies of marital relationships focus on interactions of married or committed couples without further references to the composition of their families. Consequently, when dealing with research that does not involve child respondents, it is often impossible to determine whether the participating couples are parents or not, despite the ostensibly obvious grounds for this distinction.

The present work focuses on families with children and therefore on the experiences of parents in conflict. In keeping with the systemic approach espoused by this research, it is proposed that children as structural members of families ought to be considered in conceptualisations of couple conflict that is parental, as conflicted parents may be subject to contextual influences provided by children, which do not affect childless couples. The most salient example of children's direct influence on parental behaviour in the context of conflict may be their intervention in an interparental conflict episode. A recent longitudinal study of such intentional (agentic) intervention by children found that their attempts to mediate were linked to lower marital discord over time (Shermerhorn, Cummings, DeCarlo, \& Davies, 2007).

However, not all children intervene in all parental conflicts; therefore it is possible that the indirect effect of children on parents may be more ubiquitous. The indirect effects of children on parents have been supported to some extent by recent observational studies involving marital conflict resolution tasks conducted by Deal, Hogan, Bass, Hetherington and Clingempeel (1999) and Frosch, 
Mangelsdorf and McHale (1998), and by the home diary study of Papp, Cummings and Goeke-Morey (2002). Both types of studies compared conflict behaviours of parents in the presence and in the absence of children, however their findings were dissimilar. The observational results indicated that there was a significant decrease in the scores of the marital interaction variables studied including rejection, coercion, warmth (Deal, et al., 1999) and negative affect (Frosch, et al., 1998) when children were present during parental conflict. These findings indicate that presence of children may result in a toning down of the behavioural expressions of conflict between parents. In contrast, Papp et al. (2002) reported that although parents recorded fewer conflicts in the home in the presence of children than in their absence, conflicts in the presence of children involved more destructive behaviours and greater emotional negativity. A possible explanation for this seemingly paradoxical finding is that in the presence of children only the most significant, urgent and emotionally intense interparental conflicts manifest themselves, as they are impossible to suppress. Otherwise, parents might tend to hold back their verbal disagreements in an effort not to upset the children, as indicated in the following statement of a thirty nine year old father: "We try not to row, not to argue and to keep things calm for the kids" (Kielpikowski \& Pryor, 2008).

In view of compelling indications of children's influence on parental functioning it was proposed that in conflict situations parents will be motivated to reduce their expression of conflict, at least to some degree, by protectiveness towards their offspring. Therefore, it was hypothesised that SIC will be predicted by parental concern for their children's emotional wellbeing. In sum, the following hypotheses were posed: 


\section{Hypotheses}

H1. Reports of silent interparental conflict will be predicted both concurrently and after one year by:

- Perceptions of partner's hostility - people will report silent conflict in response to partners' hostile behaviour

- Own conflict avoidant behaviour - avoidance of confrontation will predict silent conflict with partner

- Concern for the children - parents will use silent conflict in an effort to protect children from witnessing arguments

$\underline{\mathrm{H} 2}$. Despite equivocal indications regarding gendering of conflict behaviours in the reviewed research, it was expected that processes resulting in SIC would play out differently for mothers and fathers.

H3. In keeping with the systemic conceptualisation of family functioning adopted in this work, it was expected that one partner's perceptions will influence the other partner's perceptions both concurrently and longitudinally.

\section{STUDY 1}

\section{Method}

Participants are described in Part one of this chapter.

Measures

The Silent Interparental Conflict Scale was described in Chapter 2.

Partner's Hostility ${ }^{21}$ was measured with the adapted Hostility subscale used in the Iowa Youth and Family Project (Melby, et al., 1993; Melby, Conger, Ge, \& Warner, 1995). The four items were scored from one (never) to seven

\footnotetext{
${ }^{21}$ The subscale is presented in Appendix H.
} 
(always) on a Likert scale with higher scores representing greater hostility.

Cronbach's $\alpha$ s for the measure obtained at T1 and T2 ranged from .88 to .89 .

Conflict avoidant behaviour was measured with three items from the pool originally proposed for the SIC scale. In particular, the following items were used:

'When we argue and my partner tries to get to the bottom of the problem I reach a point when I don't want to talk any more.'

'When we have a quarrel I refuse to continue arguing and leave the room.'

'I want to be alone when my partner and I cannot agree on an issue.'

The internal consistency of the scale was acceptable with Cronbach's $\alpha$ s ranging from .72 to .79 .

Child concern was measured with one item scored from one (never) to five (always), created on the basis of findings from my qualitative research:

'We try to keep things calm for the kids, so instead of arguing we stop talking to each other.'

\section{Results}

As in Part one of this chapter, data were organised in SPSS into a set enabling dyadic level analyses (Kenny, et al., 2006, p.17).

Descriptive statistics and correlations for all measured variables at both measurement times are presented in Tables $3.10-3.13$. 
Table 3.10. Means and standard deviations for men and women $(N=115$ each) on measured variables.

\begin{tabular}{cccccc}
\hline Scale & $\begin{array}{c}\text { Number } \\
\text { of }\end{array}$ & \multicolumn{1}{c}{ Men } & Women & Men & Women \\
\cline { 3 - 6 } & items & Mean(SD) & Mean(SD) & Mean(SD) & Mean(SD) \\
\cline { 3 - 6 } Marker SIC & 5 & $14.89(3.82)$ & $14.93(3.895)$ & $14.53(3.878)$ & $14.64(3.802)$ \\
Costs SIC & 4 & $12.18(3.28)$ & $12.20(3.50)$ & $12.02(3.50)$ & $12.01(3.46)$ \\
$\begin{array}{c}\text { Benefits } \\
\text { SIC }\end{array}$ & 3 & $10.23(2.17)$ & $10.19(2.43)$ & $10.25(2.43)$ & $10.11(2.29)$ \\
SICS Total & 12 & $37.29(6.99)$ & $37.32(6.82)$ & $33.21(7.23)$ & $33.21(6.77)$ \\
$\quad \begin{array}{l}\text { Own } \\
\text { Avoidant }\end{array}$ & 3 & $8.55(2.29)$ & $7.67(2.14)$ & $8.45(2.40)$ & $7.63(1.16)$ \\
$\begin{array}{c}\text { Behaviour } \\
\text { Partner's }\end{array}$ & 4 & $11.61(3.94)$ & $10.22(3.79)$ & $11.47(4.12)$ & $9.93(3.53)$ \\
$\begin{array}{c}\text { Hostility } \\
\text { Concern for }\end{array}$ & 1 & $2.62(0.84)$ & $2.54(0.87)$ & $2.58(0.93)$ & $2.50(0.81)$ \\
$\quad$ Child & & & & & \\
\hline
\end{tabular}

\section{Mean group differences}

Paired samples t-tests were conducted to compare scores of men and women on all variables. No significant differences were found for the sexes, except that men and women differed significantly on their reports of Partner's Hostility and their own Conflict Avoidant Behaviours. Consistently at both measurement times, the wives' perceptions of husbands hostility were significantly lower than the husbands' perceptions of the wives' hostility towards them $(\mathrm{T} 1: t(114)=3.44, p<.01 ; \mathrm{T} 2: t(114)=3.90, p<.001)$. Additionally husbands reported significantly higher levels of conflict avoidance $(\mathrm{T} 1: t(114)=$ 3.26, $p<.01 ; \mathrm{T} 2: t(114)=2.95, p<.01)$ than wives.

As gender constellation effects might arise due to various combinations between genders of parents and genders of children, the reported levels of child protectiveness were compared between mothers of girls and mothers of boys and between fathers of girls and fathers of boys. No significant differences were found. 
Concurrent and Longitudinal Links among Study Variables

Significant positive correlations were found for fathers between all of the proposed predictors and SICS at both measurement times ( $r$ s between .25 and .62 , $p<.01)$. Similarly, for mothers, the proposed predictors and SICS were significantly positively correlated ( $r$ s between .28 and $.40, p<.01)$ except for the nonsignificant relationship between reported conflict avoidant behaviour at Time1 and SICS at Time $2(r=.18)$. Correlations are presented in Table 3.11.

Table 3.11. Intercorrelations among measured variables for men (in red above the diagonal) and women (in black below the diagonal) at T1 and T2.

\begin{tabular}{|c|c|c|c|c|c|c|c|c|}
\hline Variable & $\begin{array}{l}\text { SIC } \\
\text { T1 }\end{array}$ & $\begin{array}{c}\text { Partner's } \\
\text { Hostility } \\
\text { T1 }\end{array}$ & $\begin{array}{c}\text { Own } \\
\text { Avoidant } \\
\text { Behaviour } \\
\text { T1 }\end{array}$ & $\begin{array}{l}\text { Concern } \\
\text { for } \\
\text { Child } \\
\text { T1 }\end{array}$ & $\begin{array}{l}\mathrm{SIC} \\
\mathrm{T} 2\end{array}$ & $\begin{array}{l}\text { Partner's } \\
\text { Hostility } \\
\text { T2 }\end{array}$ & $\begin{array}{c}\text { Own } \\
\text { Avoidant } \\
\text { Behaviour } \\
\text { T2 }\end{array}$ & $\begin{array}{l}\text { Concern } \\
\text { for } \\
\text { Child } \\
\text { T2 }\end{array}$ \\
\hline $\begin{array}{c}\text { SIC } \\
\mathrm{T} 1\end{array}$ & - & $.32 * *$ & $.42 * *$ & $.53 * *$ & $.74 * *$ & $.23 *$ & $.41 * *$ & $.30 * *$ \\
\hline $\begin{array}{c}\text { Partner's } \\
\text { Hostility } \\
\text { T1 }\end{array}$ & $.38 * *$ & - & $.21 *$ & .18 & $.25 * *$ & $.73 * *$ & .12 & .12 \\
\hline $\begin{array}{c}\text { Own } \\
\text { Avoidant } \\
\text { Behaviour } \\
\text { T1 }\end{array}$ & $.39 * *$ & ,20* & - & $.37 * *$ & $.51 * *$ & $.28 * *$ & $.75 * *$ & $.33 * *$ \\
\hline $\begin{array}{l}\text { Concern } \\
\text { for Child } \\
\text { T1 }\end{array}$ & $.37 * *$ & .07 & $.40 * *$ & - & $.54 * *$ & $.18 *$ & $.34 *$ & $.60 * *$ \\
\hline $\begin{array}{c}\mathrm{SIC} \\
\mathrm{T} 2\end{array}$ & $.75^{* * *}$ & $.39 * *$ & .18 & $.28 * *$ & - & $.30 * *$ & $.62 * *$ & $.51 * *$ \\
\hline $\begin{array}{c}\text { Partner's } \\
\text { Hostility } \\
\text { T2 }\end{array}$ & $.30 * *$ & $.75^{* *}$ & $.19 *$ & .08 & $.36 * *$ & - & $.27 * *$ & .16 \\
\hline $\begin{array}{c}\text { Own } \\
\text { Avoidant } \\
\text { Behaviour } \\
\text { T2 }\end{array}$ & $.25 * *$ & $.26 * *$ & $.68 * *$ & $.32 * *$ & $.31 * *$ & $.37 * *$ & - & $.38 * *$ \\
\hline $\begin{array}{c}\text { Concern } \\
\text { for Child } \\
\mathrm{T} 2\end{array}$ & $.40 * *$ & $.19 *$ & $.23 *$ & $.38 * *$ & $.39 * *$ & $.30 * *$ & $.34 * *$ & - \\
\hline
\end{tabular}

A majority of correlations among the reports of men and of women (between sexes) on the predictor variables at $\mathrm{T} 1$ and perceptions of SIC at T2 
were positive and significant indicating general similarities in links between the perceptions of the partners. Correlations are presented in Tables 3.12 and 3.13.

Table 3.12. Intercorrelations among predictor variables at T1 and men's and women's scores on SICS at T2.

\begin{tabular}{|c|c|c|c|c|c|}
\hline Variable & $\begin{array}{c}\text { MSIC } \\
\text { T1 }\end{array}$ & $\begin{array}{l}\text { MPartner's } \\
\text { Hostility } \\
\text { T1 }\end{array}$ & $\begin{array}{c}\text { MOwn } \\
\text { Avoidant } \\
\text { Behaviour } \\
\text { T1 } \\
\end{array}$ & $\begin{array}{l}\text { MConcern for } \\
\text { Child } \\
\text { T1 }\end{array}$ & $\begin{array}{c}\text { MSIC } \\
\text { T2 }\end{array}$ \\
\hline $\begin{array}{c}\text { WSIC } \\
\text { T1 }\end{array}$ & $.33 * *$ & $.22 *$ & $.35 * *$ & $.33 * *$ & $.36^{* *}$ \\
\hline $\begin{array}{l}\text { WPartner's } \\
\text { Hostility } \\
\text { T1 }\end{array}$ & .18 & $.36^{* *}$ & .07 & -.03 & .12 \\
\hline $\begin{array}{c}\text { WOwn Avoidant } \\
\text { Behaviour T1 }\end{array}$ & $.25 * *$ & $.30 * *$ & .14 & $.25^{* *}$ & $.20 *$ \\
\hline $\begin{array}{l}\text { WConcern for } \\
\text { Child } \\
\text { T1 }\end{array}$ & $.25 * *$ & .12 & .16 & $.31 * *$ & $.29 * *$ \\
\hline $\begin{array}{l}\text { WSIC } \\
\text { T2 }\end{array}$ & $.35 * *$ & .10 & $.32 * *$ & $.34 * *$ & $.35^{* *}$ \\
\hline
\end{tabular}

Table 3.13. Concurrent intercorrelations among predictor variables and men's and women's scores on SICS at T2.

\begin{tabular}{ccccc}
\hline Variable & $\begin{array}{c}\text { MSIC } \\
\text { T2 }\end{array}$ & $\begin{array}{c}\text { MPartner's Hostility } \\
\text { T2 }\end{array}$ & $\begin{array}{c}\text { MOwn Avoidant } \\
\text { Behaviour } \\
\text { T2 }\end{array}$ & $\begin{array}{c}\text { MConcern for } \\
\text { Child } \\
\text { T2 }\end{array}$ \\
\hline $\begin{array}{c}\text { WSIC } \\
\text { T2 }\end{array}$ & $.35^{* *}$ & .13 & $.43^{* *}$ & $.32^{* *}$ \\
$\begin{array}{c}\text { WPartner's Hostility } \\
\text { T2 }\end{array}$ & .07 & $.38^{* *}$ & $.24^{* *}$ & .06 \\
$\begin{array}{c}\text { WOwn Avoidant } \\
\text { Behaviour T2 }\end{array}$ & .14 & .13 & .15 & .09 \\
$\begin{array}{c}\text { WConcern for Child } \\
\text { T2 }\end{array}$ & $.29^{* *}$ & .11 & $.38^{* *}$ & $.31^{* *}$ \\
\hline Note. ${ }^{* *} p<.01$. & & & & \\
\end{tabular}

Hypothesis one (H1) stipulated the following predictors of SIC: own avoidance of conflict, hostility from partner and protectiveness towards children. In order to test the hypothesised predictors, concurrent path models were constructed for fathers and mothers at $\mathrm{T} 1$ and $\mathrm{T} 2$, followed by a longitudinal model for each parental group. Analyses employing structural equation modelling (SEM) were performed using AMOS 16.0 (Arbuckle, 2006). The models are 
presented in Figures 3.13 - 3.18; to aid interpretation the standardised estimates are shown.

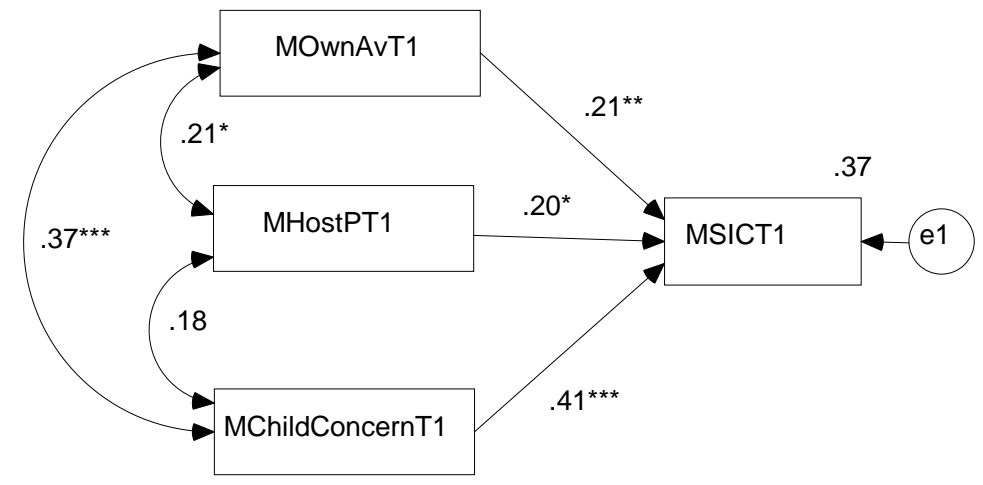

Figure 3.13. Concurrent predictors of SIC for men at T1- standardised estimates.

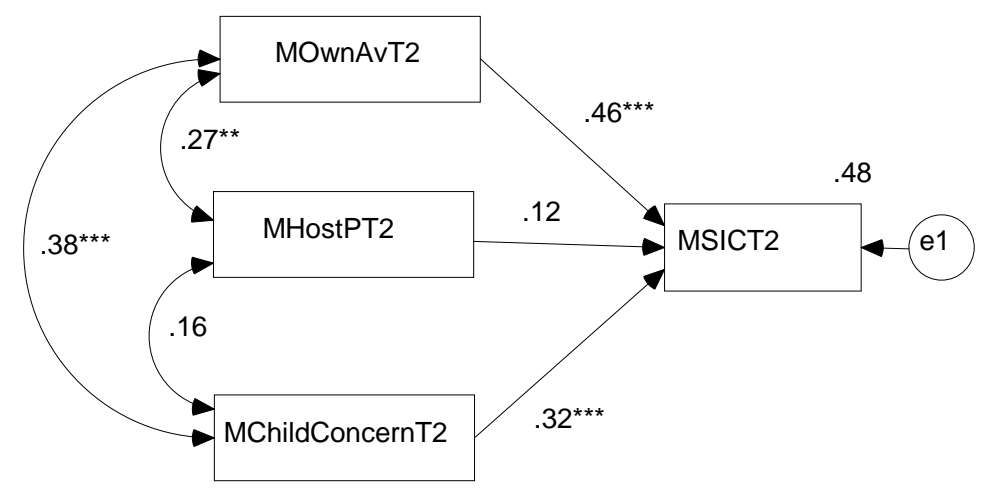

Figure 3.14. Concurrent predictors of SIC for men at T2 - standardised estimates.

Concurrent analyses at T1 and T2 indicated that fathers' own conflict avoidant behaviour and concern for the children consistently predicted their reports of SIC; however inconsistent results were obtained for perceived hostility from partner. Therefore the hypothesised concurrent links for fathers were partially supported. 


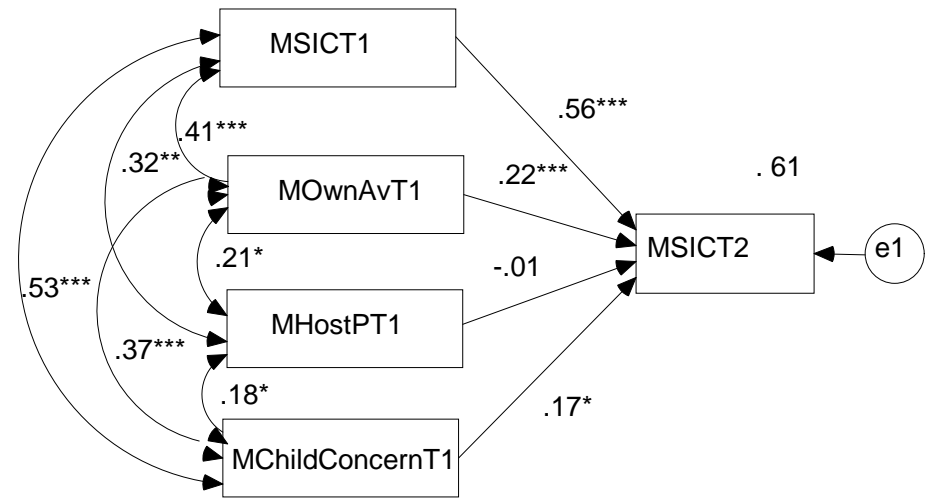

Figure 3.15. Longitudinal predictors of SIC for men controlling for autocorrelation of SICS scores at T1 and T2 - standardised estimates.

The longitudinal model was constructed for fathers including all of the proposed predictors and controlling for the autocorrelation effect of SIC at T1 and T2 (see Figure 3.15). The results of the analysis provided support for longitudinal links between men's own avoidance of conflict and child concern with SIC, but not for perceived hostility from partners. Notwithstanding the preliminary nature of these findings, their consistency both concurrently and over time offers some confidence in their robustness and further research utility.

All of the proposed theoretical models were saturated; therefore no model fit indices were produced by AMOS. In order to establish whether the model of the longitudinal relationship between the proposed predictors and SIC for fathers fit the data, the nonsignificant path from partner's hostility at T1 to SICS at T2 was pruned resulting in a nested model and freeing up one degree of freedom. According to accepted criteria (R. B. Kline, 2005), the pruned model of SIC predictors for fathers over time fit the data very well, $\chi^{2}=.01 ; d f=1 ; p=.91$; $\chi^{2} / d f=.01 ; \mathrm{GFI}=1.00 ; \mathrm{AGFI}=1.00 ; \mathrm{CFI}=1.00 ; \mathrm{sRMR}=.001$ and $\mathrm{RMSEA}=$ 0.001 . 
An identical analytical procedure was followed to examine the hypothesised predictors of SIC for mothers in the sample. Corresponding structural models are presented in Figures 3.16-3.18. Concurrent analyses at T1 and $\mathrm{T} 2$ produced an inconsistency in the significance of own conflict avoidant behaviour as a predictor of SIC for women, as the path was positive and significant at $\mathrm{T} 1$ and nonsignificant at $\mathrm{T} 2$. However, partners' hostility and concern for the children emerged as consistent concurrent predictors of SIC.

Similarly to the results of the analyses of men's data, the hypothesised concurrent links for women were partially supported, however only child concern acted as a consistent significant concurrent predictor of SIC reports for both sets of parents.

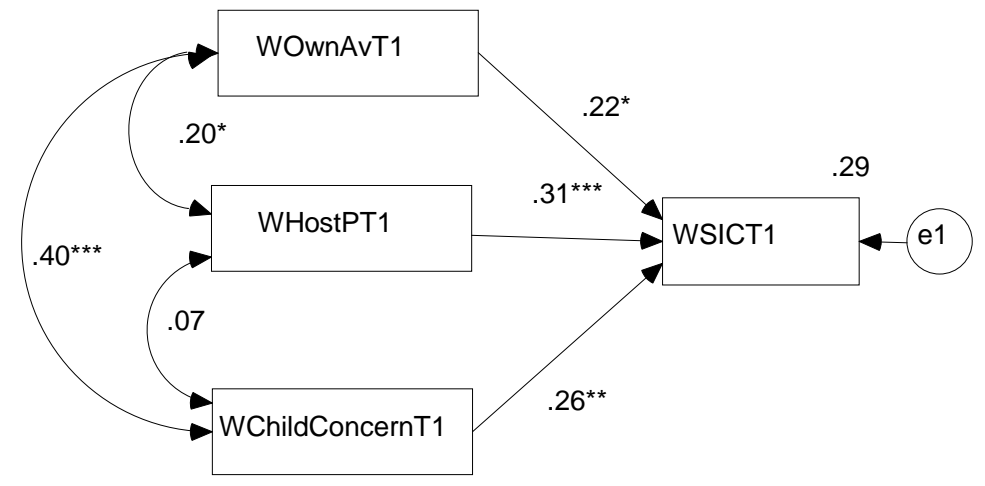

Figure 3.16. Concurrent predictors of SIC for women at T1- standardised estimates.

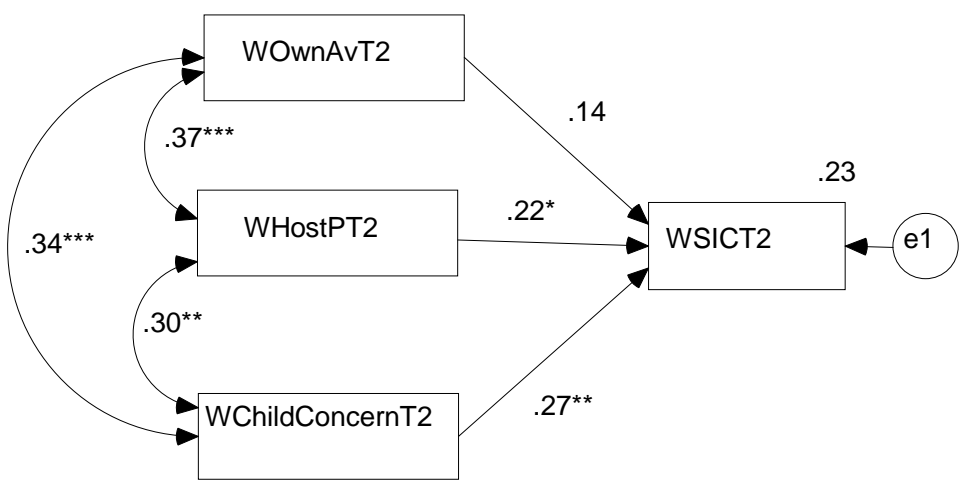

Figure 3.17. Concurrent predictors of SIC for women at T2 - standardised estimates. 
The longitudinal model was constructed for mothers including all of the proposed predictors and controlling for autocorrelation effect of SIC at T1 (see Figure 3.18).

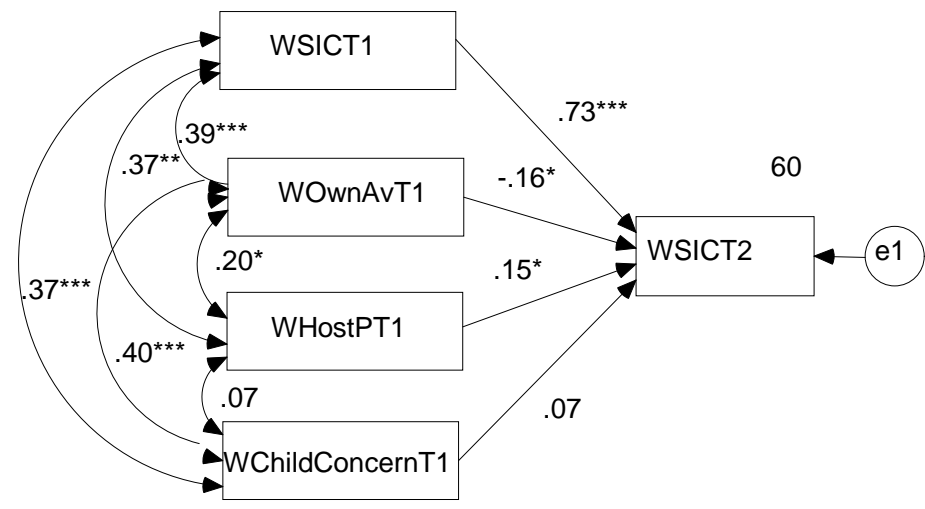

Figure 3.18. Longitudinal predictors of SIC for women controlling for effects of SICS scores at T1- standardised estimates.

The analysis provided support for longitudinal links between hostility from partner and change in SIC over time. This link deserves particular attention in interpreting the arising of SIC for mothers, due to its robustness both concurrently and longitudinally. However, the positive concurrent links between child concern and silent conflict reports for women were not repeated longitudinally, pointing to the immediate rather than enduring nature of the effects of child concern on mothers' perceptions of SIC. The link between women's own conflict avoidance and SIC proved unstable, as it was significant and positive at $\mathrm{T} 1$, nonsignificant at $\mathrm{T} 2$ and significant negative over time.

As was the case for fathers, all of the proposed theoretical models for mothers were saturated; therefore no model fit indices were produced by AMOS. In order to obtain the fit indices for the effects of the propose predictors on SIC over time, the empirically established nonsignificant path from women's child concern to SIC was pruned resulting in a nested model with one degree of 
freedom. The pruned model of SIC predictors for mothers over time met the accepted criteria of fit to the data (R. B. Kline, 2005) producing $\chi^{2}=.98 ; d f=1$; $p=.32 ; \chi^{2} / d f=.98 ; \mathrm{GFI}=1.00 ; \mathrm{AGFI}=.95 ; \mathrm{CFI}=1.00 ; \mathrm{sRMR}=.01$ and $\operatorname{RMSEA}=0.001$

The next step of the analytic process consisted of testing for the potential reciprocal influences between the partners, which were expected consistent with the systemic approach taken in this work. Recall from Part one of this chapter the reasoning of Kenny and colleagues (2006) that measures taken from married couples are 'nonindependent'. Accordingly, the predictors were tested using a version of the Actor-Partner Interdependence Model (APIM) proposed by Kenny (1996), which provides simultaneous estimates of both the effects of the person's own variables (actor effects) and the partner's variables (partner effects). Two concurrent models were constructed and a longitudinal model controlling for the autocorrelation effect of SIC scores at two measurement points (Figures 3.19 3.20). The mutual influences of partners are depicted by direct paths from husbands' scores on the predictor variables to wives' scores on SIC and by direct paths from wives' scores on predictor variables to husbands' scores on SIC. Additionally, interdependence of partners is captured by correlating all of the exogenous variables and by allowing the error terms of the outcome scores to correlate also. This resulted in saturated concurrent models; therefore fit indices could not be obtained. The hypothesised concurrent APIM is presented in Figure 3.19 and the standardised path coefficients for T1 and T2 models in Table 3.14. 


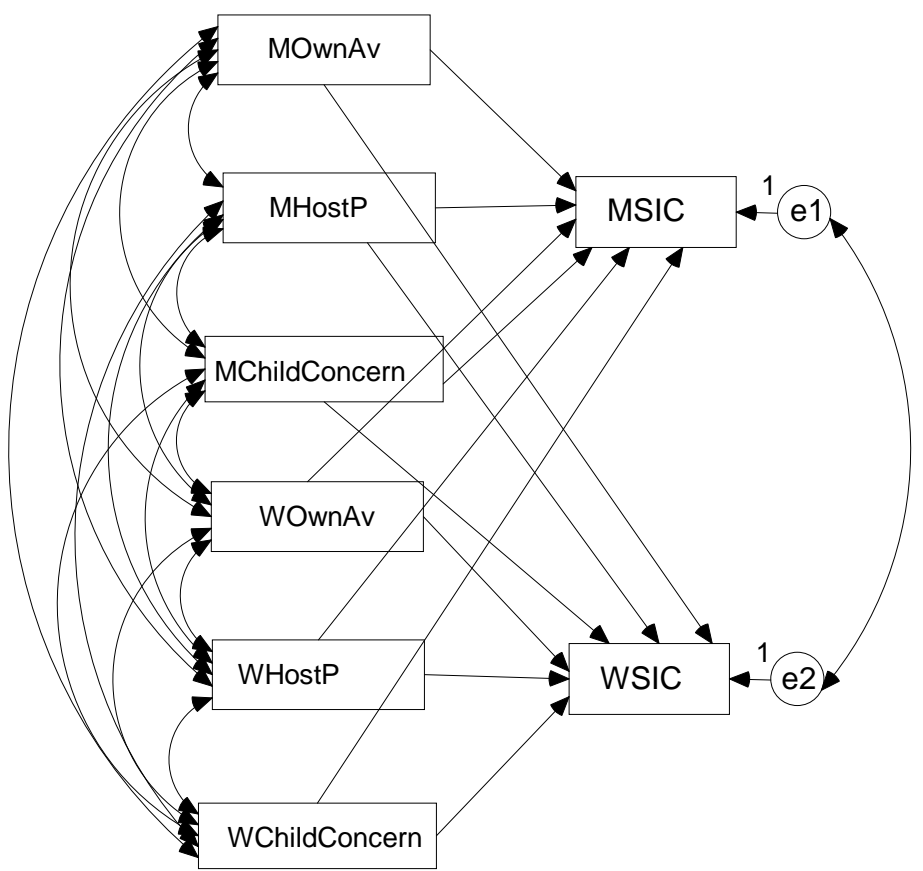

Figure 3.19. Hypothesised concurrent APIM for predictors of SIC for fathers and mothers at Time 1 and Time 2.

At Time 1, all of the hypothesised Actor paths were significant except for the path from fathers' scores of partner hostility to fathers' reports of SIC. In respect to Partner effects, the only significant path was from fathers' avoidant behaviour to mothers' scores on SIC.

At Time 2, all Actor effects for fathers were significant, but the only significant path for Mothers was from their scores for partner hostility to SIC. The significant Partner effects at Time 2 were found for the paths from fathers' avoidant behaviour to mothers' SIC, from fathers' child concern to mothers' SIC and from mothers' reports of partner hostility to fathers' SIC. 
Table 3.14. Standardised path coefficients for concurrent predictor models.

\begin{tabular}{lll}
\hline & \multicolumn{2}{c}{ Estimate } \\
\cline { 2 - 3 } & Time1 & Time 2 \\
\hline MOwnAv - MSIC & $.21 * *$ & $.48^{* * *}$ \\
MOwnAv - WSIC & $.23 * *$ & $.26^{* *}$ \\
MHostP - MSIC & .14 & $.17^{*}$ \\
MHostP - WSIC & -.06 & -.09 \\
MChildConcern - MSIC & $.40^{* * *}$ & $.30^{* * *}$ \\
MChildConcern - WSIC & .15 & $.17 *$ \\
WOwnAv - WSIC & $.19 *$ & .14 \\
WOwnAv - MSIC & .03 & .07 \\
WHostP - WSIC & $.33 * * *$ & $.23 *$ \\
WHostP - MSIC & .11 & $-.16^{*}$ \\
WChildConcern - WSIC & $.20 *$ & .13 \\
WChildConcern - MSIC & .06 & .02 \\
\hline Note. $* p<.05 ; * * p<.01 ; * * * p<.001$.
\end{tabular}

The longitudinal model was constructed controlling for autocorrelation effects of scores of SIC at Time 1 for fathers and mothers. With two degrees of freedom, model fit indices were available and according to the established criteria indicated that the model fit the data very well. The hypothesised model is presented in Figure 3.20, the standardised path coefficients are in Table 3.15 and the model fit indices in Table 3.16. 


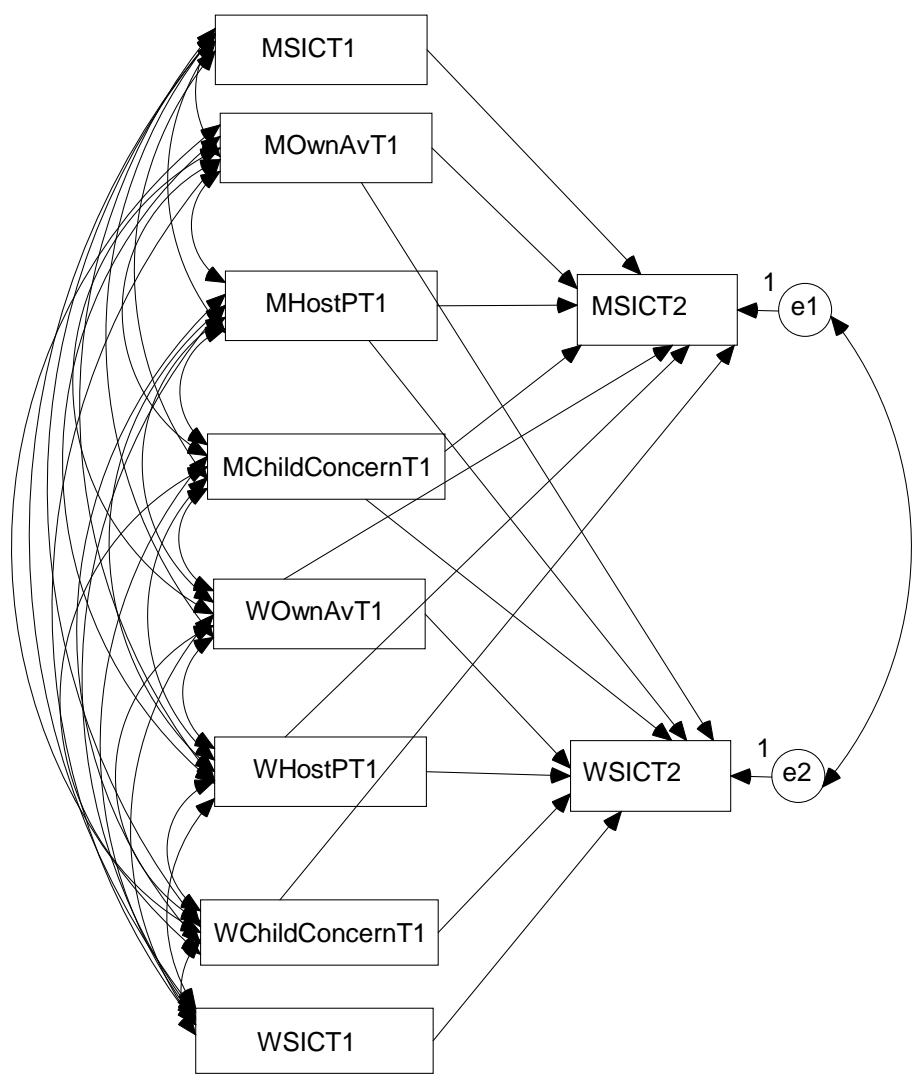

Figure 3.20. Hypothesised longitudinal APIM for predictors of SIC for fathers and mothers.

Table 3.15. Standardised path coefficients - longitudinal dyadic predictors.

\begin{tabular}{ll}
\hline & Estimate \\
\hline MSICT2 - MSICT1 & $.56^{* *}$ \\
\hline MOwnAvT1 - MSICT2 & $.22^{* * *}$ \\
MOwnAvT1 - WSICT2 & .04 \\
MHostPT1 - MSICT2 & -.01 \\
MHostPT1 - WSICT2 & -.06 \\
MChildConcernT1 - MSICT2 & $.16^{*}$ \\
MChildConcernT1 - WSICT2 & $.15^{*}$ \\
WOwnAvT1 - WSICT2 & $-.16^{*}$ \\
WOwnAvT1 - MSICT2 & -.04 \\
WHostPT - WSICT2 & $.20^{* *}$ \\
WHostPT1 - MSICT2 & .01 \\
WChildConcernT1 - WSICT2 & .04 \\
WChildConcernT1 - MSICT2 & .09 \\
WSICT1 - WSICT2 & $.67 * * *$ \\
\hline Note. $*$ < 05 .05;* $p<.01 ; * * * p<.001$.
\end{tabular}


In order to establish whether there were significant differences between fathers' and mothers' effects, an omnibus equality constraint test was performed by setting the parameters for all hypothesised Actor effects to be equal between parents as well as for all the potential Partner effects to be equal between parents. The fit of the resulting model (model 2) was compared with model 1 (Table 3.16). A significant difference $\left(\Delta \chi^{2}(11)=34.62, \mathrm{p}<.001\right)$ was found between the unconstrained and the parameter-constrained models, indicating that an overall difference between fathers and mothers was found. As the location of the difference remained to be established, the next step consisted of constraining only the Actor parameters to be equal. Once again the fit of the resulting model (model 3) was compared to the unconstrained model, and once again a significant difference was found $\left(\Delta \chi^{2}(5)=24.27, \mathrm{p}<.001\right)$ indicating that fathers and mothers differed on at least one path coefficient among the Actor parameters. Separate equality constraints were then imposed for each pair of the corresponding predictors, and two points of difference were found. A significant difference $\left(\Delta \chi^{2}(1)=15.49 ; p<.001\right)$ was found for own avoidance, with the standardised coefficient for fathers $(\beta=.20)$ found to be higher than for mothers $(\beta=-.16)$. The second significant difference $\left(\Delta \chi^{2}(1)=4.44 ; p<.05\right)$ was found for partner's hostility, with mothers' standardised coefficient $(\beta=.20)$ higher than fathers' $(\beta=.01)$.

Table 3.16. Model fit comparison for nested longitudinal SIC predictors models.

\begin{tabular}{clllllllllllll}
\hline Model & $\chi^{2}$ & $d f$ & $p$ & $\chi / d f^{2}$ & GFI & AGFI & CFI & RMSEA & sRMR & $\begin{array}{c}\text { Comp. } \\
\text { to } \\
\text { Model }\end{array}$ & $\begin{array}{c}\Delta \\
\chi^{2}\end{array}$ & $\begin{array}{c}\Delta \\
d f\end{array}$ \\
\hline 1 & 1.55 & 2 & .46 & .77 & 1.00 & .93 & 1.00 & .00 & .01 & & & \\
2 & 36.17 & 13 & .00 & 2.78 & .95 & .77 & .94 & .13 & .05 & 1 & $34.62 * * *$ & 11 \\
3 & 25.92 & 7 & .00 & 3.70 & .96 & .68 & .95 & .15 & .04 & 1 & $24.37 * * *$ & 5 \\
4 & 9.38 & 7 & .23 & 1.34 & .98 & .88 & .99 & .06 & .03 & 1 & 7.83 & 5 \\
\hline
\end{tabular}


Finally, the Partner parameters were constrained to be equal. Comparison between the thus constrained (model 4) and the unconstrained model (model 1) was nonsignificant indicating that fathers and mothers did not differ in respect of Partner effects; therefore the partners in the study influenced each other equally.

\section{Summary of Part two of Chapter 3}

In this section of Chapter 3 the predictors of SIC were proposed and tested. In order to consider what might motivate parents to engage in silent conflict, relevant theoretical concepts and empirical findings including the Dual Concern Model (Pruitt \& Kim, 2004) and the effects of children on parents were critically discussed (e. g. Ambert, 2001; Kerr \& Stattin, 2003; Maccoby, 2003a). Additionally, as it was expected that SIC-related processes might differ for mothers and fathers, pertinent findings related to gender and conflict (e. g. Christensen \& Heavey, 1990; Gottman \& Krokoff, 1989; Kluwer, et al., 1997; Roberts, 2000) were considered and critiqued.

Own avoidance of conflict, partner's hostility and concern for children were proposed as predictors of SIC guided by my qualitative findings (Kielpikowski, 2004; Kielpikowski \& Pryor, 2008). Separate concurrent and longitudinal structural models were tested for fathers and mothers. Due to the preliminary nature of the findings a conservative approach was taken focusing on the consistency of findings concurrently and over time.

Own avoidance of conflict and concern for children emerged as consistent concurrent and longitudinal predictors of SIC for fathers. In contrast, hostility from partner and concern for children predicted SIC concurrently for mothers, with partner's hostility the only consistent predictor both concurrently and over time. 
One of the aims of this investigation was to explore the process of SIC from the dyadic perspective of the parental subsystem, looking at the potential mutual influences between partners. The reciprocity of influences was tested using a version of Actor Partner Interdependence Model (Kenny, et al., 2006) both concurrently and longitudinally. A consistent significant Partner effect was found at Time1 and Time 2 for the path from fathers' avoidant behaviour to mothers' SIC. Mothers and fathers differed significantly on the Actor effects over time, with fathers' standardised path coefficient higher than mothers' for own avoidance and mothers' higher than fathers' on partner's hostility. No significant differences were found for Partner effects over time. The hypothesised interdependence of mothers' and fathers' processes was partially supported concurrently, but not longitudinally.

In sum, the results largely supported the hypothesised predictors of SIC (H1). Additionally, in support of Hypothesis 2, different processes were indicated for men and women in the sample pointing to distinct paths to silent conflict related to the role played within a couple and within a family.

Own conflict avoidant behaviour proved a robust concurrent and longitudinal predictor of SIC for men, but not for women. Additionally, women's perceptions of SIC were concurrently affected by men's perceptions of their own avoidance. These findings underscore the significance of the avoidant stance within men's repertoire of conflict behaviours. They also appear to echo the thread of research portraying men as characteristically avoidant, especially in response to women's more approaching and expressive tactics (Christensen \& Heavey, 1990; Gottman, 1994) and the existing evidence of men displaying more avoidance than women (e. g. Stanley \& Markman, 1996). As in this study no 
significant differences were found between the sexes on their self reports of conflict avoidance, the finding indicates the importance of the processes leading to SIC for mothers and fathers, rather than of their level of endorsement of particular conflict behaviours.

Interestingly, hostility from partner was found to be the consistent concurrent and longitudinal predictor of SIC for women. It is possible that women in this study perceived SIC as a consequence of hostile encounters with their partners, a proposition that would suggest that according to them anger expressed by their partners turned into SIC rather than ending in a resolution or reconciliation. This interpretation concurs with the findings of my qualitative work (Kielpikowski, 2004; Kielpikowski \& Pryor, 2008), whereby the participants reported that silent conflicts with their partners stemmed from unresolved differences of opinion or arguments that were abandoned.

Concern for children acted as a concurrent predictor of SIC for women and as both a concurrent and a longitudinal predictor of SIC for men. This finding is of particular significance for several reasons. The predictor, hypothesised on the basis of my interview data (Kielpikowski, 2004), provides an insight into parental motivation leading to SIC, which is not related to self or the spouse, therefore lies outside the quadrants charted by the Dual Concern Model (Pruitt \& Kim, 2004). It appears that for mothers the motivation was solely situational, whereas for fathers concern for children acted as a concurrent predictor, however, additionally predicted silent discord over time. The longitudinal relationship between child concern and SIC for fathers indicates that for them SIC is not only a momentarily motivated method of managing the effects of interparental discord on children, but that it may also stems from motivation that acts over time. The 
predictive significance of 'child concern' supports the concept of child effect (Ambert, 2001) and illustrates how in response to children parents adapt their behaviours (Kerr \& Stattin, 2003). It also demonstrates that agentic actions from children are not necessary to induce the child effect on parents. Finally, the finding resoundingly signals a difference between couples and parents, as the predictor applies uniquely to the latter group.

In this chapter I attempted gaining some understanding of the motives that compel parents to engage in silent conflict and the mechanisms behind the effects the constituents of silent conflict exert on psychological wellbeing of the involved parents. The results of the studies from Part one and Part two of this chapter allowed me to conclude that the hypothesised processes were generally supported. Importantly for further investigations, the findings highlighted the significant differences found between mothers and fathers in the processes leading to SIC, as well as in the ways that SIC affected their psychological adjustment. 


\title{
Chapter 4: In a World of Their Own? Adolescents' Perceptions of Silent Interparental Conflict and Its Effects on Their Psychological Adjustment
}

\begin{abstract}
I don't know that they are aware of it... Maybe it's because kids are quite egocentric, they kind of think about themselves a lot and just wander around in this sort of bubble a lot of the time. And they're just not aware of the other things that are going on; especially if they're thinking 'I want to go and watch TV or read a book'.

(Female, 42)
\end{abstract}

Are children indeed oblivious to silent conflicts between their parents, as observed by a mother participating in my qualitative study cited at the opening of this chapter (Kielpikowski, 2004)? Not according to the findings of Pryor and Pattison (2007). Recall from Chapter 1, that indications of negative impact of nonverbal and non-physical interparental conflict on children's wellbeing gleaned from a handful of studies (De Arth-Pendley \& Cummings, 2002; Goeke-Morey, et al., 2003; Tschann, et al., 1999) compelled these researchers to begin a process of inquiry. Their findings of their study with 27 young New Zealanders showed that during such 'silent' conflicts, the young people experienced a tense and uneasy emotional atmosphere between their parents, which coloured the interactions within the whole family. The parents avoided contact with each other and also withdrew from other family members. There was an accompanying sense of unresolved differences that endured unexpressed. The young people in the study experienced silent interparental conflicts as unsettling, confusing and beyond their control, causing them to feel helpless and even blame themselves for the problems. In sum, the young participants in Pryor and Pattison's study (2007) appeared to be both aware of silent interparental disagreements and affected by them. 
The aim of this chapter was to gain further understanding of the young people's perspective on silent interparental conflict and to examine the mechanisms behind the effects this conflict might have on their psychological wellbeing. This was attempted on the basis of quantitative analyses of longitudinal data collected from a sample of adolescent children, who participated in this research project with their parents.

The chapter consists of three studies. In the first study, the psychometric instrument for the measurement of adolescents' perceptions of silent interparental conflict (APSIC) designed by Pryor (2003) was subjected to a validation procedure in order to corroborate its factorial structure. To that end confirmatory factor analyses were conducted at two measurement points separated by one year.

The second study comprised analyses of the processes linking APSIC with adolescents' psychological adjustment. Explanatory process models of the effects of APSIC on adolescents' functioning were hypothesised and tested using the cognitive-contextual framework (Grych \& Fincham, 1990) and the spillover hypothesis (Erel \& Burman, 1995). The young people's functioning was conceptualised as bi-valenced and consisting of maladjustment measured with the Strengths and Difficulties Questionnaire (Goodman, et al., 1998) and of wellbeing measured with the Future Outlook scale designed for this study.

The aim of the third study was to attempt bringing together the perspectives of parents and adolescents. To that end the process of the effects of SIC on adolescents' wellbeing was modelled using parents' reports of silent conflict alongside adolescents' in the spillover based structural models. The approach reflects the systemic nature of family processes and is recognised as 
methodologically advantageous in reducing method variance confounds (Paley, et al., 2000).

\section{STUDY 1}

The item pool for the instrument for the measurement of adolescents' perceptions of silent interparental conflict was designed by Pryor (2003) on the basis of the findings of a preliminary qualitative study, in which young people were asked about their experiences of non-verbal non-physical conflicts between their parents. The items reflected the descriptions of silent interparental conflict episodes, as well as the attendant cognitions and emotions described by the young interviewees. The scale is presented in Appendix I. The proposed measure consisted of seventeen positively formulated items scored on a Likert scale from one (never) to four (very often). Care was taken to use language that was accessible to young participants and to avoid semantic ambiguity. Examples of the items are: 'When they are cross with each other, my parents avoid each other around the house.'; 'One or other of my parents refuses to talk when things are not right between them.'; 'I feel as if I am to blame for their unhappiness with each other.'

Pryor conducted an exploratory factor analysis (Principal Component Analysis) to establish the structure of the measure with data collected from 242 undergraduate psychology students (Pryor, 2003). In order to test the conceptual distinctiveness of the construct of silent interparental conflict from verbal interparental conflict, items representing the latter were also included in the administered questionnaire. It was expected that the two types of conflict would be distinct; therefore, the items representing each of them were hypothesised to load uniquely on discrete factors. As a result of the exploratory factor analysis, 
five factors of adolescent-perceived interparental conflict were identified. The obtained factors were provisionally labelled: Verbal conflict; Silent conflict; Distress, Self blame, and Threat. The last three factors comprised items designed specifically to reflect the young people's appraisals of SIC, rather than any other form of parental discord. The composition of these items echoed the structure of appraisals proposed by Grych and colleagues (Grych, Seid, \& Fincham, 1992). Cronbach's alphas obtained for the factors were satisfactory ranging from .72 to .90 (J. E. Pryor, personal communication, August, 17, 2010). The EFA provided crucial direction in the shaping of the measure, as the distinction between the silent and verbal modes of interparental conflict was supported. Consequently, it was concluded that after excluding the Verbal conflict factor, the four factor (Silent conflict, Distress, Self blame and Threat) structure of Adolescents' Perceptions of Silent Interparental Conflict Scale (APSICS) could be accepted.

The aim of the current study was to verify the proposed four- factor structure of the APSICS. Confirmatory factor analyses (CFA) were conducted using the statistical procedure of structural equation modelling with the data collected from a sample of adolescents at two time points separated by approximately one year. 


\section{Part 1 of Study 1 - Time 1}

\section{Method $^{22}$}

\section{Participants}

Sixty six girls and sixty eight boys, who returned completed questionnaires after the initial round of data collection (Time 1), comprised the sample. The young people were between 12 and 16 years of age at the first point of measurement $(M=14.37, S D=1.23)$. The ethnic composition of the sample mirrored the parents' sample in over-representing New Zealand Europeans. The young people reported their ethnic identities as follows: 74\% European/Pakeha, 5\% Maori, 2\% Pacific Nation, 11\% other European, 3\% Other; and seven adolescents did not provide ethnicity information.

\section{Measures $^{23}$}

The measure of adolescents' perceptions of silent interparental conflict (APSIC) was developed by Pryor on the basis of qualitative interviews with young people (Pryor, 2003). The items of the APSICS are rated on a Likert scale scored from one (never) to four (very often); higher scores reflect higher perceived frequencies.

\section{Data screening}

Data were screened for non-normality of distribution and missing values prior to conducting the confirmatory factor analysis. None of the variables were found to be overly skewed or kurtotic according to the accepted criteria (R. B. Kline, 2005, p. 50; Tabachnick \& Fidell, 2007, pp. 79-83). Examination of the

\footnotetext{
${ }^{22}$ The recruitment process, the procedure for the whole family and the demographic details of the parents were described in Chapter 2.

${ }^{23}$ The APSIC was administered to adolescents as a part of a battery of measures described further in Study 2 of this chapter.
} 
missing values patterns revealed that three cases in the dataset were missing seven or more values; these cases were deleted. Additionally, six cases were found to be missing one value and for those cases data were imputed using the series mean substitution function of SPSS 16.0. The final sample for CFA at Time 1 consisted of 131 adolescents (65 girls and 66 boys).

\section{Results}

In this study, the entire $\operatorname{APSICS}^{24}$ was administered to the adolescents. However, only four of the seven items constituting the original Silent conflict factor were used in the analyses, as a shorter scale was desirable. This enabled bringing all of the factors to a similar number of items (items 4,5 , and 7 were removed due to their semantic ambiguity) and improved the internal consistency of the factor). Following the same rationale, three items (13, 16 and 17) were omitted from the Distress factor.

Prior to conducting CFA with the Time 1 data, correlations between the factors were computed and Cronbach's alphas for the whole instrument as well as the individual factors were calculated. The whole APSICS and the subscales demonstrated satisfactory reliability. As would be expected, the factors were positively correlated with each other, indicating the relatedness of the perceptions of the incidence of SIC and the cognitive and emotional appraisals; the correlations were moderate except for the strong correlation between the Distress and the Threat factors $(r=.59, p<.01)$. Correlations among the factors of the APSICS, the reliability coefficients and descriptive statistics are presented in Table 4.1.

\footnotetext{
${ }^{24}$ The scale is presented in Appendix I.
} 
Table 4.1. Time 1: APSICS factor intercorrelations, reliability coefficients and descriptive statistics $(N=131)$.

\begin{tabular}{|c|c|c|c|c|c|c|}
\hline & 1 & 2 & 3 & $\begin{array}{c}\text { Number } \\
\text { of } \\
\text { items }\end{array}$ & $\begin{array}{l}\text { Cronbach's } \\
\text { alpha }\end{array}$ & Mean(SD) \\
\hline 1. Silent Conflict T1 & & & & 4 & .72 & $6.42(1.94)$ \\
\hline 2. Distress T1 & $.34 * *$ & & & 3 & .70 & $5.44(1.66)$ \\
\hline 3. Self-blame T1 & $.45^{* *}$ & $.36^{* *}$ & & 2 & .83 & $2.79(1.11)$ \\
\hline 4. Threat T1 & $.36^{* *}$ & $.59 * *$ & $.36 * *$ & 2 & .70 & $3.33(1.29)$ \\
\hline APSICS Total T1 & & & & 11 & .83 & 17.97(4.50) \\
\hline
\end{tabular}

Note. $* * p<.01$.

The shortened version of the measure was subjected to confirmatory factor analysis (CFA) using AMOS 16.0 (Arbuckle, 2006). The model specified that the four factors of the proposed scale covaried with each other and that the measurement errors associated with the indicator variables were unrelated. This was a continuation of the stringent approach favouring model parsimony over fit assumed in similar analyses presented in Chapter 2 .

Standardised coefficients are presented in the resulting model depicted in Figure 4.1. In keeping with the SEM convention, latent variables are represented by ellipses (factors); errors by circles, and manifest variables by rectangles. All of the factor loadings proved to be satisfactory and significant at $p<.001$. It needs to be noted that two-indicator latent factors, such as Self-blame and Threat, are generally seen as problematic and discouraged (e.g. R. B. Kline, 2005); however in this study the factors were retained due to their conceptual significance.

Similarly, the conceptual separateness of Distress from Threat was desirable for theoretical reasons despite the strength of their covariance. 


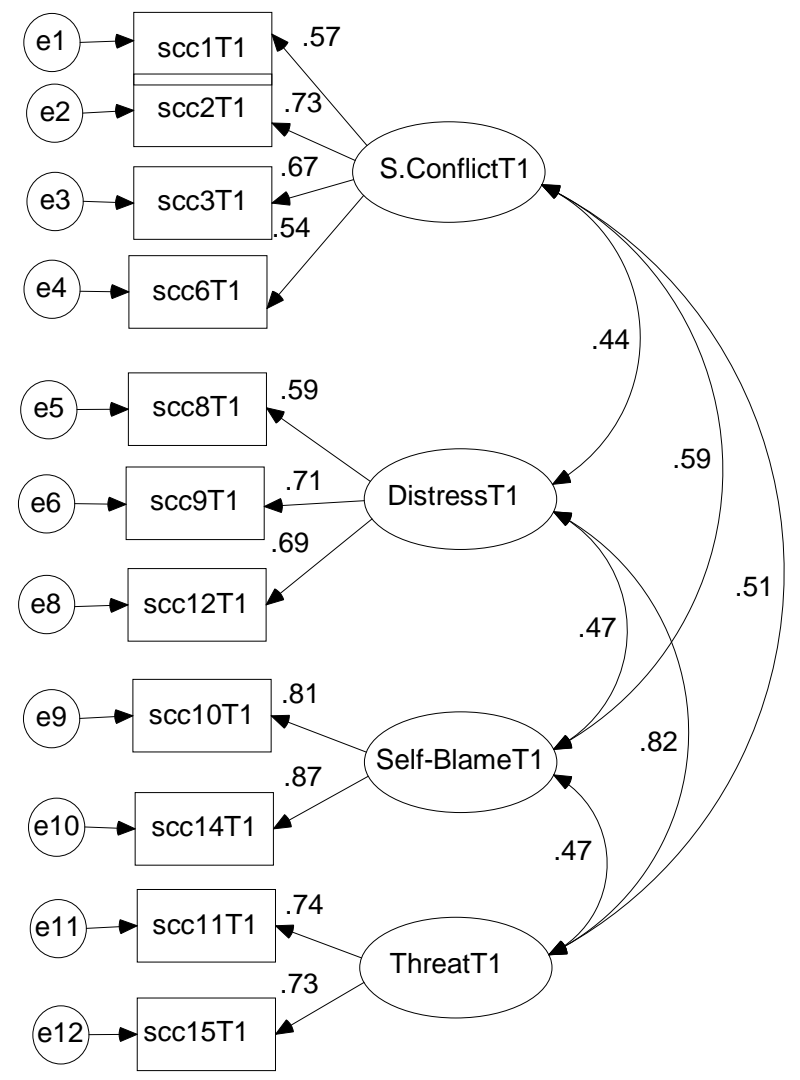

Figure 4.1. Hypothesised four factor model of the APSICS fitted to Time 1 adolescents' data $(\mathrm{N}=131)$; item labels correspond to the content of questionnaire presented in Appendix I.

Several model fit indices were examined in order to establish if the hypothesised APSICS model fit the data well. The indices are presented in Table 4.2 .

Table 4.2. APSICS CFA at T1 - Model fit indices.

\begin{tabular}{llllllllll}
\hline Model & $\chi^{2}$ & $d f$ & $p$ & $\chi / d f^{2}$ & GFI & AGFI & CFI & RMSEA & sRMR \\
\hline T1 & 50.21 & 38 & .09 & 1.32 & .93 & .88 & .97 & .05 & .06
\end{tabular}

Recall that the value of chi-square ratio for a well fitting model ought to be less than 3, and the GFI and AGFI ought to be greater than 0.90 (R. B. Kline, 2005). The desired value of CFI is greater than 0.95 (Byrne, 2001; Kline, 2005). $\mathrm{Hu}$ and Bentler (1999) suggest 0.08 as a value acceptable for sRMR and values 
less than 0.06 for RMSEA. The obtained fit indices for the confirmatory four factor model of the APSICS closely approached the prescribed cut-offs. It may be concluded that the CFA procedure conducted with Time 1 data supported the four factor model of the APSICS proposed by Pryor (2003).

\section{Part 2 of Study 1 - Time 2}

\section{Method $^{25}$}

\section{Participants}

Sixty girls and sixty three boys returned their completed questionnaires at Time 2, approximately one year after the first wave of data collection. (Compared to Time 1 , this represented a loss of eight complete reports, or $6 \%$ of the data.) The ethnic composition of the sample was not altered by the attrition.

\section{Measures $^{26}$}

The Adolescents' Perceptions of Interparental Silent Conflict Scale (APSICS) was described in Part 1 of this Study.

\section{Data screening}

Data were screened for non-normality of distribution and missing values prior to conducting CFA. No non-normality issues were identified according to the accepted guidelines (R. B. Kline, 2005, p. 50; Tabachnick \& Fidell, 2007, pp. 79-83). Examination of the missing values patterns in the dataset revealed that ten

\footnotetext{
${ }^{25}$ The recruitment process, the procedure for the whole family and the demographic details of the parents were described in Chapter 2; the adolescents sample is described in Part 1 of this study.

${ }^{26}$ The APSIC was administered to adolescents as a part of a battery of measures described further in Study 2 of this chapter.
} 
cases were missing one value and for these cases data were imputed using the series mean substitution function of SPSS 16.0.

\section{Results}

The entire APSICS was administered to the adolescents at Time 2; however, as in Part 1 of this Study, the shortened eleven item version of the scale with a four item Silent conflict factor and a three item Distress factor was used in the analyses.

Prior to conducting CFA with the Time 2 data, correlations between the proposed factors were computed and the overall reliability of the eleven item instrument was calculated, as well as Cronbach's alphas for the individual factors. The whole scale and the subscales demonstrated satisfactory reliability. Consistent with the results of Part 1 of this Study, the factors were positively correlated; however, a majority of the correlations at Time 2 were strong ( $r s$ ranging between .50 and $.69 ; p<.01)$. Intercorrelations among the four factors of the APSICS, reliability coefficients and descriptive statistics are presented in Table 4.3.

Table 4.3. Time 2: APSICS factor intercorrelations, reliability coefficients and descriptive statistics $(N=123)$.

\begin{tabular}{lcccccc}
\hline & & & & $\begin{array}{c}\text { Number } \\
\text { of } \\
\text { items }\end{array}$ & $\begin{array}{c}\text { Cronbach's } \\
\text { alpha }\end{array}$ & Mean(SD) \\
& 1 & 2 & 3 & 4 & .75 & $6.44(2.01)$ \\
1. Silent Conflict T2 & & & & 3 & .75 & $5.12(1.71)$ \\
2. Distress T2 & $.33^{* *}$ & & & 2 & .77 & $2.67(1.03)$ \\
3. Self-blame T2 & $.50^{* *}$ & $.51^{* *}$ & & 2 & .73 & $3.12(1.22)$ \\
4. Threat T2 & $.50^{* *}$ & $.69^{* *}$ & $.60^{* *}$ & 2 & & \\
APSICS Total T2 & & & & 11 & .86 & $17.35(4.74)$ \\
\hline
\end{tabular}

Note. ${ }^{*} p<.01$.

The shortened version of the APSICS was subjected to confirmatory factor analysis (CFA) using AMOS 16.0 (Arbuckle, 2006). The hypothesised 
model fitted to the Time 2 data stipulated that the four factors of the APSICS covaried and that the measurement errors associated with the indicator variables were unrelated. This model was a continuation of the rigorous approach favouring model parsimony over fit assumed in Chapter 2 and in Part 1 of this Study.

The standardised results are presented in Figure 4.2. All of the factor loadings were satisfactory and significant at $p<.001$. It needs to be noted that the strong covariance between Distress and Threat observed for Time 1 CFA became even stronger at Time 2. Consistent with the approach taken in Part 1 of this Study, in order to retain the conceptual separateness of Distress and Threat, alternative models of the APSICS were not considered despite the strength of the covariance.

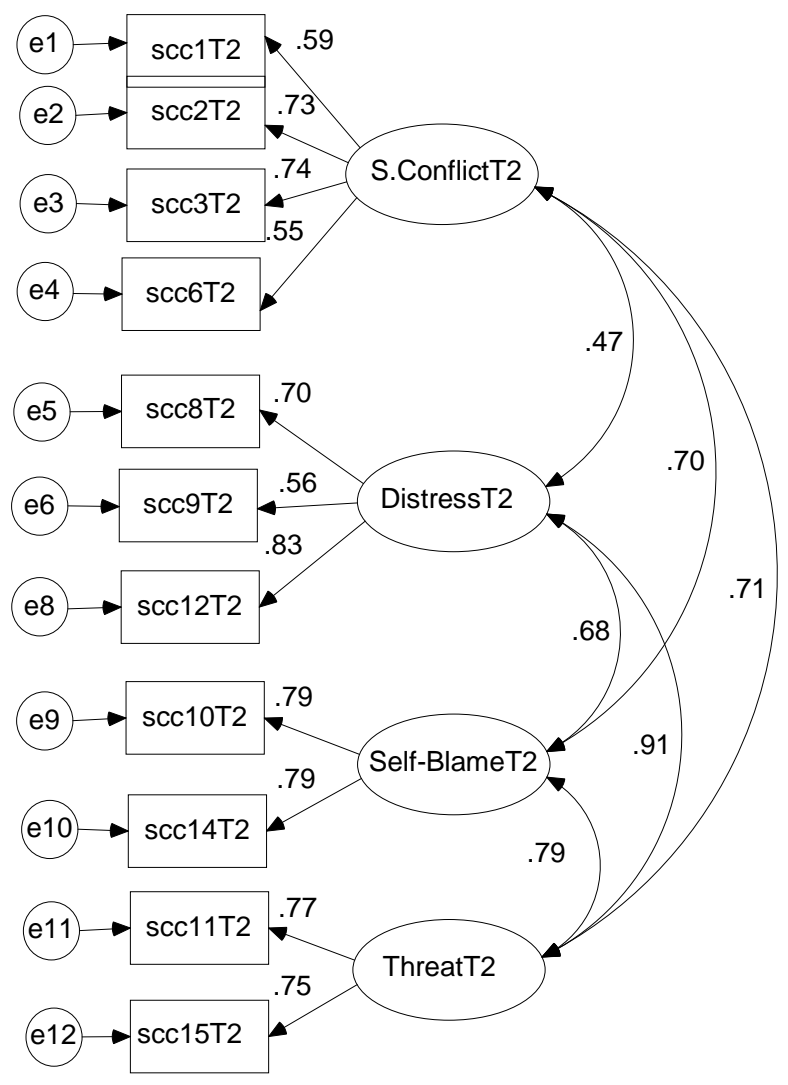

Figure 4.2. Hypothesised four factor model of the APSICS fitted to Time 2 adolescents' data $(\mathrm{N}=123)$; item labels correspond to the content of questionnaire presented in Appendix I. 
The fit indices for the confirmatory four factor model of the APSICS at Time 2 presented in Table 4.4 closely approach the prescribed guidelines (Byrne, 2001; Hu \& Bentler, 1999; R. B. Kline, 2005) and would improve further were the error terms allowed to correlate. This was not done, however, consistent with the approach taken in this work, which favours parsimony over fit.

Table 4.4. CFA T2 - Model fit indices.

\begin{tabular}{llllllllll}
\hline Model & $\chi^{2}$ & $d f$ & $p$ & $\chi / d f^{2}$ & GFI & AGFI & CFI & RMSEA & sRMR \\
\hline T2 & 73.04 & 38 & .01 & 1.92 & .90 & .83 & .93 & .09 & .06 \\
\hline
\end{tabular}

\section{Summary of Study 1}

The purpose of this study presented in two parts was to verify the factorial structure of the APSICS proposed by Pryor (2003). The confirmatory factor analyses conducted with the two waves of data from adolescents produced satisfactory model fit indices in support for the factorial validity of the instrument. Notwithstanding, two caveats need to be acknowledged. First, it would be expected that the robustness of the factor structure would improve with additional items for the two-item Threat and Self-blame factors. Second, an alternative factorial structure could be considered, wherein Threat and Distress are combined, but this was not done in the present case due to a theoretical need to distinguish these two constructs. In sum, however, the results of the conducted CFAs permit confident use of the measure in further process-oriented analyses.

\section{STUDY 2}

In this study two theoretical perspectives were applied in proposing explanatory models of the effects of SIC on adolescents' functioning. The first was the cognitive-contextual framework (Grych \& Fincham, 1990), used to test 
the role of adolescents' appraisals of SIC on their adjustment. The second was the spillover hypothesis (Erel \& Burman, 1995), used to explore the role of the relational dynamic of parental hostility toward the adolescents in the context of SIC on young people's psychological functioning.

\section{The cognitive-contextual framework}

It is unquestionable that children must not be seen simply as indifferent and passive bystanders witnessing their parents' interactions, instead when faced with an interparental disagreement, they inevitably attempt to make sense of the experience and its significance for them. This premise was taken up by Grych and Fincham $^{27}$ (1990), who proposed a cognitive-contextual framework for investigating children's responses to interparental conflict. In designing the framework the authors drew on the stress and coping work of Richard Lazarus and his formulation of the process of appraisal of stressful events (Lazarus, 1991; Lazarus \& Folkman, 1984). As a result, parental disagreements were conceptualised as stressors encountered by children and appraised in a two-stage process. According to the framework, during the initial primary processing, children appraise the properties of conflict including its intensity, content, resolution, and their relevance to them. Consequently, it has been argued that interparental disagreements on the subject of children are of particular consequence to children's adjustment as they may perceive them as particularly salient and threatening (Grych \& Fincham, 1993). The purpose of primary processing is to appraise the potential threat posed by a parental disagreement. Within the cognitive-contextual framework threat is conceptualised broadly, from

\footnotetext{
${ }^{27}$ Grych and Fincham illustrate individual aspects of the framework with the findings of contemporary research by Kurdek, Compas, Rutter, Hetherington, and E. M. Cummings, among others.
} 
immediately affecting children's physical or emotional wellbeing, to implying the possibility of a future breakdown of the parental relationship and the family. Although the subtlety of the appraisal process increases developmentally, even infants recognise angry facial and vocal expressions (e.g. Grych \& CardozaFernandes, 2001), an ability which may be interpreted as adaptive recognition of potential threats to survival.

If the process of appraisal of an episode of interparental conflict results in children concluding that it is non-threatening and irrelevant to them, they may turn their attention away from it. Otherwise, they proceed to the second stage of appraisal labelled secondary processing. Grych and Fincham (1990) propose that secondary processing consists of construing the causal attributions, attributions of blame for the arising of the conflict, as well as the appraisals of children's own coping efficacy. Once again, the style and substance of secondary processing is based on children's development and the related capacity for causal and hypothetical reasoning. For example, due to their relatively egocentric perspective on the world, young children may find it difficult to recognise the separateness of the parental and the parent-child relationships and to consequently look to themselves for the causes of interparental conflicts and to blame themselves for them. Older children and adolescents, who are capable of recognising multiple factors contributing to interparental conflict, such as previous experiences of discord or parental personality traits, may be able to make more accurate causal attributions and therefore are less likely to ascribe blame for interparental disagreements to themselves (Grych \& Fincham, 1990). 


\section{Contextual factors}

Grych and Fincham differentiate between distal and proximal contextual factors that influence the way children respond to interparental conflicts. The psychological aspects of context are considered to be of particular interest, and the authors recognise their relative importance over factors such as the physical setting.

Distal context encompasses such factors as children's previous experiences of interparental conflict; perceptions of the emotional climate in the family, including the quality of parent-child relationships; children's temperament; and gender. For example, perceiving one's family environment as warm and supportive has been found to act as a protective factor against stressors; a similarly buffering effect have positive perceptions of the parent-child relationship (e. g. Forehand, et al., 1991).

The contribution of temperament rests mainly on individual differences in children's sensitivity and reactivity to stressors and their general responding predispositions (e.g. aggression, sadness). It needs to be recognised that the contextual elements interact; therefore, a child's temperament is not inconsequential to the development of the parent-child relationship, and in turn also the child's perception of its quality.

The effect of gender on children's responding to stressors, such as interparental conflict, is conceptualised within the cognitive-contextual framework as arising from differential socialisation of girls and boys and the related gender-specific social expectations of their behaviours. Accordingly, regardless of their predispositions, children are expected to react to parental disagreements in keeping with their socialisation. As social expectations operate 
not only prescriptively, but also proscriptively, therefore, instead of delineating specific gender-appropriate behaviours, they may define the inappropriate ones. To illustrate, in response to stressors, girls are not socially expected to respond with aggression and equally, boys are not expected to respond with emotional displays of sadness or crying.

The elements of distal context are essentially stable and enduring. In contrast, the nature of proximal context is fleeting and momentary, dictated by its immediate relatedness to a particular episode of interparental conflict. Regardless of the transitory nature of proximal context, according to Grych and Fincham, its influence on processing is significant. The two main constituents of proximal context are children's expectations for the course of conflict and children's mood at the time of conflict.

The contextual factors co-occur and affect one another; therefore, the expectations of the course of conflict are influenced by a combination of the characteristics of the current disagreement and by children's previous experiences of interparental conflicts. Consequently, children who have experienced intense and unresolved exchanges between their parents might feel greater threat and distress even during relatively benign interparental disputes. The converse may be true of children whose parents as a rule resolve their conflicts successfully and beyond doubt. Thus, previous experiences of interparental conflict act as primers for children's appraisals.

The affective state of children preceding an encounter of interparental conflict is important to how they experience the stressfulness of the situation. Consequently, negative affect may amplify the distress; conversely, positive 
affect may alleviate it, unless the disagreement is particularly hostile or protracted.

The role of affect

Grych and Fincham (1990) note that regardless of children's affective state prior to encountering an episode of interparental conflict, witnessing a parental disagreement is likely to trigger a negative affective response in them, which in turn influences their appraisal process. For example, children may become emotionally overwhelmed by an argument between parents and react by crying instead of proceeding with cognitive processing. However, the appraisal process also influences and shapes the particular emotional outcome of the experience of interparental conflict. Therefore, for example, ascribing responsibility and blame for conflicts to one parent may influence the child's relationship with that parent, the child's emotional security in the family system, and the future expectations of intimate relationships in general.

\section{Links between appraisals and adjustment}

The cognitive-contextual framework organises the process by which exposure to interparental conflict leads to maladjustment of children, linking appraisals of threat and self-blame with internalising problems in particular. The suggested pathways from parental discord to youth maladjustment have been tested in numerous studies hypothesising appraisals as mediators of the $\operatorname{link}^{28}$. Thus far, however, the findings have largely eluded firm systematisation, and it is not possible to unequivocally connect particular appraisals with particular outcomes. This is hardly unexpected considering the complexity of the framework

\footnotetext{
${ }^{28}$ For an exception see a study by Kerig (1998b), where appraisals were conceptualised as both mediators and moderators.
} 
and the interrelatedness of its components. Additionally, the dimension of time seems to influence the operation of processes, as they appear to differ concurrently and over time.

To date, the most consistent empirical support has been found for the link between the appraisal of threat and children's internalising problems (Dadds, et al., 1999; Fosco \& Grych, 2008; Grych, et al., 2000; Grych, et al., 2003; Kerig, 1998a; McDonald \& Grych, 2006). However, Grych, Harold, and Miles (2003) have also found that over time threat predicted externalising problems for boys. Having noted that the finding contradicted the stipulations of the cognitivecontextual hypotheses, these scholars tentatively explained the result as boys' angry reaction to threat.

Findings related to the mediating role of self-blame appear to indicate that it acts as a mediator for both internalising and externalising. Most cross-sectional studies have demonstrated links between self-blame and internalising, but not externalising (Dadds, et al., 1999; Grych, et al., 2000; Kerig, 1998a), although Grych and colleagues (2003) found this association only for girls. However, in their study, externalising problems were predicted by self blame both concurrently and longitudinally for children of both sexes. The association between exposure to interparental conflict and externalising through self blame was also found in a longitudinal study by Dadds and colleagues (1999) for boys, whereas a cross-sectional study of Fosco and Grych (2008) found self blame to be concurrently associated to both internalising and externalising problems. Compellingly, studies assessing multiple mediators conducted by Davies, Harold, Goeke-Morey and Cummings (2002), Gerard, Buehler, Franck and Anderson (2005) and Buehler, Lange and Franck (2007) found that self-blame predicted 
both internalising and externalising problems. Fosco and Grych (2008) suggest that the internalising symptoms such as shame, helplessness and sadness may be related to self-blame when children believe that they have caused the discord or that they ought to repair the parental falling out, but feel unable to do so. In contrast, externalising problems may arise when self-blaming children engage in disruptive behaviours in an attempt to end interparental disagreements (Davis, Hops, Albert, \& Sheeber, 1998).

The cognitive-contextual framework attempts to comprehensively map the mechanisms of the direct effects of interparental conflict on children. The framework takes the perspective of children. Accordingly, the fluctuations in the parental relationship, including episodes of conflict, may be interpreted as contextual/environmental factors affecting children's functioning. However, from a systemic perspective (Cox \& Paley, 1997), strain within the marital subsystem may be expected to affect its interactions with other subsystems and the functioning of the greater family system. Therefore, in order to fully explain the systemic effect of interparental conflict on children's adjustment the indirect pathways also need to be considered.

The spillover hypothesis

Conceptual and empirical attempts at explaining the indirect effects of interparental conflict on children's adjustment have focused mainly on the quality of parent-child relationship and of parenting practices. This approach concurs with the conceptualisation of interparental conflict by Fauber and Long (1991) as a contextual factor contributing to compromised parenting practices that affect children directly and with the findings of a meta-analytic study by Erel and 
Burman (1995), who identified a process of transmission (spillover) of conflictrelated marital affect into parent-child relationships.

The spillover hypothesis proposes that the behaviours and affect predominating in a marital relationship are transferred to relationships with children and are observable especially in the deterioration of parenting practices and their effectiveness. Accordingly, conflicted parents may enforce atypically harsh discipline, exercise diminished control or be inconsistent in their parenting approach. Additionally, preoccupation with marital disagreements may reduce parental emotional availability to children, which is demonstrated by lower levels of empathy, support and acceptance (Cox, Paley, \& Harter, 2001; Krishnakumar \& Buehler, 2000).

The hypothesis has received substantial empirical support from both crosssectional and longitudinal studies (Buehler \& Gerard, 2002; Gerard, Krishnakumar, \& Buehler, 2006; Harold \& Conger, 1997; Schoppe-Sullivan, Schermerhorn, \& Cummings, 2007). Scholars use process-oriented models to hypothesise and test the mediational effects of various dimensions of the parentchild relationship on the link between interparental conflict and children's adjustment. The proposed mediators have included marital conflict related parental hostility aimed at adolescents, various aspects of parenting and parentchild conflict.

One of the first longitudinal studies that provided support for the mediating role of the parent-child relationship was conducted by Harold and Conger (1997) with nearly 400 Midwestern adolescents. The findings of the study indicated that interparental conflict affected adolescents' psychological distress 
indirectly through parents' and observers' reports of parental hostility towards the adolescents and through adolescents' awareness of interparental conflict.

In a more recent cross-sectional study with a large sample of early adolescents, Benson, Buehler and Gerard (2008) tested the mediational role of four dimensions of maternal parenting (acceptance, harsh parenting, inconsistency and intrusiveness). Each of the parenting dimensions acted as a partial mediator of the relationship between interparental hostility and the young people's internalising and externalising problems.

Longitudinal process models posing dimensions of parenting (behavioural control, psychological autonomy and warmth) as mediators of interparental conflict on children's adjustment were tested by Schoppe-Sullivan, Schermerhorn and Cummings (2007). The results of the study showed that having controlled for the initial level of adjustment, behaviour control partially mediated the effects of interparental conflict on children's internalising problems.

Harsh discipline and parent-child conflict mediated the concurrent relationship between marital conflict and children's externalising problems in a study by Gerard, Krishnakumar and Buehler (2006). Parent-youth conflict was a mediator of both the concurrent and longitudinal effects of conflict on internalising problems.

As illustrated by the preceding selection of studies, the available findings provide consistent support for the indirect pathway of influence from interparental conflict to children's adjustment through the symptoms of deterioration in the parent-child relationship. However, the findings lack consistency regarding which areas of children's functioning are affected (internalising, externalising, or both) and the disparity of results remains largely unexplained. Similarly inconclusive 
are the findings in respect to the moderating role of children's gender on the causal pathways.

\section{Gender differences}

The effects of interparental conflict on boys and girls have largely eluded systematisation. Two main theoretical perspectives guiding scholarly attempts to understand the moderating role of child gender on the pathway between marital conflict and child adjustment have been the male vulnerability model and the differential reactivity model (P. T. Davies \& Lindsay, 2001).

The differential reactivity model poses that children express distress in different gender-specific ways; therefore, in accordance with gender-prevalent psychological problems, boys are more prone to externalising symptoms and girls to internalising symptoms (Zahn-Waxler, 1993). According to the male vulnerability model, boys are more affected by the harmful effects of interparental conflict than girls, a hypothesis that is effectively opposite to the application of the concept of differential socialisation of boys and girls (discussed in Chapter 3) in the process of explaining the effects of interparental conflict on children. Recall that the differential socialisation concept has been employed to suggest greater susceptibility of girls to dysfunctions in family relationships (Davies \& Lindsay, 2004). Accordingly, due to their relational and communal orientation, girls may be more aware of the state of the parental relationship and more worried about the consequences of any relational disruptions for the parents, themselves and the whole family unit, therefore more affected by them.

Notably, none of these theoretical perspectives has found convincingly consistent support. As a result, a general agreement appears to be emerging 
among researchers that interparental conflict represents comparable risk to children of both genders (Schoppe-Sullivan, et al., 2007).

One more aspect deserving recognition within the research sphere of the effects of interparental conflicts on children's outcomes is the additional level of complexity that arises from inclusion of parental gender and parent-child gender constellations in the analyses. In an attempt to clarify the complexities, Crockenberg and Forgays (1996) proposed a conceptual framework incorporating a blend of social learning and systems theories for explaining the differential outcomes for boys and girls in relation to the behaviours of mothers and fathers in conflict. According to the framework, children identify with the same sex parents and model their behaviours (the social learning component). Therefore, argue the authors, the child's perception of power and efficacy demonstrated in a conflict situation by the same-sex parent imparts to the child a similar sense of power and efficacy, which may be either high or low. Accordingly, perceptions of the samesex parents' powerlessness and sadness increase children's risk of internalising problems (P. T. Davies \& Lindsay, 2001). Because children identify with their same-sex parents, in situations of interparental conflict, they may generalise to themselves the partner-directed hostility of the opposite-sex parents and consider themselves the objects of parental anger (the systems theory component).

The framework maps out complex relational mechanisms suggesting that children's wellbeing is a product of not only identification with the same-sex parents, but also of the perceptions of their relationships with the opposite-sex parents. Although some empirical support for the framework has been found, there are also findings that counter it (P. T. Davies \& Lindsay, 2001). Therefore, 
at this point in time, the effects of parent-child gender constellations on parental conflict related children's outcomes still cannot be meaningfully systematised.

The general absence of consistency in findings is undoubtedly attributable to the complexity of the involved processes, which is also reflected in the explanatory frameworks that attempt to capture them, a point demonstrated earlier in this chapter with the examples of cognitive mediators in relation to the cognitive-contextual framework. Recognising the intricacy of the involved processes and the accompanying empirical inconsistencies, Davies and Lindsay (2001) put forward the following challenge: “...a key task facing researchers is to try to uncover the wide range of developmental and socialization pathways that lead to multifinality...". In sum, it may be concluded that although the specific outcomes cannot be predicted, given the present state of knowledge of the involved phenomena, the available evidence indicates that they cannot be assumed to be the same. In other words, although we do not know how the outcomes will differ, we have enough evidence to expect them to differ, which in turn does not permit us to expect them to be the same and analyse them as such.

\section{Relevance to silent interparental conflict}

In trying to explain how silent interparental conflict may affect children's adjustment with the aid of the cognitive-contextual framework, it is necessary to conceptualise the arising of a stressful situation. Why may SIC be stressful to children if it is not expressed through aggressive behaviours and words between parents?

It needs to be remembered that children's language acquisition and with it the ability to use silence communicatively, occurs very much in the same way as their acquisition of other linguistic skills. Moreover, linguists observe that not 
only is it a skill that comes late in child development, but also that children in general characterise themselves with low tolerance of communicative silences compared to their relatively advanced linguistic/communicative ability (Jaworski, 1993). Therefore, silences between their parents are unlikely to either pass unnoticed or be interpreted as affectively neutral. Additionally, the social norms held in Western society that operate for parents, also apply to children. Therefore, in acquiring these skills, children develop an awareness of the socially normative presence of talk and to the rule being broken by their parents during an episode of SIC. Moreover, the inherent closeness of family relationships affords children an 'insider view', which enables them to accurately recognise the variations from baseline behaviours between the parents. Some evidence may be found in the reports of the adolescents in the study of Pryor and Pattison (2007). Although lacking in verbal intensity, SIC has been identified and described as accompanied by relational tension by the young people in the study.

It has been shown that the awareness of parents resolving their differences, whether it takes place in their presence or behind closed doors, is important to children's wellbeing (E. M. Cummings, Ballard, El-Sheikh, \& Lake, 1991; E. M. Cummings, Simpson, \& Wilson, 1993). As silent interparental conflict is not articulated, it is likely not to end in an explicit resolution or any resolution at all, as indicated by my qualitative findings (Kielpikowski, 2004; Kielpikowski \& Pryor, 2008). Additionally, the obscurity of the content of SIC invites speculations; consequently, SIC may cause children to wonder whether they might be its subject, whether the relationship between their parents is in jeopardy and what the implications might be for the whole family unit. In sum, it is very likely that SIC is the type of interparental conflict that is not dismissed as 
irrelevant and unthreatening, but rather that it triggers causal attributions and attributions of blame in the children who are exposed to it.

Indications that a conflict spillover process accompanies episodes of SIC could be gleaned from my qualitative work preceding this investigation (Kielpikowski, 2004; Kielpikowski \& Pryor, 2008; Pryor \& Pattison, 2007). The interviewed parents reported that when engaged in silent conflict with their partners they were not only distracted and preoccupied, but also at times irritable and impatient in their relations with children. These reports suggest that the negative affect unexpressed by parents within the marital subsystem my have been instead released in the parent-child subsystem.

The following extracts serve as an illustration:

You snap at them over something very little and you shouldn't have done that. (Male, 27)

(It) affects me with relation to the kids, I'd snap at them and I'd be grumpy with them, be like a little Hitler at home. (Female, 45)

Overall, the blueprint mapped out by the cognitive-contextual framework and the spillover hypothesis appears highly appropriate for testing the working processes of the effects of SIC on the psychological adjustment of children who are exposed to it.

It is undeniable that the novelty of the central construct of SIC and the consequent largely exploratory nature of this research have a bearing on the possible level of precision in formulating the hypotheses. However, in addition to conceptual analogies with existing conflict research, indications of the contemporaneous impact SIC exerts on adolescents' functioning were gleaned from the study of Pryor and Pattison (2007) and from preliminary findings by Pryor (2003) of concurrent associations between SIC and internalising problems. 
Although it was not possible to make exact predictions regarding the longitudinal effects of the adolescents' perceptions of SIC on their wellbeing, their presence was expected. Moreover, exploring the long term consequences of the phenomena comprising the experience of silent interparental conflict for adolescents was seen as at least as important as trying to understand the concurrent ones. If longitudinal linkages between SIC and adjustment were supported by the data from adolescents, there would be a possibility that these patterns persisted over time and maintained the challenges to young people's wellbeing, and thus contributed to its ongoing erosion.

The processes were expected to take place both directly as adolescents' perceptions of SIC influenced their adjustment, and indirectly. The envisaged indirect pathways were through adolescents' appraisals of the experience of SIC, according to the cognitive-contextual framework of Grych and Fincham (1990) and through their perceptions of parental SIC related hostile behaviours directed at them, according to the 'spillover' hypothesis (Erel \& Burman, 1995).

Three outcomes were proposed for testing. The internalising and externalising problems that have been linked to interparental conflict in previous research were hypothesised as the negative outcomes of SIC for adolescents. However, in recognition that a person's successful adjustment encompasses not only the absence of problems, but also a dimension of positive functioning (Keyes, Shmotkin, \& Ryff, 2002; Ryff \& Keyes, 1995), I introduced a construct named "Future Outlook". I theorised that for adolescents to have positive expectations of the future and to envision the future (including the domains of romantic and family relationships) as promising and appealing indicates their positive functioning. This conceptualisation was inspired by several sources. It 
includes an aspect of the motivational impetus of future orientation for present actions and aspirations encapsulated within Kurt Lewin's 'psychological future' (Seginer, 2009). It also draws on the work of Taylor and Brown $(1988,1994)$, who proposed that positively biased perceptions of the self and the world are beneficial to wellbeing, and on Elkind's concept of the 'personal fable' (Elkind, $1967,1985)$, a normative tendency of adolescents to perceive their own lives as special and laden with meaning. As marital dysfunction undermines the functioning of the whole family system and its components, it was expected that SIC would have a detrimental effect on the young people's expectations of the future. Because of the relational aspect of the construct, it was expected that the girls' Future Outlook would be more affected by SIC, and that owing to differential socialisation, their sensitivity to relational interactions and focus on relationships in general would be greater in comparison to that of adolescent boys.

Due to the inconsistency of the findings regarding the pathways between interparental conflict and maladjustment for boys and girls, no further gender specific pathways between SIC and maladjustment of adolescents were hypothesised. However, based on the available empirical evidence, they were hypothesised with confidence to differ between genders.

\section{Hypotheses}

Guided by the findings of the existing research, it was hypothesised that silent interparental conflict would increase adolescents' internalising and externalising symptoms through their appraisals of threat and self-blame as well as through the SIC-related mother's and father's hostility towards them. These effects were expected to occur both situationally and over time. The longitudinal effects were hypothesised to be exerted by a conglomerate of Time 1 phenomena. 
Therefore, it was proposed that the experience of silent conflict between parents and the accompanying adolescents' appraisals of threat and self blame would have long term consequences to adolescent adjustment. Similarly, long term effects were hypothesised to be exerted by experiences of SIC and the ensuing hostility from parents.

SIC was hypothesised to affect the adolescents' outlook on the future both situationally and over time through appraisals of threat and self blame and through perceptions of SIC-related parental hostility directed towards them.

The hypotheses are presented visually in Figures 4.3 and 4.4 .

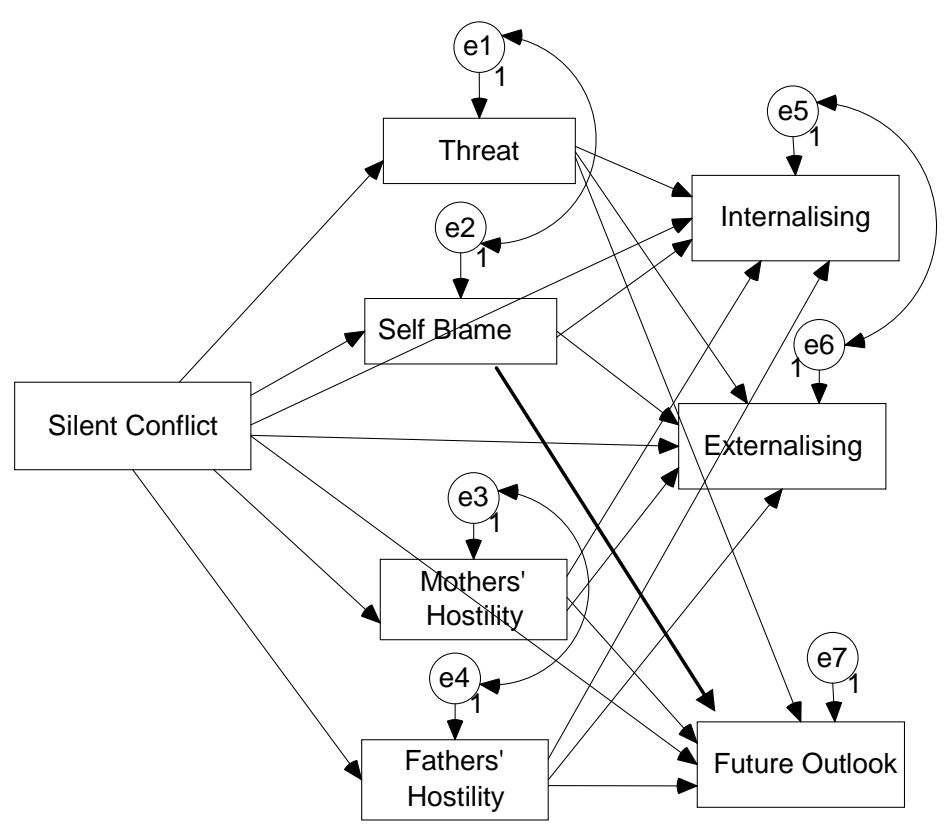

Figure 4.3. Hypothesised cross-sectional process model of the effects of SIC on adolescents' adjustment.

\section{Longitudinal processes}

An essentially identical model was hypothesised to account for the processes of the effects of silent interparental conflict on adolescents' wellbeing over time. 
The only alteration to the model consisted of controlling for the baseline level of adjustment measured at $\mathrm{T} 1$ in order to isolate the change in adjustment.

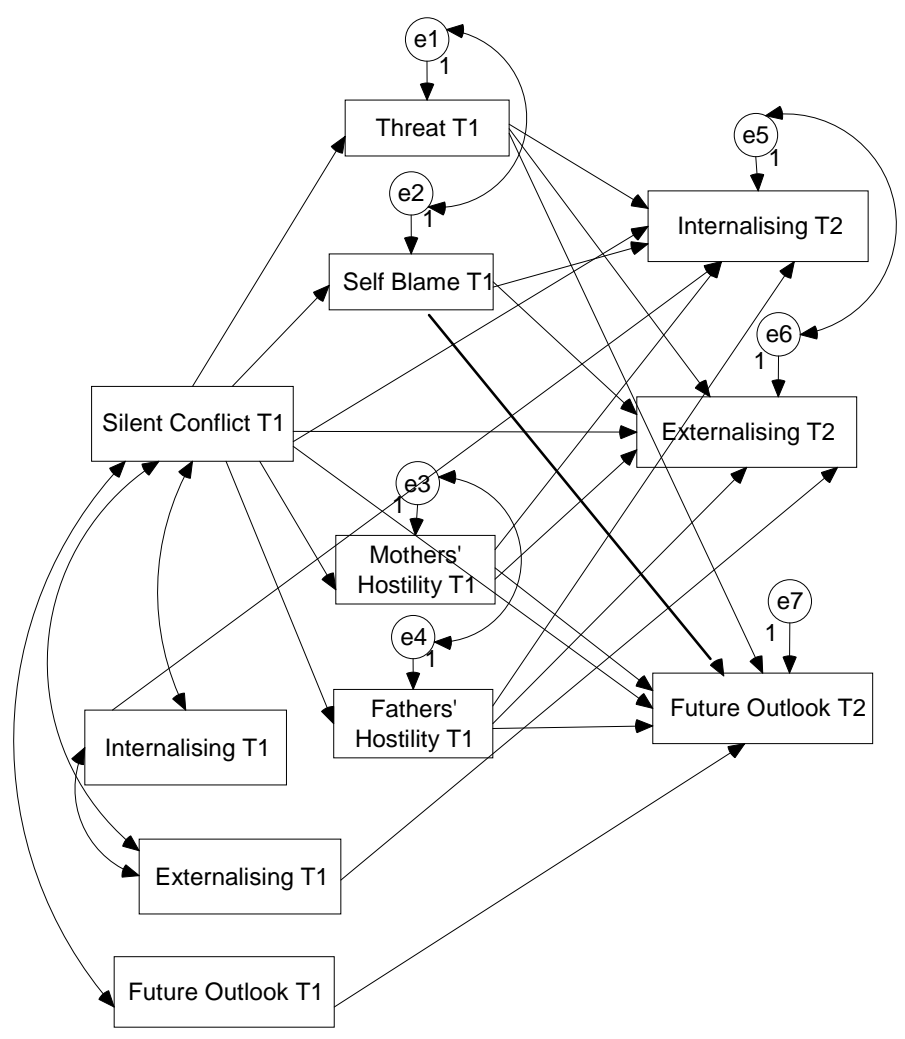

Figure 4.4. Hypothesised process model of the effects of SIC on adolescents' adjustment over time.

\section{Analytic strategy}

The main foci of the analyses were the hypothesised mediation processes. Due to the complexity of the hypothesised process models relative to the sample size, in order to best answer the posed research problems, the following strategy was adopted:

Correlations between the study variables were computed separately for boys and girls in the sample in recognition of previous findings that indicated that 
the processes underlying the effects of interparental conflict on children adjustment were not identical for the genders.

As the hypothesised models centre on mediational processes, the correlations between variables were scrutinised to establish the presence of significant associations between the proposed mediators and the independent and the dependent variables necessary for testing mediation.

Separate mediational path models were built for boys and girls based on the obtained empirical indications.

As a rule, researchers adopt either a 'snapshot' approach by reporting cross-sectional findings obtained on the basis of a single measurement in time, or report a longitudinal process based on two or more measurement points. This enables presenting conclusive and elegant findings, however tells little about the concurrent stability of phenomena at different points of time, as different snapshots are not compared.

In the absence of empirical indications combined with inconsistencies in the findings for boys and girls, I decided to adopt a conservative approach and test the stability of the involved processes by constructing and comparing the concurrent models at Times 1 and 2. The results would communicate not only the presence or absence of process differences between the sexes but also within the sexes at different points of time.

\section{Method}

\section{Participants}

The adolescents' sample comprised 54 girls and 61 boys matching the parental dyads that participated in the two phases of the study, who themselves returned questionnaires at both measurement points. 


\section{Measures}

Adolescents' perceptions and appraisals of interparental conflict were measured with the APSICS described in Study 1 of this chapter. The instrument was used to measure Silent conflict, Self-blame, Distress and Threat.

Parental Hostility towards adolescents was measured with the Hostility subscale used in the Iowa Youth and Family Project (Melby, et al., 1993; Melby, et al., 1995). The items were scored from one (never) to seven (always) on a Likert scale with higher scores representing greater hostility. ${ }^{29}$ Cronbach's $\alpha$ s for the measures obtained at $\mathrm{T} 1$ and $\mathrm{T} 2$ ranged from .88 to .89 .

Adolescents' psychological adjustment was conceptualised and measured in a twofold way, namely as dysfunction as well as positive functioning. Items adapted from the Strengths and Difficulties Questionnaire (SDQ) (Goodman, 1997; Goodman, et al., 1998) were used to measure the young people's adjustment problems. The original scale consists of five subscales: Hyperactivity, Emotional symptoms, Conduct problems, Peer problems, and a positively formulated scale of Prosocial behaviour representing a positive dimension of adjustment. The subscales of Emotional symptoms (corresponding to internalising problems) and of Conduct problems (corresponding to externalising problems) were used in this study ${ }^{30}$. Each subscale consists of five items scored from 0 (not true) to 2 (certainly true). The reverse-scored items are recoded, so that higher scores consistently represent greater difficulties. In this study, the Emotional symptoms subscale produced satisfactory Cronbach's alphas between .67 and .83 , however the Conduct problems subscale proved more problematic, therefore to

\footnotetext{
${ }^{29}$ The subscale is presented in Appendix H; identical scales were administered separately to assess the Mother's and the Father's hostility.

${ }^{30}$ The two subscales are presented in Appendix $\mathbf{J}$.
} 
bring the reliability coefficients to within the acceptable levels, the number of items was reduced to three, by removing the poorly loading items. The resulting Cronbach's alphas fell between .61 and .63. (Comparably, the internal reliability coefficients reported by Goodman (2001) for a community sample of over 5,000 American youth were .66 for Emotional symptoms and .60 for Conduct problems.)

Positive functioning of the participating adolescents was measured with the Future Outlook scale ${ }^{31}$ I newly developed for the study. In designing the scale, I theorised that for adolescents to have positive expectations of the future and to envision the future as appealing indicates their positive functioning. Accordingly, it was expected that the scores for Future Outlook would be relatively high for adolescents in community samples. The scale consists of seven items scored on a Likert scale from one (strongly disagree) to five (strongly agree). Low scores represent low levels of positive functioning. In this study, item number 6 'There are many rewarding things to do' was excluded to optimise the internal reliability of the scale.

\section{Results}

Reliability coefficients and descriptive statistics for all variables in this study are presented in Table 4.5; the intercorrelations are presented in Table 4.6.

The average scores of both boys and girls on Silent Conflict were above the middle point of the scale indicating that adolescents noted moderate frequency of silent conflict between their parents at both measurement times. The average

\footnotetext{
${ }^{31}$ The scale is presented in Appendix K.
} 
scores for Distress, Self blame and Threat at both T1 and T2 were below the middle points of the scales.

Table 4.5. Reliability coefficients for the whole sample and descriptive statistics for boys and girls at Time 1 and Time 2.

\begin{tabular}{|c|c|c|c|c|c|c|}
\hline \multirow{3}{*}{ Scale } & \multicolumn{3}{|c|}{$\mathrm{T} 1$} & \multicolumn{3}{|c|}{$\mathrm{T} 2$} \\
\hline & \multirow{2}{*}{$\begin{array}{c}\text { Cronbach's } \\
\alpha\end{array}$} & \multicolumn{2}{|c|}{ Mean(SD) } & \multirow{2}{*}{$\begin{array}{c}\text { Cronbach's } \\
\alpha\end{array}$} & \multicolumn{2}{|c|}{ Mean(SD) } \\
\hline & & Boys & Girls & & Boys & Girls \\
\hline $\begin{array}{l}\text { Silent } \\
\text { Conflict }\end{array}$ & .71 & $11.86(3.65)$ & $11.86(3.65)$ & .76 & $11.96(3.51)$ & $11.86(3.65)$ \\
\hline Self Blame & .88 & $2.64(.89)$ & $2.64(.89)$ & .79 & $2.64(.92)$ & 2.64(.89) \\
\hline Threat & .64 & $3.36(1.30)$ & $3.36(1.30)$ & .67 & $3.13(1.22)$ & $3.36(1.30)$ \\
\hline $\begin{array}{l}\text { Mother's } \\
\text { Hostility }\end{array}$ & .80 & $12.36(4.66)$ & $12.36(4.66)$ & .80 & $12.11(4.71)$ & $12.36(4.66)$ \\
\hline $\begin{array}{l}\text { Father's } \\
\text { Hostility }\end{array}$ & .87 & $12.55(5.31)$ & $12.55(5.31)$ & .84 & $12.21(4.76)$ & $12.55(5.31)$ \\
\hline Internalising & .67 & $2.64(2.07)$ & $2.64(2.07)$ & .83 & $2.68(2.20)$ & $2.64(2.07)$ \\
\hline Externalising & .61 & $.95(1.10)$ & $.95(1.10)$ & .63 & $1.16(1.32)$ & $.95(1.10)$ \\
\hline $\begin{array}{l}\text { Future } \\
\text { Outlook }\end{array}$ & .83 & $30.60(3.44)$ & $30.60(3.44)$ & .87 & $30.44(3.76)$ & $30.60(3.44)$ \\
\hline
\end{tabular}

The mean comparison showed that the level of threat related to interparental silent conflict reported by the young people was significantly higher than the level of self blame both at Time 1 and Time $2(t=5.64, d f=114$, $p<.001 ; t=5.21, d f=114, p<.001)$. The levels of Emotional symptoms (internalising) reported by the adolescents in the study $(M \mathrm{~s}=2.64$ and $2.68 ; S D \mathrm{~s}$ $=2.07$ and 2.20) were similar to the normative scores obtained from a large national survey of British young people (Meltzer, Gatward, Goodman, \& Ford, 2000) as well as an Australian sample (Mellor, 2005), who reported them between 2.6 and 2.9; SDs between 1.9 and 2.1. In contrast, the level of the reported Conduct problems (externalising) $(M \mathrm{~s}=.95$ and $1.16 ; S D \mathrm{~s}=1.10$ and 1.32$)$ fell below the norms obtained in the British and Australian studies, which were between 1.3 and $2.2 ; S D$ s between 1.5 and 1.7. As expected from a community 
sample, the scores on Future outlook were relatively high at both measurement times.

Analyses of variance conducted for boys and girls on their scores of the frequency of SIC, and the measures of psychological adjustment showed no significant differences between the sexes at either of the measurement points. Similarly, no significant differences were found between males and females for the appraisals of self blame, threat, or father's and mother's hostility towards them.

Scrutiny of the correlations among the study variables showed that the subscales of APSICS at Time 1 and Time 2 were not significantly related. Similarly, the correlations between the $\mathrm{T} 1$ and the $\mathrm{T} 2$ scores for the perceptions of Mother's hostility, Father's hostility and Future Outlook scales were nonsignificant. These results were carefully considered, especially in view of the novelty of the APSIC and the Future Outlook scales. In trying to understand this finding it is helpful to call on DeVellis (2003), according to whom the absence of the temporal stability of a measure must not be understood as simply its test retest unreliability. Factors such as the actual change in the measured construct; fluctuations in the measured phenomenon; changes related to the participants (such as mood or fatigue) all play a part, in addition to the potential score instability associated with the reliability of the instrument or the method of measurement (J. R. Kelly \& McGrath, 1988). Typically, all of these factors are confounded; therefore, their individual contribution is not easily disambiguated. As the confirmatory factor analyses have supported the structural integrity of the construct of APSIC, and the internal reliability of the scale was satisfactory at both measurement times, it is conceivable that the occurrences of silent 
interparental conflict might have been perceived by adolescents as highly situational, separate events. Additionally, developmental changes in adolescents might have taken place between the two measurement times affecting the way they perceived their environment, including interparental conflict, the relationships with their parents, and also how they envisioned their future. 
Table 4.6. Intercorrelations between boys' $(N=61)$ and girls' $(N=54)$ perceptions of SIC, adolescent-directed maternal and paternal hostility, emotional symptoms, conduct problems, and future outlook at Time 1 and Time 2. (Boys' correlations are shown in blue below the diagonal and girls' are shown in red above the diagonal.)

\begin{tabular}{|c|c|c|c|c|c|c|c|c|c|c|c|c|c|c|c|c|}
\hline & 1 & 2 & 3 & 4 & 5 & 6 & 7 & 8 & 9 & 10 & 11 & 12 & 13 & 14 & 15 & 16 \\
\hline 1. Silent Conflict T1 & & $.41^{* *}$ & $.31 *$ & $.31 *$ & $.40 * *$ & .20 & .10 & $-.39 * *$ & .02 & -.03 & -.04 & .09 & -.05 & .24 & -.01 & -.25 \\
\hline 2. Threat $\mathrm{T} 1$ & $.26^{*}$ & & $.42 * *$ & .05 & $.30 *$ & .17 & .06 & $-.32 *$ & .03 & .02 & .01 & -.05 & -.04 & $.29 *$ & .00 & -.14 \\
\hline 3. Self Blame T1 & $.25^{*}$ & .16 & & .20 & $.34 *$ & .14 & -.06 & -.27 & .05 & .15 & .03 & .02 & .04 & .22 & .14 & -.14 \\
\hline 4. Mothers' Hostility T1 & $.29 *$ & -.23 & .11 & & $.48^{* *}$ & .04 & -.01 & $-.31 *$ & -.06 & .14 & .09 & .08 & -.01 & .12 & .05 & $-.33 *$ \\
\hline 5. Fathers' Hostility T1 & $.32 *$ & -.06 & $.32 *$ & $.62^{* *}$ & & .09 & .03 & -.16 & -.25 & .01 & .01 & -.11 & -.20 & .10 & -.06 & -.20 \\
\hline 6. Internalising $\mathrm{T} 1$ & $.30 *$ & .20 & .11 & .01 & -.01 & & .01 & -.04 & .18 & .23 & .26 & .20 & .25 & $.73 * *$ & .23 & -.26 \\
\hline 7. Externalising $\mathrm{T} 1$ & .13 & .01 & -.05 & .02 & -.02 & -.02 & & .16 & .16 & -.03 & -.05 & -.09 & .00 & .14 & .05 & -.01 \\
\hline 8. Future Outlook T1 & -.06 & -.03 & -.03 & -.08 & -.14 & .12 & .16 & & -.02 & -.22 & -.11 & $-.30 *$ & .01 & .02 & -.16 & .22 \\
\hline 9. Silent Conflict T2 & -.01 & -.05 & .02 & .10 & -.02 & .09 & .15 & .10 & & $.52 * *$ & $.48^{* *}$ & $.31 *$ & $.62 * *$ & .05 & .00 & -.07 \\
\hline 10. Threat $\mathrm{T} 2$ & -.13 & .00 & -.09 & .09 & -.04 & .20 & .00 & .15 & $.28 *$ & & $.60^{* *}$ & .13 & .26 & .09 & -.09 & -.12 \\
\hline 11. Self Blame T2 & -.06 & -.20 & -.13 & -.06 & -.17 & .09 & .15 & .23 & $.39 * *$ & $.57 * *$ & & $.40^{* *}$ & $.50 * *$ & .18 & .13 & -.04 \\
\hline 12. Mothers' Hostility T2 & .06 & -.05 & -.04 & -.14 & -.18 & -.16 & -.01 & .14 & $.37 * *$ & -.02 & .10 & & $.35 *$ & .25 & $.42 * *$ & -.23 \\
\hline 13. Fathers' Hostility T2 & .03 & -.09 & .01 & .16 & .06 & .04 & .12 & .03 & $.44^{* *}$ & -.03 & .16 & $.45^{* *}$ & & .12 & .10 & -.01 \\
\hline 14. Internalising $\mathrm{T} 2$ & $.33 * *$ & .07 & .04 & .24 & $.25^{*}$ & $.61 * *$ & .09 & .11 & .18 & .17 & .23 & .04 & $.27 *$ & & .22 & -.23 \\
\hline 15. Externalising T2 & .01 & -.08 & -.06 & .01 & .00 & .00 & $.37 * *$ & .05 & $.35^{* *}$ & .14 & $.29 *$ & $.35^{* *}$ & $.47 * *$ & .24 & & -.24 \\
\hline 16. Future Outlook T2 & -.01 & -.06 & .06 & .06 & .10 & -.06 & .01 & -.09 & -.06 & .13 & .00 & -.09 & -.12 & -.06 & $-.34 * *$ & \\
\hline
\end{tabular}

Note. ${ }^{* *} p<.01 ; * p<.05$ 
Prior to conducting the mediational analyses their appropriateness for the data was established. As the relationship between the independent (IV) and the dependent variable (DV) is no longer postulated as a mandatory requirement for testing mediation (Hayes, 2009; MacKinnon, et al., 2002), therefore, the feasibility of a hypothesised mediation is determined by the presence of statistically significant associations between the proposed intervening variable (mediator) and the independent and the dependent variables. These relationships were examined for the hypothesised mediated relationships between adolescents' perceptions of SIC and their wellbeing indicators. The potential significant paths indicated by the zero-order correlations have been mapped onto the hypothesised models and are visually presented in Figures 4.5 - 4.7 (boys' processes) and 4.8 4.10 (girls' processes).

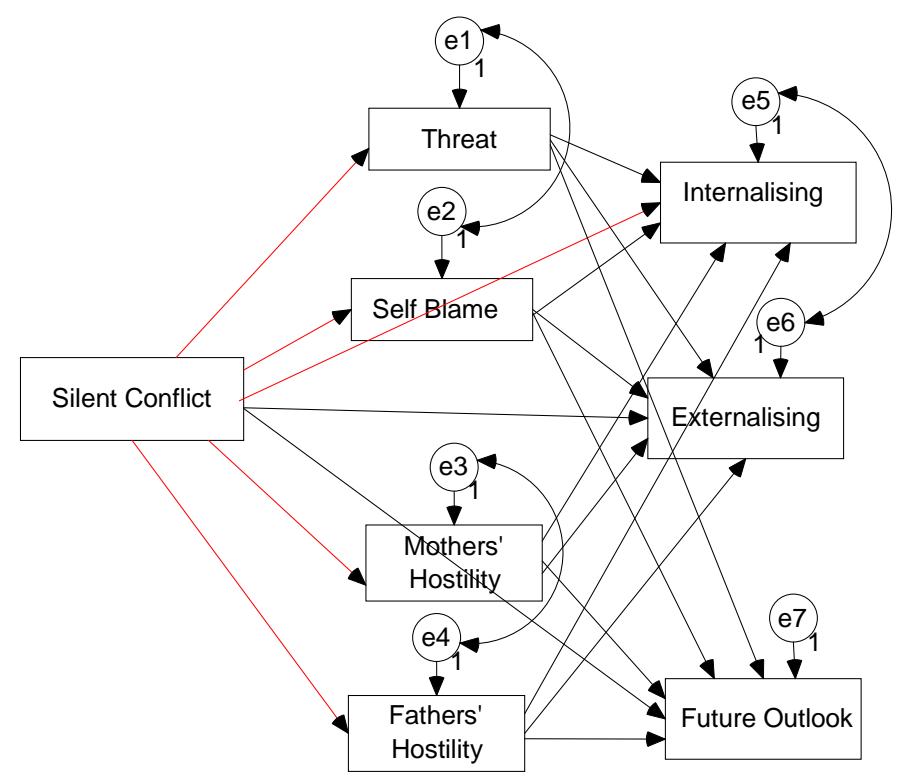

Figure 4.5. Hypothesised concurrent model for boys $(\mathrm{N}=61)$ showing significant correlations between the IV, MVs and DVs at Time 1 in red ink. 


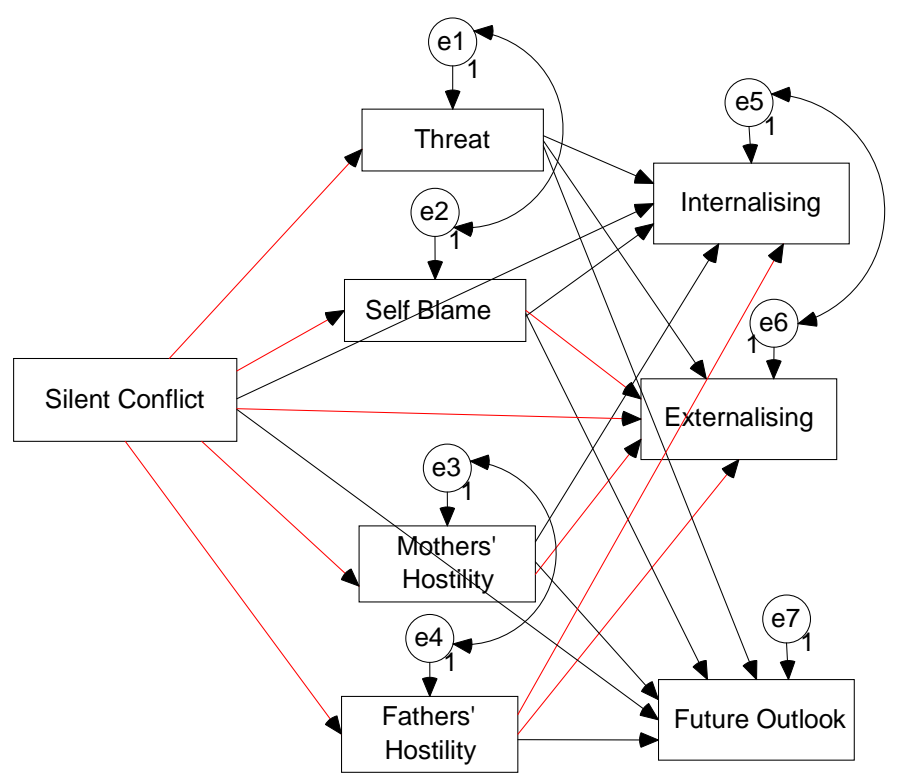

Figure 4.6. Hypothesised concurrent model for boys $(\mathrm{N}=61)$ showing significant correlations between the IV, MVs and DVs at Time 2 in red ink.

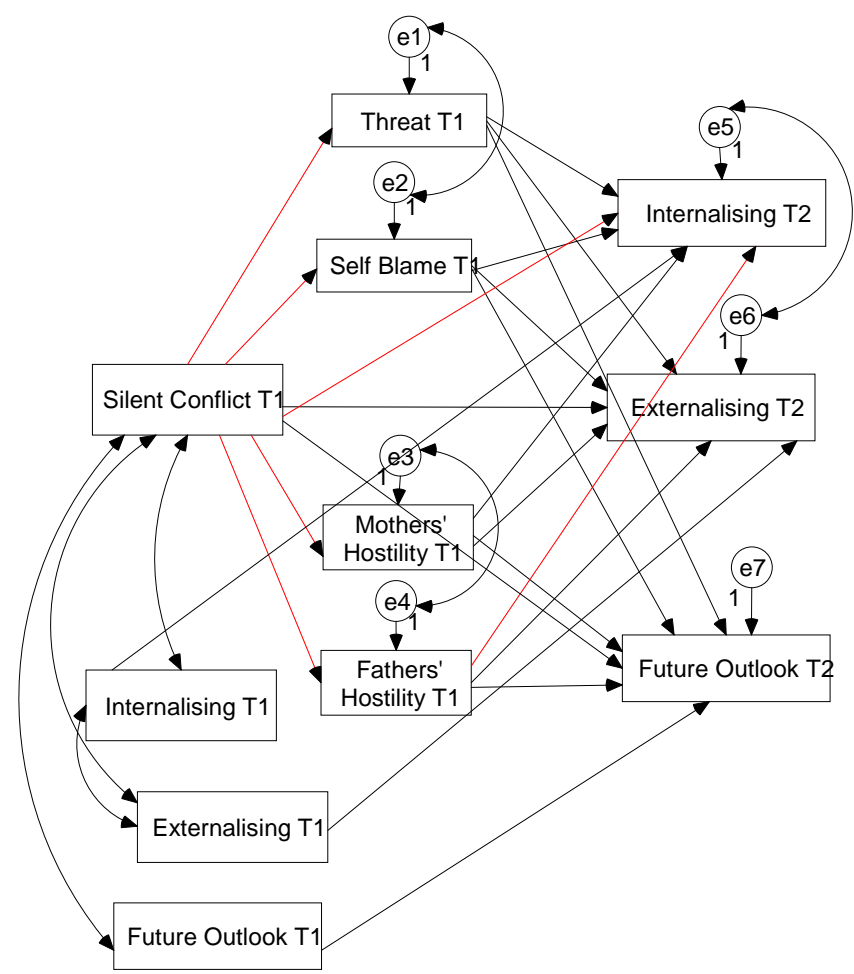

Figure 4.7. Hypothesised concurrent and longitudinal models for boys $(\mathrm{N}=61)$ showing significant correlations between the IV, MVs and DVs in red ink. 


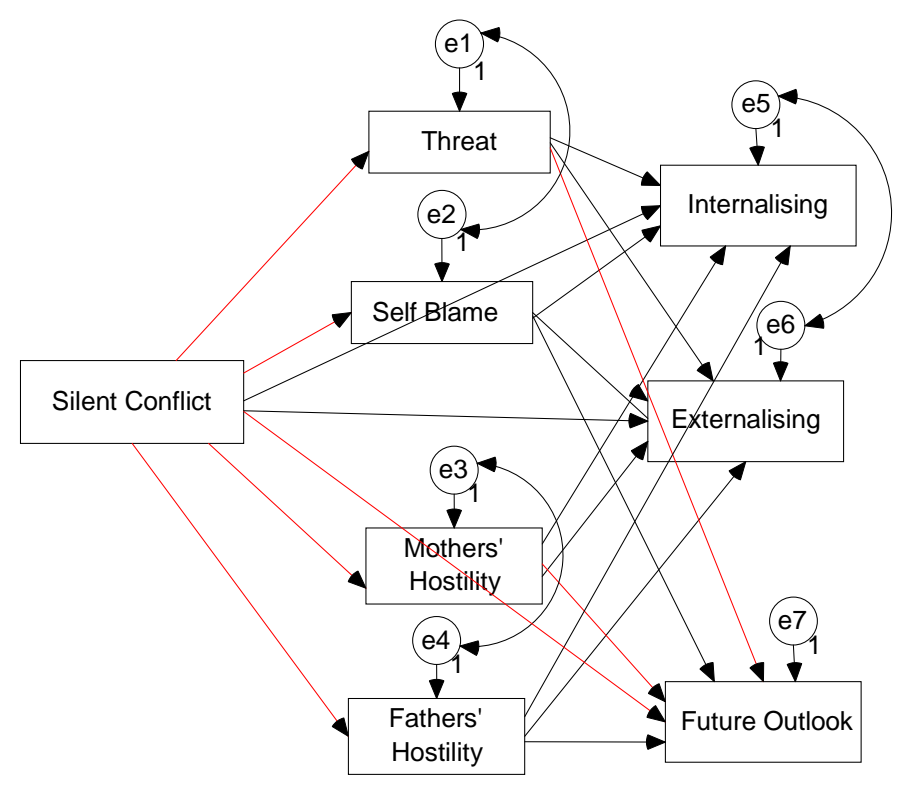

Figure 4.8. Hypothesised concurrent model for girls $(\mathrm{N}=54)$ showing significant correlations between the IV, MVs and DVs at Time 1 in red ink.

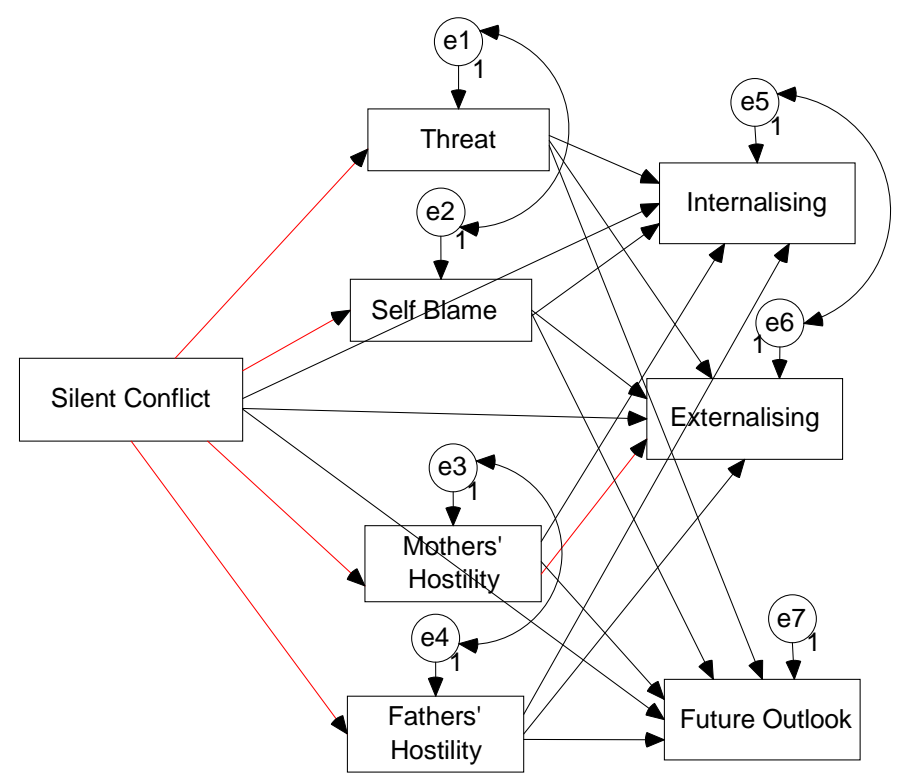

Figure 4.9. Hypothesised concurrent model for girls $(\mathrm{N}=54)$ showing significant correlations between the IV, MVs and DVs at Time 2 in red ink. 


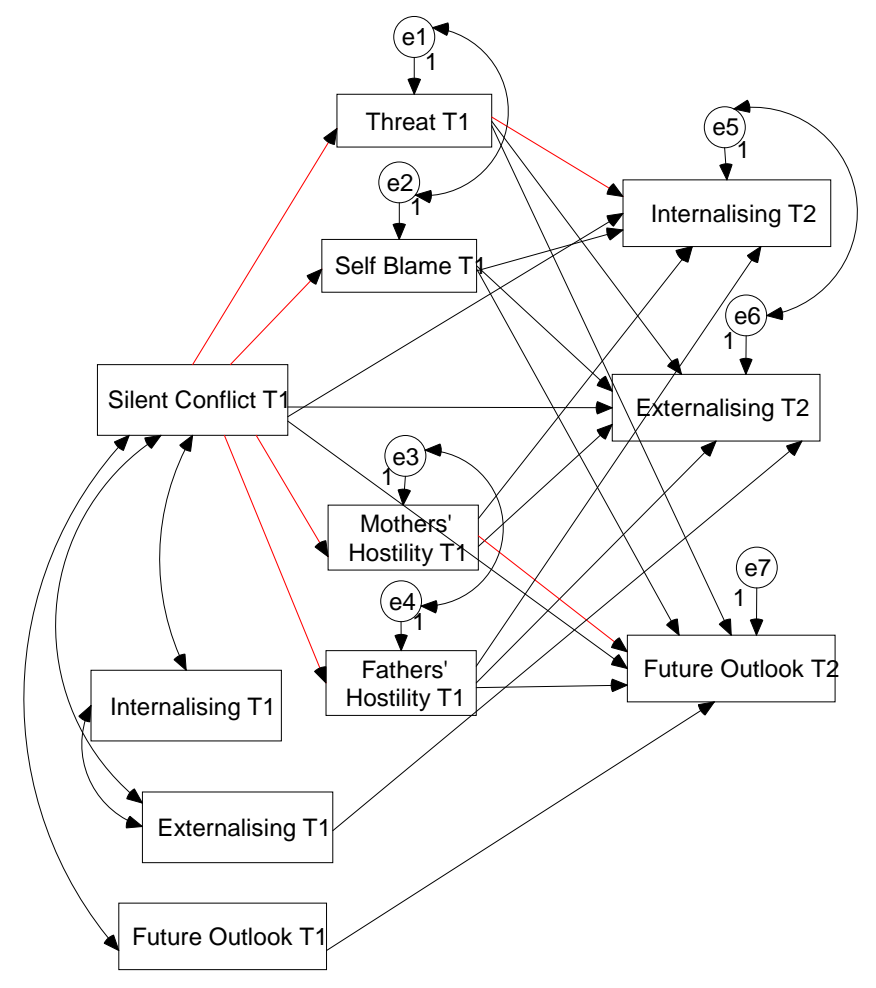

Figure 4.10. Hypothesised longitudinal model for girls $(\mathrm{N}=54)$ showing significant correlations between the IV, MVs and DVs in red ink.

The overview of the correlations (Table 4.6) examined for the purpose of constructing and testing mediational models pointed to a multiplicity of processes. The associations between the independent variable, the mediator variables and the dependent variables were apparently different between the sexes and within the sexes depending on the measurement time and the perspective taken (concurrent or longitudinal).

The correlations indicated potential gender differences in both the dimensions of adolescents' functioning that were affected by SIC and in the processes. Silent interparental conflict appeared to be associated both concurrently and over time to Internalising for boys and to Future Outlook for girls. The mechanisms that emerged as the most consistently likely mediators of the processes were Father's hostility for boys and Mother's hostility for girls. 
For boys the links suggested by the correlations were: a direct one between SIC and Internalising problems at Time 1; one mediated by Father's hostility at Time 2, and both a direct one and through Father's hostility over time.

At Time 2 the links were indicated between SIC and Externalising; a direct one, as well as indirect ones through Self blame, Mother's hostility and Father's hostility.

Path models depicting the relationships indicated by the significant zeroorder correlations were built and tested separately for boys and girls. The longitudinal models were designed to control for the initial levels of the outcome variables. These focused analyses were dictated by the relatively small sample size.

Process models tested for boys

Concurrent effects

Time 1

At Time 1 a significant direct effect was found between SIC and boys' internalising problems, $\beta=.30, p<.05$ (see Figure 4.11).

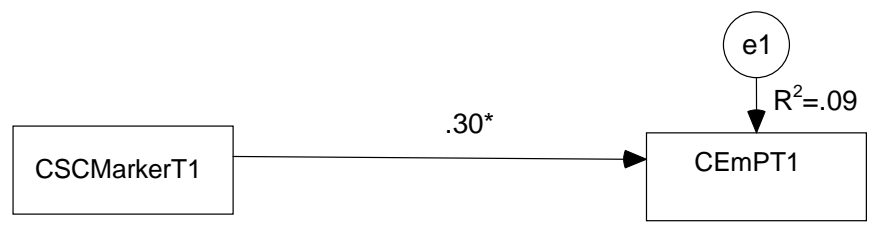

Figure 4.11. Boys' path model of the concurrent effect of SIC on Internalising at $\mathrm{T} 1$, standardised estimates $(* \mathrm{p}<.05)(\mathrm{CEmP}=$ internalising $)$.

Time 2

The tested path model for boys is presented in Figure 4.12. The significance of mediation effects was calculated using AMOS 16.0 bootstrap 
approximation obtained by constructing two-sided bias-corrected confidence intervals.

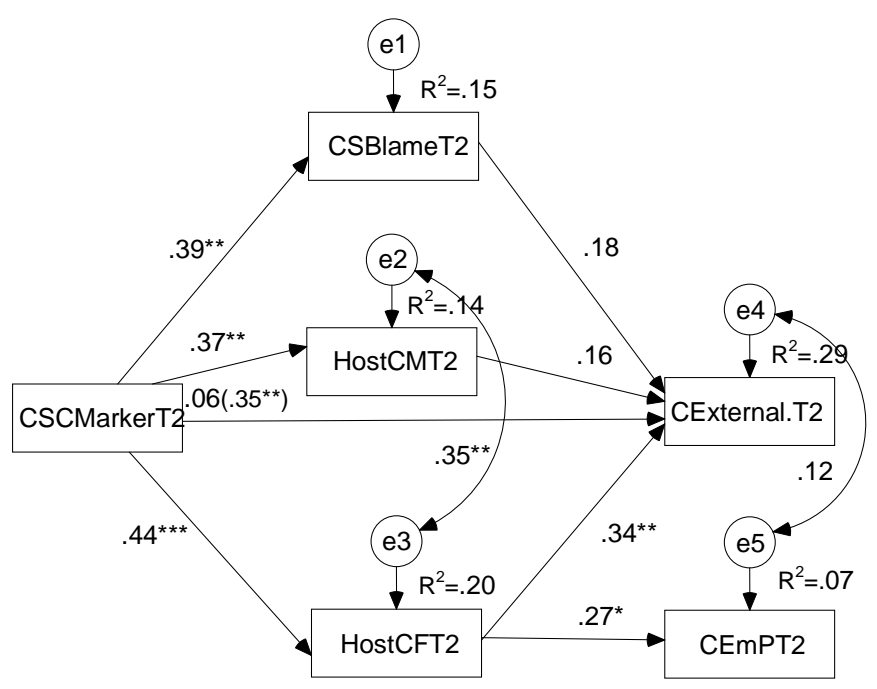

Figure 4.12. Boys' mediation model of the concurrent effect of SIC on Externalising and Internalising at T2, standardised estimates $(* * * p<.001 ; * * p<$ $\left..01 ;{ }^{*} \mathrm{p}<.05\right),($ HostCM $=$ Mother's hostility to child; HostCF $=$ Father's hostility to child, $\mathrm{CEmP}=$ internalising).

Before the introduction of mediators, a significant direct effect was exerted by SIC on Externalising, $\beta=.35, p<.01$. Structural equation analysis showed that the boys' perceptions of SIC affected their internalising problems at Time 2 through their perceptions of Father's hostility at T1, the standardised indirect effect was $.12, p<.05$. Neither Self blame nor Mother's hostility acted as mediators of the effects of boys' perceptions of SIC on their externalising problems. Instead, similarly to the effect on internalising problems, the effect of SIC on boys' externalising was fully mediated by their perceptions of Father's hostility towards them; the standardised indirect effect was $.28, p<.01$. The obtained model fit indices were acceptable as follows: $\chi^{2}=14.34, \mathrm{p}=.12, \chi / d f=$ $1.53, \mathrm{GFI}=.96, \mathrm{AGFI}=.82, \mathrm{CFI}=.95, \mathrm{RMSEA}=.07, \mathrm{sRMR}=.05$. 


\section{Longitudinal effects}

The zero-order correlations indicated that boys' Internalising problems might be adversely affected by SIC over time. The suggested mediational mechanism was Father's hostility. Consequently, a model of the longitudinal effects of SIC on boys' adjustment suggested by the correlations was tested and is presented in Figure 4.13.

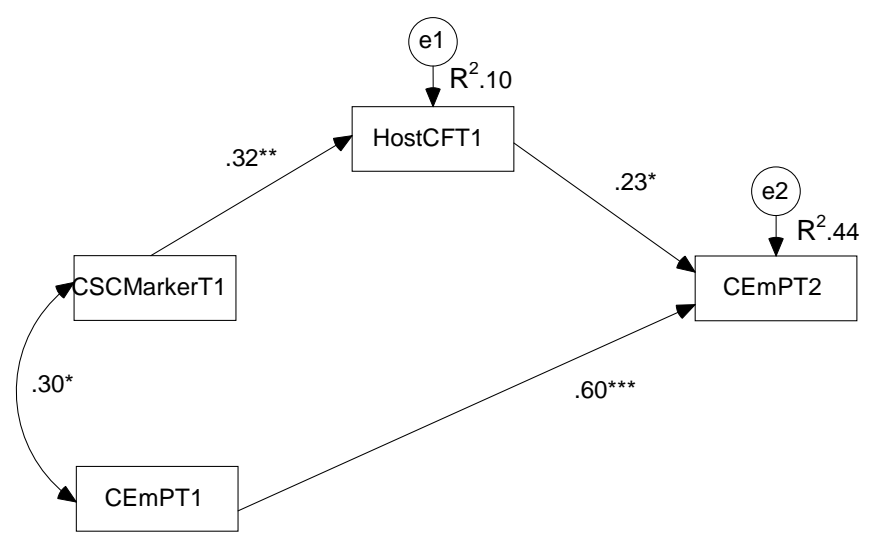

Figure 4.13. Boys' longitudinal path model of the effect of SIC on Internalising mediated by Father's hostility, standardised estimates $(* * * p<.001 ; * * p<.01 ; * p$ $<.05),($ HostCF $=$ Father's hostility to child, $\mathrm{CEmP}=$ internalising).

Structural equation analysis showed that over time the effect of SIC on Internalising problems for boys was fully mediated by Father's hostility. The standardised indirect effect of SIC at T1 on Internalising problems at T2 for boys was $.07, p<.01$. The proposed longitudinal model fit the data very well, $\chi^{2}=$ 2.29, $p=.68, \chi / d f=.57, \mathrm{GFI}=.99, \mathrm{AGFI}=.95, \mathrm{CFI}=1.00, \mathrm{RMSEA}=.001$, sRMR $=.05$. The results of the longitudinal analysis echo the patterns observed in the concurrent processes in underscoring the importance of the spillover effect of SIC in the form of paternal hostility to the psychological adjustment of sons. Moreover, consistent with the concurrent results, the longitudinal findings indicate that the area of vulnerability for boys resides in their emotional problems. 


\section{Process models tested for girls}

\section{Concurrent effects}

Time 1

The tested path model for girls at T1 is presented in Figure 4.14. The significance of mediation effects in this work was calculated using AMOS 16.0 bootstrap approximation obtained by constructing two-sided bias-corrected confidence intervals.

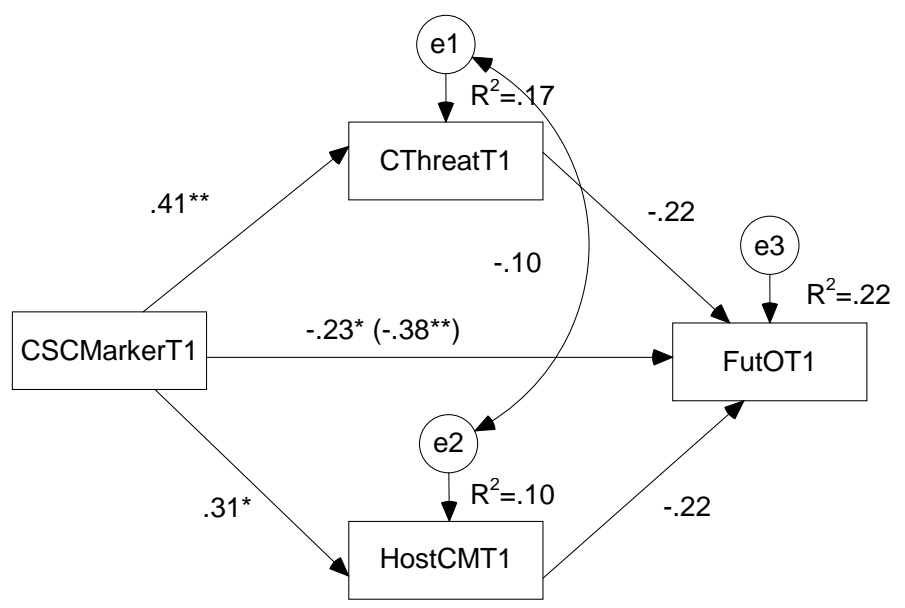

Figure 4.14. Girls' composite mediation model of the concurrent effect of SIC on Future Outlook at T1, standardised estimates $\left({ }^{*} \mathrm{p}<.01 ;{ }^{*} \mathrm{p}<.05\right)$, $(\mathrm{HostCM}=$ Mother's hostility to child; FutO = Future Outlook).

Before the introduction of mediators it was established that a significant direct effect was exerted by SIC on Future Outlook, $\beta=-.38, p<.01$. Introducing the mediators into the model resulted in partial mediation, although none of the resulting regression weights was significant, as may be seen in Figure 4.14. The standardised direct effect of Silent conflict on Future Outlook was -.23, significant at $p<.05$. The standardised indirect effect of SIC on Future Outlook was -.16 , significant at $p<.05$. As the model is fully saturated, no fit indices were available. 
Time 2

The tested path model for girls at T2 is presented in Figure 4.15.

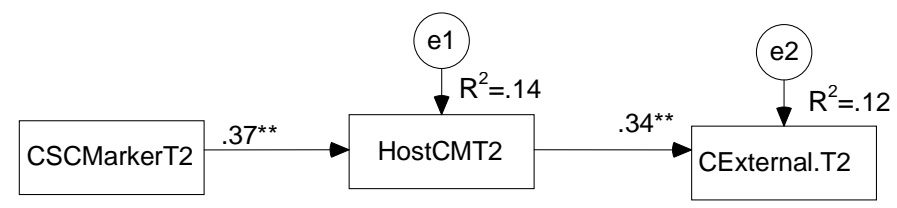

Figure 4.15. Girls' path model of the concurrent effect of SIC on Externalising mediated by Mother's hostility at T2, standardised estimates $(* * \mathrm{p}<.01)$, (HostCM = Mother's hostility to child).

At Time 2, an effect of SIC on Externalising problems was found; the effect was fully mediated by the girls' perceptions of Mother's hostility. The standardised indirect effect of the Marker of SIC at T2 on Externalising problems at T2 for girls was .13, significant at $p<.01$. The obtained model fit indices were as follows: $\chi^{2}=5.09, p=.08, \chi / d f=2.55, \mathrm{GFI}=.97, \mathrm{AGFI}=.83, \mathrm{CFI}=.90$, $\mathrm{RMSEA}=.11, \mathrm{sRMR}=.08$.

\section{Longitudinal effects}

The raw correlations indicated that for girls two outcomes might be affected by SIC over time: Future Outlook and Internalising. The suggested mediating mechanisms were Mother's hostility for the former and Threat for the latter outcome. The tested model of longitudinal effects of SIC on girls' adjustment is presented in Figure 4.16. 


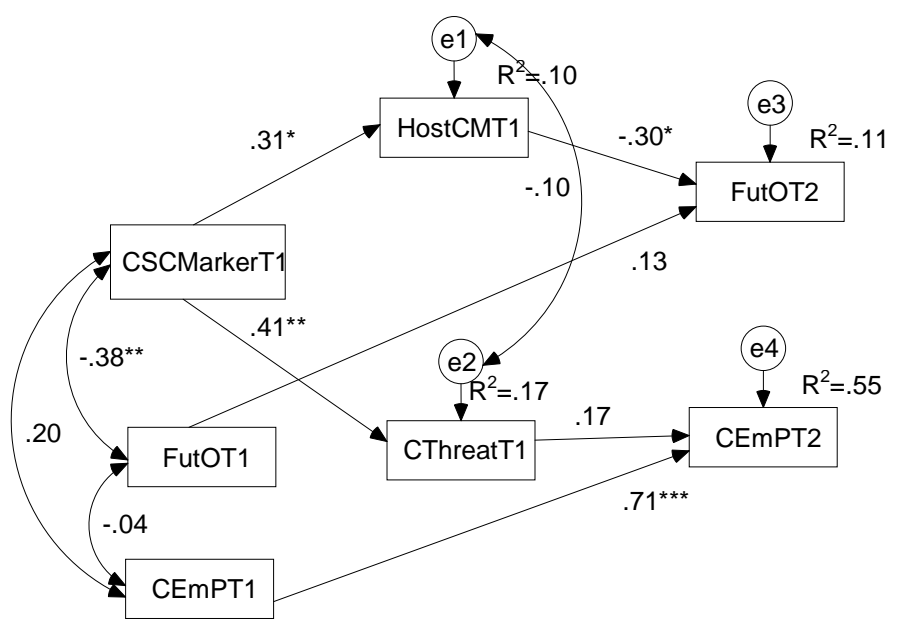

Figure 4.16. Girls' longitudinal model of the effects of SIC on Future Outlook and Internalising, standardised estimates $\left(* * * \mathrm{p}<.001 ; * * \mathrm{p}<.01 ;{ }^{*} \mathrm{p}<.05\right)$, (HostCM $=$ Mother's hostility to child; $\mathrm{CEmP}=$ internalising, FutO $=$ Future Outlook).

The path model analysis revealed that the longitudinal effect of SIC on Future Outlook was fully mediated by Mother' hostility. The standardised indirect effect of SIC at T1 on Future Outlook at T2 was -.09, significant at $p<.05$. Additionally, the longitudinal effect of SIC on Internalising was fully mediated by Threat, although the path from Threat to Internalising was nonsignificant, girls' perceptions of SIC exerted a significant indirect effect on their emotional problems through it. The standardised indirect effect of SIC at T1 on girls' internalising problems at T2 was .07, significant at $p<.05$. The proposed longitudinal model fit the data well, $\chi^{2}=21.87, p=.47, \chi / d f=.99, \mathrm{GFI}=.95$, $\mathrm{AGFI}=.88, \mathrm{CFI}=1.00, \mathrm{RMSEA}=.001, \mathrm{sRMR}=.06$

The obtained results illuminating the longitudinal processes of the effects of SIC on psychological adjustment of girls supported the importance of the spillover mechanism in the form of maternal hostility in the dampening of the daughters' expectations of the future. A longitudinal outcome unobserved concurrently for girls was the increase in their internalising problems over time. 
The long-term effect of SIC on the emotional problems for girls was fully mediated by their appraisals of SIC-related Threat. The finding underscores the importance of Threat in mediating the girls' processes, evidenced by its contribution to the erosion of girls' future expectations at Time 1.

\section{Summary of Study 2}

The aim of this study was to shed light on the processes underlying the effects of silent interparental conflict on children. Two conceptual frameworks were described and considered for their relevance to SIC. Both the cognitivecontextual framework (Grych \& Fincham, 1990) and the spillover hypothesis (Erel \& Burman, 1995) were found appropriate as explanatory vehicles for the investigated processes and were employed in constructing the hypothesised models. Three outcomes were investigated: internalising and externalising, representing maladjustment, and Future Outlook, representing positive functioning.

Silent interparental conflict was hypothesised to exert its effect on adolescents' adjustment directly and indirectly, through appraisals of self blame and threat, and through parental hostility directed at adolescents. The processes were expected to operate both concurrently and over time.

Although the existing findings regarding the effects of parental discord on children's outcomes lack gender-specific consistency, they appear persuasively different. Therefore, the processes were expected to differ for the boys and the girls in the study. In particular, owing to its relational component, the effects on Future Outlook were expected to be more pronounced for girls than for boys, in view of their differential socialisation (Maccoby \& Jacklin, 1974). 
Separate focused process models suggested by the correlational analyses were tested for boys and girls. The results supported the hypothesised multifinality. Additionally, the processes of influence of SIC on adjustment differed between sexes and within sexes in relation to the measurement point (T1 or T2) and perspective (cross-sectional or longitudinal).

Internalising problems emerged as the most robust outcome for boys, affected directly by SIC at Time 1 and through Father's hostility over time. The spillover mechanism of Father's hostility appeared to be the most influential mediator of the boys' processes, as it also fully mediated the effects on SIC on boys' Externalising problems at Time 2.

Analyses of the girls' models revealed a greater complexity of processes. The most consistent outcome for girls was the erosion of their expectations of the future. The effects of SIC on Future Outlook were fully mediated by a combination of Threat and Mother's hostility at Time 1, the two mediators that proved influential in the girls' processes. Mother's hostility fully mediated the effects of SIC on girls' Externalising problems at Time 2. The longitudinal process took place along two pathways: SIC affected the girls' Future Outlook at Time 2 through Mother's hostility at Time 1, and their Internalising problems at Time 2 through their perceptions of Threat at Time 1.

The hypothesised mediations by Self-blame were not supported, possibly due to the developmental stage of the adolescent children constituting the sample, capable of more accurate causal attributions than their younger counterparts and therefore less likely to ascribe blame for parental problems to themselves (Grych \& Fincham, 1990). Overall, the only findings in support of the mediational processes postulated by Grych and Fincham's cognitive-contextual framework 
(1990) were found for Threat mediating the effects of SIC on girls' Future

Outlook at T1 and on their internalising problems over time. As the employed conceptualisation of Threat comprises the element of uncertainty regarding the stability of the family unit, the finding is consistent with the affiliative portrayal of females encompassed within the differential socialisation theory (P. T. Davies \& Lindsay, 2001). Moreover, the finding is also consistent with plentiful existing evidence for the link between the appraisal of threat and children's internalising problems (Dadds, et al., 1999; Fosco \& Grych, 2008; Grych, et al., 2000; Grych, et al., 2003; Kerig, 1998a; McDonald \& Grych, 2006).

The findings that the SIC-related parental hostility directed at adolescents mediated the causal processes are important, not only because they have provided support for the operation of the hypothesised spillover mechanism (Erel \& Burman, 1995), but also as they have consistently demonstrated the significance of the same-sex parent-child relationships (P. T. Davies \& Lindsay, 2001). Additionally, in exposing the contrasting pathways to maladjustment (or diminished adjustment) for boys and girls, the findings attest to the conceptual currency of the differential socialisation theory (Maccoby \& Jacklin, 1974).

In keeping with the conservative approach to analyses guiding this work, the links that were not replicated and did not appear to represent a pattern are reported cautiously. This relates to the processes resulting in Externalising problems found at Time 2 for both sexes, although the finding for boys concurs with the longitudinal results of Harold and Conger (1997). 


\section{STUDY 3}

The aim of this study was to integrate the perspectives of parents and adolescents on the phenomenon of silent interparental conflict, the associated parent-child relations, and the psychological outcomes for the young people.

As discussed in Chapter 1, the systemic view of the family (e.g. Cox \& Paley, 1997) emphasises the dynamics of interrelatedness and mutual influences between the constituent parts. Accordingly, family members are seen as coming together to form multiple subsystems (parents, children, siblings, males, females), and interact and influence one another both on systemic and individual levels, between and within the subsystems.

Notwithstanding the inescapable systemic connections among the family members, each person within the system experiences reality through his or her own individual perceptions. Typically, the perceptions within couples have been found to show greater similarities than the perceptions of parents and children, and the overall level of agreement among family members has been shown to be modest (Tschann, et al., 1999). Consequently, for scholars seeking advancement in understanding of family-related phenomena it is important to study families from multiple perspectives (Kerig, 1995), as it needs to be recognised that each of the family members contributes a unique, but equally valid, view of the shared reality.

Children's reports represent information of unique salience to young people, which is not always accessible to parents and may therefore be omitted, underestimated or misinterpreted in parental reports (Grych, et al., 1992), as has been noted for the assessment of internalising problems. Unsurprisingly, the individual's own experiences are the best predictors of his or her outcomes, a 
regularity that has been demonstrated in regard to children's perceptions of interparental conflict and their adjustment (Emery \& O'Leary, 1982; Wild \& Richards, 2003).

The issue of accuracy arises when multiple reports are available, as similarities and dissimilarities between the perceptions of family functioning by individuals are inevitable. In the context of couples' relationship satisfaction they have been studied on the bases of two main perspectives, the first issuing from the behavioural tradition and the second from the cognitive behavioural tradition (Segrin, Hanzal, \& Domschke, 2009). The former standpoint emphasises the importance to marital success of perceptual accuracy in decoding the intentions and behaviours of one's partner and has been widely applied in couple therapy (e.g. 'active listening', Markman, Stanley, \& Blumberg, 1994). The latter stems from the attribution patterns of spouses in distressed and nondistressed relationships, who have been found to differ on the levels of positivity and negativity ascribed to partners' behaviours. Recall from Chapter 1 that in conflict situations, satisfied couples have been found to make characteristically positive attributions in contrast to distressed couples, who made characteristically negative attributions (Bradbury \& Fincham, 1990). Accordingly, a positive attribution bias in spousal relationships has been interpreted as a contributor to marital success.

The existing scholarship offers no directions as to the utility of either of the frameworks in relation to interparental conflict-related perceptions of children and parents. In the context of interparental conflict, the consequences of parental positive bias in perceiving the relationships with children and related children's adjustment may not be beneficial to children, as the positive bias may result in parental underestimation of children's distress. For this reason, the congruence of 
perceptions between parents and children appears important, especially as conflicted couples may base their parenting of children on misconceived sense of comfort.

\section{Gender constellations}

The inclusion of multi-informant reports in study design allows a multidimensional insight into the operation of gender constellations consisting of combinations of the sex of a child, the sex of a parent and the sex-typed treatment of children by parents. Gender-oriented research indicates that parental behaviours depend much more on the sex of the parent than the sex of the child (Maccoby, 2003a, p. 197), thus the gender of children elicits different responses from parents depending on the gender of a parent (e. g. fathers play more roughly with boys; mothers talk more to daughters than to sons). In general, mothers are more involved in the lives of children than fathers, and are more responsive to children's communication. But, both mothers and fathers spend more time with children of the same sex as theirs, therefore mothers know more about daily activities of daughters and fathers of sons; however, mothers know more about children's activities regardless of sex than fathers do (McHale, Crouter, \& Whiteman, 2003).

\section{Relevance to silent conflict}

The phenomenon of silent interparental conflict poses unique challenges for attempts to compare perspectives of multiple informants. Due to the subtle nature of SIC, it may be expected that it is not accessible to children to the same extent as it is to parents, who, as the protagonists, are personally involved in it. Consequently, it is plausible that SIC may not always be accurately perceived by 
children, particularly, as parents motivated by protectiveness engage in it to conceal their disagreements from them.

The results of Study 2 in this chapter have indicated the operation of gender constellation mechanisms in the process of SIC exerting its effect on adolescents' adjustment. For boys, the mediating mechanism was their perception of fathers' hostility; for girls, it was the perception of their mothers' hostility. The findings indicate the importance of within-sex bonds between parents and children. Additionally, in view of the differential time investment of parents with the same-sex children established in research (McHale, Crouter, \& Tucker, 1999), it is plausible that the accuracy of perceptions of SIC and the related dynamics would be greater within same-sex parent-child dyads than within opposite-sex dyads.

Systemic approach to studying family dynamics

In this work attempts have been made to study the SIC-related processes within families from a systemic perspective. To this end the systemic influences have been hypothesised as environmental and relational variables (see Chapter 3 and Chapter 4) and dyadic analyses based on the APIM (Kenny, 1996; Kenny, et al., 2006) have been employed focusing on mutual influences and nonindependence characteristic of couples (Chapter 3). Another powerful approach to studying family processes involves including reports of multiple informants on phenomena under study within a single process model, a method which offers statistical advantages in reducing the method variance confounds (Paley, et al., 2000). This approach has been articulated in the familywide process models of interparental conflict effects on children's adjustment, which include both the 
children's and the parents' reports (e.g. Franck \& Buehler, 2007; Harold \& Conger, 1997; Harold, et al., 1997).

\section{Hypotheses}

$\underline{\text { H1}}$. In order to broaden the systemic insight into the process of the effects of SIC on adolescents' adjustment, a path model suggested by a latent variable familywide model of interparental conflict and its effects on children of Harold, Fincham, Osborne and Conger (1997) was hypothesised. The model presented in Figure 4.17 reflects the expectation of both the concurrent and the long-term effects of adolescents perceptions of SIC and the associated parental hostility towards them on adolescents' adjustment and is conceived as a series of mediational processes. Following Harold and colleagues, the hypothesised model does not stipulate a direct link between interparental conflict and child adjustment, as longitudinal designs controlling for the initial level of psychological outcomes have generally failed to find it (e.g. Grych, et al., 2003; Harold, et al., 1997; Shelton \& Harold, 2007). As this study is a continuation and extension of Study 2 in this chapter, the model design has been guided by the empirical findings pointing to specific processes for boys and for girls.

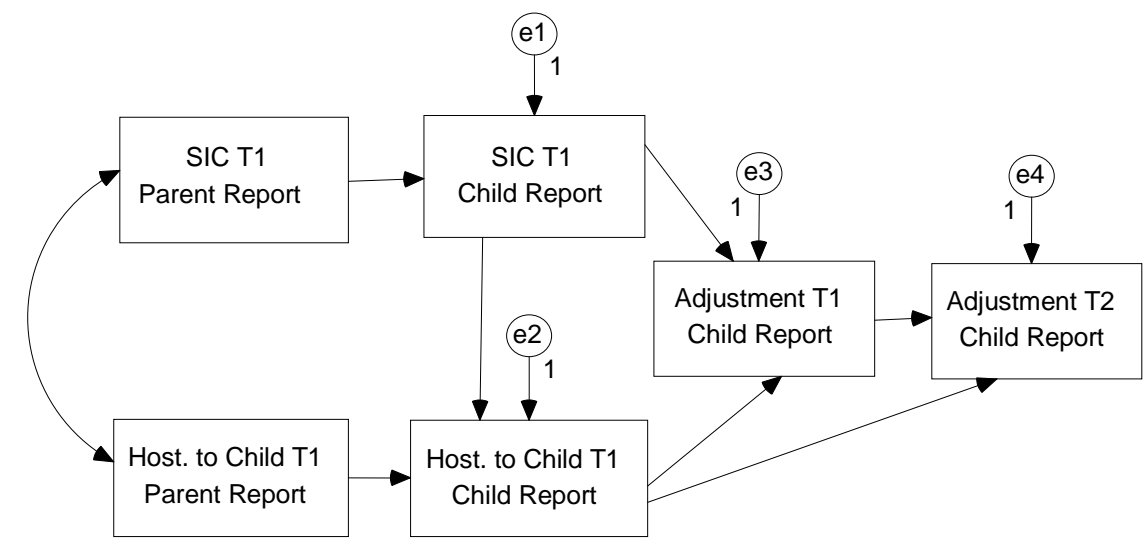

Figure 4.17. Conceptual path model of the effects of SIC on adolescents' adjustment after Harold and colleagues (1997). 
$\underline{\mathrm{H} 2}$. The existing research findings demonstrate that fathers spend relatively more time with sons and mothers with daughters (McHale, et al., 2003), which suggests that boys might be more influenced by paternal perceptions and girls by maternal perceptions of SIC. Additionally, the same-sex parent-child processes have been found in Study 2 in this chapter. As a result, it was hypothesised that the processes encapsulated in the conceptual model would reflect the congruence of perceptions between same-sex dyads of parents and adolescents. Consequently, mothers' perceptions of SIC and child-directed hostility were expected to predict their daughters' perceptions; fathers' perceptions of SIC and child-directed hostility were expected to predict their sons' perceptions.

Analytic strategy

The adopted conceptual model postulates a relationship between the parent's and the child's perceptions of SIC. As SIC is a subtle phenomenon, not expressed verbally or physically and is intended by parents to protect children from distress, it was unclear how accurate the adolescents' perceptions of the incidence of SIC might be. Additionally, as observers, children are alerted to silent conflicts between their parents via different processes than the parents, who are actors. Therefore the associations hypothesised in the model were to be tested by first conducting correlations between the adolescents' perceptions of the frequency of SIC and the mothers' and the fathers' perceptions of the frequency of SIC as well as the Costs and the Benefits of SIC, as potential signals of SIC to children.

The empirically established predictors were to be combined with the mediating mechanisms of father hostility for boys and mother hostility for girls, 
empirically supported in Study 2, into separate boys' and girls' versions of the model. On the basis of the links between variables found in Study 2, the outcome variable of interest for boys was Internalising and for girls it was Future Outlook.

\section{Method}

Participants were 115 adolescents (54 females and 61 males; described in Study 1 of this Chapter) and their parents (described in Chapters 2 and 3).

\section{Procedure}

The recruitment process and the procedure for the whole family were described in Chapter 2.

\section{Measures}

Silent interparental conflict was measured with the SICS for parents and the ASICS for adolescents. The characteristics of the scales were described in chapters 2 and 3 for SICS and in Parts 1 and 2 of this chapter for the APSIC.

Parental hostility to adolescents was measured with the Hostility subscale of the Iowa Youth and Family Project (Melby, et al., 1993; Melby, et al., 1995). The items are scored from one (never) to seven (always) on a Likert scale and higher scores represent greater hostility. Reliability coefficients obtained for the measure at $\mathrm{T} 1$ and $\mathrm{T} 2$ ranged from .88 to .89 for the adolescents and from .80 to .88 for the parents. The subscale is presented in Appendix $\mathrm{H}$.

Adolescents' psychological adjustment measures were described in Part 2 of this chapter. In this study the scores on Future Outlook scale were used as a measurement of adjustment for girls and the scores on the Emotional Problems subscale of the SDQ (Goodman, 1997, 2001; Goodman, et al., 1998) as a measure of adjustment for boys. 


\section{Results}

Descriptive statistics and intercorrelations among the study variables for

boys and girls are presented in Tables 4.8 and 4.9 respectively.

Table 4.7. Descriptive statistics and intercorrelations among the variables constituting the hypothesised familywide model for boys $(N=61)$.

\begin{tabular}{lccccccc}
\hline & 1 & 2 & 3 & 4 & 5 & 6 & M (SD) \\
\hline 1. Child Silent Conflict T1 & & & & & & & $6.49(2.32)$ \\
2. Child Father's Hostility T1 & $.32^{*}$ & & & & & & $13.13(5.36)$ \\
3. Child Internalising T1 & $.30^{*}$ & -.01 & & & & & $2.62(2.12)$ \\
4. Father Benefits of Silent Conflict T1 & $.26^{*}$ & -.03 & $.41^{* *}$ & & & & $10.16(2.22)$ \\
5. Father Hostility to Child T1 & .03 & .09 & .10 & .23 & & & $10.79(3.24)$ \\
6. Child Silent Conflict T2 & -.01 & -.02 & .09 & -.08 & .13 & & $6.47(2.15)$ \\
7. Child Internalising T2 & $.33^{*}$ & .23 & $.61^{* *}$ & $.27^{*}$ & .06 & .18 & $2.73(2.22)$ \\
\hline
\end{tabular}

Note. ${ }^{* *} p<.01 ;{ }^{*} p<.05$.

Table 4.8. Descriptive statistics and intercorrelations among the variables constituting the hypothesised familywide model for girls $(N=54)$.

\begin{tabular}{lccccccc} 
& 1 & 2 & 3 & 4 & 5 & 6 & M (SD) \\
\hline 1. Child Silent Conflict T1 & & & & & & & $6.58(1.96)$ \\
2. Child Mother's Hostility T1 & $.31^{*}$ & & & & & & $11.98(4.55)$ \\
3. Child Future Outlook T1 & $-.39^{* *}$ & $-.31^{*}$ & & & & & $30.50(3.66)$ \\
4. Father Costs of Silent Conflict T1 & $.35^{* *}$ & -.15 & -.12 & & & & $11.78(3.40)$ \\
5. Mother Hostility to Child T1 & .18 & .02 & -.17 & .12 & & & $11.51(3.59)$ \\
6. Child Silent Conflict T2 & .02 & -.06 & -.02 & .23 & .11 & & $6.80(2.34)$ \\
7. Child Future Outlook T2 & -.25 & $-.33^{*}$ & .22 & .17 & $-.39^{* *}$ & -.07 & $30.51(3.81)$ \\
\hline
\end{tabular}

Note. ${ }^{* *} p<.01 ;{ }^{*} p<.05$.

\section{Correlational analyses}

The correlational analyses were conducted to identify the potential links between the perceptions of SIC and hostility of mothers, fathers, sons and daughters in the study. For boys a significant positive correlation was found between their perceptions of the frequency of SIC and the Fathers' perception of the Benefits of SIC $(r=.33 p<.01)$. For girls a significant positive correlation was found between their perceptions of the frequency of SIC and the Fathers' 
perceptions of the Costs of SIC $(r=.35 p<.01)$. The hypothesised congruence of perceptions within same-sex parent-adolescent dyads was partially supported, as it was statistically significant for fathers and sons, but not for mothers and daughters.

Despite the established importance of parental hostility to adolescents' functioning in the context of SIC (see Study 2 in this chapter), the expected congruence of perceptions between fathers' and sons', and mothers' and daughters' perceptions was not supported by the zero-order correlations.

The hypothesised model was modified accordingly to reflect the associations between variables indicated by the zero-order correlations excluding the predictive path between the parents' perceptions of their hostility to adolescents to the adolescents' perceptions of parental hostility. To reflect the gender-specific processes and outcomes, separate path models were constructed for boys and girls. The models are presented in Figures 4.18 (boys) and 4.19 (girls). The boys' model is essentially dyadic as the identified elements of the process pertain only to boys and fathers; in contrast, the girls' model includes variables related to both parents. 


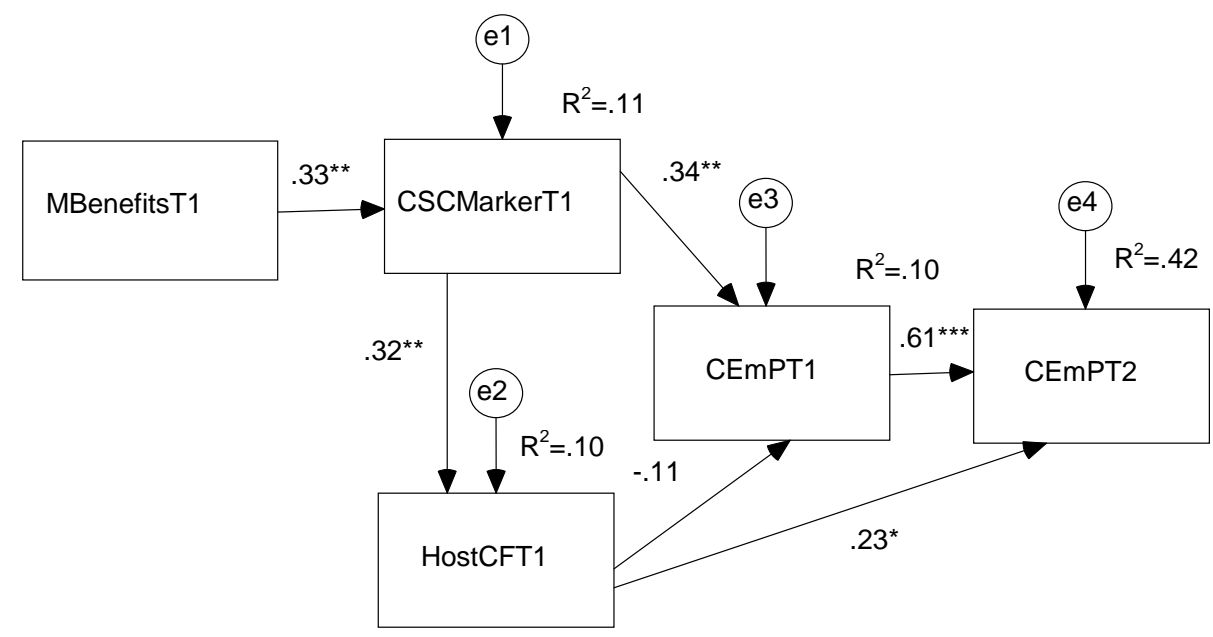

Figure 4.18. Familywide path model of the effects of SIC on boys' internalising problems $\left(* * * p<.001 ; * * p<.01 ;{ }^{*} p<.05\right)$, (HostCF $=$ Father's hostility to child, $\mathrm{CEmP}=$ internalising).

Apart from the inclusion of Fathers' perceptions of the Benefits of silent conflict, the rest of the model bears similarities with the longitudinal model for boys presented in Study 2 of this chapter. However, instead of a covariance between CSCMarkerT1 and HostCFT1 of the longitudinal model, the familywide model stipulates a causal path from CSCMarkerT1 to HostCFT1, as well as a causal path from HostCFT1 to CEmpT1. This resulted in positing six possible mediational effects within the model instead of one. The standardised direct effects found may be seen in Figure 4.24. Additionally, four significant indirect effects were found including the effect of fathers' perceptions of the Benefits of SIC at $\mathrm{T} 1$ on sons' internalising problems at $\mathrm{T} 2$. The significance of mediation effects was calculated using AMOS 16.0 bootstrap approximation obtained by constructing two-sided bias-corrected confidence intervals.

The significant indirect effects were as follows: 
The standardised indirect effect of fathers' perceptions of the Benefits of SIC at T1 (MBenefitsT1) on sons' internalising problems at T1 (CEmPT1) was $.10, p<.05$.

The standardised indirect effect of fathers' perceptions of the Benefits of SIC at T1 (MBenefitsT1) on sons' internalising problems at T2 (CEmPT2) was $.09, p<.05$.

The standardised indirect effect of fathers' perceptions of the Benefits of SIC at T1 (MBenefitsT1) on sons' perceptions of fathers' hostility at T1 (HostCFT1) was .11, $p<.05$.

The standardised indirect effect of sons' perceptions of the frequency of SIC at T1 (CSCMarkerT1) on their internalising problems at T2 (CEmPT2) was $.26, p<.01$.

The proposed familywide model for boys fit the data very well, $\chi^{2}=3.27$, $\mathrm{p}=.92, \chi / d f=.41, \mathrm{GFI}=.99, \mathrm{AGFI}=.96, \mathrm{CFI}=1.00, \mathrm{RMSEA}=.001, \mathrm{sRMR}=$ .04 .

Longitudinal familywide process model for girls

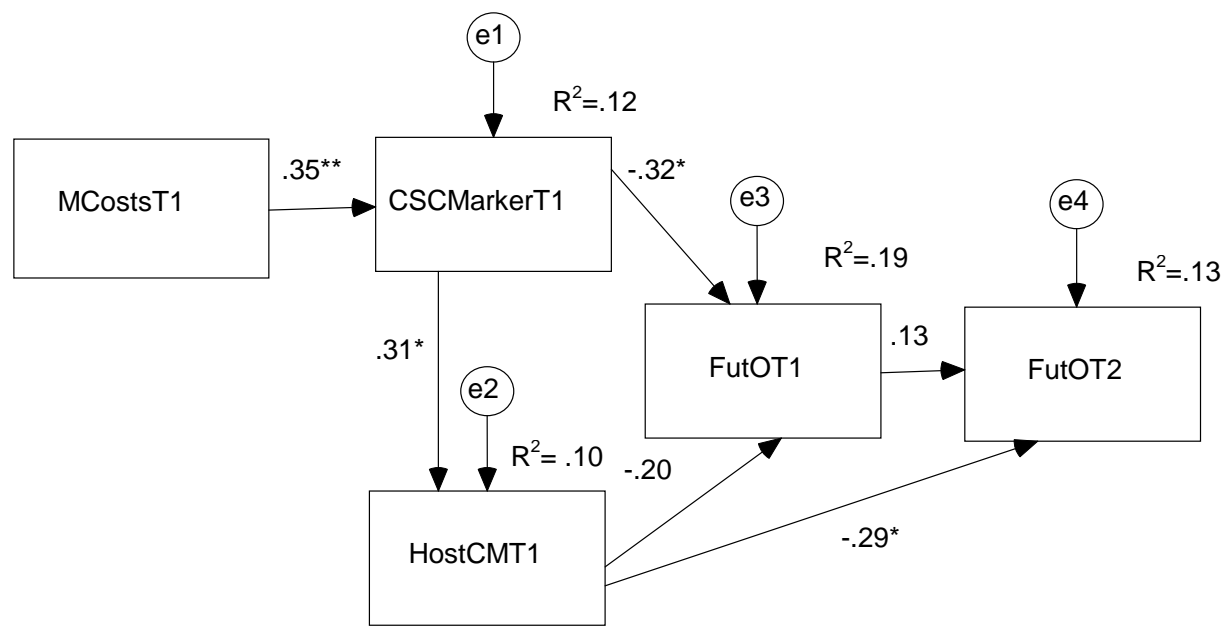

Figure 4.19. Familywide path model of the effects of SIC on girls' Future Outlook $(* * \mathrm{p}<.01 ; * \mathrm{p}<.05),($ HostCM $=$ Mother's hostility to child; FutO = Future Outlook). 
Although the structure of the familywide model proposed for girls is identical to the boys' model, the two models differ in respect of the empirically established variables significant to the processes. Consequently, the girls' model includes fathers' reports of the perceived Cost of SIC instead of Benefits; adolescents' perceptions of mothers' hostility instead of fathers' hostility; and the outcome of Future Outlook instead of internalising problems.

The standardised direct effects found may be seen in Figure 4.25. Additionally, out of the six indirect effects posited in the model, four were found to be significant, including the effect of fathers' perceptions of the Costs of SIC at T1 on daughters' Future Outlook at T2. The significance of mediation effects was calculated using AMOS 16.0 bootstrap approximation obtained by constructing two-sided bias-corrected confidence intervals.

The significant indirect effects found for girls were as follows:

The standardised indirect effect of fathers' perceptions of the Costs of SIC at T1 (MCostsT1) on daughters' perceptions of mothers' hostility at T1 (HostCMT1) was .11, $p<.01$.

The standardised indirect effect of fathers' perceptions of the Cost of SIC at T1 (MCostsT1) on daughters' Future Outlook at T1 (FutCT1) was -.14, $p<.01$

The standardised indirect effect of fathers' perceptions of the Cost of SIC at T1 (MCostsT1) on daughters' Future Outlook at T2 (FutCT2) was $-.05, p<.05$. The standardised indirect effect of daughters' perceptions of the frequency of SIC at T1 (CSCMarkerT1) on their Future Outlook at T2 (FutCT2) was -.14, $p<.05$. 
The proposed familywide model for girls fit the data reasonably well, $\chi^{2}=$ $10.84, p=.21, \chi / d f=1.35, \mathrm{GFI}=.97, \mathrm{AGFI}=.87, \mathrm{CFI}=.0091, \mathrm{RMSEA}=.05$, $\mathrm{sRMR}=.05$.

\section{Summary of Study 3}

In this study a familywide approach was used to test the processes behind the effects of silent interparental conflict on adolescent's psychological adjustment by including parental reports of silent interparental conflict. The results of the study provided further support for the hypothesised spillover effect of SIC in the form of parental hostility towards adolescents, as for both the boys and the girls in the study the perceived SIC-related hostility of the same-sex parents acted as a mediator of the long-term effects of SIC on their adjustment. However, no concurrent spillover effects on adjustment were found, as the concurrent effects of SIC on internalising problems for boys and the expectations of the future for girls were direct.

The model revealed further evidence of differential SIC-related processes for boys and girls. The hypothesised same-sex parent effect indicating a level of accuracy between parents' and children's perceptions of SIC was not supported for girls. Instead, fathers' perceptions of SIC emerged as predictors of adolescents' perceptions of SIC for both boys and girls, albeit different aspects of paternal perceptions of SIC affected the perceptions of each of the sexes of children. The reports of the frequency of SIC for boys were related to their fathers' perceptions of the Benefits of SIC, which indicates that sons of men who perceived greater benefits of SIC reported more silent disagreements between their parents and also saw their fathers as more hostile. Fathers' perceptions of the Benefits of SIC exerted indirect effects on boys internalising problems both 
concurrently and over time as well as on their perceptions of paternal hostility towards them. In contrast, for girls the perceived frequency of SIC was related to the fathers' perceptions of the Costs of SIC, which indicates that girls in keeping with their relational and affiliative profile are sensitive to their fathers' unavailability and distracted behaviours subsumed within the Costs of SIC. Interestingly, daughters of men, who reported greater Costs of SIC perceived their mothers as more hostile. Fathers' perceptions of the Costs of SIC indirectly affected their daughters' expectations of the future both concurrently and over time as well as their perception of their mothers' hostility towards them.

The concurrent effects of paternal perceptions of SIC on adolescents' outcomes were mediated by the adolescents' perceptions of the frequency of SIC; however, the longitudinal processes differed between the boys and the girls in the study. The longitudinal effects of SIC on internalising problems for boys took two pathways: one was mediated by their internalising problems at $\mathrm{T} 1$; the other was mediated by their perceptions of SIC-related fathers' hostility towards them at T1. For girls there was only one longitudinal process pathway of the effects of SIC on their Future Outlook, which led through the perceptions of maternal hostility, as the girls' expectations of the future were situationally driven and unrelated at $\mathrm{T} 1$ and $\mathrm{T} 2$.

Employing the adapted version of the familywide model of interparental conflict and its effects on children of Harold, Fincham, Osborne and Conger (1997) led to further evidence of detrimental effects of silent interparental conflict on adolescents' adjustment illuminating some direct and indirect processes and a complex interplay among family members. Consequently, in combination with the findings reported in the previous sections of this chapter, they are an 
important and exciting addition to the existing scholarship focused on the effect of interparental discord on children's socio-emotional functioning. Employing the new construct of SIC resulted in added evidence of the detrimental consequences parental discord carries for adolescents and highlighted the contextual, cognitive, emotional and relational mechanisms involved in the destructive process. The implications of the findings will be further discussed in Chapter 5 . 


\section{Chapter 5: General Discussion}

Make everything as simple as possible, but not simpler.

Albert Einstein

\section{Introduction and overview}

The research presented in this thesis has been prompted by a conspicuous gap in the rich scholarship related to interparental conflict. Within a vast body of literature a small number of studies examined various expressions of discord between parents and reported adverse reactions of children to interparental conflict behaviours that were neither verbal nor physical (e. g. Buehler, et al., 1998; E. Mark Cummings, et al., 2003; De Arth-Pendley \& Cummings, 2002; ElSheikh \& Reiter, 1996). Reviews of relationship-focused literature appeared to indicate that non-verbal non-physical expressions of couples' conflict have been identified as detrimental to marital quality and even predicted relationship dissolution for some couples (Gottman, 1994, 1998). This body of largely clinically-driven research originated from observations of couples and resulted in identifying behaviours such as conflict avoidance, withdrawal, stonewalling (Gottman, 1994) and a dyadic pattern of interaction labelled 'demand-withdraw' (Christensen \& Heavey, 1990). However, at close inspection, it became apparent that the covert, non-verbal non-physical couple conflict was poorly understood as it has not been examined adequately (Fincham \& Beach, 1999, p. 61) and therefore required further investigation.

Preliminary qualitative studies were conducted in response to this apparent gap in knowledge with samples of New Zealand parents and adolescents (Kielpikowski, 2004; Kielpikowski \& Pryor, 2008; Pryor \& Pattison, 2007). The 
findings revealed commonalities in the perceptions of the non-verbal non-physical silent interparental conflict reported by theses two groups of informants. A comparison of findings showed that both groups identified changes in the behaviour of the conflicted parents, the lack of resolution, and the impact that the experience of silent conflict exerted on them. However, only parents have identified the perceived benefits of silent conflicts. The preliminary qualitative work carried out in these studies provided a foundation for the research agenda for this thesis.

The research programme was designed in response to several investigative goals. In order to conduct systematic analyses of the phenomena surrounding silent conflict a measurement instrument for parents was developed and validated over a series of studies with two samples of parents, one of them surveyed twice within one year. Validation of the adolescents' instrument proposed by Pryor (2003) was also conducted using longitudinal data. In an attempt to better understand the causal processes leading parents to engage in silent disagreements, predictors of silent conflict were hypothesised on the basis of my qualitative research with parents (Kielpikowski, 2004; Kielpikowski \& Pryor, 2008) and by drawing on pertinent literature explaining motivations behind various conflict behaviours (Pruitt \& Kim, 2004) and the effects of children on parents (e. g. Ambert, 2001; Kerr \& Stattin, 2003; Maccoby, 2003a). Moderating role of partners' gender on the SIC-related processes was examined in view of the indications from the existing conflict- related marital research (e. g. Christensen \& Heavey, 1990; Gottman \& Krokoff, 1989; Kluwer, et al., 1997; Roberts, 2000). The effects of silent interparental conflict on psychological wellbeing were investigated from the parents' and the adolescents' perspectives. The 
analyses took advantage of two measurement points; therefore concurrent and longitudinal explanatory process models were built. Additionally, the investigated processes were conceptualised adopting a systemic perspective in order to reflect interrelatedness and reciprocity of influences among family members. Gender differences and gender constellation effects were explored based on the existing theoretical and empirical guidelines (e. g. P. T. Davies \& Lindsay, 2001; Fincham, et al., 1997).

I began this dissertation by stating that conflict is ubiquitous but complex, a combination of characteristics illustrated by the multiplicity of definitions in simultaneous use by scholars. As a relational phenomenon, couples' conflict essentially involves two 'opponents', whose relationship is dynamically located within a greater environmental context, and should they be parents, within an immediate family context. In turn, parents provide the most direct and influential environment for development of children, who as thinking, feeling and agentic beings participate in it and influence it. Accordingly, children experience the environmental phenomenon of interparental conflict and respond to it dynamically. These dynamic networks of mutual influences are inseparable from the developmental changes in individuals, who develop (and therefore change) throughout the lifespan. Thus, the layers of complexity multiply. In an inspired fashion George Bateson (1972) likened the resulting quandary facing researchers investigating interacting biological organisms to a croquet game scene from Alice in Wonderland (Carroll, 1865/1966). In the scene, Alice famously attempts to use a flamingo (in place of a hockey stick) to direct a hedgehog (a ball) towards wickets created by bent-over soldiers, who notoriously get up and walk away. The simile has been poignantly recalled by Kuczynski, Lollis and Koguchi (2003) in 
relation to the richness of contextual and agentic interactions characterising parent-child relations.

Notwithstanding the difficulties, as scholars, we are typically motivated by the quest for singular and universal truths, which necessitates seeking of order and synthesising. The following recollection of the main findings of my research represents an attempt to coalesce the multiple facets of the story of silent interparental conflict discussed in detail within the preceding chapters. In doing so, I endeavour to compare the effects of SIC on various family members and evaluate the soundness of parental motivation behind it from the perspectives of psychological outcomes for parents and children.

\section{Parents' perspective}

I begin with parental perspective, as notwithstanding the presence of child effect, it is the parents who initiate the chain of events in focus. According to the findings of my research, the structure of silent conflict is not simple, as the benefits and the costs perceived by parents who engage in it coexist and are positively related. The perceived befits of silent conflict include an opportunity to regain emotional calm, to consider the contentious issues from a broader perspective and to understand the behaviour of one's partner. The costs are the inner tension, preoccupation and becoming disinterested and unavailable to other members of the household, including children. Therefore, silent conflict is experienced by parents as simultaneously good and bad, which in itself implies emotional dissonance for the persons engaging in it.

Both for mothers and fathers their perceptions of incidence of silent conflict lead to psychological distress. Additionally, psychological distress results from their perceptions of costs of silent conflict for the both groups of parents. 
However, importantly, these detrimental consequences of SIC for parents are contemporaneous. Additionally, only for mothers, their perceptions of greater benefits of silent conflict result in reduced distress over time.

Consistent with the well known and documented mutual influences between relational and psychological problems (e. g. Beach \& O'Leary, 1993a; Fincham, et al., 1997) psychological maladjustment appears to affect parental perceptions of silent conflict. In contrast to the short term effects of SIC on wellbeing, this relationship plays out longitudinally, as maladjustment for men seems to lead to their increased perception of costs of silent conflict over time. Unlike the distressed fathers, the distressed mothers perceive greater benefits of SIC over time, although this relationship is weakened by concurrent future distress. $^{32}$

Attempting to explain the modus operandi of silent conflict, in this work I have reached out to linguistics and social psychology. According to linguistics scholars, silent responses constitute intentional acts of communication, and as competent users of language people acquire the ability to both use them and decode them (Sifianou, 1997; Sobkowiak, 1997). Yet, regardless of this competence, silence is fraught with ambiguity of content, which stimulates speculation and is open to multiple unfavourable interpretations, such as lower than desired relational valuation, rejection, and ostracism, all of which are distressing (Leary, 2001; Williams, 2001, 2007). At the same time, communication acts terminated via silence are easier to resume than those terminated through direct verbal messages, as the very ambiguity of silence

\footnotetext{
${ }^{32}$ Longitudinal research with more than two measurement points could show more completely the effects of the cascade of mutual influences between perceptions of benefits of SIC and distress on women's wellbeing over time.
} 
allows for multiple interpretations and favourable re-interpretations (Jaworski, 1993). Accordingly, silent conflicts characteristically lack explicit reconciliation or resolution (Kielpikowski, 2004; Kielpikowski \& Pryor, 2008), as the communicative nature of silence facilitates reverting to the normal mode of interaction.

The predictors of silent conflict are threefold. It appears that the consistent concurrent and longitudinal predictor of silent conflicts for men is their own conflict avoidance, which also affects women's concurrent perceptions of SIC. For women, hostility from partner acts as the concurrent and longitudinal predictor, suggesting that according to women, anger expressed by their partners turns into SIC rather than ending in a resolution or reconciliation. This is consistent with the findings of my qualitative study (Kielpikowski, 2004; Kielpikowski \& Pryor, 2008), where silent conflicts were reported to stem from unresolved differences of opinion or arguments that were abandoned.

Concern for children acts as a concurrent predictor of SIC for women, and as both a concurrent and a longitudinal predictor of SIC for men. This finding is of particular significance for several reasons. Unlike the other two predictors (avoidance of conflict for husbands; wives' perception of husbands' hostility), concern for children implies a complicity of silence between parents, as expressed by the dyadic phrasing of the item used to measure it: ' We try to keep things calm for the kids, so instead of arguing we stop talking to each other'. Hypothesised on the basis of my interview data (Kielpikowski, 2004), it appears that for mothers the motivation is solely situational, whereas for fathers concern for children acts as both a concurrent and a longitudinal predictor of SIC. The longitudinal relationship between child concern and SIC for fathers indicates that 
for them SIC is not only a momentarily motivated method of managing the effects of interparental discord on children, but that it may also stems from a motivation that acts over time. In the context of these findings, in the next section I discuss the effects of SIC on adolescent children and consider the success of the apparent parental complicity in silence 'for the sake of children'.

\section{Adolescents' perspective}

My analyses of adolescents' data were shaped by the cognitive-contextual framework of Grych and Fincham (1990), the spillover hypothesis (Erel \& Burman, 1995), and the familywide model of interparental conflict and its effects on children of Harold and colleagues (1997). The results consistently indicated that silent interparental conflict detrimentally affected psychological adjustment of boys and girls. Moreover, in contrast to the effects of SIC on parental wellbeing, the consequences for adolescents occured not only concurrently, but also over time, which rendered them even more grievous. Additionally, adolescents experiencing silent interparental conflicts perceived their same-sex parents as more hostile, a perception that mediated the long-term effects of SIC in their adjustment. Internalising problems appeared as the most robust outcome for boys, affected directly by SIC at Time 1 and through Father's hostility ${ }^{33}$ over time. The most consistent outcome for girls was the erosion of their expectations of the future, an outcome, which according to the conceptualisation of the construct relates to pessimism, lowered motivation, and negative priming for romantic relationships. Moreover, for girls the appraisal of threat acted as an

${ }^{33}$ At Time 2, the effects of SIC on Externalising problems were fully mediated by the spillover mechanism of Father's hostility for boys and Mother's for girls, however as not replicated in other analyses; the results are reported cautiously until further research has been conducted. 
additional mediator, consequently, the effects of SIC on girls' Future Outlook were fully mediated by a combination of Threat and Mother's hostility at Time 1 . The longitudinal process for girls was twofold: SIC affected their Future Outlook at Time 2 through Mother's hostility at Time 1, and their Internalising problems at Time 2 through their perceptions of Threat at Time 1.

Analyses of the familywide model revealed that the fathers' perceptions of SIC informed the adolescents' perceptions of SIC; for boys the predictor was fathers' perception of the Benefits of SIC, and for girls it was fathers' perceptions of the Costs of SIC. Effectively, boys, whose fathers perceived greater benefits of SIC, reported more silent disagreements between their parents and also saw their fathers as more hostile. Additionally, fathers' perceptions of the Benefits of SIC exerted indirect effects on boys internalising problems both concurrently and over time as well as on their perceptions of paternal hostility towards them. Interestingly, girls whose fathers reported greater Costs of SIC perceived their mothers as more hostile. Fathers' perceptions of the Costs of SIC indirectly affected their daughters' expectations of the future both concurrently and over time as well as their perception of their mothers' hostility towards them.

In sum, the potential outcomes for girls revealed by the two longitudinal models appeared particularly dire, as apart from the emotional problems affected by threat, their expectations of the future were diminished and their relationships with both parents were affected. Whereas for boys, for whom the long-term effects centred on internalising problems and father-related processes, at least the relationships with mothers appeared undisturbed by SIC.

Overall, the consequences of SIC for adolescents, especially for girls, appear more serious than for parents. At this point it is not possible to fully 
explain why, however several reasons may be proposed. First, although the content of silent conflict is ambiguous and open to multiple interpretations to the involved partners, it is even more opaque to children, whose access to its context and history is not as immediate and complete as that of parents. Second, at least some silent conflicts may result from parents abandoning unresolved verbal arguments, only to eventually slip back to interacting normally without ever resolving the contentious issue. Although experts emphasise the importance of conflict resolution (e. g. Wilmot \& Hocker, 2007), it may not be imperative to the success of marital relationships (Gottman \& Silver, 1999). However, research indicates that resolution of interparental conflicts is of significant consequence to the wellbeing of children (Cummings, Ballard, El-Sheikh \& Lake, 1991; Cummings, Simpson \& Wilson, 1993). Third, as parents consider silent conflicts preferable to verbal arguments out of protectiveness for children, they may engage in them regularly. However, silent conflict is not innocuous to children, and its effects may also worsen through regular exposure to it, as children do not habituate to interparental conflicts, but rather become sensitised to them (Cummings \& Davies, 1994). Finally, the psychological wellbeing of parents is of consequence to children's own wellbeing, as parents provide an influential and ongoing context for children's development. In general terms, compromised parental wellbeing threatens providing for children's needs, both on the material and psychological level. More particularly, my findings indicate that for men, greater distress foretold experiencing silent conflict as more emotionally costly over time, a pattern of importance for girls' processes, as daughters' perceptions of SIC were informed by fathers' perceptions of its Costs. 


\section{Contributions of this research}

\section{Theory and measurement}

This research advanced the understanding of a newly introduced construct of silent interparental conflict. One of its major contributions is the development of the SICS, a new psychometric instrument for parents, which although multidimensional, consists of only 12 items and is accessible and easy to administer. The scale may be used to collect data from one parent representing a family, but it is preferable that it be used with parental dyads, in keeping with the systemic conceptualisation of families underpinning this work. In view of its excellent psychometric properties the SICS may be a useful addition to the available family measurement instruments. Importantly, the SICS enables comprehensive measurement of a new concept of silent interparental conflict offering the potential to open a new area for research within the field of family relationships and ultimately for professional intervention.

Another contribution is the refinement and validation of the APSICS , a multidimensional psychometric scale for the measurement of the perceptions of silent interparental conflict for adolescents designed by Pryor (2003). Based on the structural and psychometric indications obtained in this work it appears that the scale may be used with confidence.

The novelty of the concept demanded innovative and eclectic theorising in an attempt to explicate the processes behind the detrimental effects of SIC on the involved parents and reaching beyond the scholarly domain of family psychology. Explanations of the modus operandi of silence were sought drawing on linguistic sources (e. g. Jaworski, 1993, 1997; Kurzon, 1992, 1997; Sobkowiak, 1997) and social psychological findings were summoned to illuminate the distress resulting 
from silence (e. g. Leary, 2001; Williams, 2001). Additionally, relationships research and conflict and communication research were consulted in exploring conflict tactics in relation to silence, goals and gender (e. g. Pruitt \& Kim, 2004; Saville-Troike, 2003; Tannen, 1996; Wilmot \& Hocker, 2007; Zerubavel, 2006) The novel integration of the multidisciplinary findings and thought contributes to the understanding of the psychological processes surrounding silent interparental conflict.

This work contributes also to conceptualising and measurement of psychological adjustment of adolescents by construing it as two dimensional, consisting of maladjustment (internalising and externalising problems) and positive adjustment represented by a newly introduced concept of Future Outlook. Measured with an instrument developed for this study, the construct tapped into the relational aspect of the functioning of girls and proved a robust outcome in the process of the effects of SIC on their psychosocial functioning.

The vexing issue of gender

I began this research without setting out to seek gender differences; to the contrary, philosophically I am inclined to minimise them and consider males and females as similar and equal. However, the divergence between sexes in couple and children conflict-related processes found in reviewing the existing research was compelling, albeit inconsistent. Therefore, considering the moderating effect of gender on the investigated processes could not be ignored. Having completed the series of studies, it became apparent that the processes under investigation differed between mothers and fathers, as well as sons and daughters. This was sufficiently convincing to prompt the conclusion that analysing them at the level of parents and children would result in obscuring important findings of 
significance to research and practice. It has been suggested that the robustness of gender-related findings increases when parents' and children's genders are considered jointly (McHale, et al., 2003), and the results of studies presented in Chapter 4 support the importance of such fine grained gender analyses of parentchild dyadic processes.

\section{Child effect}

As discussed in the Introduction to this work, marriage research focuses on couples with the goal of better understanding and aspiration of improvement of their functioning. Family research, on the other hand, takes a perspective of children's wellbeing, largely casting parents in the roles of enablers of children's functioning. These two perspectives assume heuristic and essentially quite categorical views and focus narrowly on either the couples' or the children's outcomes. The reality of family life is more complex and has parents continuously navigating between the goals related to the welfare of their children, but also those focused on their own relationship happiness and satisfaction. The life span perspective on development has altered our conceptualisation of children as 'becomings' (Ambert, 2001, p. 15) and parents as finished and unchangeable beings. Instead it is increasingly recognised that both groups are agents, participants in their own development and influencers on their environment and relationships. Therefore, in the context of conflict, problematic child behaviours affecting parents add to the vulnerability of parents already weakened by marital challenges.

The child effect in my research was demonstrated not through agentic behaviours of children per se, but through the perceptions of men and women, who saw the need to protect children form overt expressions of discord with their 
partners. Accepting the effect of children on parents throws new light on the Dual Concern Model. It appears that the model does not adequately explain tactical options faced by parents in conflict situations, as for them the dimension of concern for children comes to play, which does not apply to childless couples. How might concern for children's welfare affect parental choices? It may depend on whether self concern is related to the best interest of the children or not. In the former case, with the two positively related, the effect would be a reinforcement of each of the four options proposed by the model $^{34}$, including stronger contending on account of a motivation to win on behalf of self and the child. When outcomes for self and the child are unrelated, it is conceivable that consideration for the child would have an ameliorating effect through lessening of the importance of own outcomes for parents and motivating them toward more altruistic tactic choices (less contending, more problem solving and yielding). Future research comparing parents to childless couples is needed to test these hypotheses.

Recognising the child effect highlights the importance of differentiating between parents and childless couples and even suggests that the existing findings regarding couples' interactions without consideration for their parenting status might need to be reconsidered. It also suggests the need for practitioners' awareness of the distinctiveness of the two groups and the potential need for specific advice and treatment despite many overlaps.

\footnotetext{
${ }^{34}$ These options are: contending, avoiding, problem solving and yielding; for discussion of the Dual Concern Model, see Part 2 of Chapter 3.
} 
Relatively little is known about the specific contribution of father-related processes in the context of interparental conflict, as until recently family studies relied predominantly on mother and child dyads as proxies for families. The importance of fathers has been highlighted by their influences on the wellbeing of both boys and girls in this research. It was found that fathers' perceptions of the Costs of silent conflict uniquely informed the daughters' perceptions of SIC occurring; whereas in the case of boys it was the fathers' perceptions of the Benefits of silent conflict. Additionally, their perceptions of father's hostility mediated the effects of SIC on boys' internalising problems over time.

Suggestions that supportive and close parent-child relationships positively influence young people regardless of the level of parental conflict (Fosco \& Grych, 2007; Grych, Raynor, \& Fosco, 2004) ${ }^{35}$. Importantly, according to one of the studies (Grych, et al., 2004), the relationships with fathers appeared to be particularly salient, as adolescents close to their fathers demonstrated lower levels of aggression and internalising. Clearly further research focusing on the individual roles of fathers and mothers within the realm of interparental conflict is needed.

\section{Strengths, limitations and suggestions for future research}

\section{Methodology}

The programme of this research was designed with the awareness of the common limitations encountered in studies of family processes. The participants were a community sample of family triads; therefore unlike numerous studies

\footnotetext{
35 The role of parental warmth towards children in mediating/moderating the effects of interparental conflict on children's adjustment is still under-researched and needs to be further examined in future studies also in the context of SIC.
} 
utilising mothers' reports to represent the parents' perspective, the parental samples in this study consisted of both fathers and mothers. Similarly, boys and girls were equally represented in the adolescents' sample, with a slight majority of males ( 61 boys to 54 girls). The composition of the sample enabled analyses reflecting the systemic links between family members, both dyadic and in samesex and opposite-sex parent-child constellations.

As the measurement was taken twice with an interval of one year, both the concurrent and the longitudinal views of processes were possible. It needs to be noted, that most researchers present either a snapshot or a long-term perspective of the investigated processes, thus circumventing justification of potentially contradictory multiple views. In this work the analyses were taken a step further as the available data were utilised to examine the cross-sectional process at both measurement times to establish the presence or absence of stability of the researched relationships, as well as longitudinally. Systemic approach to studying family dynamics

Studying the systemic dynamics within families may progress along various paths, several of which were explored throughout this thesis. It may be attempted through hypothesising the systemic influences as environmental and relational variables. (This approach was taken when constructing the adolescents' mediational adjustment models in the context of SIC and described in Part 2 of Chapter 4.) Alternatively, it may be structured through specific conceptual models, like the APIM (Kenny, 1996; Kenny, et al., 2006), which focus on mutual influences and non-independence characterising dyadic relationships. The APIMbased dyadic analyses were employed in Chapter 3 to explore the mutuality of effects between partners' perceptions in relation to SIC, its predictors and its 
effects on psychological maladjustment of spouses. Another powerful approach to studying family processes involves including reports of multiple informants on phenomena under study within a single process model. Within the domain of interparental conflict family research the approach is articulated by familywide process models of interparental conflict effects on children's adjustment, which include both the children's and the parents' reports. The approach was taken in Study 3 of Chapter 4 using a version of the model proposed by Harold and colleagues (Harold \& Conger, 1997; Harold, et al., 1997)

The sample

The sample of families participating in this series of studies is a strength but also a limitation of this research. On the one hand retaining participation of a group of 115 mothers, fathers and adolescents over 12 moths enabled asking numerous interesting questions of the data. However, several reservations may be raised about the composition of the group. The demographic characteristics of parents reveal a set of 'successful couples' judging on the basis of the longevity of their relationships. Such couples are likely to have found adaptive and mutually satisfactory ways of managing their conflicts, therefore their reports of silent conflict may possibly be lower than those of couples in less harmonious relationships.

The size of the sample and the duration of the study have been limited by the constraints on resources and time. This has precluded certain analyses, especially of adolescents' models. Introducing gender and parent-child gender constellations into analyses requires large numbers of participants. Moreover, in order to do justice to transactional processes evolving over time a longer time 
frame is necessary. Therefore, intense multiinformant longitudinal or lifespan studies would be particularly desirable and illuminating.

Recalling the ecological ideas of Uri Bronfenbrenner $(1979,1986)$ in describing the sample and situating it in a context prompts further caveats. The reality of considerable economic stability and prosperity characterising the New Zealand social landscape of the early $21^{\text {st }}$ Century (as demonstrated by exceptionally low unemployment statistics) needs to be acknowledged as a factor potentially stabilising family lives and acting to minimise incidence and intensity of interparental conflict in this study.

The families constituting the sample were predominantly white, well educated and middle class; therefore further research on samples of different demographic composition is necessary. As the sample consisted of New Zealanders, the findings reported in this research may be culture specific and require replication with members of other cultures. It needs to be noted, though, that New Zealand European culture is similar in many ways to those of Australia, Europe, and to a large extent the US. Consequently, at this point a lager question arises for future consideration, namely, whether SIC is essentially a Western phenomenon.

\section{Final conclusions}

Silent conflict is a complex and subtle phenomenon, classified within the conflict rubric on the basis of arising from disparity of goals between partners. The research programme reported in this work indicates that it adversely affects the wellbeing of parents, albeit crosscurrently, and their children, both crosscurrently and over time. Additionally, in regard to parents, it is conceivable that ongoing silent discord may result in relationship breakdown, as according to 
conflict experts, in order to achieve a satisfactory resolution conflict encounters demand mutual verbal communication (Wilmot \& Hocker, 2007). Consequently, not articulating one's reservations and grudges may instead lead to a bilateral accumulation of resentment and helplessness.

The assumption of normality and ubiquity of conflict within the realm of human interactions has moved family scientists to propound the importance for couples to manage their conflicts rather than to attempt eradicating them. According to my findings, silent conflict may be, to some extent at least, a result of attempts at such conflict management on the part of parents with a purpose of protecting children. Parents appeared to engage in it deliberately, preferring it over other types of conflict, on the assumption that it is less harmful to child witnesses.

Is it therefore legitimate to assume that in SIC parents have found the elusive satisfactory solution? Not according to the findings of my research, which demonstrate that silent conflict compromises, albeit concurrently, the wellbeing of the involved spouses; negatively affects the relationships with partners and children, and perhaps most importantly, seriously erodes children's wellbeing, as demonstrated by the long term effects on boys' and girls' internalising problems and girls' expectations of the future. Naturally, the presented programme of studies requires replication with different samples; moreover, further research is needed to show how the effects of this type of conflict compare to those of other conflict types. Nevertheless, a clear implication that emerges from it for practitioners and policy makers is to raise the awareness of parents to the detrimental psychological effects of SIC for children, which they obviously underestimate in a mistaken belief that they are protecting them. 
Despite the vastness of research examining the pathways between interparental conflict and children's outcomes, a lot still remains to be explained. Clearly new approaches that allow asking new questions are needed. To that end, some of the recent research has begun examining the process from a genetic perspective (Mannering, et al., 2011; Rhoades, et al., 2011).

In this thesis I have argued that due to the systemic nature of families and the ensuing embeddedness of one family relationship within other relationships, the wellbeing of children suffers when parental relations are compromised. However, as family researchers and practitioners we must remain optimistic in our efforts to broaden our knowledge in order to assist families. After all, as dysfunctional parental relationships communicate distress across to other family members, equally, by working to improve them, parents benefit not only themselves but also exert a positive parent effect on their children. 


\section{References}

Abramson, L. Y., Seligman, M. E., \& Teasdale, J. D. (1978). Learned helplessness in humans: Critique and reformulation. Journal of Abnormal Psychology, 87, 149-174.

Akman, V. (1994). When silence may mean derision. Journal of Pragmatics, 22, 211-218.

Ambert, A.-M. (2001). The effect of children on parents (2nd ed.). New York: Haworth Press.

Arbuckle, J. L. (2006). AMOS User's Guide 7.0: Amos Development Corporation.

Arellano, C. M., \& Markman, H. J. (1995). The Managing Affect and Differences Scale (MADS): A self-report measure assessing conflict management in couples. Journal of Family Psychology, 9, 319-334.

Bandura, A. (1977). Social learning theory. Englewood Ciffs, NJ: Prentice Hall.

Baron, R. M., \& Kenny, D. A. (1986). The moderator-mediator variable distinction in social psychological research: Conceptual, strategic, and statistical considerations. Journal of Personality and Social Psychology, $51,1173-1182$.

Bateson, G. (1972). Steps to ecology of mind: Collected essays in anthropology, psychiatry, evolution, and epistemology. New York: Ballantine.

Beach, S. R. H., Fincham, F. D., \& Katz, J. (1998). Marital therapy in the treatment of depression: Toward a third generation of therapy and research. Clinical Psychology Review, 18, 635-661.

Beach, S. R. H., \& O'Leary, K. D. (1993a). Dysphria and marital discord: Are dysphoric individuals at risk of marital maladjustment? Journal of Marital and Family Therapy, 19, 355-368. 
Beach, S. R. H., \& O'Leary, K. D. (1993b). Marital discord and dysphoria: For whom does the marital relationship predict depressive symptoms? Journal of Social and Personal Relationships, 10, 405-420.

Beaver, K. M., \& Wright, J. P. (2007). A child effect explanation for the association between family risk and involvement in an antisocial lifestyle. Journal of Adolescent Research, 27, 640-664.

Belsky, J. (1990). Children and marriage. In F. D. Fincham \& T. N. Bradbury (Eds.), The psychology of marriage: Basic issues and applications (pp. 172-200). New York: Guilford Press.

Benson, M. J., Buehler, C., \& Gerard, J. M. (2008). Interparental hostility and early adolescent problem behavior: Spillover via maternal acceptance, harshness, inconsistency, and intrusiveness. The Journal of Early Adolescence, 28, 428-454.

Block, J. H. (1983). Differential premises arising from differential socialization of the sexes: Some conjectures. Child Development, 54, 1335-1354.

Bowlby, J. (1969). Attachment and loss: Vol. 1. Attachment. London: Hogarth Press.

Bowman, M. L. (1990). Coping efforts and marital satisfaction: Measuring marital coping and its correlates. Journal of Marriage and the Family, 52, 463-474.

Bradbury, T. N., \& Fincham, F. D. (1990). Attributions in marriage: Review and critique. Psychological Bulletin, 107, 3-33.

Bradbury, T. N., \& Fincham, F. D. (1992). Attributions and behavior in marital interaction. Journal of Personality and Social Psychology, 63, 613-628. 
Bradbury, T. N., Fincham, F. D., \& Beach, S. R. H. (2000). Research on the nature and determinants of marital satisfaction: A decade in review. Journal of Marriage and the Family, 62, 964-970.

Bradford, K., Vaughn, B. L., \& Barber, B. K. (2007). When there is conflict: Interparental conflict, parent-child conflict, and youth problem behaviurs. Journal of Family Issues, 29, 780-805.

Braun, V., \& Clarke, V. (2006). Using thematic analysis in psychology. Qualitative Research in Psychology, 3, 77-101.

Bronfenbrenner, U. (1979). The ecology of human development: Experiments by nature and design. Cambridge, MA: Harvard University Press.

Bronfenbrenner, U. (1986). Ecology of the family as a context for human development: research perspectives. Developmental Psychology, 22(6), 723-742.

Brown, T. A. (2006). Confirmatory factor analysis for applied research. New York: Guilford Press.

Buehler, C., \& Gerard, J. M. (2002). Marital conflict, ineffective parenting, and children's and adolescents' maladjustment. Journal of Marriage and the Family, 64(February), 78-92.

Buehler, C., Krishnakumar, A., Stone, G., Anthony, C., Pemberton, S., Gerard, J., et al. (1998). Interparental conflict styles and youth problem behviours: A two-sample replication study. Journal of Marriage and the Family, 60, $119-132$

Buehler, C., Lange, G., \& Franck, K. L. (2007). Adolescents' cognitive and emotional responses to marital hostility. Child Development, 78, 775-789. 
Busby, D. M., Christensen, C., Crane, D. R., \& Larson, J. H. (1995). A revision of the Dyadic Adjustment Scale for use with distressed and nondistressed couples: Construct hierarchy and multidimensional scales. Journal of Marital and Family Therapy, 21, 289-308.

Byrne, B. M. (2001). Structural equation with AMOS: Basic concepts, applications, and programming. Mahwah, NJ: Erlbaum.

Carroll, L. (1966). Alice's adventures in wonderland. In The Annotated Alice. London: Penguin Books (Original work published 1865).

Cattell, R. B. (1966). The scree test for the number of factors. Multivariate Behavioral Research, 1, 245-276.

Cattell, R. B. (1978). Scientific use of factor analysis in behavioral and life scieces. New York: Plenum Press.

Christensen, A. (1988). Dysfunctional interacton patterns in couples. In P. Noller \& M. A. Fitzpatrick (Eds.), Perspectives on marital interaction (pp. 3152). Philadelphia: Multilingual Matters Ltd.

Christensen, A., \& Heavey, C. L. (1990). Gender and social structure in the demand/withdraw patterns of marital conflict. Journal of Personality and Social Psychology, 59, 73-81.

Cloven, D. H., \& Roloff, M. E. (1993). The chilling effect of aggressive potential on the expression of complaints in intimate relationships. Communication Monographs, 60, 199-219.

Coates, J. (2004). Women, men and language: A sociolinguistic account of gender differences in language (3rd ed.). UK: Pearson Education Limited.

Cox, M. J., \& Paley, B. (1997). Families as systems. Annual Review of Psychology, 48, 243 - 247. 
Cox, M. J., \& Paley, B. (2003). Understanding families as systems. Current Directions in Psychological Science, 12, 193-196.

Cox, M. J., Paley, B., \& Harter, K. (2001). Interparental conflict and parent-child relationships. In J. H. Grych \& F. D. Fincham (Eds.), Interparental conflict and child development: Theory, research and application. New York: Cambridge University Press.

Crockenberg, S., \& Forgays, D. (1996). The role of emotion in children's understanding of and emotional reactions to marital conflict. MerrillPalmer Quarterly, 42, 22-47.

Crockenberg, S., \& Leerkes, E. (2003). Infant negative emotionality, caregiving, and family relationships. In A. C. Crouter \& A. Booth (Eds.), Children's influence on family dynamics: The neglected side of family relationships (pp. 57-78). Mahwah, NJ: Lawrence Erlbaum.

Crouter, A. C., \& Booth, A. (Eds.). (2003). Children's influence on family dynamics: The neglected side of family relationships. Mahwah, NJ: Lawrence Erlbaum

Crowne, D. P., \& Marlowe, D. (1960). A new scale of social desirability independent of psychopathology. Journal of Consulting Psychology, 24, 349-354.

Cummings, E. M., Ballard, M., El-Sheikh, M., \& Lake, M. (1991). Resolution and children's responses to interadult anger. Developmental Psychology, 27, $462-470$.

Cummings, E. M., \& Davies, P. T. (1994). Children and marital conflict. The impact of family dispute and resolution. New York: The Guildford Press. 
Cummings, E. M., \& Davies, P. T. (2002). Effects of marital conflict on children: recent advances and emerging themes in process-oriented research. Journal of Child Psychology and Psychiatry, 43(1), 31-63.

Cummings, E. M., Davies, P. T., \& Campbell, S., B. (2000). Developmental psychopathology and family process: Theory, research, and clinical implications. New York: Guilford Press.

Cummings, E. M., Goeke-Morey, M. C., \& Papp, L. M. (2003). Children's responses to everyday marital conflict tactics in the home. Child Development, 74(6), 1918.

Cummings, E. M., Simpson, K. S., \& Wilson, A. (1993). Children's responses to interadult anger as a function of information about resolution. Developmental Psychology, 29, 978-985.

Cupach, W. R., \& Canary, D. J. (1997). Competence in interpersonal conflict: McGraw-Hill.

Dadds, M. R., Atkinson, E., Turner, C., Blums, G. J., \& Lendich, B. (1999). Family conflict and child adjustment: Evidence for a cognitive-contextual model of intergenerational transmission. Journal of Family Psychology, 13, 194-208.

Davies, P. T., \& Cummings, E. M. (1994). Marital conflict and child adjustment: An emotional security hypothesis. Psychological Bulletin, 116, 387-411.

Davies, P. T., Harold, G. T., Goeke-Morey, M., \& Cummings, E. M. (2002). Child emotional security and interparental conflict. Monographs of the Society for Research in Child Development, 67(3, Serial No. 270).

Davies, P. T., \& Lindsay, L. L. (2001). Does gender moderate the effects of marital conflict on children? In J. H. Grych \& F. D. Fincham (Eds.), 
Interparental conflict and child development: Theory, research and application. New York: Cambridge University Press.

Davies, P. T., Sturge-Apple, M. L., Winter, M. A., Cummings, E. M., \& Farrell, D. (2006). Child adaptational development in contexts of interparental conflict over time. Child Development, 77, 218-233.

Davis, B. T., Hops, H., Albert, H., \& Sheeber, L. (1998). Child responses to parental conflict and their effect on adjustment: A study of triadic relations. Journal of Family Psychology, 12, 163-177.

De Arth-Pendley, G., \& Cummings, E. M. (2002). Children's emotional reactivity to interadult nonverbal conflict expressions. Journal of Genetic Psychology, 163, 97-112.

Deal, J. E., Hogan, M. S., Bass, B., Hetherington, E. M., \& Clingempeel, G. (1999). Marital interaction in dyadic and triadic contexts: Continuities and discontinuities. Family Process, 38, 105-115.

Deutsch, M., \& Coleman, P. T. (Eds.). (2000). The handbook of conflict resolution: Theory and practice. San Francisco, CA: Jossey-Bass.

DeVellis, R. F. (2003). Scale development:Theory and application (2nd ed.). Thousand Oaks, CA: Sage.

Douglass, F. M., \& Douglass, R. (1995). The Marital Problems Questionnaire (MPQ): A short screening instrument for family therapy. Family Relations, 44, 238-244.

Du Rocher Schudlich, T. D., Shamir, H., \& Cummings, E. M. (2004). Marital conflict, children's representations of family relationships, and children dispositions towards peer conflict strategies. Social Development, 13, 171. 
Dunn, J. (1983). Sibling relationships in early childhood. Child Development, 54, $787-811$.

Eckert, P., \& McConnell-Ginet, S. (2003). Language and gender. Cambridge: Cambridge University Press.

Eggeman, K. W., Moxley, V., \& Schumm, W. R. (1985). Assessing spouses' perceptions of Gottman's temporal form in marital conflict. Psychological Report, 57, 171-181.

El-Sheikh, M., Buckhalt, J. A., Cummings, E. M., \& Keller, P. (2007). Sleep disruptions and emotional insecurity are pathways of risk for children. Journal of Child Psychology and Psychiatry, 88-96.

El-Sheikh, M., Buckhalt, J. A., Mize, J., \& Acebo, C. (2006). Marital conflict and disruption of children's sleep. Child Development, 77, 31-43.

El-Sheikh, M., \& Reiter, S. L. (1996). Children's responses to live interadult conflict: The role of form of anger expression. Journal of Abnormal Child Psychology, 24, 401-415.

Eldridge, K. A., \& Christensen, A. (2002). Demand-withdraw communication during couple conflict: A review and analysis. In P. Noller \& J. A. Feeney (Eds.), Understanding marriage: Developments in the study of couple interaction. Cambridge, England: Cambridge University Press.

Elkind, D. (1967). Egocentrism in adolescence. Child Development, 38, 10251034.

Elkind, D. (1985). Egocetrism redux. Developmental Review, 5, 218-226.

Emery, R. E., \& O'Leary, K. D. (1982). Children's perceptions of marital discord and behavior problems of boys and girls. Journal of Abnormal Child Psychology, 10, 11-24. 
Epstein, N., Pretzer, J. J., \& Fleming, B. (1987). The role of cognitive appraisal in self-reports of marital communication. Behavioral Therapy, 18, 51-69.

Erel, O., \& Burman, B. (1995). Interrelatedness of marital relations and parentchild relations: A meta-analytic review. Psychological Bulletin, 188, 108132.

Fabrigar, L. R., Wegener, D. T., MacCallum, R. C., \& Strahan, E. J. (1999). Evaluating the use of exploratory factor analysis in psychological research. Psychological Methods, 4, 272-299.

Fauber, R. L., Forehand, R., Thomas, A. M., \& Wierson, M. (1990). A mediational model of the impact of marital conflict on adolescent adjustment in intact and divorced families: The role of disrupted parenting. Child Development, 61, 1112-1123.

Fauber, R. L., \& Long, N. (1991). Children in context: The role of the family in child psychotherapy. Journal of Consulting and Clinical Psychology, 59, 813-820.

Fincham, F. D. (2003). Marital conflict: Correlates, structure, and context. Current Directions in Psychological Science, 12, 123-127.

Fincham, F. D., \& Beach, S. R. H. (1999). Conflict in marriage: Inplications for working with couples. Annual Review of Psychology, 50, 47-77.

Fincham, F. D., \& Beach, S. R. H. (2007). Forgiveness and marital quality: Precursr or consequence in well-established relationships? The Journal of Positive Psychology, 14, 260-268.

Fincham, F. D., Beach, S. R. H., Harold, G. T., \& Osborne, L. N. (1997). Marital satisfaction and depression: Different causal relationships for men and women. Psychological Science, 8, 351-357. 
Forehand, R., Wierson, M., Thomas, A. M., Armistead, L., Kempton, T., \& Neigbors, B. (1991). The role of family stressors and parent relationships on adolescent functioning Journal of the American Academy of Child \& Adolescent Psychiatry, 30, 316-322.

Fosco, G. M., \& Grych, J. H. (2007). Emotional expression in the family as a context for children's appraisals of interparental conflict. Journal of Family Psychology, 21, 248-258.

Fosco, G. M., \& Grych, J. H. (2008). Emotional, cognitive, and family systems mediators of children's adjustment to interparental conflict. Journal of Family Psychology, 22, 843-854.

Fraboni, M., \& Cooper, D. (1989). Further validation of the three short forms of the Marlowe-Crowne Scale of Social Desirability. Psychological Reports, $65,595-600$.

Franck, K. L., \& Buehler, C. (2007). A family process model of marital hostility, parental depressive affect, and early adolescent problem behavior: The role of triangulation and parental warmth. Journal of Family Psychology, $21,614-625$.

Fredman, N., \& Sherman, R. (1987). Handbook of measurement for marriage and family therapy. Philadelphia, PA: Brunner/Mazel, Inc.

Frosch, C. A., Mangelsdorf, S. C., \& McHale, J. I. (1998). Correlates of marital behaviour at 6 months postpartum. Developmental Psychology, 34, 14381449.

Gerard, J. M., Buehler, C., Franck, K., \& Anderson, O. (2005). In the eyes of the beholder: Cognitive appraisals as mediators of the association between 
interparental conflict and youth maladjustment. Journal of Family Psychology, 19, 376-384.

Gerard, J. M., Krishnakumar, A., \& Buehler, C. (2006). Marital conflict, parentchild relations, and youth maladjustment: A longitudinal investigation of spillover effects. Journal of Family Issues, 951-975.

Giles, D. C. (2002). Advanced research methods in psychology. New York: Routledge.

Gilligan, C. (1992). In a Different Voice: Psychological theory and women's development. Cambridge, MA: Harvard University Press.

Goeke-Morey, M., C., Cummings, E. M., Harold, G. T., \& Shelton, K. H. (2003). Categories and continua of destructive and constructive marital conflict tactics from the perspective of U.S. and Welsh children. Journal of Family Psychology, 17, 327-338.

Goodman, R. (1997). The Strengths and Difficulties Questionnaire: A research note. Journal of Child Psychology and Psychiatry, 38, 581-586.

Goodman, R. (2001). Psychometric properties of the Strengths and Difficulties Questionnaire (SDQ). Journal of the American Academy of Child \& Adolescent Psychiatry, 40, 1337-1345.

Goodman, R., Melzer, H., \& Bailey, V. (1998). The Strengths and Difficulties Questionnaire: A pilot study on the validity of the self-report version. European Child and Adolescent Psychiatry, 7, 125-130.

Gottman, J. M. (1994). What predicts divorce. Hillside, NJ: Lawrence Erlbaum Associates.

Gottman, J. M. (1998). Psychology and the study of marriage. Annual Review of Psychology, 49, 169-197. 
Gottman, J. M., \& Krokoff, L. J. (1989). Marital interaction and satisfaction: A longitudinal view. Journal of Consulting and Clinical Psychology, 57, 4752.

Gottman, J. M., \& Levenson, R. W. (1986). Assessing the role of emotion in marriage. Behavioral Assessment, 8, 31-48.

Gottman, J. M., \& Levenson, R. W. (1988). The social psychophysiology of marriage. In P. Noller \& M. A. Fitzpatrick (Eds.), Perspectives on marital interaction. Philadelphia: Multilingual Matters Ltd.

Gottman, J. M., \& Silver, N. (1999). The seven principles of making marriage work. New York: Crown Publishers.

Grych, J. H., \& Cardoza-Fernandes, S. (2001). Understanding the impact of interparental conflict on children: the role of social cognitive processes. In J. H. Grych \& F. D. Fincham (Eds.), Interparental conflict and child development: Theory, research and application. New York: Cambridge University Press.

Grych, J. H., \& Fincham, F. D. (1990). Marital conflict and children's adjustment: A cognitive-contextual framework. Psychological Bulletin, 108(2), 267290.

Grych, J. H., \& Fincham, F. D. (1993). Children's apraisals of marital conflict: Initial investigation of the cognitive-contextual framework. Child Development, 64, 215-230.

Grych, J. H., Fincham, F. D., Jouriles, E. N., \& McDonald, R. (2000). Interparental conflict and child adjustment: Testing the mediational role of appraisals in the cognitive-contextual framework. Child Development, 6, $1648-1661$. 
Grych, J. H., Harold, G. T., \& Miles, C. J. (2003). A Prospective Investigation of Appraisals as Mediators of the Link Between Interparental Conflict and Child Adjustment. Child Development, 74(4), 1176-1193.

Grych, J. H., Raynor, S. R., \& Fosco, G. M. (2004). Family processes that shape the impact of interparental conflict on adolescents. Development and Psychopathology, 16, 649-665.

Grych, J. H., Seid, M., \& Fincham, F. D. (1992). Assessing marital conflict from the child's prspective: The Children's Perception of Interparental Conflict Scale. Child Development, 63, 558-572.

Guerrero, L. K., \& Floyd, K. (2006). Nonverbal communication in close relationships. Mahwah, NJ: Lawrence Erlbaum Associates.

Hair, J. F., Anderson, R. E., Tatham, R. L., \& Black, W. C. (1998). Multivariate data analysis (5th ed.). Englewood Cliffs, NJ: Prentice Hall.

Harold, G. T., Aitken, J. J., \& Shelton, K. H. (2007). Inter-parental coflict and child academic attainment: A longitudinal analysis. Journal of Child Psychology and Psychiatry, 48, 1223-1232.

Harold, G. T., \& Conger, R. D. (1997). Marital conflict and adolescent distress: The role of adolescent awareness. Child Development, 68(2), 333-350.

Harold, G. T., Fincham, F. D., Osborne, L. N., \& Conger, R. D. (1997). Mom and Dad are at it again: Adolescent perceptions of marital conflict and adolescent psychological distress. Developmental Psychology, 33(2), 333350.

Hayes, A. F. (2009). Beyond Baron and Kenny: Statistical mediation analysis in the new millenium. Communication Monographs, 76, 408-420. 
Haynes, S. M., Chavez, R. E., \& Samuel, V. (1984). Assessment of marital communication and distress. Bahavioral Therapy, 51-69.

Heavey, C. L., Layne, C., \& Christensen, A. (1993). Gender and conflict structure in marital interaction: A replication and extension. Journal of Consulting and Clinical Psychology, 61, 16-27.

Heene, E. L. D., Buysse, A., \& Oost, P. v. (2005). Indirect pathways between depressive symptoms and marital distress: The role of conflict communication, attribution, and attachment style. Family Process, 44, 413-440.

Henson, R. K., \& Roberts, J. K. (2006). Use of exploratory factor analysis in published research: common errors and some comment on improved practice. Educational and Psychological Measurement, 66, 393-416.

Horn, J. L. (1965). A rationale and test for the number of factors in factor analysis. Psychometrika, 30, 179-185.

Hu, L., \& Bentler, P. M. (1999). Cutoff criteria for fit indices in covariance structure analysis: Conventional criteria versus new alternatives. Structural Equation Modeling, 6, 1-55.

Huh, D., Tristan, J., Wade, E., \& Stice, E. (2006). Does problem behavior elecit poor parenting? A prospective study of adolescent girls. Journal of Adolescent Research, 21, 185-204.

Infante, D. A., Sabourin, T. A., \& Rudd, J. E. (1989). Test of an argumentative skill defficiency model if interspousal violence. Communication Monographs, 56, 163-177. 
Infante, D. A., Sabourin, T. A., Rudd, J. E., \& Shannon, E. A. (1990). Verbal aggression in violent and nonviolent marital disputes. Communication Quarterly, 38, 361-371.

Jack, D. (1991). Silencing the self: Women and depression. Cambridge, MA: Harvard University Press.

Jack, D., \& Dill, D. (1992). The Silencing the Self scale: Schemas of intimacy associated with depression in women. Psychology of Women Quarterly, $16,97-106$.

Jacobson, N. S. (1990). Commentary: Contributions from psychology to an understanding of marriage. In F. D. Fincham \& T. N. Bradbury (Eds.), The psychology of marriage: Basic issues and applications (pp. 258-275). New York: Guilford Press.

Jaworski, A. (1993). The power of silence: Social and pragmatic perspectives. Newbury Park: Sage

Jaworski, A. (Ed.). (1997). Silence: Interdisciplinary perspectives. Berlin \& New York: Mouton de Gruyter.

Johannesen, R. L. (1974). The functions of silence: A plea for communication research. Western Journal of Communication 38, 25-35.

Johnson, D., White, L., Edwards, J., \& Booth, A. (1986). Dimensions of marital quality: Toward methodological and conceptual refinement. Journal of Family Issues, 7, 31-49.

Karney, B. R., \& Bradbury, T. N. (1995). The longitudinal course of marital quality and stability: A review of theory, method and research. Psychological Bulletin, 118, 3-34. 
Katz, L. F., \& Gottman, J., M. (1993). Patterns of marital conflict predict children's internalizing and externalizing behaviors. Developmental Psychology, 29, 940-950.

Katz, L. F., \& Woodin, E. M. (2002). Hostility, hostile detachment, and conflict engagement in marriages: effects on child and family functioning. 73, 2 .

Kelly, J. R., \& McGrath, J. B. (1988). On time and method. Newbury Park, CA: Sage.

Kelly, K. M. (2001). Individual differences in reactions to rejection. In M. R. Leary (Ed.), Interpersonal rejection (pp. 291-316). New York: Oxford University Press.

Kelso, J., Stewart, M. A., Bullers, L., \& Eginton, R. (1984). The Measure of Marital Satisfaction: A questionnaire to screen parents for marital problems. Child Psychiatry and Human Development, 15, 86-103.

Kenny, D. A. (1996). Models of non-independence in dyadic research. Journal of Social and Personal Relationships, 13, 279-294.

Kenny, D. A., Kashy, D. A., \& Cook, W. L. (2006). Dyadic data analysis. New York: Guliford Press.

Kerig, P. K. (1995). Triangles in the family circle: Effects of family structure on marriage, parenting, and child adjustment. Journal of Family Psychology, 9, 28-43.

Kerig, P. K. (1996). Assessing the links between interparental conflcit and child adjustment: The Conflicts and Problem-Solving Scales. Journal of Family Psychology, 10, 454-473. 
Kerig, P. K. (1998a). Gender and appraisals as mediators of adjustment in children exposed to interparental violence. Journal of Family Violence, $15,345-363$.

Kerig, P. K. (1998b). Moderators and mediators of the effects of interparental conflict on children's adjustment. Journal of Abnormal Child Psychology, $26,199-212$.

Kerr, M., \& Stattin, H. (2003). Parenting adolescents: Action or reaction? In A. C. Crouter \& A. Booth (Eds.), Children's influence on family dynamics: The neglected side of family relationships (pp. 121-151). Mahwah, NJ: Lawrence Erlbaum.

Keyes, C. L., Shmotkin, D., \& Ryff, C. D. (2002). Optimizing well-being:The empirical encounter of two traditions. Journal of Personality and Social Psychology, 82, 1007-1022.

Kiecolt-Glaser, J. K., Newton, T., Cacioppo, J. T., MacCallum, R. C., Glaser, R., \& Malarkey, W. B. (1996). Marital conflict and endocrine function: Are men really more physiologically affected than women? Journal of Consulting and Clinical Psychology, 64, 324-332.

Kielpikowski, M. M. (2004). Silent parental conflict: Parents' perspective. Unpublished honours thesis, Victoria University of Wellington, Wellington, New Zealand.

Kielpikowski, M. M., \& Pryor, J. E. (2008). Silent parental conflict: Parents' perspective. Journal of Family Studies, 14, 217-227.

King, M. F. (2003). The Penguin history of New Zealand. Auckland, New Zealand: Penguin Books (NZ) Ltd. 
King, M. F., \& Bruner, M. (2000). Social desirability bias: A neglected aspect of validity testing. Psychology and Marketing, 17, 79-.

Klein, R. C. A., \& Johnson, M. P. (2000). Strategies of couple confict. In R. M. Milardo \& S. Duck (Eds.), Families as relationships. New York: Wiley.

Kline, P. (2000). The handbook of psychological testing (2nd ed.). New York: Routledge.

Kline, R. B. (2005). Principles and practice of structural equation modeling (2nd ed.). New York: Guilford Press.

Klinetob, N. A., \& Smith, D. A. (1996). Demand-withdraw communication in marital interaction: Tests of interspousal contingency and gender role hypotheses. Journal of Marriage and the Family, 58, 945-957.

Kluwer, E. S. (2000). Marital quality. In R. M. Milardo \& S. Duck (Eds.), Families as relationships (pp. 59-78). New York: Wiley

Kluwer, E. S., Heesink, J. A., \& Vliert, E. V. D. (1997). The marital dynamics of conflict over the division of labor. Journal of Marriage and the Family, $59,635-653$.

Kochanska, G. (1997a). Multiple pathway to conscience for children with different temperaments: From toddlerhood to age 5. Developmental Psychology, 33, 228-240.

Kochanska, G. (1997b). Mutually responsive orientation between mothers and their young children: Implications for early socialization. Child Development, 68, 908-923.

Kouros, C. D., Papp, L. M., \& Cummings, E. M. (2008). Interrelations and moderators of longitudinal links between marital satisfaction and 
deressive symptoms among couples in established relationships. journal of Family Psychology, 22, 667-677.

Krishnakumar, A., \& Buehler, C. (2000). Interparental conflict and parenting behaviors: A meta-analytic review. Family Relations, 49, 25-44.

Kuczynski, L., Lollis, S., \& Koguchi, Y. (2003). Reconstructing common sense: Metaphors of bidirectionality in parent-child relations. In L. Kuczynski (Ed.), Handbook of dynamics in parent-child relations. Thousand Oaks, CA: Sage.

Kurdek, L. A. (1994a). Areas of conflict for gay, lesbian, and heterosexual couples: What couples argue about influences relationship satisfaction. Journal of Marriage and the Family, 56, 923-934.

Kurdek, L. A. (1994b). Conflict resolution style in gay, lesbian, heterosexual nonparent, and heterosexual parent couples. Journal of Marriage and the Family, 56, 705-722.

Kurdek, L. A. (1995). Predicting change in marital satisfction from husbands' and wives' conflict resolution styles. Journal of Marriage and the Family, 57, 153-164.

Kurzon, D. (1992). When silence may mean power. Journal of Pragmatics, 18, 92-95.

Kurzon, D. (1997). Discourse of silence. Amsterdam/Philadelphia: John Benjamins Publishing.

Lazarus, R. S. (1991). Emotion and adaptation. New York: Oxford University Press.

Lazarus, R. S., \& Folkman, S. (1984). Stress, appraisal and coping. New York: Springer. 
Leary, M. R. (2001). Toward a conceptualization of interpersonal rejection. In M. R. Leary (Ed.), Interpersonal rejection (pp. 3-20). New York: Oxford Univeristy Press.

Leite, W. L., \& Beretvas, N. (2005). Validation of scores on marlowe-Crowne Social Desirability Scale and the Balanced Inventory of Desirable Responding. Educational and Psychological Measurement, 65, 140-154. Locke, H. J., \& Wallace, K. M. (1959). Short marital adjustment prediction tests: Their reliability and validity. Marriage and Family Living, 21, 251-255. Maccoby, E. E. (2003a). The gender of child and parent as factors in family dynamics. In A. C. Crouter \& B. A (Eds.), Children's influence on family dynamics: The neglected sid of family relationships (pp. 191-206). Mahwah, NJ: Lawence Erlbaum.

Maccoby, E. E. (2003b). Reply to Stattin-Kerr critique. In A. C. Crouter \& A. Booth (Eds.), Children's influence on family dynamics: The neglected side of family relationships (pp. 227-228). Mahwah, NJ: Lawrence Erlbaum.

Maccoby, E. E., \& Jacklin, C. N. (1974). The psychology of sex differences. Stanford, CA: Stanford University Press.

MacKinnon, D. P., Lockwood, C. M., Hoffman, J. M., West, S. G., \& Sheets, V. (2002). A comparison of methods to test mediation and other intervening variable effects. Psychological Methods, 7, 83-104.

Mann, B. J., \& Gilliom, L. A. (2002). Emotional security and cognitive appraisals mediate the relationship between parents' marital conflict and adjustment in older adolescents. Journal of Genetic Psychology, 165, 250-271.

Mannering, A. M., Harold, G. T., Leve, L. D., Shelton, K. H., Shaw, D. S., Conger, R. D., et al. (2011). Longitudinal associations between marital 
instability and child sleep problems across infancy and toddlerhood in adoptive families. Child Development, 82, 1252-1266.

Markman, H. J., Silvern, L., Clements, M., \& Kraft-Hanak, S. (1993). Men and women dealing with conflict in heterosexual relationships. Journal of Social Issues, 49, 107-125.

Markman, H. J., Stanley, S., \& Blumberg, S. L. (1994). Fighting for your marriage. San Francisco: Jossey-Bass.

McDonald, R., \& Grych, J. H. (2006). Young children's appraisals of interparental conflict: Measurement and links with adjustment problems. Journal of Family Psychology, 20, 88-99.

McGinn, M. M., McFarland, P. T., \& Christensen, A. (2009). Antecedants and conseuences of demad/withdraw. Journal of Family Psychology, 23, 749757.

McHale, S. M., \& Crouter, A. C. (2003). How do children exert an impact on family life? In A. C. Crouter \& A. Booth (Eds.), Children's influence on family dynamics: The neglected side of family relationships (pp. 207-220). Mahwah, NJ: Lawrence Erlbaum.

McHale, S. M., Crouter, A. C., \& Tucker, C. J. (1999). Family context and gender role socialization in middle childhood: Comparing girls to boys and sisters to brothers. Child Development, 70, 990-1004.

McHale, S. M., Crouter, A. C., \& Whiteman, S. D. (2003). The family contexts of gender development in childhood and adolescence. Social Development, $12,125-148$

Melby, J. N., Conger, R. D., Book, R., Rueter, M., Lucy, L., Repinski, D., et al. (1993). The Iowa Family Interaction Rating Scales, 2nd Edition 
Unpublished manuscript, Iowa State University Center for Family Research in Rural Mental Health.

Melby, J. N., Conger, R. D., Ge, X., \& Warner, T. D. (1995). The use of structural equation modeling in assessinf the quality of marital observations. Journal of Family Psychology 9, 280-293.

Mellor, D. (2005). Normative data for the Strengths and Difficulties Questionnaire in Australia. Australian Psychologist, 40, 215-222.

Meltzer, H., Gatward, R., Goodman, R., \& Ford, F. (2000). Mental heath of children and adolescents in Great Britain. London: The Stationery Office.

Minuchin, P. (1985). Families and individual development: Provocations from the field of family therapy. Child Development, 56, 289-301.

Murphy, C. M., \& O'Farrell, T. J. (1994). Factors associated with marital aggression in male alcoholics. Journal of Family Psychology, 8, 321-335.

Napier, A. Y. (1978). The rejection-intrusion pattern: A central family dynamic. Journal of Marriage and Family Counseling, 4, 5-12.

Netemeyer, R. G., Bearden, W. O., \& Sharma, S. (2003). Scaling procedures: Issues and applications. Thousand Oaks, CA.

Noller, P. (1993). Gender and emotional communication in marriage: Different cultures or different social power? Journal of Language and Social Psychology, 12, 132-152.

Notarius, C., \& Vanzetti, N. (1983). The Marital Agendas Protocol. In E. E. Filsinger (Ed.), A sourcebook of marital and family assessment (pp. 209227). Beverly Hills, CA: Sage.

Nye, F. I., \& MacDougall, E. (1959). The dependent variable in marital research. Pacific Sociological Review, 2, 67-70. 
O'Leary, K. D., Christian, J. L., \& Mendell, N. R. (1994). A closer look at the link between marital discord and depressive symptomatology. Journal of Social and Clinical Psychology, 13, 33-41.

Paley, B., Conger, R., \& Harold, G. T. (2000). Parents' Affect, Adolescent Cognitive Representations, and Adolescent Social Development. Journal of Marriage and the Family, 62(August 2000), 761-776.

Papp, L. M., Cummings, E. M., \& Goeke-Morey, M. (2002). Marital conflict in the home when children are present versus absent. Developmental Psychology, 38, 774-783.

Papp, L. M., Cummings, E. M., \& Goeke-Morey, M. C. (2002). Marital conflict in the home when children are present versus absent. Developmental Psychology, 38, 774-783.

Paulhus, D. L. (1984). Two-component models of socially desirable responding. Journal of Personality and Social Psychology, 46, 598-609.

Paulhus, D. L. (1991). Measurement and control of response bias. In J. P. Robinson, P. R. Shaver \& L. S. Wrightsman (Eds.), Measures of personality and social psychological attitudes. San Diego, CA: Academic Press.

Porter, B., \& O'Leary, K. D. (1980). Marital discord and childhood behaviour problems. Journal of Abnormal Child Psychology, 8, 287-295.

Preacher, K. J., \& MacCallum, R. C. (2003). Repairing Tom Swift's electric factor analysis machine. Understanding Statistics, 2, 13-43.

Proulx, C. M., Helmes, H. M., \& Buehler, C. (2007). Marital quality and personal well-being: A meta-analysis. Journal of Marriage and the Family, 69, 576-593. 
Pruitt, D. G., \& Kim, S. H. (2004). Social conflict: Escalation, stalemate, and settlement (3rd ed.). Boston: McGraw Hill.

Pryor, J. E. (2003). [Adolescents' experiences of non-verbal non-physical parental conflicts]. Unpublished data.

Pryor, J. E., \& Pattison, R. (2007). Adolescents' perceptions of parental conflict: The downside of silence. Journal of Family Studies, 13, 72-77.

Rands, M., Levinger, G., \& Mellinger, G. D. (1981). Patterns of conflcit resolution and marital satisfaction. Journal of Family Issues, 2, 297-321.

Raykov, T., \& Marcoulides, G. A. (2006). A first course in structural equation modeling (2 ed.). Mahwah, NJ: Erlbaum

Rhoades, K. A., Leve, L. D., Harold, G. T., Neiderhiser, J. M., Shaw, D. S., \& Reiss, D. (2011). Longitudinal pathways from marital hostility to child anger during toddlerhood: Genetic susceptibility and indirect effects via harsh parenting. Journal of Family Psychology, 25, 282-294.

Roberts, L. J. (2000). Fire and ice in marital communication: Hostile and distancing behaviors as predictors of marital distress. Journal of Marriage and the Family, 62, 693-707.

Romaine, S. (1999). Communicating gender. Mahwah, NJ: Lawrence Erlbaum Associates.

Ryder, R. G. (1964). Profile factor analysis and variable factor analysis. Psychological Reports, 15, 119-127.

Ryff, C. D., \& Keyes, C. L. M. (1995). The structure of psychological wellbeing revisited. Journal of Personality and Social Psychology, 69, 719-727. 
Sauers, D. A., Kennedy, J. C., \& O'Sullivan, D. (2002). Managerial sex role stereotyping: A New Zealand perspective. Women in Management Review, 17, 342-347.

Saville-Troike, M. (2003). The etnography of communication: An introduction (3rd ed.). Malden, MA: Blackwell Publishing Ltd.

Scanzoni, J. (1970). Opportunity and the family. New York: Free Press.

Schoppe-Sullivan, S. J., Schermerhorn, A. C., \& Cummings, E. M. (2007). Marital conflict and children's adjustment: Evaluation of the parenting process model. Journal of Marriage and the Family, 69, 1118-1134.

Schumm, W. R. (2001). Evolution of the family field: Measurement principles and techniques. In J. Touliatos, B. F. Perlmutter \& M. A. Straus (Eds.), Handbook of family measurement techniques (pp. 1-8). Thousand Oaks: CA: Sage.

Schwarz, J. C., \& Zuroff, D. C. (1979). Family structure and depression in female college students: Effects of parental conflict, decision-making power, and inconsistency of love. Journal of Consulting and Clinical Psychology, 56, 91-96.

Seginer, R. (2009). Future orientation: Developmental and ecological perspectives. New York: Springer.

Segrin, C., Hanzal, A., \& Domschke, T. J. (2009). Accuracy and bias in newlywed couples' perceptions of conflict styles and the association with marital satisfaction. Communication Monographs, 76, 207-233.

Seligman, M. E. P. (1975). Helplessness: On depression, development and death. San Francisco: Freeman \& Co. 
Shanahan, L., \& Sobolewski, J. M. (2003). Child effects and family process. In A. C. Crouter \& A. Booth (Eds.), Children's influence on family dynamic: The neglected side of family relationships (pp. 237-252). Mahwah, NJ: Lawrence Erlbaum.

Shantz, C. U., \& Hobart, C. J. (1989). Social conflict and development: Peers and siblings. In T. J. Brendt \& G. W. Ladd (Eds.), Peer relationships and child development (pp. 71-94). New York: Wiley.

Shelton, K. H., \& Harold, G. T. (2007). Marital conflict and children adjustment: The mediating and moderating role of children's coping strategies. Social Development, 16, 497-512.

Shepard, M. F., \& Campbell, J. A. (1992). The Abusive Behavior Inventory: A measure of psychological and physical abuse. Journal of Interpersonal Violence, 7, 291-305.

Shermerhorn, A. C., Cummings, E. M., DeCarlo, C. A., \& Davies, P. T. (2007). Children's influence in the marital relationship. Journal of Family Psychology, 21, 259-269.

Sifianou, M. (1997). Silence and politeness. In A. Jaworski (Ed.), Silence: Interdisciplinary perspectives (pp. 63-84). Berlin \& New York: Mouton de Gruyter.

Snaith, R. P., Constantopoulos, A. A., Jardine, M. Y., \& McGuffin, P. (1978). A clinical scale for the self-assessment of irritability. British Journal of Psychiatry, 132, 163-171.

Sobkowiak, W. (1997). Silence and markedness theory. In A. Jaworski (Ed.), Silence: Interdisciplinry perspectives (pp. 39-61). Berlin \& New York: Mouton de Gruyter. 
Sommer, K. (2001). Coping with rejection: Ego defensive strategies, self-esteem, and interpersonal relationships. In M. R. Leary (Ed.), Interpesonal rejection (pp. 167-188). New York: Oxford University Press.

Spanier, G. B. (1976). Measuring dyadic adjustment: New scales for assessing the quality of marriage and similar dyads. . Journal of Marriage and the Family, 38, 15-28.

Stanley, S. M., \& Markman, H. J. (1996). National survey of couples relationships in the United States. Denver, CO: University of Denver.

Stevens, F. E., \& L'Abate, L. (1989). Validity and reliability of theory-derived mesure of intimacy. American Journal of Family Therapy, 17, 359-368.

Strahan, R., \& Gerbasi, K. C. (1972). Short, homogenous version of the MarloweCrowne Social Desirability Scale. Journal of Clinical Psychology, 28, 191-193.

Straus, M. A. (1979). Measuring intrafamily conflict and violence: The Conflict Tactics (CT) Scales. Journal of Marriage and the Family, 41, 75-88.

Straus, M. A., Hamby, S. L., Boney-McCoy, S., \& Sugerman, D. B. (1996). The Revised Tactics Scale (CTS2): Development and preliminary psychometric data. Journal of Family Issues, 17, 283-316.

Sturge-Apple, M. L., Davies, P. T., \& Cummings, E. M. (2006a). Hostility and withdrawal in marital conflict: Effects on parental emotional unavailability and inconsistent discipline. Journal of Family Psychology, $20,227-238$

Sturge-Apple, M. L., Davies, P. T., \& Cummings, E. M. (2006b). Impact of hostility and withdrawal in interparental conflict on parental emotional 
unavailability and children's adjustment difficulties. Child Development, $77,1623-1641$.

Sullaway, M., \& Christensen, A. (1983). Assessment of dysfunctional interaction patterns in couples. Journal of Marriage and the Family, 45, 653-660.

Swensen, C. H., \& Fiore, A. (1975). A factored measure of the primary dimension in marriage. In J. W. Pfeiffer \& J. E. Jones (Eds.), The 1975 handbookfor group facilitators. San Diego, CA: University Associates.

Tabachnick, B. G., \& Fidell, L. S. (2007). Using multivariate statistics (5th ed.). Boston, MA: Pearson Education Inc.

Tannen, D. (1990). You just don't understand. New York: Morrow.

Tannen, D. (1996). Gender and discourse. New York: Oxford University Press.

Taylor, S. E., \& Brown, J. D. (1988). Illusion and well-being: A socialpsychological perspective on mental health. Psychological Bulletin, 103, 193-210.

Taylor, S. E., \& Brown, J. D. (1994). Positive illusions and well-being revisited: Separating fact from fiction. Psychological Bulletin, 119, 21-27.

Thomas, J. (2000). Cross-cultural pragmatic failure. In K. Bolton \& B. B. Kachru (Eds.), World Englishes: Critical concepts in linguistics (pp. 22-48). New York: Routledge.

Touliatos, J., Perlmutter, B. F., \& Straus, M. A. (Eds.). (2001). Handbook of family measurement techniques. Thousand Oaks, CA: Sage

Tschann, J., M., Flores, E., Pasch, L., A., \& Marin, B., V. (1999). Assessing Interparental conflict: Reports of parents and adolescents in European American and Mexican American families. Journal of Marriage and the Family, 61, 269-283. 
Turner, C. M., \& Barrett, P. M. (1998). Adolescent adjustment to perceived marital conflict. Journal of Child and Family Studies, 7(4), 499-513.

Van den Broucke, S., Vandereycken, W., \& Norre, J. (1997). Eating disorders and marital relationships. London: Routledge.

Watkins, M. W. (2000). Monte Carlo PCA for parallel analysis [computer software]. State College, PA: Ed \& Psych Associates.

Whitton, S. W., Stanley, S. M., \& Markman, H. J. (2002). Sacrifice in romantic relationships: An exploration of relevant research and theory. In H. T. Reiss, M. A. Fitzpatrick \& A. L. Vangelisti (Eds.), Stability and change in relationship behavior across the lifespan (pp. 56-181). Cambridge: Cambridge University Press.

Widaman, K. F. (1993). Common factor analysis versus principal components analysis: Differential bias in representing model parameters? Multivariate Behavioral Research, 28, 263-311.

Wild, L. G., \& Richards, M. P. M. (2003). Exploring parent and child perceptions of interparental conflict. International Journal of Law, Policy and the Family, 17, 366-384.

Williams, K. D. (2001). Ostracism: The power of silence. New York: Guilford Press.

Williams, K. D. (2007). Ostracism. Annual Review of Psychology, 58, 425-452.

Williams, K. D., Forgas, J. P., \& Hippel, W. v. (2005). The social outcast: Ostracism, social exclusion, and bullying. New York: Psychology Press.

Williams, K. D., \& Zadro, L. (2005). Ostracism: The indiscriminate early detection system. In K. D. Williams, J. P. Forgas \& W. von Hippel (Eds.), 
The social outcast: Ostracism, social exclusion, and bullying New York: Psychology Press.

Wilmot, W. W., \& Hocker, J. L. (2007). Interpersonal conflict (7th ed.). New York: McGraw-Hill.

Zahn-Waxler, C. (1993). Warriors and worriers: Gender and psychopathology. Development and Psychopathology, 5, 79-90.

Zerubavel, E. (2006). The elephant in the room: Silence and denial in everyday life. Oxford; New York: Oxford University Press. 


\section{APPENDIX A: Original List of Items Proposed for the Silent Interparental Conflict Scale}

We are interested in what happens between couples when they are in disagreement but not discussing the issues. Please reflect on your relationship with your partner. Please read the statements listed below and for each of them circle the option that best reflects your experience.

1. When we argue and my partner tries to get to the bottom of the problem, I reach a point when I don't want to talk any more.
Never
Rarely
Sometimes
Often
4
Always
1
2
3

2. When we argue and I try to get to the bottom of the problem my partner reaches a point when he/she doesn't want to talk any more.
Never
Rarely
1
2
Sometimes
3
Often
4
Always 5

3. When we have a quarrel I refuse to continue arguing and leave the room.
Never
Rarely
Sometimes
Often
4
Always
3

4. When we have a quarrel, my partner refuses to continue arguing and leaves the room.

$\begin{array}{ccccc}\text { Never } & \text { Rarely } & \text { Sometimes } & \text { Often } & \text { Always } \\ 1 & 2 & 3 & 4 & 5\end{array}$

5. When it's too hard to resolve an argument I become silent.
Never
Rarely
Sometimes
Often
Always

$\begin{array}{llll}1 & 2 & 3 & 4\end{array}$

6. When it's too hard to resolve an argument my partner becomes silent.
Never
Rarely
Sometimes
Often
1
2
3
4
Always

7. I want to be alone when my partner and I cannot agree about an issue.
Never
Rarely
Sometimes
Often
4
Always

8. My partner wants to be alone when we cannot agree about an issue.
Never
Rarely
Sometimes
Often
Always
1
2
3
4

9. When we are annoyed with each other we avoid each other around the house. Never Rarely Sometimes Often Always
1
2
3
4
5

10. When I feel slighted by my partner I become silent without explaining why.
Never
Rarely
2
Sometimes
Often
4
Always

11. When we have an argument I go silent so that it doesn't get out of hand.
Never
Rarely
Sometimes
Often
4
Always 
12. When my partner hurts my feelings I become silent to let him/her know how I feel.

$\begin{array}{ccccc}\text { Never } & \text { Rarely } & \text { Sometimes } & \text { Often } & \text { Always } \\ 1 & 2 & 3 & 4 & 5\end{array}$

13. When I'm angry with my partner I shut him/her out to get back at him/her.
Never
Rarely
Sometimes
Often
4
Always
1
2
3
5

14. Instead of adding more 'fuel to the fire' by arguing, I stop talking altogether.
Never
Rarely
Sometimes
Often
4
Always
1
2
5

3

15. I want to be by myself to think about the issues, when we are in conflict.
Never
1
Rarely
Sometimes
Often
4
Always
5

16. When we are in conflict we don't talk to each other at all.
Never
Rarely
Sometimes
2
Often
Always
4

17. After a period of silence following a disagreement, we get back to talking without resolving the issue.
Never
Rarely
Sometimes
Often
4
Always
1
2
3

18. After staying away from each other following a disagreement, we get back to our usual ways without resolving the issue.
Never
Rarely
Sometimes
1
2
3
Often
4
Always

We would like to know your views about silent disagreements between you and your partner. Please read the statements that follow and circle the number that best reflects your feelings and thoughts.

19. A period of silence and staying away from each other helps to put a disagreement into perspective.
Strongly disagree
Disagree
Neutral
Agree
$3 \quad 4 \quad 5$
Strongly agree

20. A period of silence and staying away from each other helps to calm the emotions.
Strongly disagree
Disagree
Neutral
Agree
$3 \quad 4 \quad 5$
Strongly agree

21. The silence between us gives me a chance to try and understand my partner's behaviour.

Strongly disagree $\quad$ Disagree $\quad$ Neutral $\quad$ Agree $\quad$ Strongly agree
2
3
4

22. When we can't agree about something there is less physical affection between us.

$\begin{array}{ccccc}\text { Strongly disagree } & \text { Disagree } & \text { Neutral } & \text { Agree } & \text { Strongly agree } \\ 1 & 2 & 3 & 4 & 5\end{array}$


23. When we are in conflict, verbal communication between us is greatly reduced. Strongly disagree Disagree Neutral Agree $\quad$ Strongly agree

$\begin{array}{lllll}1 & 2 & 3 & 4 & 5\end{array}$

24. There is little warmth in our relationship when we are in conflict.
Strongly disagree
Disagree
Neutral
Agree
Strongly agree
1
2
3
4
5

25. I hold myself back from expressing my feelings when we are in conflict.
Strongly disagree
Disagree
Neutral
Agree
4
Strongly agree 1
2
3
5

26. Our day to day communication becomes curt and icy when there is discord between us.

Strongly disagree $\quad$ Disagree $\quad$ Neutral $\quad$ Agree $\quad$ Strongly agree
1
2
3
4
5

27. During conflict there is a lot of tension between us even though we do not communicate.
Strongly disagree
1
Disagree
Neutral
3
Agree
4
Strongly agree

28. The atmosphere in the household affects everyone when my partner and I don't talk to each other.
Strongly disagree
Disagree
Neutral
Agree
3
4
Strongly agree
5

29. I get a knot in my stomach when my partner and I are not talking to each other.

$\begin{array}{ccccc}\text { Strongly disagree } & \text { Disagree } & \text { Neutral } & \text { Agree } & \text { Strongly agree } \\ 1 & 2 & 3 & 4 & 5\end{array}$

30. I can't concentrate on anything else when we don't speak to each other because of a disagreement.

$\begin{array}{ccccc}\text { Strongly disagree } & \text { Disagree } & \text { Neutral } & \text { Agree } & \text { Strongly agree } \\ 1 & 2 & 3 & 4 & 5\end{array}$

31. When we are in conflict I can't stop mulling things over.
Strongly disagree
Disagree
Neutral
Agree
Strongly agree
1
2
3
4
5

32. The discord between my partner and me shuts me down for everybody.
Strongly disagree
Disagree
Neutral
Agree
4
Strongly agree

33. When my partner shuts me out I have no means of responding.
Strongly disagree
Disagree
Neutral
Agree
4
Strongly agree

34. When my partner shuts me out things feel beyond my control.
Strongly disagree
Disagree
Neutral
Agree
34
Strongly agree
23
5

35. The lack of interaction between us makes it impossible for me to take any action.

Strongly disagree

1
Disagree

2
Neutral

3
Agree

4

Strongly agree 
36. It is frustrating that some issues between us have to remain unresolved.
Strongly disagree
Disagree
Neutral
Agree
Strongly agree
1
2
3
4
5

37. It is frustrating that some of our views can never be reconciled.
Strongly disagree
Disagree
Neutral
Agree
4
Strongly agree

$\begin{array}{lllll}1 & 2 & 3 & 4 & 5\end{array}$

38. When we disagree about fundamental issues there is no resolution.
Strongly disagree
Disagree
Neutral
Agree
$3 \quad 4$
Strongly agree

122
5

39. My partner and I have some issues we will never agree on.
Strongly disagree
Disagree
Neutral
Agree
4
Strongly agree
1
2
3
5

40. When my partner shuts me out I feel unloved.
Strongly disagree
Disagree
Neutral 3
Agree
Strongly agree
4
5

41. When my partner shuts me out I feel rejected.
Strongly disagree
Disagree
Neutral
Agree
4
Strongly agree
3
5

42. Silences between us would not occur if we could agree on the issues that cause them.
Strongly disagree
Disagree
Neutral
Agree
Strongly agree$$
1
$$

3
4
5

43. Silences between us occur because of certain issues we cannot agree on.
Strongly disagree
Disagree
Neutral
Agree
4
Strongly agree
1
2
3
5

44. We cannot agree on some issues, so they remain unresolved between us.
Strongly disagree
Disagree
Neutral
Agree
4
Strongly agree

45. Our conflicting viewpoints lead to periods of silence between us.
Strongly disagree
Disagree
Neutral
Agree
Strongly agree

$$
1
$$
2
3
4

46. Certain issues we cannot agree upon end up lingering between us.
Strongly disagree
Disagree
2
Neutral
Agree
4
Strongly agree

47. Certain topics we disagree about make me go silent and withdraw from my partner.
Strongly disagree
Disagree
2
Neutral
3
Agree
4
Strongly agree

$\begin{array}{lcccr}1 & 2 & 3 & 4 & \text { Strongly } \\ & & & 5\end{array}$

48. Certain topics we disagree about make my partner go silent and withdraw from me.

Strongly disagree
Disagree

2

Neutral
3

3
Agree

4
Strongly agree 5 
49. Unresolved issues lead to silence between my partner and me.

Strongly disagree

1
Disagree

2
Neutral

3
Agree

4
Strongly agree

Strongly agree 5

51. I do not argue even when I can't agree with my partner.

Strongly disagree
2
4

1

52. I do not approach certain issues because my partner and I disagree about them.

Strongly disagree 1

Disagree

2

Neutral

3

Agree

4

Strongly agree 5

53. I do not oppose my partner even when our views are contradictory. Strongly disagree Disagree Neutral 3 Agree 1 2

Strongly agree

54. My partner and I avoid discussing certain issues because it leads to arguments. Strongly disagree Disagree 2 Neutral 3 Agree 4

Strongly agree 1

55. Silence is preferable to heated/extended arguments.

Strongly disagree

1
Disagree

2
Neutral

3
Agree

4
Strongly agree

5 
APPENDIX B: Items from the Conflicts and Problem-Solving Scales (Kerig, 1996)

\section{YOU AND YOUR PARTNER}

What strategies do you and your partner use when you have a disagreement with each other?

Using the four-point scale below, please show how often YOU use each strategy on the left side, and how often YOUR PARTNER uses each strategy on the right side.

Remember the first response that comes to mind is probably the best.

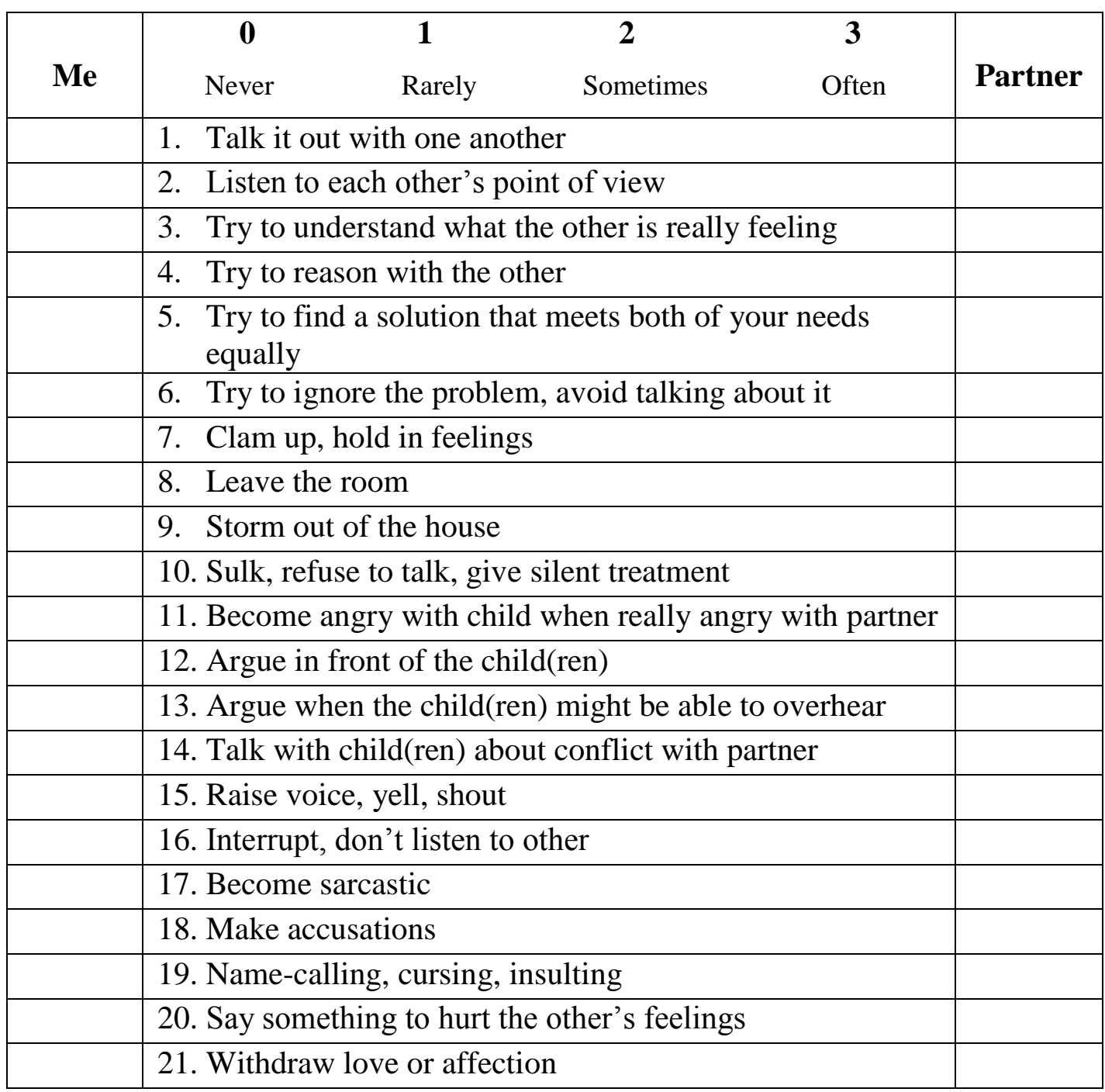


APPENDIX C: Items from the Ineffective Arguing Inventory (Kurdek, 1994b)

Below are descriptions of some of the kinds of arguments people in relationships are likely to experience. Circle the number that indicates how much you agree that each statement fits your relationship.

1. Our arguments are left hanging and unresolved.

$\begin{array}{ccccc}\text { Strongly disagree } & \text { Disagree } & \text { Neutral } & \text { Agree } & \text { Strongly agree } \\ 1 & 2 & 3 & 4 & 5\end{array}$

2. We go for days without settling our differences.

$\begin{array}{ccccc}\text { Strongly disagree } & \text { Disagree } & \text { Neutral } & \text { Agree } & \text { Strongly agree } \\ 1 & 2 & 3 & 4 & 5\end{array}$

3. Our arguments seem to end in frustrating stalemates.

Strongly disagree Disagree Neutral Agree

1

2

3

4

Strongly agree 5 
APPENDIX D: Items from the Conflict Resolution Style Inventory (Kurdek, 1994b)

Use the scale below to rate how frequently YOU use each of the following styles to deal with arguments or disagreements with your partner.

1. Remaining silent for long periods of time.

$\begin{array}{ccccc}\text { Never } & \text { Rarely } & \text { Sometimes } & \text { Often } & \text { Always } \\ 1 & 2 & 3 & 4 & 5\end{array}$

2. Reaching a limit, "shutting down", and refusing to talk any further.
Never
1
Rarely
Sometimes
3
Often
4
Always

3. Withdrawing, acting distant and not interested.
Never
Rarely
Sometimes
3
Often
4
Always
5
1
2

Use the scale below to rate how frequently YOUR PARTNER uses each of the following styles to deal with arguments or disagreements with you.

4. Remaining silent for long periods of time.

$\begin{array}{ccccc}\text { Never } & \text { Rarely } & \text { Sometimes } & \text { Often } & \text { Always } \\ 1 & 2 & 3 & 4 & 5\end{array}$

5. Reaching a limit, "shutting down", and refusing to talk any further.
Never
Rarely
Sometimes
3
Often
4
Always
1
2
5

6. Withdrawing, acting distant and not interested.
Never
Rarely
Sometimes
Often
4
Always
5
1
2
3 
APPENDIX E: M-C 1(10) (Strahan \& Gerbasi, 1972)

\section{ATTITUDES AND TRAITS}

Listed below are a number of statements concerning personal attitudes and traits. Read each item and decide whether the statement is true or false as it pertains to you personally. Please circle the appropriate option.

1. I'm always willing to admit it when I make a mistake.

$\mathbf{T} / \mathbf{F}$

2. I always try to practice what I preach.

$\mathbf{T} / \mathbf{F}$

3. I never resent being asked to return a favour.

$\mathbf{T} / \mathbf{F}$

4. I have never been irked when people expressed ideas very different from my own.

$\mathbf{T} / \mathbf{F}$

5. I have never deliberately said something that hurt someone's feelings

6. I like to gossip at times.

$\mathbf{T} / \mathbf{F}$

7. There have been occasions when I took advantage of someone.

$\mathbf{T} / \mathbf{F}$

8. I sometimes try to get even rather than forgive and forget. $\mathbf{T} / \mathbf{F}$

9. At times I have really insisted on having things my own way.

$\mathbf{T} / \mathbf{F}$

10. There have been occasions when I felt like smashing things. 


\section{APPENDIX F: Items Representing Silent Interparental Conflict Administered to Parents at Time 1 and Time 2}

We are interested in what happens between couples when they are in disagreement but not discussing the issues.

Please reflect on your relationship with your partner.

Please read the statements listed below and for each of them circle the option that best reflects your experience.

\begin{tabular}{|c|c|c|c|c|c|}
\hline & Never & Rarely & Sometimes & Often & Always \\
\hline $\begin{array}{l}\text { 1. When we argue and my partner tries to } \\
\text { get to the bottom of the problem, I reach } \\
\text { a point when I don't want to talk any } \\
\text { more. }\end{array}$ & 1 & 2 & 3 & 4 & 5 \\
\hline $\begin{array}{l}\text { 2. When we argue and I try to get to the } \\
\text { bottom of the problem my partner } \\
\text { reaches a point when he/she doesn't want } \\
\text { to talk any more. }\end{array}$ & 1 & 2 & 3 & 4 & 5 \\
\hline $\begin{array}{l}\text { 3. When we have a quarrel I refuse to } \\
\text { continue arguing and leave the room. }\end{array}$ & 1 & 2 & 3 & 4 & 5 \\
\hline $\begin{array}{l}\text { 4. When we have a quarrel, my partner } \\
\text { refuses to continue arguing and leaves } \\
\text { the room. }\end{array}$ & 1 & 2 & 3 & 4 & 5 \\
\hline $\begin{array}{l}\text { 5. I want to be alone when my partner and I } \\
\text { cannot agree about an issue. }\end{array}$ & 1 & 2 & 3 & 4 & 5 \\
\hline $\begin{array}{l}\text { When we are annoyed with each other } \\
\text { we avoid each other around the house. }\end{array}$ & 1 & 2 & 3 & 4 & 5 \\
\hline $\begin{array}{l}\text { 7. When we have an argument I go silent so } \\
\text { that it doesn't get out of hand. }\end{array}$ & 1 & 2 & 3 & 4 & 5 \\
\hline
\end{tabular}

We would like to know your views about silent disagreements between you and your partner. Please read the statements that follow and circle the number that best reflects your feelings and thoughts.

\begin{tabular}{|c|c|c|c|c|c|}
\hline & $\begin{array}{l}\text { Strongly } \\
\text { disagree }\end{array}$ & Disagree & Neutral & Agree & $\begin{array}{c}\text { Strongly } \\
\text { agree }\end{array}$ \\
\hline $\begin{array}{l}\text { 8. A period of silence and staying } \\
\text { away from each other helps to } \\
\text { put a disagreement into } \\
\text { perspective. }\end{array}$ & 1 & 2 & 3 & 4 & 5 \\
\hline $\begin{array}{l}\text { 9. A period of silence and staying } \\
\text { away from each other helps to } \\
\text { calm the emotions. }\end{array}$ & 1 & 2 & 3 & 4 & 5 \\
\hline $\begin{array}{l}\text { 10. Silence between us gives me a } \\
\text { chance to try and understand } \\
\text { my partner's behaviour. }\end{array}$ & 1 & 2 & 3 & 4 & 5 \\
\hline $\begin{array}{l}\text { 11. There is little warmth in our } \\
\text { relationship when we are in } \\
\text { conflict. }\end{array}$ & 1 & 2 & 3 & 4 & 5 \\
\hline
\end{tabular}




\begin{tabular}{|c|c|c|c|c|c|}
\hline $\begin{array}{l}\text { 12. Our day to day communication } \\
\text { becomes curt and icy when there } \\
\text { is discord between us. }\end{array}$ & 1 & 2 & 3 & 4 & 5 \\
\hline $\begin{array}{l}\text { 13. During conflict there is a lot of } \\
\text { tension between us even though } \\
\text { we do not communicate. }\end{array}$ & 1 & 2 & 3 & 4 & 5 \\
\hline $\begin{array}{l}\text { 14. I get a knot in my stomach when } \\
\text { my partner and I are not talking } \\
\text { to each other. }\end{array}$ & 1 & 2 & 3 & 4 & 5 \\
\hline $\begin{array}{l}\text { 15. I can't concentrate on anything } \\
\text { else when we don't speak to } \\
\text { each other because of a } \\
\text { disagreement. }\end{array}$ & 1 & 2 & 3 & 4 & 5 \\
\hline $\begin{array}{l}\text { 16. When we are in conflict I can't } \\
\text { stop mulling things over. }\end{array}$ & 1 & 2 & 3 & 4 & 5 \\
\hline $\begin{array}{l}\text { 17. Discord between my partner } \\
\text { and me shuts me down for } \\
\text { everybody. }\end{array}$ & 1 & 2 & 3 & 4 & 5 \\
\hline $\begin{array}{l}\text { 18. When my partner shuts me out I } \\
\text { have no means of responding. }\end{array}$ & 1 & 2 & 3 & 4 & 5 \\
\hline $\begin{array}{l}\text { 19. When my partner shuts me out } \\
\text { things are beyond my control. }\end{array}$ & 1 & 2 & 3 & 4 & 5 \\
\hline $\begin{array}{l}\text { 20. The lack of interaction between us } \\
\text { makes it impossible for me to take } \\
\text { any action. }\end{array}$ & 1 & 2 & 3 & 4 & 5 \\
\hline $\begin{array}{l}\text { 21. When my partner shuts me out } \\
\text { I feel rejected. }\end{array}$ & 1 & 2 & 3 & 4 & 5 \\
\hline $\begin{array}{l}\text { 22. We cannot agree on some issues, } \\
\text { so they remain unresolved } \\
\text { between us. }\end{array}$ & 1 & 2 & 3 & 4 & 5 \\
\hline $\begin{array}{l}\text { 23. Our conflicting viewpoints lead to } \\
\text { periods of silence between us. }\end{array}$ & 1 & 2 & 3 & 4 & 5 \\
\hline $\begin{array}{l}\text { 24. Certain issues we cannot agree } \\
\text { upon end up lingering between us. }\end{array}$ & 1 & 2 & 3 & 4 & 5 \\
\hline $\begin{array}{l}\text { 25. Unresolved issues lead to silence } \\
\text { between my partner and me. }\end{array}$ & 1 & 2 & 3 & 4 & 5 \\
\hline $\begin{array}{l}\text { 26. I do not argue even when I can't } \\
\text { agree with my partner. }\end{array}$ & 1 & 2 & 3 & 4 & 5 \\
\hline $\begin{array}{l}\text { 27. I do not approach certain issues } \\
\text { because my partner and I disagree } \\
\text { about them. }\end{array}$ & 1 & 2 & 3 & 4 & 5 \\
\hline $\begin{array}{l}\text { 28. I do not oppose my partner even } \\
\text { when our views are contradictory. }\end{array}$ & 1 & 2 & 3 & 4 & 5 \\
\hline $\begin{array}{l}\text { 29. Silence is preferable to } \\
\text { heated/extended arguments. }\end{array}$ & 1 & 2 & 3 & 4 & 5 \\
\hline
\end{tabular}

Note: Items presented in bold typeface form the final Silent Interparental Conflict scale. 


\section{APPENDIX G: Items from the Irritability, Depression, Anxiety Scale}

(Snaith, et al., 1978)

The following statements have been put together so that you can show how you have been feeling in the past few days. Please read each item in turn and circle the response which shows how you are feeling or have been feeling in the last few days.

Please complete all of the questions.

\begin{tabular}{|c|c|c|c|c|}
\hline 1. I feel cheerful. & $\begin{array}{l}\text { Yes, } \\
\text { definitely }\end{array}$ & Yes, sometimes & No, not much & $\begin{array}{l}\text { No, not at } \\
\text { all }\end{array}$ \\
\hline $\begin{array}{l}\text { 2. I can sit down and } \\
\text { relax quite easily. }\end{array}$ & $\begin{array}{l}\text { Yes, } \\
\text { definitely }\end{array}$ & Yes, sometimes & No, not much & $\begin{array}{l}\text { No, not at } \\
\text { all }\end{array}$ \\
\hline 3. My appetite is: & Very poor & Fairly poor & Quite good & Very good \\
\hline $\begin{array}{l}\text { 4. I lose my temper and } \\
\text { shout and snap at } \\
\text { others. }\end{array}$ & $\begin{array}{l}\text { Yes, } \\
\text { definitely }\end{array}$ & Yes, sometimes & No, not much & $\begin{array}{l}\text { No, not at } \\
\text { all }\end{array}$ \\
\hline $\begin{array}{l}\text { 5. I can laugh and feel } \\
\text { amused. }\end{array}$ & $\begin{array}{l}\text { Yes, } \\
\text { definitely }\end{array}$ & Yes, sometimes & No, not much & $\begin{array}{l}\text { No, not at } \\
\text { all }\end{array}$ \\
\hline $\begin{array}{l}\text { 6. I feel I might lose } \\
\text { control and hit } \\
\text { someone. }\end{array}$ & Sometimes & Occasionally & Rarely & Never \\
\hline $\begin{array}{l}\text { 7. I have an } \\
\text { uncomfortable } \\
\text { feeling like } \\
\text { butterflies in my } \\
\text { stomach. }\end{array}$ & $\begin{array}{l}\text { Yes, } \\
\text { definitely }\end{array}$ & Yes, sometimes & No, not much & $\begin{array}{l}\text { No, not at } \\
\text { all }\end{array}$ \\
\hline $\begin{array}{l}\text { 8. I'm awake before I } \\
\text { need to get up. }\end{array}$ & $\begin{array}{l}\text { For } 2 \text { hours } \\
\text { or more }\end{array}$ & For about 1 hour & $\begin{array}{l}\text { For less than } \\
1 \text { hour }\end{array}$ & $\begin{array}{l}\text { Not at all. I } \\
\text { sleep until } \\
\text { it is time to } \\
\text { get up }\end{array}$ \\
\hline $\begin{array}{l}\text { 9. I feel tense and } \\
\text { wound up. }\end{array}$ & $\begin{array}{l}\text { Yes, } \\
\text { definitely }\end{array}$ & Yes, sometimes & No, not much & $\begin{array}{l}\text { No, not at } \\
\text { all }\end{array}$ \\
\hline $\begin{array}{l}\text { 10. I've kept up my old } \\
\text { interests }\end{array}$ & $\begin{array}{l}\text { Yes, most of } \\
\text { them }\end{array}$ & $\begin{array}{l}\text { Yes, some of } \\
\text { them }\end{array}$ & $\begin{array}{l}\text { No, not many of } \\
\text { them }\end{array}$ & $\begin{array}{l}\text { No, none of } \\
\text { them }\end{array}$ \\
\hline $\begin{array}{l}\text { 11. I am patient with } \\
\text { other people. }\end{array}$ & All the time & Most of the time & Some of the time & Hardly ever \\
\hline $\begin{array}{l}\text { 12. I get scared and } \\
\text { panicky for no good } \\
\text { reason. }\end{array}$ & $\begin{array}{l}\text { Yes, } \\
\text { definitely }\end{array}$ & Yes, sometimes & No, not much & $\begin{array}{l}\text { No, not at } \\
\text { all }\end{array}$ \\
\hline $\begin{array}{l}\text { 13. People upset me so } \\
\text { that I feel like } \\
\text { slamming doors or } \\
\text { banging about. }\end{array}$ & Yes, often & Yes, sometimes & $\begin{array}{l}\text { Only } \\
\text { occasionally }\end{array}$ & Not at all \\
\hline $\begin{array}{l}\text { 14. I can go out on my } \\
\text { own without feeling } \\
\text { anxious. }\end{array}$ & Yes, always & Yes, sometimes & No, not often & $\begin{array}{l}\text { No, I never } \\
\text { can }\end{array}$ \\
\hline
\end{tabular}


APPENDIX H: The Warmth and Hostility Subscales from the Iowa Youth and Family Project (Melby, et al., 1993; Melby, et al., 1995)

\section{You and Your...}

During the past month when you and your ... have spent time talking or doing things together, how often did your ...

\begin{tabular}{|l|c|c|c|c|c|c|c|}
\hline & $\underline{\text { Always }}$ & $\frac{\underline{\text { Almost }}}{\underline{\text { Always }}}$ & $\frac{\underline{\text { Fairly }}}{\text { Often }}$ & $\frac{\underline{\text { About }}}{\underline{\text { Half }}}$ & $\begin{array}{c}\frac{\text { Not }}{\underline{\text { too }}} \\
\text { Often }\end{array}$ & $\frac{\underline{\text { Almost }}}{\text { Never }}$ & $\underline{\underline{\text { Never }}}$ \\
\hline 1. Get angry at you & $\mathbf{1}$ & $\mathbf{2}$ & $\mathbf{3}$ & $\mathbf{4}$ & $\mathbf{5}$ & $\mathbf{6}$ & $\mathbf{7}$ \\
\hline $\begin{array}{l}\text { 2. Let you know he/she } \\
\text { really cares about you }\end{array}$ & $\mathbf{1}$ & $\mathbf{2}$ & $\mathbf{3}$ & $\mathbf{4}$ & $\mathbf{5}$ & $\mathbf{6}$ & $\mathbf{7}$ \\
\hline $\begin{array}{l}\text { 3. Criticise you or your } \\
\text { ideas }\end{array}$ & $\mathbf{1}$ & $\mathbf{2}$ & $\mathbf{3}$ & $\mathbf{4}$ & $\mathbf{5}$ & $\mathbf{6}$ & $\mathbf{7}$ \\
\hline $\begin{array}{l}\text { 4. Shout at you because } \\
\text { he/she was upset with you }\end{array}$ & $\mathbf{1}$ & $\mathbf{2}$ & $\mathbf{3}$ & $\mathbf{4}$ & $\mathbf{5}$ & $\mathbf{6}$ & $\mathbf{7}$ \\
\hline $\begin{array}{l}\text { 5. Act loving and } \\
\text { affectionate } \\
\text { toward you }\end{array}$ & $\mathbf{1}$ & $\mathbf{2}$ & $\mathbf{3}$ & $\mathbf{4}$ & $\mathbf{5}$ & $\mathbf{6}$ & $\mathbf{7}$ \\
\hline $\begin{array}{l}\text { 6. Let you know that he/she } \\
\text { appreciates you, your ideas } \\
\text { or the things you do }\end{array}$ & $\mathbf{1}$ & $\mathbf{2}$ & $\mathbf{3}$ & $\mathbf{4}$ & $\mathbf{5}$ & $\mathbf{6}$ & $\mathbf{7}$ \\
\hline $\begin{array}{l}\text { 7. Help you do something } \\
\text { that was important to you }\end{array}$ & $\mathbf{1}$ & $\mathbf{2}$ & $\mathbf{3}$ & $\mathbf{4}$ & $\mathbf{5}$ & $\mathbf{6}$ & $\mathbf{7}$ \\
\hline $\begin{array}{l}\text { 8. Argued with you } \\
\text { whenever you disagreed } \\
\text { about something }\end{array}$ & $\mathbf{1}$ & $\mathbf{2}$ & $\mathbf{3}$ & $\mathbf{4}$ & $\mathbf{5}$ & $\mathbf{6}$ & $\mathbf{7}$ \\
\hline $\begin{array}{l}\text { 9. Act supportive and } \\
\text { understanding toward you }\end{array}$ & $\mathbf{1}$ & $\mathbf{2}$ & $\mathbf{3}$ & $\mathbf{4}$ & $\mathbf{5}$ & $\mathbf{6}$ & $\mathbf{7}$ \\
\hline
\end{tabular}

Note: The Hostility subscale consists of items 1, 3, 4 and 8; the Warmth subscale consists of items 2, 5, 6, 7 and 9 . 
APPENDIX I: Adolescents' Perceptions of Silent Interparental Conflict

Scale (Pryor, 2003)

\section{WHEN PARENTS DISAGREE}

It is very common that in families parents sometimes disagree about things. We are interested to know what happens in your family.

Please read the questions below and circle the answer that is most true for your parents. If you live in a stepfamily please answer these questions for your parent and stepparent.

\begin{tabular}{|c|c|c|c|c|c|}
\hline & & Never & Sometimes & Often & $\begin{array}{l}\text { Very } \\
\text { often }\end{array}$ \\
\hline 1. & $\begin{array}{l}\text { When they are cross with each } \\
\text { other, my parents avoid each other } \\
\text { around the house. }\end{array}$ & 1 & 2 & 3 & 4 \\
\hline 2. & $\begin{array}{l}\text { There is a tense atmosphere } \\
\text { between my parents. }\end{array}$ & 1 & 2 & 3 & 4 \\
\hline 3. & $\begin{array}{l}\text { Even when they don't argue there is } \\
\text { a sense of unresolved feelings } \\
\text { between my parents. }\end{array}$ & 1 & 2 & 3 & 4 \\
\hline 4. & $\begin{array}{l}\text { My parents deny that they are cross } \\
\text { with each other even when I can tell } \\
\text { there is something wrong. }\end{array}$ & 1 & 2 & 3 & 4 \\
\hline 5. & $\begin{array}{l}\text { One or both of my parents go silent } \\
\text { when they are cross with each } \\
\text { other. }\end{array}$ & 1 & 2 & 3 & 4 \\
\hline 6. & $\begin{array}{l}\text { One or other of my parents refuses } \\
\text { to talk when things are not right } \\
\text { between them. }\end{array}$ & 1 & 2 & 3 & 4 \\
\hline 7. & $\begin{array}{l}\text { My parents hurt each other's } \\
\text { feelings when they argue. }\end{array}$ & 1 & 2 & 3 & 4 \\
\hline
\end{tabular}


We would like to know how YOU feel when your parents are in disagreement. The following are some questions about how you feel when they are cross with each other but NOT talking about it. Again, this is about the parents you live with.

Please circle the number that best fits your response.

\begin{tabular}{|c|c|c|c|c|c|}
\hline & & Never & Sometimes & Often & $\begin{array}{l}\text { Very } \\
\text { often }\end{array}$ \\
\hline 8. & $\begin{array}{l}\text { I feel helpless when my parents don't } \\
\text { talk about their disagreements }\end{array}$ & 1 & 2 & 3 & 4 \\
\hline 9. & $\begin{array}{l}\text { I am confused about what is } \\
\text { happening. }\end{array}$ & 1 & 2 & 3 & 4 \\
\hline 10. & $\begin{array}{l}\text { It feels as if it is my fault when my } \\
\text { parents don't talk about their } \\
\text { disagreements. }\end{array}$ & 1 & 2 & 3 & 4 \\
\hline 11. & $\begin{array}{l}\text { I get anxious and worried when my } \\
\text { parents are cross but don't talk about } \\
\text { it. }\end{array}$ & 1 & 2 & 3 & 4 \\
\hline 12. & $\begin{array}{l}\text { I feel as if I can do nothing about } \\
\text { what is happening. }\end{array}$ & 1 & 2 & 3 & 4 \\
\hline 13. & $\begin{array}{l}\text { I can't monitor what is happening } \\
\text { when they don't talk to each other. }\end{array}$ & 1 & 2 & 3 & 4 \\
\hline 14. & $\begin{array}{l}\text { I feel as if I am to blame for their } \\
\text { unhappiness with each other. }\end{array}$ & 1 & 2 & 3 & 4 \\
\hline 15. & $\begin{array}{l}\text { I feel scared about what might happen } \\
\text { when my parents are cross and not } \\
\text { talking. }\end{array}$ & 1 & 2 & 3 & 4 \\
\hline 16. & $\begin{array}{l}\text { I feel as if I have no control over the } \\
\text { situation. }\end{array}$ & 1 & 2 & 3 & 4 \\
\hline 17. & $\begin{array}{l}\text { I have no idea what is happening } \\
\text { when my parents don't talk to each } \\
\text { other. }\end{array}$ & 1 & 2 & 3 & 4 \\
\hline
\end{tabular}




\section{APPENDIX J: The Emotional Symptoms and the Conduct Problems Subscales of the Strengths and Difficulties Questionnaire (Goodman, 1997; \\ Goodman, et al., 1998)}

Please put a tick in the box that you think is most like you. It would help us if you answered all items as best you can even if you are not absolutely certain. Please give answers on the basis of how things have been for you over the last six months.

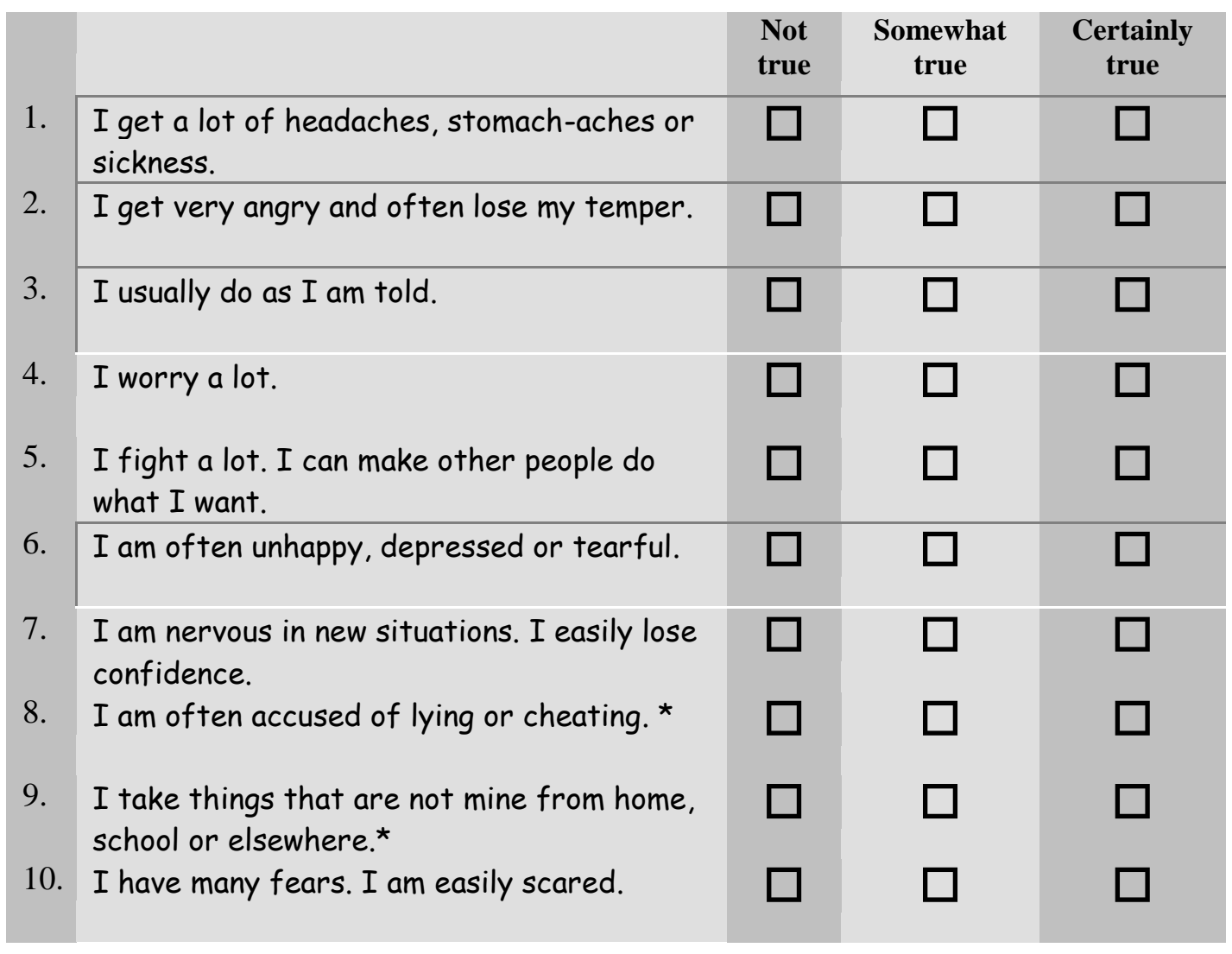

Emotional symptoms: Items 1, 4, 6, 7 and 10.

Conduct problems: Items 2, 3 (reverse scored), 5, 8 and.

* Items excluded in the current study. 


\section{APPENDIX K: The Future Outlook Scale}

And now some thoughts about your future...

How do you feel about the following statements?

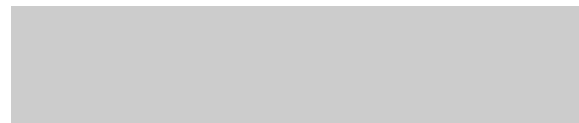

\section{Strongly disagree}

\section{Disagree \\ Neutral}

Agree

Strongly

1. There are many possibilities awaiting me.

2. There are many exciting things to experience.

3. There are lots of interesting things to learn.

4. I am optimistic about having a happy relationship.

5. I look forward to having my own family one day.

6. There are many rewarding things to do. *

7. I can contribute to society in many ways.

8. I feel positive about my future.
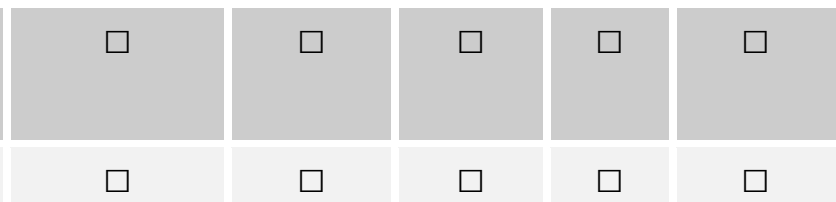
agree
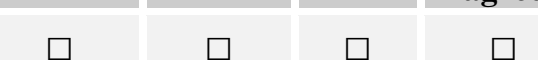

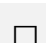

$\square$
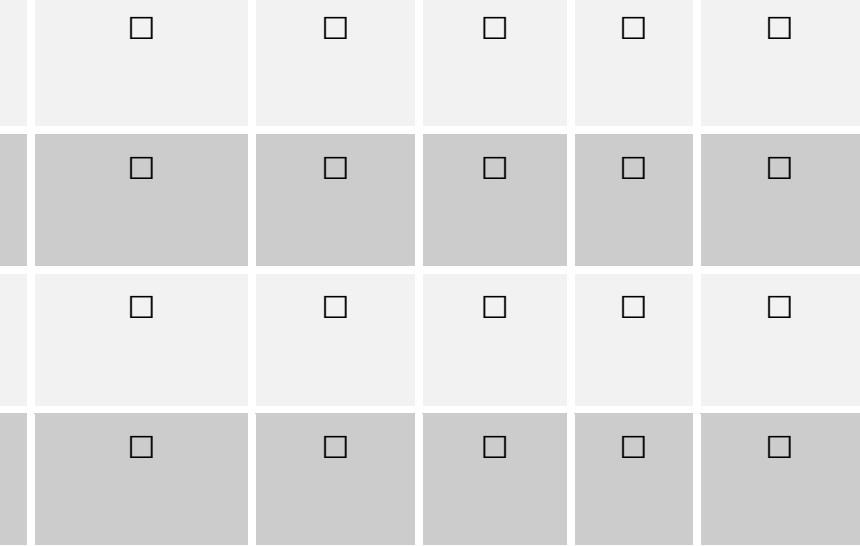

$\square$
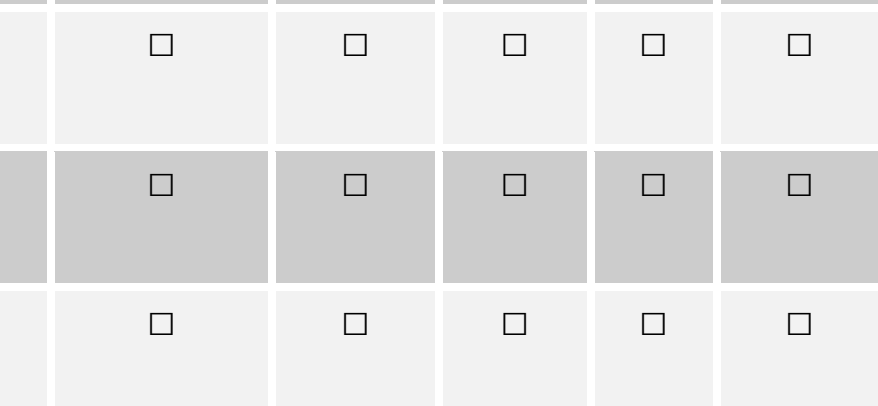